\title{
The Educational Desires of Danish and Korean \\ Environmental NGOs
}

Ph.D.-dissertation Department of Education (DPU), Aarhus University

Jonas Greve Lysgaard 
The Educational Desires of Danish and South Korean Environmental NGOs

Ph.D.-dissertation submitted to the Graduate School of Arts, Aarhus University, Denmark 2012.

(C) Jonas Greve Lysgaard, 2012

Research programme for Environmental and Health Education, Department of Education (DPU), Aarhus University, Denmark

Supervisor: Jeppe Læssøe

Co-supervisor: Karsten Schnack 


\section{Contents}

Summary ….............................................................................................................

Danish summary .........................................................................................................7

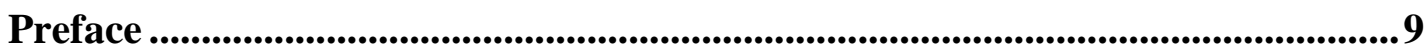

1. Introduction ......................................................................................................................10

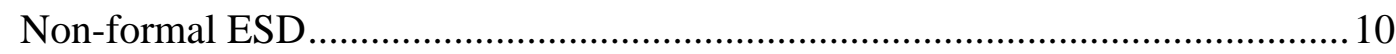

Denmark and South Korea .......................................................................... 11

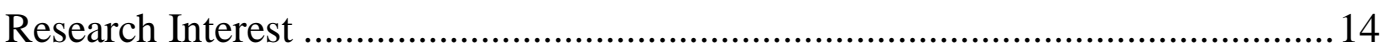

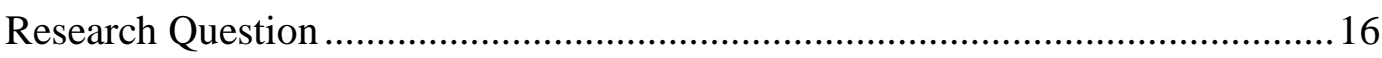

2. Research Design and Theoretical Inspiration........................................................18

Two Levels of Analytical Logic.......................................................................... 18

2.1 The Overall Research Design ...................................................................................19

2.2 Methodology.........................................................................................................21

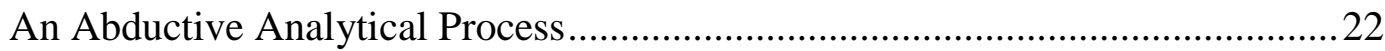

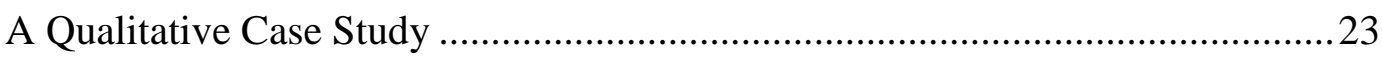

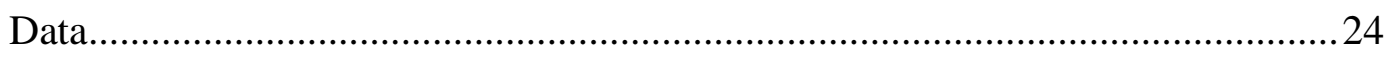

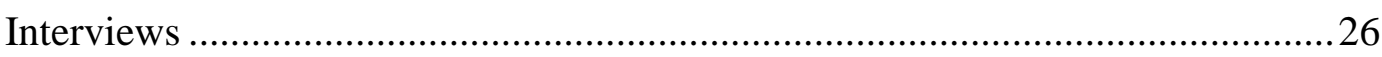

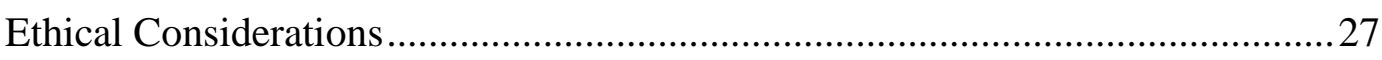

The Data Collection Process - Denmark............................................................2 28

The Data Collection Process - South Korea ........................................................29

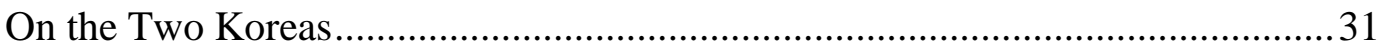

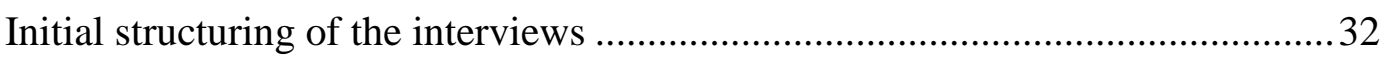

2.3 Theoretical Inspiration ...............................................................................................33

Theoretical Grounding of the Research Question and Sub-questions....................34

The First Sub-question ...................................................................................... 35

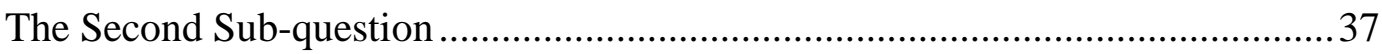

2.4 An Accelerating Presentation of the Analysis......................................................40

3. The NGOs, Civil Society and National Differences.............................................46

3.1 Past and present challenges ..........................................................................................46

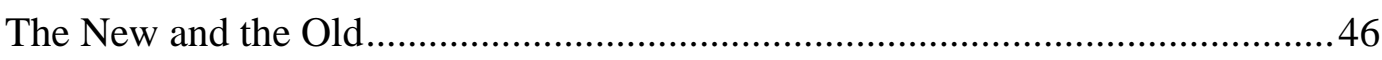

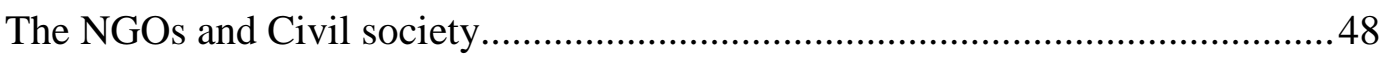


Civil Society and Environmental NGOs - South Korea 49

Civil Society and Environmental NGOs - Denmark .........................................52

The Korean and Danish Environmental NGOs ..................................................55

3.2 Contemporary Danish and Korean Environmental NGOs ...........................57

The Korean Case - Contemporary Korean NGO's, a sample of a growing field58

Korean Federation For Environmental Movements (KFEM) .............................58

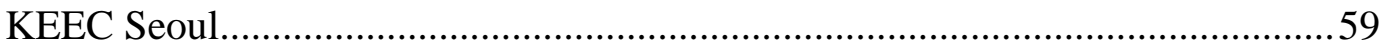

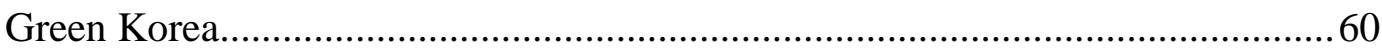

Citizen's Movement for Environmental Justice (CMEJ or Ecojustice) ................6 61

Local Agenda21 Action Council for Gyeonggi-do ...........................................6 62

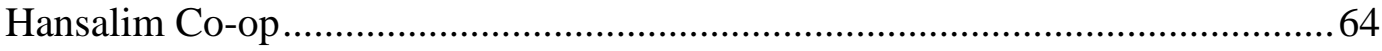

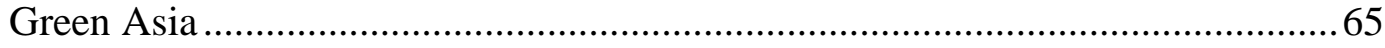

Jeju Korea Environmental Education Center (KEEC) ......................................67

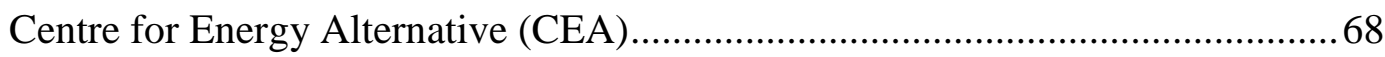

Korean NGOs: common history and differentiated future .................................69

The Danish Case: Environmental NGOs and the COP15 summit ......................69

People's Climate Action (PCA) ….............................................................. 70

Danish Adult Education Association (DAEA) .................................................... 71

World Wide Fund for Nature, Denmark (WWF) .............................................. 72

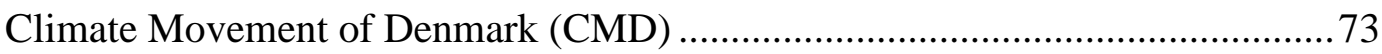

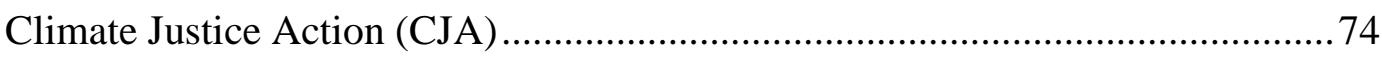

The Korean and Danish Environmental NGOs - Spanning Different Societies ...75

Chapter 4 - Perceptions of the Public as a Learning Entity in Denmark and South

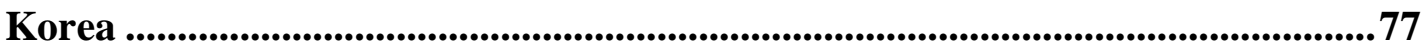

4.1 Why Engage the Public? The Perceived Role of the NGOs .............................79

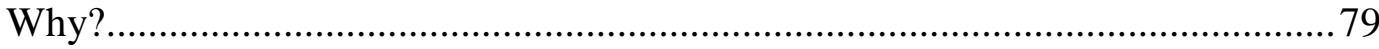

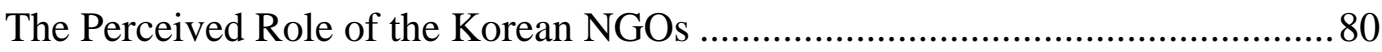

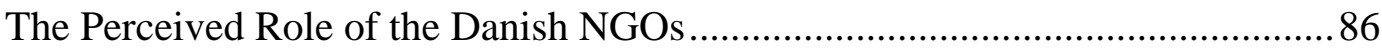

The Arborescent and Rhizomatic Structure of South Korean and Danish NGOs.92

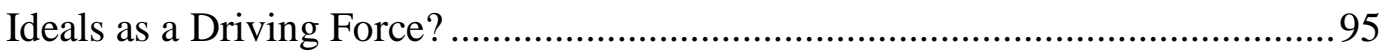


4.2 Where is Learning Happening? The Perceived Educational Perspective of the

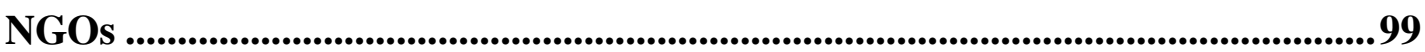

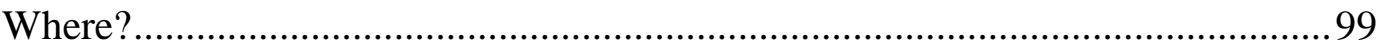

Youth in Korea and Denmark......................................................................... 101

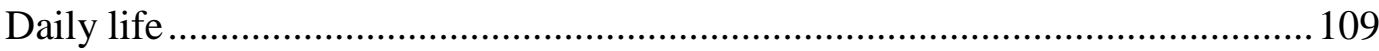

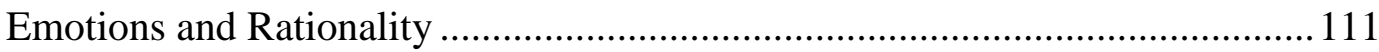

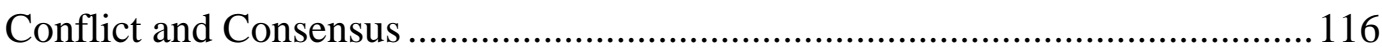

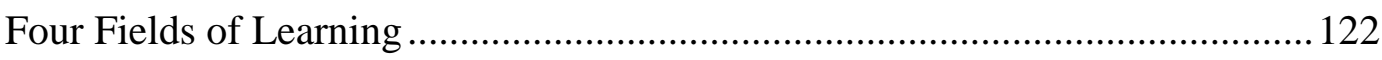

4.3 How is Participation Perceived? The Public as a Learning Entity.............. 125

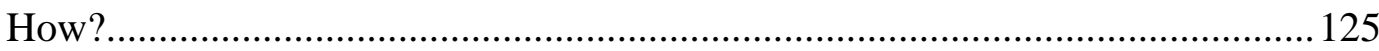

Participation in the Direct Meeting with Nature ............................................... 127

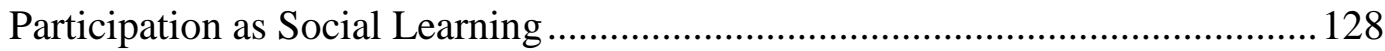

Participation as Action Oriented Learning ........................................................ 129

Participation as Deliberative Dialogue ............................................................ 131

Participation as a Political Leverage ............................................................. 132

Perceptions of the Public as a Learning Entity................................................. 133

5. The Significance of Perceptions and the Educational Desires of Environmental

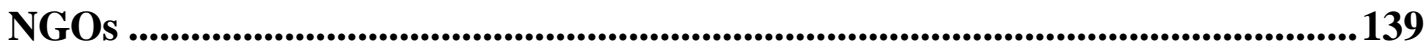

So What? The role of Theoretical Inquiry ........................................................... 139

The Importance of Perceptions, a Lacanian Take on the Perceived.................... 142

5.1 What is the significance of the NGOs engagement with the public? .......... 148

The Significance of Ideals .............................................................................. 148

The Symbolic, the Imaginary and the Real .................................................... 150

Global Climate, 'Sustainability' and the Symbolic big Other............................ 152

The Global Climate as the Lacanian Real ........................................................ 153

The big Other of 'Sustainability' and 'Climate Change' ................................... 156

Objet Petit a and the Cause for Desire............................................................. 162

What do You Want From Me? ...................................................................... 166

5.2 What is the Significance of 'Fields of Learning'? .....................................169

Fields of Learning as ideological fantasms ................................................... 170

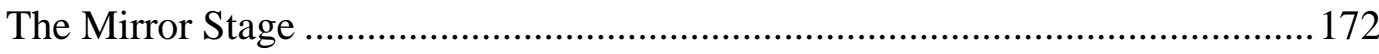


The NGOs and the Constant Risk of False Activity......................................... 176

The Public as the Subject Supposed to Know ................................................... 184

The Fall of 'Sustainability' and 'Climate Change' ........................................... 189

5.3 The Importance of Bad Practice and Possibilities of Traversing the Fantasm192

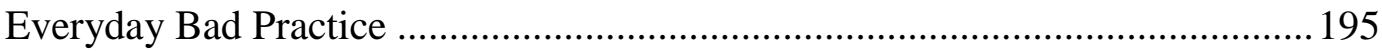

Bad Practice as Lacanian Disavowal ............................................................... 198

The need for a Cynical identification ................................................................ 200

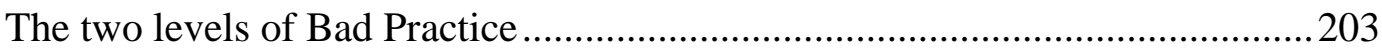

Traversing the Fantasm of 'Sustainability' and 'Climate Change' ..................... 206

Chapter 6 Perspectives, Findings and Emerging Thoughts ................................209

6.1 The Lack in Lacan and Žižek.....................................................................209

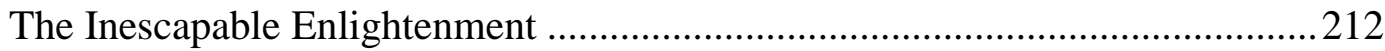

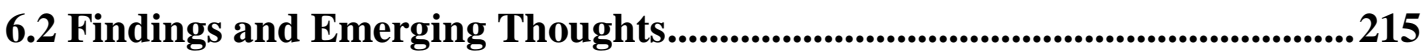

Empirical findings - the Educational efforts of the Danish and South Korean NGOs 216

Theoretical Findings - the Educational Desires of the Environmental NGOs....220

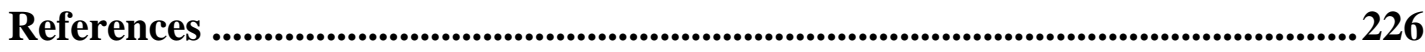

Appendix 1 Interview Guide ......................................................................................245 


\section{Summary}

This study explores how it is possible to understand non-formal Education for Sustainable development (ESD) as reflected by Danish and South Korean environmental Non Governmental Organisations (NGOs). The two cases present a picture of how NGOs understand the public as a learning entity, and how notions of sustainability and mitigating climate change at the same time act as productive ideals and as barriers for understanding the public and thinking in new ways about learning, change and the inherent limitations of the NGOs.

Based on interviews with key employees from Danish and Korean NGOs this study identifies and analyses five central themes when engaging the public: Youth, Daily life, Emotional/rational involvement and Conflict/consensus. In both countries these themes are embedded in the NGOs' ideals of a better society and visions of how to move forward. In Korea this is expressed via the hope for a different political structure, while the Danish NGOs are part of a consensual focus on changing society through lifestyle changes and how the individual can participate via personal choices. Based on the empirical material at hand it is argued that in both cases the NGOs build their approach on the idea of enlightening the public about the issues, an approach that is hoped to produce critical reflections and spur change. Such approach does from time to time work, but it can also be argued that the goal of actually engaging the public remains very hard to reach. This is hard to grasp for the NGOs, which have a strong tendency to rely on 'proven' methods, irrespective of their efficiency. Alas 'more of the same' might not be the wisest plan, when the existing strategies have had a relatively limited impact on the way the public lives, acts and consumes.

Based on the empirical material and inspired by the use of Lacanian psychoanalysis and the theories of Slavoj Žižek this study analyses how the significance of engaging the public as a learning entity. It is argued that working with ESD and the public makes a cynical identification with the foundational ideals of the NGOs' work possible. On one hand the NGOs navigate in a field where the possibilities of reaching ideals and instigating change are slim, but on the other hand the inherent impossibility of the task they have set out on creates meaning for the individual subject. To fully describe this mechanism this study develops the analytical concept named Bad Practice. This 
concept deals with how the individual constructs meaning through everyday actions that are perceived to be bad, but nonetheless very hard to get rid of. This enables a situation where it is possible to uphold the belief that ideals are followed, while living out their opposites. The overall contribution of the study is thus not only an addition to the existing critique of the concept of ESD as well as the notions of sustainability and climate change. The point being that it is not enough to be able to critique the concept of ESD, our own position as interpreters and users of the concept needs to be included in the analysis. This facilitates an understanding and critique of the processes, desires and mechanisms of meaning making that are harboured by all subjects involved in ESD. 


\section{Danish summary}

Denne Ph.D. afhandling fokuserer på danske og sydkoreanske folkelige organisationer eller Non Governmental Organisations (NGO'er) der arbejder med miljø- og klima spørgsmål og Uddannelse for Bæredygtig Udvikling (UBU). Afhandlingen tager empirisk fat i hvordan nøglepersoner i udvalgte danske og sydkoreanske NGO'er opfatter befolkningen som en lærende enhed. Afhandlingen har særligt fokus på betydningen af at engagere sig i non-formel UBU og professionelt at arbejde med idealer i et lærings- og uddannelsesperspektiv.

Analysen er baseret på interviews med nøglepersoner fra udvalgte danske og sydkoreanske NGO'er der til daglig arbejder med folkeoplysning, læring og aktiviteter rettet mod befolkningen. I begge lande er der et udpræget fokus på temaerne unge, hverdagsliv, følelsesmassig og rational involvering og konflikt/konsensus. Igennem arbejdet med disse temaer udtrykkes de idealer om samfundsmæssig forandring, der fungerer som grundlaget for NGO'ernes arbejde. Tilgangen til folkeoplysning og læring varierer dog også de to lande imellem. Den konfliktfyldte koreanske historie og demokratiseringsprocessen i 1980'erne og 1990'erne er således tydelig i arbejdet med at engagere befolkningen, hvor revolutionære undertoner stadig er fremtrædende i NGO'ernes arbejde. I Danmark er NGO'erne derimod påvirket af traditionen for deliberativ demokratisk diskussion og en konsensusbaseret politisk udvikling. Tilgangen i begge lande kan dog siges at være præget af en relativt instrumentel tænkning om hvordan læring fungerer og en uvanthed med at bryde med eksisterende mønstre. 'Mere af det samme’ er gerne opskriften på at møde udfordringer på vejen mod et bæredygtigt samfund og begrænsning af klimaforandringerne.

På dette grundlag og med inspiration fra lacaniansk psykoanalyse og Slavoj Žižek's teorier analyseres det hvordan betydningen af at engagere sig i nonformel UBU kan forstås. Der argumenteres for at arbejdet med UBU muliggør en kynisk identifikation med de bagvedliggende idealer. På den ene side mødes NGO'erne ofte med nederlag når de forsøger at engagere befolkningen og ændre verden til det bedre. På den anden side kan umuligheden af at nå idealerne og de mange barrierer netop være med til at konstruere mening for den enkelte. Til at begrebsliggøre denne dynamik udvikles det analytiske begreb Bad Practice, der kan udfordre NGO'ernes opfattelse af deres arbejde på to 
niveauer. For det første i forhold til NGO'ernes opfattelse af befolkningens træghed overfor NGO'ernes budskaber. Det er vigtigt at forstå hvordan handlinger, der ikke passer med idealer om bæredygtighed og begrænsning af klimaforandringer, kan medvirke til at skabe mening for den enkelte, ved at muliggøre troen på idealer, men deres modsætninger udleves. For det andet sættes der fokus på hvordan også NGO'er selv er den del af denne mekanisme og selv tager del i hvad man kan kalde for UBU-Bad Practice, hvor den tilbagevendende brug af ineffektive læringsmetoder ikke bare hæmmer deres eget arbejde, men også strukturer og skaber mening for deres ageren indenfor feltet. 


\section{Preface}

This study reflects my interest in how the best of intentions often end up having the opposite effect. It seems that both as individuals and on a societal level we often mess the things that we value up. The field of Education for Sustainable Development (ESD) offers a wonderful opportunity of looking into this conundrum as the hard work of educators continues and a truly sustainable society remains hard to grasp or envision. All the people I have meet during the 3 years of working within the field are engaged in changing the world for the better, yet it still seems that we as a society are amiss when the question turns to how to actually do it. A sustainable world might not be around the corner, but I am convinced that ESD, both in formal and non-formal settings are part of solution, and as history shows us nothing is constant except for change, and perhaps the chance of not screwing up our planet too is part of such change.

This study could not have been carried out without the unselfish help and support of a wide array of people. I owe great thanks to my colleagues and supervisors here at the Department of Education (DPU), AU. They guided me in the world of research on learning and ESD and supported my project throughout. Discussions with colleagues in Sweden, South Korea and Australia among other places have further nurtured the findings of this study. During my field work I got a glimpse of the extremely dynamic and hard to grasp field of ESD. The NGOs involved in both Denmark and South Korea where extremely open and generous, and their insights and enthusiasm became an all important source of inspiration for this study. The anxiety involved when travelling to a foreign country like South Korea with the intentions of doing research was expelled by the wonderful colleagues at Seoul National University. Without their help it would not have been possible to include the stimulating insights from the Korean society and NGOs. At last this study could not have been done without the support of my friends and family with a special thanks to Malthe Ibsen Sørensen and my girlfriend Signe Andreasen for their relentless support and help. 


\section{Introduction}

"Moral education ought never, in any circumstances, be rational"

The Director of Hatcheries and Conditioning In Aldous Huxley's Brave New world

A sustainable life does not drop from the sky. Contemporary industrialized societies struggle to understand and incorporate notions of how to develop along a path that will ensure future generations can enjoy the same standard of living that Danes and South Koreans do at the beginning of the 21th century. This makes the concept of sustainability one of the great conundrums of our time. On one hand we want to continue the unprecedented growth that we enjoy and which enables a comfortable lifestyle. On the other hand we are now witnessing how such growth threatens our future. Education for sustainable development (ESD) is a way to understand, challenge and develop a way of living that aims to combine the possibility of living a full life while not destroying the opportunity for future generations to do the same.

The aim of this study is twofold. Firstly to understand and learn from the work of environmental NGOs in Denmark and South Korea as they address the public, and secondly to try and go beyond the concrete settings and probe the desires that are embedded in the work of conducting non-formal ESD.

\section{Non-formal ESD}

The term 'non-formal education for sustainable development' does not cover an easily outlined field of research. Focusing on the latter part of the term, UNESCO's official definition stresses that "Education for sustainable development aims to help people to develop the attitudes, skills and knowledge to make informed decisions for the benefit of themselves and others, now and in the future, and to act upon these decisions." 
(UNESCO, 2005) This presents a very broad understanding of what can be comprehended as ESD (UNESCO, 2009). Adding 'non-formal' does not really limit the scope of the term. On the contrary it introduces an almost limitless palette of settings that could be understood as non-formal ESD. The topic of this study will not be the formal educational field; i.e., compulsory schooling with a curriculum. Instead, it will focus on non-formal learning as "education, learning and training which takes place outside recognized educational institutions" (Fordham 1993). This could be workshops, community courses, interest based courses, short courses, or conference style seminars (Hamadache, 1991). In Denmark this notion of non-formal education is often connected to the Scandinavian concept of 'Folkeoplysning' that emphasises the importance of notions like lifelong learning and the development of democratic skills (Korsgaard, 2002)

This entails a focus on the work done by traditional NGOs, grassroots organisations and other social movements. This study will focus on forms of non-formal ESD that deal with climate change issues and/or other environmental issues. In short, non-formal ESD in this study will revolve around NGO initiatives outside the formal educational system focusing on climate change and environmental issues and which have an explicit strategy of influencing how the public thinks and acts in order to pursue the notion of 'sustainable development'.

\section{Denmark and South Korea}

Drawing inspiration from and qualifying a study through data from two countries vastly removed from each other both in a geographical, political and cultural sense always presents a number of inherent challenges. It also forces the analyst to look beyond the national scope that is often a part of both the fields of environmental and educational research. Choosing to study Denmark and South Korea is thus not an attempt to perform a strict comparative analysis of the relative advantages of each country in relation to nonformal ESD. Instead, it is an effort to gain a deeper understanding of two very different approaches to non-formal ESD in order to highlight the challenges that these national approaches harbour, and of how we can conduct non-formal ESD that matters to the NGOs, the public and the planet. The cases are viewed as being representative of many of 
the main issues that non-formal ESD struggles with, but should not be seen as an exhaustive foray into the field.

Choosing Denmark was a relatively straightforward choice as it would be foolhardy to undertake a study of this scale without securing a firm link to the author's interest in his immediate surroundings. Furthermore, Denmark's position as a perceived 'green country' makes it an interesting case in an international perspective (Parajuli, 2012). The fact that environmental and climate change issues figure strongly in the ongoing public debate also underlines how pointless it would be to detach academic curiosity from a fervent interest in the development of Danish society.

The choice of an East Asian country, however, does not perhaps present itself as a straightforward choice. Normal practice would have prompted a comparative study of Denmark with Sweden, Finland, Holland or another typical medium-sized Northern European welfare society. Such studies are numerous and present valuable knowledge on how differences within a distinct extended cultural sphere lead to varied practices (Stubager, 2010; Allardt, 1976; Gallego, 2008). The choice of a Southeast Asian country is, however, an effort to force a different and radical perspective onto the study, and pursue an idea of taking an 'informed leap of faith' out of the academic comfort zone. The choice to focus on two very different countries hopefully induces an inherent critical stance to the way non-formal ESD is conducted in both countries. Based on these arguments, the choice of Southeast Asia, and South Korea in particular, is no more logical than, say, South America and Chile. The chosen region and country does, however, present interesting aspects beyond the novelty of the comparison.

South Korea might seem distant and of little importance to Denmark compared to its bigger neighbours China and Japan, but therein also resides a number of possibilities. There are major differences between Denmark and South Korea, but important similarities also exist. South Korea is a relatively small country compared to its neighbours and like Denmark relies heavily on a high level of education among its population in order to stay competitive: with heavy industrial production increasingly outsourced to countries such as China and India, countries with a high standard of living must find ways to secure their development in a globalized market economy. The country depends on a highly evolved liberal market economy which also guides much of the 
official 'Green Growth' policy that was officially adopted in South Korea in 2003, mirroring the Danish move toward an ever tighter relationship between financial interests and efforts to promote sustainable development (Taehee, 2010)

In both countries we also find traits of what can be seen as non-formal ESD, as witnessed in the Danish notion of 'Folkeoplysning' where a strong focus on lifelong learning and non-formal adult education is regarded as a cornerstone of the development and continued success of the Danish democracy (Læssøe, 2007a: 122). In South Korea the tradition of 'Dure' is an institution and a method of cooperation. It derives from the early Joseon Dynasty (1392 - 1897) where farmers pooled their workforce in special situations in order to overcome labour-intensive periods and ensure enthusiasm about the work that had to be done. The Dure tradition also fostered a focus on the importance of cultural aspects of solving problems through music and art and remains an important part of Korean society (Bunkowski, 2003: 6). The Danish 'Folkeoplysning' and the Korean 'Dure' do not of course correspond on all levels, but they are both indicators that nonformal ESD within these two countries draws on distinct traditional cultural settings for non-formal education and knowledge sharing.

Non-formal ESD has a very different history in the two countries. In Denmark non-formal ESD can be understood as a product of the social and political changes during the late 1960s and early 1970s where grassroots movements emerged and raised criticism of how modern society exploits natural resources and triggers the extinction of species. During the Seventies, the grassroots movements held a strong position in Danish society and politics, and they managed to prevent the construction of a nuclear power plant in Denmark. During the Eighties, larger, professional organisations such as Greenpeace and WWF took over and focused to a greater extent on political activism and lobbyism than on civil society involvement (Læssøe, 2007a: 235). Before the 1980s, environmental organisations and grassroots movements had no say in South Korea. The booming economy that had seen the country transformed from a third world developing country to a sprawling world economy in a matter of decades had left little room for concerns about the environmental consequences. This changed during the Eighties when the environmental movements started addressing the environmental changes that were becoming increasingly obvious (Esook, 2006: 76). 
Since then both countries have moved though the phases of the so called ecological modernization and a growing emphasis on market-based solutions to the ever changing challenges resulting from environmental and climate changes. South Korea is now in a situation where there is a strong focus on the environmental consequences of five decades of explosive growth, and also a growing understanding of the dire effects that global warming will have on the peninsula. Activities to engage civil society in the issues of climate change and environmental challenges, and to incite the population to act on these problems, are growing throughout the country, backed by a strong governmental support (Ying et al. 2009: 784).

Choosing Denmark and South Korea as cases for studying contemporary non-formal ESD presents great possibilities for exploring the cultural differences that affect how the field is developing and determining which challenges should be pinpointed in order to encourage a critical and informed understanding of the field and facilitate further development. However, it also traps the study within the confines of the construction of the nation state, and thus fails to respond to the truly global nature of the challenges at hand. Even though it could be argued that the choice of cases negates some of these problems, in as much as the two countries could be seen as representing different regions, it still does not circumvent the problem that a truly global study of how nonformal ESD is developing and which barriers it meets is unlikely to ever surface. The cases at hand, in the classic traditions of the liberal arts, therefore represent the author's take on the best scenario for generating understanding and analysis which may serve as a call to arms.

\section{Research Interest}

This study reflects an interest in how meaning is created by the individual in contemporary society, and especially how different notions of the 'rational' are constructed, often entailing choices that are seemingly rational and common sense, but which in a longer term perspective might prove counterproductive to fulfilling notions of the good life. The dissertation will be an examination of what is seen as rational 'truth' within the field of non-formal ESD and how this correlates with the actions and perception of the environmental NGOs. 
Much of this study draws on the field of sociology. Max Weber has raised the issue of the 'rational' paradox. This concept stresses the relationship between formal rationality and substantial rationality, where substantial rationality can be pushed aside by a logical rational agenda (Turner, 1992: 117). This paradox is illustrated by Weber's Stahlhartes Gehäuse, where individuals are controlled by an unavoidable calculation of effective means to reach distinct goals which have the possibility of undermining the individuals' opportunities to pursue a life based on values and ideals (Weber, 1995:121122). This notion, that the ideals which we pursue also have the potential to lead us in directions we do not want, is a central theme to this study. A way of understanding and analysing these issues is via inspiration from Lacanian psychoanalysis and the contemporary take on this by the Slovenian thinker Slavoj Žižek. Their epistemological approach, combined with the Weberian focus on different levels of rationality, is an important part of the curiosity that guides this study.

Conducting research in a field like non-formal ESD which sometimes resembles more a battleground than a space for deliberation and cooperation in service of a greater good does offer certain advantages; there is always something new going on and the possible perspectives are almost limitless, but the fact that the field is so contested also carries some disadvantages. That the field moves so fast and deals with contemporary problems makes it almost impossible to remain 'neutral' and not get involved. During the data collection under COP15, and during interviews with key persons from the NGOs in the following months, it was impossible not to feel more attracted to some organizations' take on non-formal ESD than others. That being said, the author is not a member of any environmental organization and views himself as an informed outsider, trying to assume the role of the 'critical friend' in an effort to strengthen the field of non-formal ESD.

Nevertheless, it must be made clear that it impossible not to be influenced by discourses provoking greater scepticism toward some of the prevalent ideas in the field than others. This corresponds well with this study's general epistemological foundation which stresses that no theory, understanding or conception of any social phenomenon can be implemented without forcing itself onto a diversity that will never be fully encapsulated by any approach. In such a perspective, theorizing the social will always manifest itself as violence against 'reality'. No matter how hard we try to include all possible perspectives, 
something will always be lost in the translation from the 'real' to language and the written word.

Of course this only underlines the importance of critical navigation between theoretical stances and the need for a continuous development of theories concerning our perceptions of the society around us. This study should be seen as a contribution to this, and far from a definitive take on the 'evident' workings of NGOs within the field of nonformal ESD.

\section{Research Question}

Based on the above considerations, the aim of this thesis is to explore the following primary research question by analysing two specific sub-questions.

Overall research question:

- What is the significance of engaging in non-formal ESD?

Sub-questions

- How do Danish and Korean NGOs in the field of non-formal ESD understand and engage the public as a learning entity?

- What is the significance of the NGOs perceptions of the relationship between the public and the NGOs in the field of non-formal ESD?

The sub-questions stress the dual focuses of the study which, although intertwined, represent two different agendas. The first sub-question relates to the empirical analysis of how the individual NGO staff members understand their work and think about the public that forms the basis of the study. Using the notion of the public as an 'learning entity' has been develop through the work with the empirical material, but also rests on an assumption that it can be claimed that the public, or parts of it, can be viewed as a entity that can be engaged through educational activities. This represents an effort to understand 
and visualise a varied field and be able to extract particularly interesting topics and examples. The second sub-question draws on an interest in theory development and the possibilities of establishing new ways of thinking about non-formal ESD. The focus of this part of the analysis is the significance of the individual NGO key person's perceptions of the public and the NGO's role in relation to the public.

By answering these questions, the intention is to add another layer to the discussion of how to understand the path towards sustainability, ESD and the challenges of non-formal ESD via an exploration of the role of the individual's key person's perceptions about these topics. The approach chosen is to analyse the two sub-questions from different perspectives. To do so requires that these perspectives are developed into a concrete and theoretically, empirically, and methodologically based research design. This will be the emphasis of the next chapter. 


\section{Research Design and Theoretical Inspiration}

This study builds on two distinctive cases: The efforts of, respectively, Danish and South Korean environmental NGOs to engage the public in the issues that they find pressing. In order to translate these cases from the activities and reflections of the individual NGO staff member into an academic study, it is essential to take decisions on how to delimit, collect and interpret data. This calls for the development of an analytical strategy, a theoretical framework and an applicable methodology that has the potential for making the invisible visible, to illuminate certain attributes of a more general order emerging from the empirical experience (Egmose, 2011: 43). By developing and applying a theoretical framework there is always the risk of forcing a square peg into a round hole or reaching conclusions already inherent to the theoretical outset. None of these strategies adds scientific validity or value. The ability to critique both one's own theoretical assumptions and that which is being taken for granted in the empirical field is therefore key to letting new insight emerge. Both the theoretical and the empirical basis have the potential to provide new insight, but they also enter the study with certain prerequisites. At the same time, new insight should also be able to emerge through the combination of the empirical data and the theoretical framework. The following is an attempt to make transparent the choices regarding the overall research design, the methodological choices, and the theoretical framework that demarcate this study.

\section{Two Levels of Analytical Logic}

When discussing the research design, methodology and theoretical framework, it is helpful to remember the classic Marxian distinction between the logic of performing analysis and the logic of presenting analysis (Ilyenkov, 2008: 13). Two different processes are at play; an open, interpretive and at times unwieldy analytic process is needed in order to extract the maximum from the empirical data, yet the final product must assume a distinct pedagogical form that presents the analysis via a comprehensible structure. Sections 2.2; methodology and 2.3; theoretical inspirations describe the logic of performing analysis, with an emphasis on the abductive nature of moving between empirical insight and theoretical inspiration. Section 3.4 describes the logic of presenting this analysis, applying the metaphor of an accelerating presentation of the analysis. 


\subsection{The Overall Research Design}

The analysis that forms this study focuses on the individual NGO staff member's perceptions of the public as a learning entity and the role of NGOs in relation to the public. This focus stems from an interest in the practical and theoretical importance of how the individual subject, the key person, perceive the public as an entity that should be engaged and educated. It also reflects considerations about how to delimit the scope of such an interest and the possibilities of acquiring data material.

The potential field is huge, with hundreds of NGOs that could have been part of the empirical data collection. Apart from the number of NGOs involved, the number of different stakeholders that influence the field is potentially limitless: governmental, financial, political, environmental etc. The analytical choices of this study emphasize the individual NGO 'key person' as a way of cutting though the empirical 'noise' that surrounds any given social object or process and trying to pinpoint a specific theme and analytical field while acknowledging that nothing exists in a vacuum. The chosen analytical field and the strategy for retrieving data are designed in order to move from the multifaceted and elusive setting of non-formal ESD towards a specific perspective for understanding ESD in a real life setting. It is important to note that the notion of ESD, with its links to the UN and the UN Decade of Education for Sustainable Development, is not explicitly deployed by all of the NGOs involved in this study.

This does not, however, clash with the understanding of the term proposed by the UN: "Education for sustainable development (ESD) is not a particular programme or project, but is rather an umbrella for many forms of education that already exists, and new ones that remain to be created" (UNESCO, 2009). The notion of ESD may be at the centre of this study, but in several cases the NGOs involved paid little attention to such a notion. Most of the interviewees are familiar with the term and are applying it to their work on a daily basis, but not all. The NGOs are nevertheless, for the sake of this analysis all understood as partaking in versions of what the UN describes as Non-formal ESD. All of the NGOs involved share an overall focus on environmental and climate challenges, and on education in non-formal settings. 
The NGOs involved in this study are thus understood as participating in various forms of ESD, whether they know the term itself or not. This demands a broad understanding of the term ESD and its application in a non-formal setting. Of interest here is not to what extent NGOs use the actual term ESD, but how its constituent elements education, sustainability and development are interpreted, combined and applied by the NGOs. Rather than extrapolating principals of the UN definition of ESD onto the practice of the NGOs, the goal is to understand how the NGOs deal with the core concepts of ESD, explicitly or implicitly, and how 'non-formal' education, is understood by the NGOs. A descriptive mapping of how NGO key persons perceive the public and their own role is part of this, in order to understand how such an elusive conception as the 'public' is engaged, but this still leaves the question of what the significance of such perceptions might be.

The approach to analysing such a question and the overall field relies on centrally positioned staff members or 'key persons' who deal with the public and activities related to non-formal education. These 'key persons' thus become the main point of entry into the analysis of the activities and everyday workings of the NGOs within the field of ESD. This focus is inspired by Eyerman and Jamison's concept of 'movement intellectuals' (Eyerman \& Jamison, 1991). Such individuals are regarded as central to the articulation of the collective identity of a movement or organisation. They can act in prominent positions as organisers, leaders or spokespersons. An important aspect of such 'movement intellectuals' is that they create situations which facilitate the spreading of the organization's messages to movement members and the general public (Eyerman \& Jamison, 1991: 94). The interviewees involved in this study are all understood to have a role along these lines and are thus identified as 'key persons' within their respective organisations.

Through these key persons, the study strives for a deeper understanding of the perceptions and their significance within environmental NGOs, as inspired by the Swedish sociologist Johan Asplund: “...after the cause for a phenomenon is indicated, we can continue with the question of the significance of this phenomenon" (Asplund, 1970: 65). The primary concern is not only to contextualize, map and present how the environmental NGOs engage the public as a learning entity. The task is also to inquire into 
the significance or meaning of the NGOs perceptions about the relationship between the public and the nongovernmental organisations. The outset for the different parts of this analysis is thus the NGOs and the interviewed key persons. As such the point of interest is to understand what the perceptions of the public and the organisations efforts toward the public mean for the NGOs and what the significance is for the key persons of engaging the public with and without success.

The process of this study and the journey into the field have been characterized by both a steep learning curve for the author, with little prior knowledge of either ESD or environmental NGOs, but as a consequence also with a certain level of openness. There was no preordained 'villain'. No set choice of theory or methodological approach. This situation has developed as the study has moved along, with the constant being an enduring interest in how the NGOs understand and engage the public as a learning entity. That also means that, even though the overall research strategy, the choice of cases, and the empirical focus have been part of the study from the start, the theoretical focus and the analytical themes has been developed based on the empirical data, not the other way round. The study is an empirical study that ultimately aims to present knowledge about practices in the field and hopefully give something back to the people who actually constitute the field. This does not mean that an abstract theoretical bias is not present, but it means that such emphasis on theory should be understood as having been developed through the work with the empirical material.

\subsection{Methodology}

Choosing a research method is just as much a matter of identifying a potent mix of approaches as it is a way of understanding the epistemological and ontological background and interest of the author. The methodology that frames this study is thus both a way of pushing the limits of established knowledge and an inquiry that is set within an explicit humanistic and hermeneutic research tradition. It is an effort to answer the research question though the means of qualitative research and satisfy the curiosity about the field that drives this study. Below, I will shed some light on the logic of performing analysis that is applied in this study and explain the reasoning behind it. 


\section{An Abductive Analytical Process}

The traditional dichotomy of the hypothetico-deductive and the inductive approaches is often met when wanting embark on research in the field of the social. However, by establishing this strict dichotomy, an important third method, the abductive method, is overlooked (Haig, 2005). The abductive method was introduced by Charles Sanders Peirce, who argued that little new knowledge can be generated from hypotheticodeductive research, as it is confirmatory in nature and thus the conclusion is embedded in the premise (Seebok, 1979, Anderson, 1995). Likewise he argued that induction cannot lead to genuine new ideas, only to superficial conclusions, and never to the nature of things, as induction only leads to empirical laws and never theoretical laws (Anderson, 1995). While this might seem like a harsh critique of both the deductive and inductive approaches, it emphasises how this study is a result of a constant movement back and forth between the empirical data and the theoretical inspiration.

As the foundation of this study is not a grand theory on ESD and the public as a learning entity, but rather theories pieced together, it is difficult to frame the dissertation as being strictly deductive. There is simply not a lot of existing knowledge on the subject to be 'tested'. However, the thesis is not truly inductive either, as the analysis is not solely based on empirical data, but rather on interaction between existing theoretical knowledge about different elements of the issue and the empirical findings. The thesis thus mixes the two scientific approaches, which makes the abductive approach relevant.

Supporters of the abductive method regard the research process as circular, rather than a linear process going from either theory to reality or reality to theory. Against this backdrop a truly abductive approach combines, deduction and induction by moving between these concepts in order to achieve the most fruitful analytic process: '... the researcher, by constantly going "back and forth" from one type of research activity to another and between empirical observations and theory, is able to expand his understanding of both theory and empirical phenomena.' (Dubois and Gadde 2002: 555) By combining the inductive and deductive approaches, abduction in a way makes use of the strengths of both '...not only of the systemic character of the empirical world, but also of the systemic character of theoretical models.' (Dubois and Gadde 2002: 556) Abduction is closely linked to the hermeneutic tradition, where interpretation of empirical findings is 
circular or spiralling, i.e. relating the whole to the part and the part to the whole, thereby gaining knowledge that cannot otherwise be obtained (White, 1997).

This study does not aim, in a Popperian sense, at falsifying a theory (Popper, 2000: 121). Rather it aims at conducting an exploratory rather than confirmatory data analysis. It rests on the belief that there are millions of possible explanations of a phenomenon, such as how NGOs perceive the public as a learning entity, making it difficult to falsify each and every one. Therefore one has to accept and acknowledge that it is not necessary to know everything in order to know something.

The abductive method presents a very generative approach to research and aims at generating hypotheses, rather than confirming them (Yu, 1994). The generative element fits the point of departure of this study well, namely a curiosity about possible paradoxes in the perceptions of the learning relationship between environmental NGOs and the public. An explorative research strategy such as the one described above is a better fit for some studies than others. Working with the two cases of Denmark and South Korea can be argued to align with the use of an abductive approach as "case studies enjoy a natural advantage in research of an explorative nature"(Gerring, 2001: 39), and they consist of highly circular processes which aids a theory generating process. At the same time case studies are less suitable for falsifying a hypothesis or considering it definitively proved. This study combines the explorative research strategy of abduction with a case study approach, which will be elaborated further below.

\section{A Qualitative Case Study}

The qualitative case study approach of this thesis is an effort to facilitate an in-depth analysis of the relationship between environmental NGOs and their perception of the public as a learning entity in Denmark and South Korea. Focusing on the nuanced perceptions and processes that the NGOs and their staff members are part of is made tangible by involving the concrete cases of Denmark and South Korea. The aim is to benefit from the case studies which can "provide unique means of developing theory by utilizing in-depth insights of empirical phenomena and their contexts" (Dubois \& Gadde, 2002: 555)

Since this study deals with highly differentiated structures of meaning which 
are difficult to fully grasp and unfold in e.g. a large quantitative survey, the qualitative case-study approach provides the better alternative. Case studies also prove particularly useful in identifying and exploring what Flyvbjerg, building on Popper's famous proposition 'all swans are white', calls 'black swans'; i.e., somewhat paradoxical findings which might not be visible from afar, but which become apparent upon closer examination (Flyvbjerg, 2006: 294). This analogy fits the study quite well, as the cases clearly reveal that any notions of a uniform environmental movement are marred by the distinct differences and different perspectives of the NGOs. Case studies are often criticised for a lack of explanatory power or external validity. However, Flyvbjerg and Gerring, among others, argue that this critique represents a common misunderstanding which is overly simplified and hence misleading. In opposition to this common stance within the social sciences, Flyvbjerg argues that whether or not one can generalize on the grounds of a case study depends on the case in question and, not least, how it is chosen. In other words one cannot rule out the possibility of generalization simply because of a choice of method (Flyvbjerg, 2006: 393) However, case studies do not allow for statistical generalizations; instead the inference is analytical (Dubois and Gadde 2002: 559). Following these arguments, this study seeks to produce findings of interest to the different research fields that are involved in the emerging areas of ESD research as well as Environmental Education research. The empirical findings are thus expected to have theory generative potential of general use within such fields (Bryman, 2004: 285).

\section{Data}

Case studies are inherently linked to the type of data that can be produced and the main empirical data used in this study falls within two overall groups. The data collected before, during and after the sharp rise in activity connected to the COP15 global summit held in Denmark in December 2009, and the data collected during a 3 month stay, autumn and winter 2010, in the South Korean capital Seoul. Within these two datasets there is another important overall distinction to make. Focusing on how key personnel within different environmental NGOs perceive the public as a learning entity, and their own role as public educators, the main focus will be on interviews that were conducted during 2010 in Denmark and South Korea. In a perfect world this material could stand on its own and 
describe how the interviewed persons perceive and think about the public and their own role towards it. The interviews did stress precisely the individuals' perceived relationship to the public and their own work, and this relationship is also expressed in countless other ways, impossible to capture through a relatively short interview. During the data retrieval process, a great amount of energy has been spent on gathering a large array of different material that will be used as input to ensure an ongoing contextualization of the analysis of the interviews and the themes they dwell upon. This 'contextual' material is not so much the result of a planned attempt to systematically cover the field, but more a collection of different material that either turned up as part of the interview process, or more often simply happened to be available at the right moment. The urge to perform an exhaustive mapping of such complex and varying organizations as the environmental NGO's presents an interesting prospect. Especially as masses of knowledge exist within the many different informational channels that a society driven by information harness. It could, however, also cloud the perspective of this study with the risk of fostering an unwieldy entity with everything seeming interesting and immensely detailed, but impossible to synthesize into a tangible idea or possibility of development.

While this could mirror parts of the indefinite complexity of the social, it would also present a major obstacle when taking the step from data collection to analysis. It is easy to get bogged down in data with little chance of acquiring a structured perspective on the material. The secondary material that has found its way into this study nonetheless offers an important and humbling lesson in not taking everything the primary material indicates for granted and constantly forcing a good measure of contextualization into the analysis. The secondary material thus covers information materials from the various NGOs participating in the activities surrounding the COP15 summit and a large number of internal documents describing the discussions and focus points of the Danish NGOs during COP15 and their work to channel funds from the Ministry of Foreign Affairs toward a multitude of civil society activities. From South Korea, a large number of educational materials, publications, and other documents in both English and Korean are also part of the contextualization of the study.

The handful of environmental NGOs included in the present study cannot provide an exhaustive analysis of current developments. It can, however, be argued that 
they present a broad picture of the contemporary environmental movement with its various interests, opinions and desires, and of the educational ballast of environmental NGOs in Denmark and South Korea. The choice of NGOs is thus an attempt to both cover the breadth of different environmental NGOs in both Denmark and South Korea. The specific NGOs will be described in section 3.2.

\section{Interviews}

The interviews that form the bulk of the data for this study were conducted in a 'semistructured' way to ensure desired topics would be covered, while at the same time allowing for a certain amount of flexibility in the order of the questions as well as openness to pursuing interesting or surprising responses by probing further (Kvale, 1997:129). The process relied on a written interview guide, but great effort was put into making the conversations open and generative in nature, instead of following a strict pattern. The interview guide was developed via a processual focus on first establishing the fields of interest and then transforming each field into one or more questions ${ }^{1}$.

The interview guide was initially prepared in Denmark, and reviewed and revised several times during its use in both Denmark and South Korea in order to develop the initial research questions and identified items into interview questions in an everyday language with no academic terms (Kvale 1997: 133, Bryman 2004: 324). To ensure that the interview guide 'made sense' locally, it was discussed with members of both Danish and Korean environmental NGOs before the actual interviews were carried out. These discussions led to several changes in e.g. the order of the questions posed and the phrasing of each question, and they also generated new questions.

The targeted interviewees are 'key-persons' within the NGOs dealing directly with educational approaches to the public. In most cases this means heads of educational departments or staff members in charge of engaging the public. Some of the NGOs do not, however, deal explicitly with notions of 'education', but nonetheless work with concepts that arguably can be understood as falling under the remit of non-formal ESD. This includes several of the interviewees who are in charge of campaign planning,

\footnotetext{
${ }^{1}$ See appendix 1: Interview guide.
} 
initiating participatory activities, and/or communicating the views and intentions of the NGO to the public.

The process of data collection was quite different in Denmark and South Korea, as the context and deadlines varied. This led to different and at times surprising findings, and also to deeper understanding of the distinctive settings of the two cases.

\section{Ethical Considerations}

Several ethical considerations are at play when doing research on the social and especially when producing empirical material that forms the platform of theoretical analytical research. Different positions are held by a researcher and the respondents in the process of collecting empirical material (AERA, 2006). In this study the primary respondents represent different Danish and Korean environmental NGOs. The interviewees have vested interests when discussing their perspectives. These naturally differ from the interests of the researcher. It can be claimed that partaking in this study is not only a way of bringing information to the researcher, but also a way of presenting the respondents respective organizations in the most favourable light. Different personal, political and ethical considerations of the respondents might also bias the opinions, views and perspectives expressed. These concerns have been part of the process of developing the interview guide.

The NGOs' key employees that took part in the data collection and the interviews all did so voluntarily. They are presented anonymously in this study and described as 'interviewees', 'respondents', 'representatives' etc. Before commencing the interview the respondents were all informed that the name of their organization would be presented in the study, and none of them expressed any concern about this matter. It can be argued that insiders from the organizations or even the overall field might be able to guess and identify the names of the respondents via the opinions expressed in the interviews. It has however still been chosen to present the names of the NGOs, as this is understood to strengthen the study without compromising the rights or integrity of the interviewees.

The topic of this study is not understood as being sensitive to the privacy, working environment and wellbeing of the interviewees. This is demonstrated by the fact 
that all of the interviewees have publicly uttered opinions of the same nature as those in the interviews either in print or through public presentations before and after the process of data collection. Furthermore the questions that guided the interviews all relate to the professional lives of the interviewees, and do not touch upon their personal lives.

\section{The Data Collection Process - Denmark}

Navigating the sprawl of activity that marked the time before, during and after the COP15 summit in Copenhagen December 2009 introduced a number of challenges to the process of collecting data. For one, the number of activities and stakeholders involved, both in the form of NGOs and state backed initiatives, was startling. Efforts to map the activities and devise a strategy were often thrown into disarray by the emergence of new possibilities and activities. The process of identifying the most interesting NGOs for this study was nonetheless only possible by attending as many as possible of the different debates, demonstrations, educational activities, hearings and many other forms of events and activities that took place.

The aim was to get a broad and, as far as possible, representative take on what is going on in a Danish setting. Such an aim could not disguise a tendency to look more towards organizations that presented new and promising perspectives to the eye of the beholder. The NGOs represented in this study all played an outspoken role during the COP15 process and actively participated in the many discussions which proliferated at the time both within the media and at various public debates and events. During the autumn and winter of 2009, approximately 15 environmental NGOs were listed by the author and supervisor as the most interesting in the context of this study and subsequently contacted. This list was influenced by discussions with colleagues and actors from different NGOs and the end result was five interviews which took place at the beginning of 2010. Each of them is between one and two hours long, and in most cases subsequent follow-up e-mail correspondence and further discussion took place.

These interviews comprise the core data, but they also constitute the proverbial tip of the iceberg in relation to the secondary materials, in the form of publications and discussions, that help contextualize this study. In comparison with the South Korean case, the five interviews represent relatively fewer NGOs, but this should be 
seen as an outcome of a process where time and resources permitted a more detailed look into the work of the NGOs perceived as the most interesting. During the three month field stay in Seoul, a larger number of key persons from NGOs were interviewed due to a constant fear of returning to the far away Denmark with material that had a radically different nature, due to possible language and logistic challenges, compared to the Danish material. Most of the interviews from Seoul did, however, measure up to their Danish counterparts.

\section{The Data Collection Process - South Korea}

When focusing on ESD in a Danish and 'western' setting, South Korea is somewhat off the beaten track. Many people in the field of education may be aware of South Korea, mostly as a high scorer in the international PISA tests, and a strong economy with an ongoing focus on 'Green Growth'. While preparing a trip to such a country, it is easy to get lost in the bewilderment of travelling to a very different country where culture, language, history and ESD practice are extremely different to Denmark. Brushing up on language skills, digesting every available English language paper on the topic and spending time preparing the data collection process with contacts at Seoul National University, it became quite clear that, although different and exotic, even the most faraway place quickly becomes local when spending sufficient time there. The special history of South Korean Environmental NGOs, the many links between the organisations and the substantial number of people that swapped jobs between the larger NGOs, meant that an initial pattern of recognition developed into an understanding that, even though South Korea is a vastly different country, many of the same mechanisms that apply in Denmark also apply when trying to Koreans NGOs.

The task of identifying which Korean NGOs are of most interest to this study could not have been undertaken without ongoing support from the Department for Environmental Education at Seoul National University. Several South Korean colleagues offered substantial help in this process. From the head of the department to freshmen, all seemed to have a varied knowledge of the environmental movement in Korea. The major environmental NGOs could be identified based on academic papers, but many of the smaller NGOs are either not described in the international literature or mentioned so 
briefly that their focus and activities are very hard to gauge from afar. Based on input from various South Korean colleagues and the available literature, it was possible to compile a list of around 20 relevant NGOs that focused on the educating the public on environmental issues. During prolonged discussions with colleagues from Seoul National University the list was further reduced to around 15 of the most interesting environmental NGOs in South Korea. These NGOs all have a focus on the public as something that must be engaged, often through a dedicated educational department at the organization or explicit strategies and tangible goals for this process.

An initial target of around 10 interviews with the most relevant NGOs in Korea made the number 15 viable when drafting a prioritized list of which NGOs should form the basis of an analysis of the South Korean case. This process ensured that varied samples were singled out and, but also a degree of flexibility as the selected group of NGOs constantly evolved as new input and new possibilities presented themselves.

The interviews that were eventually secured represent discussions with 14 different informants within 9 different South Korean environmental NGOs. Interviews based on the interview guide have been conducted with 9 of these informants; other forms of more informal discussion and enquiry have taken place with the remaining five. As in the Danish case, a large amount of secondary material was also secured, ranging from books published by the NGOs, brochures, documents and such, but also including observations made during visits to several NGOs such as the KFEM centre in Seoul and during an environmental education class at the Korean Environmental Education Centre (KEEC).

Collecting data in Korea and conducting interviews with Koreans, who are not always fluent in English, posed certain challenges. Most of the interviews from the Korean case were conducted without the help of a translator, as the interviewees had a sufficient level of English language skills in order to enter a meaningful discussion. Two of the interviews did take place with the aid of a translator proficient in both English and Korean. Great effort was spent on avoiding misunderstandings and ensuring that open questions allowed for the context and issues of importance to the individual interviewee could be reflected in the conversations. There is, however, no doubt that something will always be lost in translation, and that a native Danish speaker interviewing a native 
Korean speaker in English offers plenty of opportunities to miss the point, but alas this seems to be hard to avoid.

The interviews were recorded using a Dictaphone. This was done in order to document the interviews and get the most accurate foundation for the subsequent analysis, and to ensure the possibility of returning to the interviews to avoid misinterpretations (Kvale 1997: 161).

\section{On the Two Koreas}

Throughout this study, South Korea will be at the centre of both analysis and discussions. It should, however, be noted that today, two distinct Koreas exist. The communist, largely inaccessible country of the Democratic People's Republic of Korea, more commonly referred to as North Korea, and the liberal democratic Republic of Korea, known as South Korea. The work at hand solely focuses on the dynamics, NGOs, environmental policies, practices etc. found within the South Korea. North Korea is almost impossible to enter with any ambitions of undertaking critical research, and the conditions there are extremely different from those found in Denmark. Of course, daily life in South Korea, and Seoul in particular situated only $40 \mathrm{~km}$ from the border, is influenced by having a neighbour it is still formally at war with. All these influences have, however, not been the subject of the study, and the otherwise extremely interesting and sometimes explosive relationship (the famous North Korean shelling of the nearby Yeonpyong Island happened during the data collection process in Seoul) will not be a part of this work. When 'Korea' is mentioned in this study, it should thus not be understood as a political statement seen from someone who wants to see the Korean peninsula unified, but a pragmatic use of a country's name that mirrors the local South Koreans description of their own country. Whatever great academic interest and possibilities that to be found in the ongoing conflict between North and South, it did not feature in any way during the interviews with the different key persons from South Korean NGOs, apart from discussions of the extraordinary wildlife that exists near the no man's land of the Demilitarized Zone between the two countries. The focus will thus be only on the South Korean side of things and when discussing 'Korea', 'Koreans', 'Korean' politics, culture and industrialization etc. this should be seen as a reference only to South Korea. 


\section{Initial structuring of the interviews}

After collecting the data, each interview was processed in order to develop it from the multifaceted nature of unhurried and open interviews into a form that could be used in analysis. The process can be compared to what abductive theorists' term "detecting phenomena" (Haig, 2005: 373) by this Haig among others points out the difference between data, phenomena and theory. Phenomena are a form of empirical generalisations or tendencies in the data. Through subsequent analysis of detected phenomena it is possible to generate theory. In other words theories, in Haig's perspective, aim at explaining phenomena, not data in their raw form.

The interviews were not transcribed but listened to several times in their unedited form during the initial phase as well as during the process of analysis, and particularly crucial parts were revisited repeatedly.

The initial processing of the interviews or 'phenomenon detection' was enabled by a thorough structuring exercise. The process of the initial structuring made use of a mix of open themes, whereby unexpected phenomena or topics in the data were able to manifest themselves, and already established themes which were primarily those themes and interests already applied to develop the interview guide (Kvale, 1997:190). To ensure as little manipulation and error in the process as possible, all interviews went through this process twice. Furthermore the interviews have continuously been reviewed throughout the process of analysis, thereby practising 'constant comparison', in an attempt to keep a tight link to the data and ensure that as few phenomena as possible were overlooked (Bryman, 2004: 403).

The initial structuring and categorising of data enabled a condensation of the phenomena into more manageable analytical themes. This means that the following analysis sometimes presents raw data in the form of quotations while also making use of the overall themes established during the initial process of structuring. 


\subsection{Theoretical Inspiration}

In order to utilize the empirical material in answering the research question, the study draws on distinct theories of the social. The study combines a relatively open hermeneutic reading of the empirical material with inspiration from the French psychoanalyst and philosopher Jacques Lacan and the contemporary Slovenian sociologist and political theorist Slavoj Žižek's blend of Lacan, Hegel and Marx (Lacan, 2006a; Žižek, 2006b). The combination of a hermeneutic stance and Lacanian psychoanalysis is an attempt to draw the best from both: the hermeneutical focus on interpreting the social and Lacanian psychoanalysis with its focus on how the unconsciousness guides us and is highly affected by the social (Žižek, 2006a: 22). This approach is based on an epistemological assumption that all theories of the social represent possibilities for understanding and interpreting the social, but also ultimately distinct levels of theoretical violence upon the multitude of factors and facets that influence and guide individual actions and reflections. The victim of this theoretical violence is both the unfathomable Lacanian all-encompassing 'Real' and eventually also the empirical data that is the subject of the probing by the chosen theoretical perspectives (Lacan, 2006a: 58). As became clear when conducting interviews in Korea, something is always lost in translation and this also applies to theoretical translations of the social. This is not only to argue that the multifaceted nature of any social process and relationship is ultimately lost when applying different theories to it, but also to emphasise that the Real is always lost to the subject and translating any encounter into empirical data and understanding it through the lens of theory is also a way of liberating meaning and understanding. This discussion continues in chapter 5.

Such an assumption draws on sociological and philosophical theories linked with social constructivism, but have also been nurtured on the basis of the theories of Lacan and Žižek. This entails that there is little hope of transcending such theoretical violence because statements on behalf of the social always need to emphasize certain areas of the irreducible Kantian Ding an sich. Theoretical violence on the social is thus not to be entirely avoided, but this neither means that the Ding does not exist, nor that it is possible to completely eliminate theoretical violence. With inspiration from Lacan (and as thoroughly discussed in chapter 5), theories of the social are understood as missing something, as being incomplete in their descriptions, but, at the same time, their 
incompleteness makes it possible to identify the lack that cannot be represented. This can take the form of addressing gaps in the fabric of the social, where some social practices remain unexplained or materialise as paradoxes. This is where theoretical analysis has the potential to add new layers of understanding of what cannot be fully comprehended or translated into language. At the same time, it can be argued that certain ways of introducing theoretical violence into the social are more intrusive than others. The effort of this study is to learn as much as possible from the empirical data while combining different levels of theoretical violence, from a hermeneutic take on providing a voice to the interviewees to a highly conceptualized take on Lacanian psychoanalysis.

\section{Theoretical Grounding of the Research Question and Sub-questions}

The research question and the fundamental interest in the field have influenced and guided the methodological reflections and theoretical framework. The choice of theory is thus inseparable from the research question as such choices are rooted in the perspectives and insights that the work with the overall research question and the sub-questions has offered. Embedding the research questions into the overall theoretical perspectives reflects the abductive process that involved the empirical data, the research questions and the theoretical interests and bias of the author. A consequence is that no definitive demarcation line exists between the overall research question of the thesis and the applied sub-questions. The sub-questions do signify distinct analytical perspectives, but in essence they form a part of the overall question at hand and they combine in and act as the principal guidelines for the work with the empirical data and the theoretical inquiries.

The overall research question "What is the significance of engaging in nonformal ESD?" has evolved from an interest in how the many actors involved in nonformal ESD, and in this case the work of the environmental NGOs, keep their spirits up while engaging in work that seemingly meets massive resistance. From a policy standpoint there have been successes, especially concerning issues linked with 'economic modernisation', 'green living' and the move towards notions of 'Green growth' and lower levels of CO2 emission. At an individual level, for both Danes and South Koreans, it can be argued that personal goals of success and prosperity are still at odds with much of the environmental NGOs' teaching. Focusing on the significance of engaging in non-formal 
ESD is an effort to focus on the individuals' perceptions of how the work they do is worthwhile. The overall research question probes how meaning is created around an activity that others might liken to a desire to fly to the moon: it might be possible, but remains beyond the means of most. Using the word significance is a nod to the influence of the sociological perspective of Johan Asplund and his aforementioned emphasis on a will to go beyond the cause and effect of a given phenomenon and ask what it means. This is the site of the struggle to incorporate Lacanian psychoanalysis into an analysis of the 'educational' efforts of the NGOs. The setting is the social, but under the prism of the analytical inquiry is how the individual creates meaning via the social.

In order to answer such a question, it has been deemed of great importance by the author to postpone the direct use of Lacanian theory until a robust empirical foundation is established before unleashing such an intrusive theoretical position. Lacanian theory and Žižekian philosophy have their merits, but a great understanding of the value of empirical data and field work are not among them. In order to answer the overall research question and still balance the urge to obtain empirical data and treat it as fairly as possible with a great interest in the potential of Lacan and Žižek, the two sub questions have their own theoretical premises and potentials.

\section{The First Sub-question}

This first sub-question sets the scene for the analysis and paves the road for the second sub-question and the by asking the important question of what is actually going on in the field:

How do Danish and Korean NGOs in the field of non-formal ESD understand and engage the public as a learning entity?

This question, however, is informed by an effort to avoid strict macro-theoretical guidelines for the handling of the empirical material. It would have been relatively straightforward to use such theories, for example through the application of discursive theory as per Laclau and Mouffe, or other frameworks for handling linguistic statements such as the interviews that form the backbone of this study (Laclau \& Mouffe, 2001). 
Even though the use of a more explicit theoretical framework might enable interesting findings and help reveal the power relations present in the cases, this is not the preferred approach here. With an understanding of the inevitability of theoretical violence and the often irresistible urge to classify statements and thoughts whenever the possibility arises, much effort has been put into choosing a less insistent theoretical setting. This subquestion has been posed on the basis of an outsider's great interest in the work and challenges of the environmental NGOs. The author had little prior insight into the daily work of Danish environmental NGOs and almost no insight into the Korean setting. It is relatively easy to gain knowledge on the overall strategies of the NGOs and get a general picture of the national settings and notions of environmental movements, but it has been hard to gain insight into what the individual member of an NGO thinks about the public as a learning entity before the fieldwork was commenced. Collecting data and getting acquainted with the field led to a process of developing new perspectives and revisiting theoretical perspectives in order to make sense of the different fields. The choice of an open interpretive hermeneutic approach is linked directly with the overall epistemological stance of this study, and the effort to understand what is going on in the field, while still accepting that something will always be lost in the work to analyse any social event or setting.

In the German philosopher Johann Gottfried von Herder's perspective, the job of the hermeneutical researcher is to "Fühle dich in Alles Hinein" (Herder, 1967: 37). This 'feeling into' the field and the people who form it is an attempt to project "one's mind into the object of one's contemplation, of seeing and thinking and experiencing from its perspective and so coming to understand it better, of turning it into a subject and oneself into the object of its gaze" (Daly, 1995: 26). This ability was necessary because there was, for Herder, no universal pattern for societies or history. Society should be considered without imposing any single pattern upon it, least of all a pattern derived from one's own culture. Instead, one should project oneself into other perspectives: "gehe in das Zeitalter, in die Himmelsgegend, die ganze Geschichte, fühle dich in alles hinein" (Herder, 1967: 37). The effort of this study is not to try and transcend existing perspectives, but instead to apply different perspectives and try to engage the material with an open mind in order to lure out the most interesting insights of any given 
perspective. The ideal is to recognize what the persons involved in any given field perceive and understand, well knowing that this remains and unapproachable ideal for qualitative research that nonetheless functions as an important critical utopian horizon (Nielsen \& Nielsen, 2005).

This positions the first sub-question along the lines of a traditional take on qualitative research. The aim is to be pragmatic, interpretive and grounded in the lived experience of the people involved (Marshall \& Rossman, 1999: 2). The aim of the theoretical background and inspiration for this sub question is to facilitate an open approach to understanding what the individuals in the field perceive about their audience and their own role in such a relationship.

\section{The Second Sub-question}

Having established a broad base for understanding the field, the job for the second sub question is to rattle the cage and facilitate a heavier dose of theoretical violence:

What is the significance of the perceptions of the relationship between the public and the NGOs in the field of non-formal ESD?

The focus on the individual perception of the interviewees is carried over to the second sub question, but the purpose is now to attempt to go a bit deeper into the meaning-making potential of the perceptions. This analysis relies on the theories of the French psychoanalyst and philosopher Jacques Lacan and the mix of Lacan, Hegel and Marx that the Slovenian thinker Slavoj Žižek represents. It might seem odd to combine an analysis of perceptions and the social with psychoanalysis. Several questions must be raised: Is psychoanalysis not primarily linked to clinical practice and the analysis of the individual's psyche? And how is it possible to link an analysis of the individual's mind to a broader sociological analysis of culture and politics?

An important point here is that Jacques Lacan's psychoanalysis does not aim at an in-depth psychological analysis of the unconscious, but instead to approach it through the 'subject' and though language. Lacan did develop much of his work with a clinical purpose, but also stressed the social as the important factor when the individual 
constitutes meaning. Applying a Lacanian perspective as a way of analyzing the perceptions of the NGO key persons stresses the importance of the 'unconscious' and the 'desires' involved in the different activities.

It is important to state that in a Lacanian perspective the unconscious is not the preserve of wild drives that have to be tamed by the Freudian Ego, but the site where a traumatic truth speaks out (Žižek, 2006a: 3). This also marks the approach of Lacan, compared to other schools of psychoanalysis, as having a more philosophical focus. For Lacan, psychoanalysis is, at its most fundamental, not a theory and technique of treating psychic illnesses or disturbances, but a theory and practice that confronts the individuals with the most radical dimension of human existence (Laustsen, 1999: 167). It does not show an individual the way to accommodate the demands of social reality; instead it tries to explain how something like 'reality' constitutes itself in the first place. It does not merely aim at enabling a human being to accept the repressed truth about himself; it tries to explain how the dimension of truth emerges in human reality (Žižek, 2006a: 9). The goal of applying Lacan and Lacanian theory to the case of environmental NGOs is thus not to disclose some kind of brutal underlying logic that controls the actions of the NGOs, but to understand how the 'truth', as the interviewees see it in their relationship to the public as a learning entity and themselves, emerges, and what the function of such a 'truth' might be.

This theoretical foundation facilitates a focus on the significance of the perception of the NGO by wielding the elaborate theoretical framework developed by Lacan. The teachings of Jacques Lacan will not stand alone in answering this sub-question as the wok of his most prolific contemporary interpreter, Slavoj Žižek, is of great relevance to the focus of this study. Žižek is first and foremost a Lacanian, but ties Lacan with a Hegelian and Marxist understanding of contemporary society (Žižek, 2006c: 5). Žižek's work removes Lacan entirely from the clinical setting and into a sociological analysis of how the social and the subject relate. A recurring current in the writing of Žižek is the critique of social structures that enable individual subjects to create meaning in an often confusing world, while simultaneously limiting the emancipatory potential of the individual's actions. The analysis related to the second sub question will draw on the writings of both Lacan and Žižek, as the former infuses the work of the latter and Žižek 
represents a focus on the potential of interrogating the social that fits this study. The details of a Lacanian and Žižekian analytical framework are explained through the analysis of the empirical data in chapter 5.

The use of such a theoretical perspective entails several issues that have influenced the analytical setting of the study and the sub-question. Lacanian psychoanalysis is not a well-developed empirical theoretical framework. Both Lacan and Žižek draw on anecdotal data and work within the philosophical tradition of revisiting the existing work of great thinkers (Freud, Hegel, Kant etc.), while reflecting on the peculiarities of contemporary society that they find interesting. This requires a certain amount of analytical distance from the theories of both. Unlike other theorists such as Michel Foucault, who sought to produce a 'tool box' that can be applied by other researchers, Lacan and Žižek are not shy of developing all-encompassing macro theories of everything and everybody (Foucault, 1974: 523, Boyle, 2008). At the same time, the Lacanian concept of the 'unconscious' always forces something into the unknown, as his take on the social always leaves something behind that theory cannot explain or contain. This study draws on such a take on the Lacanian and Žižekian theories. The chosen theories are, by their very nature as 'theories', viewed as fallible, and at best offer potential explanations of the social around us.

They are both firmly rooted in continental philosophy and history of ideas, and Žižek in particular frequently refers to his contemporary sources of inspiration such as Emmanuel Levinas, Peter Sloterdijk and Jacques Derrida (Žižek, 1989: 38, 2006d, 2008b: 78). Employing these theories does not reflect a hope that they offer possibilities of 'getting to the bottom of it all' and disclosing the secret workings of the environmental NGOs - far from it. The choice instead rests on a presumption that the theories of Lacan and Žižek hold great potential for presenting new and worthwhile perspectives on the topic at hand.

Such a theoretical framework not only represents a demarcation of the study, it also represents an emphasis that is not always directly linked with notions of sustainability, learning or ESD. Other theoretical perspectives could have been applied with arguably fruitful results. John S. Dryzek's take on environmental discourses presents an interesting framework for analysing how sustainability and environmental challenges 
are being interpreted via the social (Dryzek, 2005). Andrew Jamison's work to understand how knowledge is formed and produced around environmental questions also represents a worthwhile foray into how environmental issues can be understood (Jamison, 2001). These perspectives on how environmental challenges and sustainability infuse the social are inspirational and have influenced the study at hand, but are not a key element of the theoretical framework.

Another approach that has influenced this study and the analysis is the Danish research concerning Action Competence (Jensen \& Schnack, 1997). This concept draws on critical theory and the potentially emancipatory aspects of environmental education. Action competence is a strong voice against the lure of behaviour modification within environmental education in both formal and non-formal settings and has inspired the study with its unquenchable focus on the intrinsic importance of each individual's norms, values and actions. The choice of a philosophical and sociological theoretical emphasis is not an attempt to dodge the overall focus on learning and change, but a way to draw on sources of inspiration from other fields. This is done in an understanding of learning theory as part of a greater humanistic tradition of thinking about the individual, the social, knowledge and societal change. Non-formal ESD operates at the intersection of these perspectives and is open to analysis that draws on very different perspectives on why people act and think the way they do.

\subsection{An Accelerating Presentation of the Analysis}

While the preceding sections focused on the analytical process, it is also relevant to discuss the different logic of presenting the analysis, which can be explained by using the metaphor of a trick from the world of cinema. In movies, it is a popular visual trick to start with an image of the entire planet Earth, then gradually zoom in, first on a continent (for some reason often North America), continuing to a country, a region, a city, a city block, a house and finally home in on a single individual person ${ }^{2}$. The neat thing about such a trick is that, while everyone recognizes the image of planet Earth, it is very hard to establish a drama on that level. By zooming in, the onlooker's attention is piqued as the viewpoint

\footnotetext{
${ }^{2}$ This effect is put to use in the 1998 Touchstone Pictures blockbuster Enemy of the State
} 
accelerates from the eye in the sky down to the individual. At the same time, the trick conveys how a country, an area and, finally, each individual is linked to the entire globe, and the myriad of countries, neighbourhoods and individuals that could just as well have been at the end of the great microscope in the sky. In an effort to mimic this dramaturgical move from the important, but often less engaging general field to the very specific, and engaging, viewpoint, the presentation of the analysis will be understood as an accelerating process.

The idea behind the notion of an accelerating process is to minimize the level of theoretical violence that is an inevitable part of performing and presenting theory-informed analysis. On an overall level it means starting out in the wide contextual field of general notions, the field of civil society and learning on an international level and gradually zoom in on the subject at hand ending in an effort to understand what goes on in the mind of the key persons via theoretical insights. The analytical focus moves from the international perspective to the national, then to the distinct NGOs and finally to the individual key person. As in the movies, much will be lost in the process and the question of how the plot develops and whether other actors could have performed the respective roles better will arise. What will be gained are, hopefully, a more intense drama, and a precise understanding of a clearly defined area and the chosen perspective on that area. As in movies, offering a sense of arbitrariness in the selection of the setting, the cast, and the plot is, however, a deceitful lie. While the camera could have zoomed in on other parts of the globe and found something worthwhile and interesting, the movement is in reality in the opposite direction. Ideas for good stories and interesting settings seldom start with the overall general perspective of the whole globe, but are born out of an interest for the particular and how this might be utilized to create emotions ( as might be the case with movies) or new understandings (as is often the aim of research on the social). Had the lens captured NGOs in Laos and Ireland, the plot might have taken a radically different turn and the story ended up with another outcome. That outcome could probably have yielded other interesting understandings, but the truth is that, in this case, the camera was from the outset aimed at Korea and Denmark.

Another important point to take from this metaphor is that the camera in the sky that zooms in on the specific does not remain in the sky. As the action starts, it 
is rare to only see the top of the actors' heads throughout the movie. The camera always moves around the main characters, engages with them and displays different and sometimes surprising perspectives and angles. While the camera in most movies acts as a silent guide, rarely being an actor in itself that is spoken to or can act on its own (the camera seldom engages in fisticuffs in even the most rowdy of Western bar fights), that cannot be feigned here. As the camera in reality is the crucial actor in most movies (without it we could not take part in the drama, and the drama would not be there), the perspectives in this study are likewise intentional. The difference being that research most of the time benefits from an explicit role and stance of the researcher, while it might destroy some of the action if the camera suddenly lost interest in the ensuing gun fight and went home to Skype its girlfriend.

Setting the contextual scene is thus not an attempt to dilute the fact that the specific setting of this study has a large influence on how the context is understood and that other focal points would lead to different settings and different findings. It is instead a pedagogical effort to unravel the 'drama' of this study and reassure that the different perspectives and characters are offered sufficient room to take part in the overall argument of the study.

The analysis will move from a general level to a specific, from a broad emphasis on secondary literature toward a strict emphasis on the empirical material, and gradually approach a theory-driven analysis of the empirical. Through this move, not only will the camera, the focus of this study accelerate, towards the individual key person in the NGOs, the use of theory will also accelerate. As demonstrated in fig. 1, the analysis will accelerate from the general level toward the individual's perceptions and, when reaching an appreciation of how the key persons understand the educational relationship between their NGO and the public, theory will be added as a powerful form of fuel. This should not be seen as a break with the abductive approach and its emphasis on the constant move between theory and empirical data, but as an effort to withhold the theoretical violence and the tendency to force the fragile opinions and perceptions of the interviewees into prearranged theoretical boxes and categories. The analytical process is one of wandering back and forth between expectations and experience, but adhering to a form where the 'voice of the data' is centre stage and sought represented and handled with 
care. As described in fig. 1, the field and the data will be treated in three stages: an initial presentation of the overall setting in chapter 3, a thorough analysis of the empirical material and the perceptions present in chapter 4 , and a theory-driven analysis revisiting the empirical findings in chapter 5.

Fig. 1 The overall analytical path

Ch. 3 General focus on civil society, NGOs
Ch. 4. Giving voice to the empirical data
Ch.5. theorydriven analysis of the empirical findings

Fig. 2, the specific analytical path, describes in greater detail how the analysis will unfold and which analytical layers will be highlighted during the individual chapters. The four arrows should be understood as parallel, describing the same process, and the figure will be used throughout the different chapters to show which part of the presentation of the analysis is currently in focus. The different layers each denote the same process, but also represent different interlinking focuses that guide the analysis. 
Fig. 2 The specific analytical path

\begin{tabular}{|c|c|c|c|c|c|c|}
\hline chapters & $\begin{array}{c}3.1 \text { NGOs, } \\
\text { civil society } \\
\text { and national } \\
\text { differences }\end{array}$ & $\begin{array}{l}\text { 3.2 Danish \& } \\
\text { Korean NGOs }\end{array}$ & $\begin{array}{l}\text { 4.1 The role } \\
\text { of the NGOs }\end{array}$ & $\begin{array}{l}4.2 \text { The } \\
\text { educational } \\
\text { perspective }\end{array}$ & $\begin{array}{c}\text { 4.3 Public as } \\
\text { a learning } \\
\text { entity, }\end{array}$ & $\begin{array}{c}5 . \\
\text { Educational } \\
\text { desires of } \\
\text { the NGOs }\end{array}$ \\
\hline Question & When? & Who? & Why & Where? & How? & What? \\
\hline $\begin{array}{l}\text { Methodological } \\
\text { emphasis }\end{array}$ & $\begin{array}{l}\text { Historical } \\
\text { and societal } \\
\text { analysis }\end{array}$ & $\begin{array}{c}\text { Empirical } \\
\text { data }\end{array}$ & $\begin{array}{l}\text { Interviews } \\
\text { with key } \\
\text { persons }\end{array}$ & $\begin{array}{l}\text { Interviews } \\
\text { with key } \\
\text { persons }\end{array}$ & $\begin{array}{l}\text { Interviews } \\
\text { with key } \\
\text { persons }\end{array}$ & $\begin{array}{c}\text { Theoretical } \\
\text { enquiry }\end{array}$ \\
\hline $\begin{array}{l}\text { Analytical } \\
\text { purpose }\end{array}$ & $\begin{array}{l}\text { Establishing } \\
\text { the context }\end{array}$ & $\begin{array}{l}\text { Establishing } \\
\text { the specific } \\
\text { context }\end{array}$ & $\begin{array}{l}\text { Examining } \\
\text { the purpose } \\
\text { of the NGOs }\end{array}$ & $\begin{array}{l}\text { Developing } \\
\text { analytical } \\
\text { themes }\end{array}$ & $\begin{array}{l}\text { Developing } \\
\text { the analytical } \\
\text { themes }\end{array}$ & $\begin{array}{l}\text { Understandi } \\
\text { ng the } \\
\text { analytical } \\
\text { themes }\end{array}$ \\
\hline $\begin{array}{l}\text { Level of } \\
\text { abstraction }\end{array}$ & $\begin{array}{l}\text { National and } \\
\text { international } \\
\text { focus }\end{array}$ & $\begin{array}{c}\text { Focus on the } \\
\text { individual } \\
\text { NGOS }\end{array}$ & $\begin{array}{c}\text { Focus on the } \\
\text { key } \\
\text { personnel }\end{array}$ & $\begin{array}{c}\text { Focus on } \\
\text { percepetions } \\
\text { of education }\end{array}$ & $\begin{array}{c}\text { Focus on } \\
\text { perceptions } \\
\text { of } \\
\text { participation }\end{array}$ & $\begin{array}{c}\text { Theoretical } \\
\text { enquiry }\end{array}$ \\
\hline
\end{tabular}

This 'accelerating' presentation will be a guide through the 'five $\mathrm{W}$ (and one $\mathrm{H}$ )' didactic and journalistic questions (Klafki, 1995: 17). One of the good things about doing research is that it is not crucial to the same degree as it is in journalism in which order we look into Who, What, Where, When, Why and How in terms of the development of our field of interest. The process here is to go through the interesting questions of When the context was established, Who is involved, Why the NGOs engage the public, Where and How it happens, and in the end focus on the question of What the significance of findings could be.

Further down, the 'methodological emphasis' layer expresses the range of analytical methods applied in a given chapter, focusing on the source of data that is being analyzed; i.e., empirical data, secondary sources, theory-driven inquiry etc. The 'analytical purpose' describes the role the individual chapters play for the continued analysis, from the contextualization of the early analysis to the focus on the interviewees' perceptions, to the analysis of the questions that arise from these perceptions. The 'level of abstraction' describes at what overall level the analysis is focused, from a general supranational level to the level of individual perceptions.

The logic behind this accelerating presentation of the analysis is formed by the abductive analytical approach and its constant movement between the data and the theoretical framework. There is, however, a limit to the wandering, liquid nature of 
qualitative generative research, as a form must be found that can convey the findings of a study. A final form must be found. The form of the study at hand emerged as an effort to present the findings while still maintaining a sense of progression and hopefully even a little suspense. 


\section{The NGOs, Civil Society and National Differences}

In presenting the background for the two cases, it is important to get a feeling for the subtly distinctive traits of the two countries and the different NGOs. The contexts in of the two cases, the Danish and South Korean environmental NGOs, can be described as a continuum that draws on the political history, the social setting and the differing objectives NGOs in each country. This chapter begins with a historical contextualization of the two cases and links a discussion of the role of the NGOs with a presentation of each of the NGOs involved in this study.

\subsection{Past and present challenges}

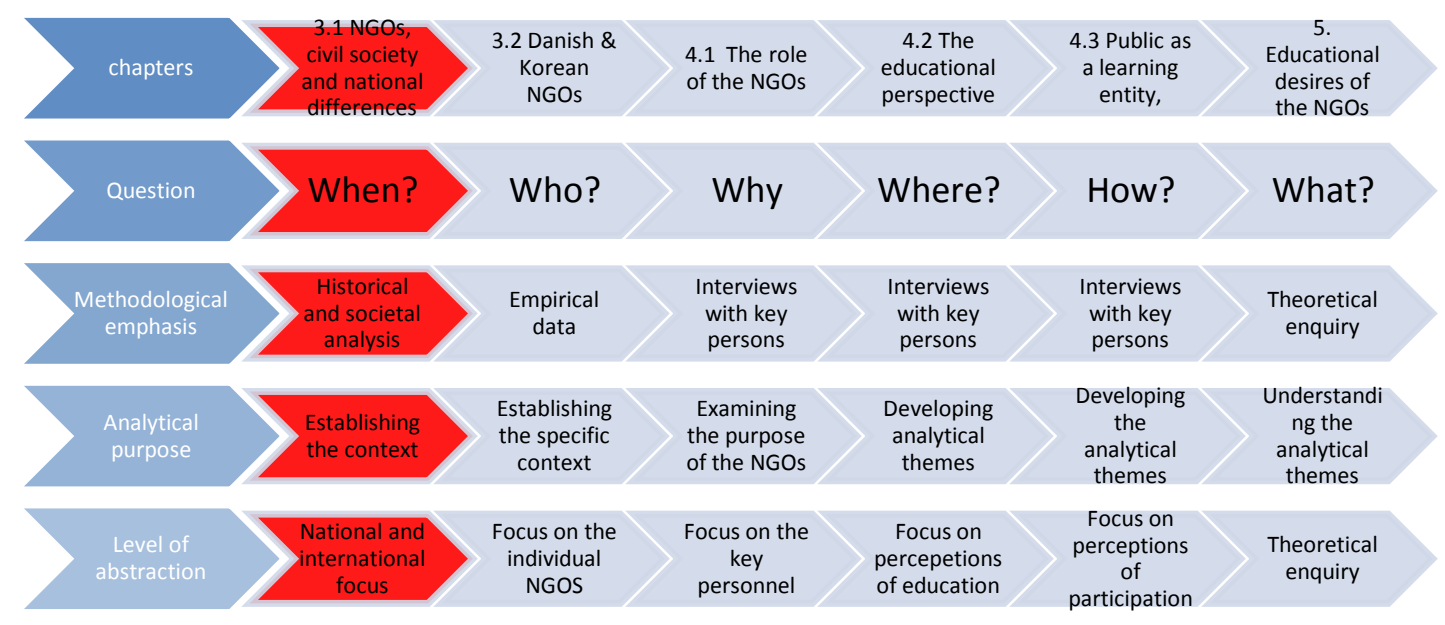

\section{The New and the Old}

The process of describing the context for this study is a look into the historical background for each of the two cases. Such a process of probing into the historical development in Denmark and South Korea might appear odd when the challenges related to climate change and environmental education are embedded in highly contemporary issues, uncertainties about the future, and debates about how best to deal with them. Living in a culture obsessed with the New, and where the Old mostly serves as something that can be reconfigured as a revitalisation of the new via the 'retro' moniker, the genuinely Old often has very little say. 
Slavoj Žižek calls this the 'dialectic of the New and the Old': those who constantly propose new terms ('postmodern society', 'risk society', 'information society' etc.) in order to grasp what is new often miss what is actually new. Žižek argues that the only way to understand what is new is to analyze it through the lens of what was 'eternal' in the Old (Žižek, 2009a: 6). Which values, norms and discourses governed a period? How were they perceived as differing from previous, contemporary and subsequent discourses? Working with the Old and dealing with it though remnants in the form of documents and discussions with the people who experienced it often leads to a dizzying array of different takes on the Old. What did yesterday's people believe was the right way of doing things, and how is this perception influenced by present ideas and 'what history's victors retrospectively deem right and wrong. Being interested in the Old and the ideas that governed any given period is always a difficult balancing act between looking for some kind of 'truth', whilst simultaneously aware that any 'truth' found is merely another perspective, often diluted by time and hindsight.

Alas, just as the present seems hard to grasp and categorize, the Old is no clearer, but does at least offer an often more limited material as a base for understanding. Trying to 'cover' a historical event is thus doomed to failure from the outset as it inevitably displays a lack of 'objective' sources. As always, dealing with the old, and its hegemonic narratives, is a matter of being ever critical towards the sources presented. The intermediaries who have been involved in the "production" of these sources are not only human, and thus biased, but, in the case of a hot bed of opinions such as the context of the environmental NGOs, almost always heavily involved in the matters at hand and with strong opinions on the actors in the field. In the search for the governing, and changing, paradigms of the development of environmental NGOs in two different countries, this study mostly relies on existing research and analysis, as it is neither within the scope or the objective of this study to delve into historical archives in search of a 'smoking gun' in the historical development. Instead, the aim is to paint a picture of the gradually changing emphasis within the field, and how this corresponds with the present practice of environmental NGOs in both countries.

In order to understand what is going on now, it is crucial to include the historical development within any given field and not only try to relate to contemporary 
peers, but, in a hermeneutic move, also to try to understand the mechanisms and the subjective 'eternal truths' of any given time. Looking into the educational ambitions and strategies of environmental NGOs during the last 40 years serves as a wonderful backdrop for understanding what made the NGOs tick during a period when considerable changes in focus occurred, ranging from the early outcries against pollution and measures to establish a new society to the influence of the concept of the 'Green Economy' on the work of environmental NGOs.

In both Denmark and South Korea it can be argued that the environmental NGOs were founded as part of social movements. The basis for such a development varies greatly between the two countries. The social movement of the late 60's spurred the establishment of an environmental movement in Denmark, whereas the South Korean environmental movement and NGOs have their roots in the so-called 'Democratic movement' of the 80 's and early 90's. Both represented a counterculture when they started out, rebelling against a perceived consumerist society, pollution levels or oppressive politics, and in both countries the 'environmental movement' has since diversified to a degree where it makes little sense to talk about one coherent movement. Eyerman and Jamison argue that social movements can be understood as temporary public spaces, as movements that provide societies with ideas, identities and even ideals (Eyerman \& Jamison 1991). They also stress the temporary nature of most social movements; as they cease to act as a space for new thinking and later change shape, turn into traditional organizations. The trajectory of the environmental NGOs in Denmark and South Korea mirrors this notion, developing in multiple directions, with new perspectives on their work, educational praxis and interaction with the public.

\section{The NGOs and Civil society}

NGOs are often positioned as part of the tricky concept of 'civil society'. Civil society is an inclusive concept and encompasses the entire range of intermediary associational actors that are juxtaposed between the state and market (Kim, 1996). Defining civil society broadly and discussing its roles and functions in general terms could easily prove counterproductive to analysis and precise description of the specific development of the environmental NGOs. The concept of civil society includes virtually all forms of 
associational organizations such as non-governmental organizations (NGOs), voluntary associations, non-profit organisations, charitable organizations, and benevolent societies. Among these associational actors, the NGO is essentially defined by what it is not. It is a non-state actor. However, the main characteristic of the NGO is that it is private in its form, has a public character and non-profit orientation in its objectives and activities (Salamon and Anheier 1994: 123; Weiss and Gordenker 1996: 221).

Focusing on environmental NGOs in Denmark and South Korea, and understanding them as part of a more or less loosely defined civil society, not only raises numerous questions regarding how to qualify such intangible institutions, but at the same time stresses the importance of the historical context in understanding contemporary differences between the two countries. The traditions and practices embedded in the notions of civil society and NGOs vary greatly between Denmark and South Korea, making a mockery of any ambitions of conducting a homogeneous analysis leading to clear-cut conclusions; however, these differences also present the opportunity for a radical focus on how to understand the environmental NGOs participation in civil society and attempts to engage the public.

\section{Civil Society and Environmental NGOs - South Korea}

Whereas the notion of civil society has a relatively long history in Denmark, going back to the Danish cooperative movement of the 1800s (Busck et al, 2002), the beginning of a recognized civil society on the Korean Peninsula can only be traced to the latter half of the twentieth century. Pre-twentieth-century colonial Korea 'was lacking in autonomous civic organisations, entirely divorced from state control (Kim, 1996). In many ways the modern South Korea was born out of the Korean war 1950-53. Not only was the country now split in two, but the feudal organization of most of the country changed rapidly, in the north towards a communist model and in the south towards a fast-moving capitalist model. The chosen capitalist path did not, however, have any immediate impact in terms of a stronger emphasis on civil society organizations, nor did the situation improve as directive state intervention pervaded South Korea, leaving little room for organizational growth initiated by citizens. For several decades authoritarian regimes severely repressed and restricted basic democratic rights and freedoms for the purpose of rapid economic growth (Koo 
2002; Kim \& Moon, 2003). These successive authoritarian regimes prohibited trade unions and selectively co-opted with industrial corporations to form a strong coalition for economic development. This created little room for more organizational civil society structures during the 1950s and 1960s. Korean scholars argue about the roles of the market and the state in the development of South Korea, but it is widely acknowledged that state intervention has been a determining force in the nation's economic development (Kim, 2000), while simultaneously impeding the development of civil society.

In the 1960s and 1970s, the development of capitalism was seen as an important factor for securing a strong state, and the growth of civil society continued to be hindered, the environment damaged, equitable distribution of development aid more or less forgotten, and democratic development postponed (Ahn \& Lee, 2005). The particular tactic the state used during this period was to suppress an indigenous bourgeoisie and to provide the new ruling class with autonomy in all areas of society. In the process, the state held power in a firm grasp and represented the interests of the ruling class. Meanwhile, diverse sectors of civil society slowly formed their own organizations which paved the way for the radical labour movements which later fought against the authoritarian regimes.

Several factors are important when discussing why civil society organizations had such a hard time gaining momentum in South Korea: State-centred authoritarianism, the incomplete formation of a middle class to promote civic consciousness, and the lack of organizational capacity of civic movements have been mentioned by various Korean researchers (Kim, 1996, Kim, 2000, Hwang, 2009). It is, nevertheless, apparent that, even though rapid economic growth with pervasive state intervention did impede and even distort the development of civil society organizations, it paradoxically enhanced the potential advancement of civil society. The rapid economic development led to a new empowerment of the industrial workforce which had been growing rapidly in numbers, mainly due to government-led heavy and chemical industrialization in the 1970s. It also manifested in the fostering of a growing middle class who had emerged during the industrial boom of the late 60s and early 70s. Paradoxically, both industrial working class and the middle class had played significant roles in politics of establishing broad social movements. Through visions of collaboration and solidarity shared by the still struggling labour movement and a now vitalized civil rights movement, 
they formed an alliance focusing on democratic rights within the public space, and on the severe problems associated with huge monopolistic companies and the dominance of state power in the late 1980s (Kim, 1996).

NGOs did not exist on larger scale in South Korea until the 80s, and, until the 1987 Democratic Movement, strong government control had maintained a virtual monopoly on decision-making authority and jurisdiction over public issues. Excessive intervention in most aspects of the everyday lives of South Koreans was thus a trademark of the authoritarian regimes that led the country through the rapid process of industrialization and economic growth. In this 'authoritarian' era, 'public' became equated with 'official' in the process of South Korea's modernization (Cumings, 1997).

In this context, social movements were mainly characterized by their antigovernment and anti-corporate position. This image has changed considerably, if not totally, particularly since 1987, which was the turning point of political democratization. Civil society and NGOs did not begin to form until the Democratic Movement that crossed the threshold of democratic transition in Korea and resulted in the election of Roh Tae Woo (Cho 1997; Choe and Im 1993; Chung 1997; Han 1997; Yu and Kim 1995). Since then, Korea has experienced a transition toward democratization, which in turn has opened up the organizational space for the differentiation of diverse social interests and interest group politics. Although state repression of civil society reappeared during the Roh administration, it has substantially declined since the election of the civilian government of Kim Young Sam in 1993. The Kim administration implemented a series of political and socio-economic reforms, and further encouraged the activities of moderate civil society groups by recruiting several high-ranking public officials from the citizens' movement organizations. Since the democratic movement, NGOs have been rapidly expanding and representing a new generation of organizations, differentiating themselves from the dissident and often militant so-called 'minjung' movements (Wells, 1995).

In the midst of this change, moderate citizens' movement organizations started to emerge. At the same time, formally government-sanctioned organizations as well as NGOs were involved in the work to make social issues independent of the state and push for a democratic transition. As a result, the organizational space for associations of diverse interest groups expanded. This, in turn gave momentum to a diversification of 
issues, activities, and orientations in the arena of interest group politics (Kim, 2002). Despite differences in interest and politics, the citizens' movements have played a significant role in seeking an expansion of citizens' rights, developing the public space, and the a focus on social issues that is not only governed by the opinions of the state. A new generation of citizens' movement organizations was thus established in the late 1980s and early 1990s, as in the cases of the Citizens' Coalition for Economic Justice (CCEJ), the Korean Federation of Environmental Movements (KFEM), and the People's Solidarity for Participatory Democracy (PSPD), recognized as the most representative and influential NGOs. The situation now is that a sprawl of highly active environmental NGOs influences the development in Korea, with well-established larger organizations and smaller organizations at both national and regional level.

\section{Civil Society and Environmental NGOs - Denmark}

The development of the Danish environmental NGOs has a different trajectory than the Korean. Not only is the concept of civil society older in Denmark, the environmental NGOs also started out earlier and are to a large degree intertangled with the overall development of the field and organisations in western Europe and North America.

A key concept when discussing NGOs and civil society in a Danish context is the notion of People's enlightenment or 'Folkeoplysning' in Danish. This notion has its roots in the work of the Danish historian, priest and philosopher N.F.S. Grundtvig. At the beginning of the $19^{\text {th }}$ century, he successfully worked for the establishment of so-called 'Folk high Schools' that aimed at educating the public, and especially adults, in accordance with the educational ideals linked to the enlightenment (Borish, 1991: 167). While this concept is also known in the other Scandinavian countries, it remains a distinctive take on educating the public.

'Folkeoplysning' entails a dual focus. On one hand the concept argues that every human being is born into a distinct cultural and historical context, and that it is within this framework that their own personal drama of Enlightenment must be played out. On the other hand, it suggests that there is a collective as well as individual aspect to the experience of Enlightenment, and that it must be the goal of a society to create, though wise and farsighted policies, the conditions that will facilitate 'Folkeoplysning' or 
People's Enlightenment (Borish, 1991: 169). This concept has remained central to the development of Danish civil society initiatives for almost 200 years and is today in use to describe non-formal adult education, but also education focusing on youth and children. This includes the aforementioned Folk high schools, with emphasis on general 'Bildung' and with no examinations, but also liberal education at evening schools, and sporting, youth and cultural associations. 'Folkeoplysning' thus focuses on developing the individual's competences to be part of a democratic society via subjects that often are not part of the formal educational system (Korsgaard, 2002: 8).

The political development in Denmark during the $20^{\text {th }}$ century, with emphasis on consensus driven democratic and economic progress, encouraged a large variety of civil society organizations, with the environmental NGOs becoming active in the late 1960s. Before that the Danish Nature Conservation society had focused on the recreative qualities of nature. The members of this organization were largely representatives of the political establishment and encouraged a view on nature as something that should be protected so that it could be enjoyed by humans (Jamison et al. 1990: 74).

Spurred on by the new left and the ever more visible environmental consequences of industrialization during the 1960s, a new organization, NOAH, was established in 1969. This marked the beginning of a tumultuous decade where NOAH in the early 1970s became the main representative of the fledgling struggle to combat pollution in the Danish environment and focused on issues related to an overall notion of a deterioration of nature in modern society. The concept of NOAH was inspired by new thoughts from a growing alternative leftist political movement with a flat, leaderless structure and emphasis on individual agency and empowerment.

From the mid 70s onward, a new emphasis on the fight against nuclear power took over the agenda and the work of groups such as OOA (The Organization for Information about Nuclear Power). This group changed the focus as the aim was to win, and the method was to inform the people. The fight against nuclear power plants in the 70s in Denmark was successful, but it also led to a surge of professionalization that marked a move in the 80s away from the amateur grassroots movements and towards more professional organizations with relatively large numbers of staff (Jamison et al. 1990: 
110). The NGOs received massive support among the Danish population, with environmental organizations having more members than the political parties, but the nature of the organizations had also changed. The professional organizations now no longer relied primarily on the input and activity of their members, but instead opted for a model where expert knowledge and political lobbyism became central and the support wanted from members and the public was often reduced to paying annual fees in order to provide a financial basis for the work of the NGOs (Jamison et al. 1990: 117).

This period also saw a tendency for the aims and policies of the larger NGOs to merge with the political agenda of successive Danish governments. The environmental NGOs successfully pushed for state-funded activities and a close cooperation between the NGOs and the political establishment. This effectively installed a consensus driven relationship between the environmental NGOs and the Danish state and ended any links to the more revolutionary left wing heritage of some of the larger NGOs.

With ecological modernization entering the stage in the late $90 \mathrm{~s}$, the scene was set for yet another change in the setting of the environmental NGOs. The discussion now emphasized how both the environment and economic and technological development could work together and create a win-win situation. This was linked with the Brundtland report and new ideas regarding sustainable development (UN, 1987). While most of the NGOs stopped initiating participatory activities aimed at the public, government backed funding schemes now started to support such activities. These schemes offered "top-down money for bottom-up action oriented co-operative citizen projects focusing on environmental improvements in the local community” (Læssøe, 2007b: 238).

This spurred a wide range of activities that, throughout the $90 \mathrm{~s}$, focused on citizen involvement and installed so-called 'green guides' in most of the Danish municipalities with the intent of initiating activities that focused on the interrelation of environmental and social practices. The Danish environmental NGOs also benefitted from government backing and prospered during this period, with focus on further professionalization, but also a greater emphasis on citizen involvement and continued efforts to stress the possibility of a development both beneficial to the environment and the economy. The rise of the pioneering and global market leading Danish wind turbine 
industry was part of this movement toward a notion of Denmark as a green country (Krohn, 2002: 4).

This situation changed abruptly when a right-wing government was elected in 2001. Support for 'green activities' was slashed and an overall focus on commercial funding instead of state support was introduced. With the controversial Bjørn Lomborg as the representative of the new government's strategy based on a neo-classical economic orientation, the government set out to get "more environment for the money" (Schoenbrod, 2002). This meant an overall decline in participatory activities and new challenges for the environmental NGOs. The general dissociation from the importance of environmental issues by the government changed in the latter part of the 2000s as Copenhagen was selected as the host country for the important COP15 summit. This led to a new rise in activities, new funding possibilities and a resurrection of the interest of both established and new NGOs in the field of environmental and climate issues (Meilstrup, 2010: 113).

\section{The Korean and Danish Environmental NGOs}

In both countries there are at present a large number of NGOs operating at local, regional and national levels, with considerable emphasis on participatory activities. The marked differences and similarities between the two countries will be discussed during the forthcoming analysis, but some more structural differences already stand out. The different histories of the NGOs, with the Korean conflict riddled past and the Danish emphasis on consensus driven development, will influence the analysis and also raise the question of how an NGO is understood as being non-governmental. It can be argued that, throughout their history, the Korean NGO's have either operated in direct opposition to the government or even as outright enemies of the established political structures. This means that the Korean NGOs very much existed and exist as outside the governmental sphere. At the same time it must be stressed that the development in Korea during the last decade has meant that many former members of the democratic movement are now in government and still in good contact with their former colleagues from the social movements who often work as highly ranked NGO staff. This has created an elusive 
demarcation line between the Korean NGOs and the government, but the antagonistic heritage from the democratic movement is still strong.

Some of the Danish NGOs might arguably not even be considered NGOs by Korean standards (Armstrong, 2007: 4). The tradition of government backing of NGOs and the often direct links between especially left wing politicians and environmental NGOs has created a situation where the line determining what can and cannot be considered non-governmental organisations is often complicated by receipt of government money or other types of support. The is not the primary discussion of this study, but the differences in the perceived concepts of the 'NGO', both between the two countries and among NGOs from the same country, is interesting and will only become more visible in the following sections. The study does not differentiate between the NGOs based on a formal definition of characteristics of an NGO, but focuses on the organizations' perceptions of their own work and their relationship to the public. 


\subsection{Contemporary Danish and Korean Environmental NGOs}

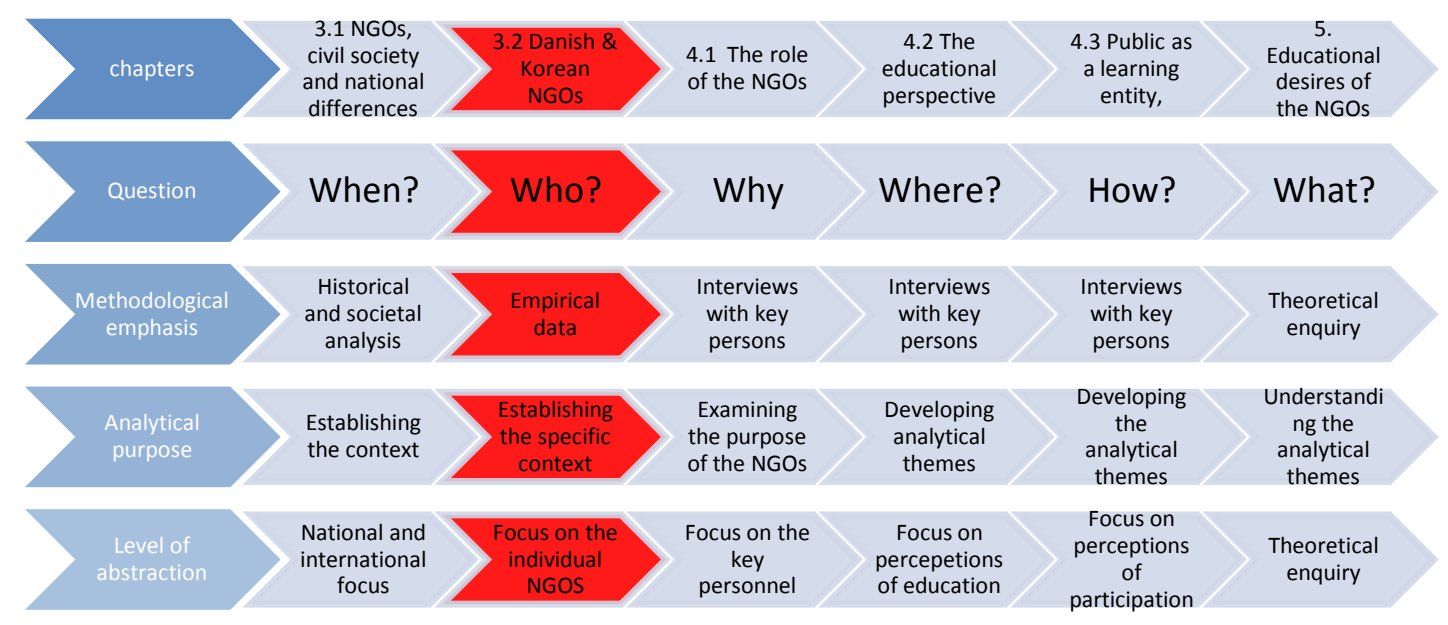

Moving on from the general description of the contextual setting of this study in both Denmark and South Korea, the task is now to introduce the specific NGOs that form the backbone of this study. The notion of the contemporary environmental NGO covers a large and diverse field. From the enthusiastic one man show, run out of a cellar, to corporation like entities with large numbers of employees and a very diverse field of interest. Some NGOs focus on a single issue, others work with more general topics; some depend on subsidies from governments while others are volunteer based or run on support from members. The NGOs that are directly involved in this study are not representative of every different type of NGO found in Denmark and South Korea; instead they represent a distinct perspective on important NGOs in the Danish and South Korean setting or are perceived by the author as having potential for developing new and interesting ways of engaging the public, or both.

In order to establish the distinct framework for this study, the following section will provide a detailed presentation and discussion of how the nine South Korean and six Danish NGOs that form the bulk of the empirical data present themselves, and how they differ from and relate to each other. They are all rooted in the previously discussed historical background, but also represent unique takes on how to understand and formulate the work of contemporary environmental NGOs. This detailed, and yet 
reductionist, account of the contemporary environmental movements in South Korea and Denmark creates the vital backdrop enabling specific analysis of the educational perceptions identified within the individual organizations. It also remains an effort to present a picture of how, even at a casual glance, both great similarities and great differences exist within the Korean and Danish cases. This positions the following descriptions of the organizations and interviewees as a move from the general description of the historical development to the specific examples from a given context.

\section{The Korean Case - Contemporary Korean NGO's, a sample of a growing field}

\section{Korean Federation For Environmental Movements (KFEM)}

KFEM was officially established in 1993, but was the end result of several small scale initiatives that began in the early 80s. Not only has KFEM managed to establish itself as the leading Korean environmental NGO, it has also branched out with special divisions for education, policymaking, research etc. The early development of the organization was intrinsically linked to the Democratic movement and its social and labour rights focus, but also to a wave of protests against the growing problems with pollution, and especially concerns about Korea's high dependence on nuclear energy. The early anti-pollution focus changed during the 90s to include a broader focus on environmental and societal hazards. KFEM has worked to stay independent from governmental subsidies and support, but was nonetheless hit hard by the Lee Myung-Bak administration's decision to cut all support and most of the communication with civil society actors (Doucette, 2010: 22).

The educational focus of the organization has also changed since the early days, where the focus was on university students and disclosing information about the environment that the government suppressed. This generation of university student activists faded away during the $90 \mathrm{~s}$, and has been replaced by activists and members that represent a wider segment of society, but who also have to fit volunteer work within the confines of an often stressful daily life. This has resulted in more after-hours activities aimed at specialized segments of the members: women, children, business keepers, house owners etc. Much of this is channelled though the KEEC sister organization, resulting in 
less direct contact between KFEM staff and the public. This has sparked new ideas for a more proactive and direct educational approaches from the different departments at KFEM, utilizing web based methods and replacing an anti-establishment strategy, "always fighting with everyone" as the interviewee from KFEM puts it, with a focus on citizens' opportunities to change their lives through greater knowledge and discussion about how to alter and reform society from the inside (KFEM, 2010).

\section{KEEC Seoul}

The Korean Environmental Education Centre (KEEC) in Seoul is first and foremost among a number of KEECs in Korea. KEEC Seoul was established in 2000 as the specialized education wing of KFEM. Before the KEEC, there was a team focusing on education, but establishing the KEEC formalized that. KEEC Seoul now has a staff of 10 working with a wide range of educational efforts, from pre-school activities and work in formal settings, to teacher training and a comprehensive focus on non-formal education of the public. The organization also runs three educational centres in and around the sprawling city of Seoul. From an early focus on traditional one way information, the journey since the centre's launch has been towards a more participatory educational approach, where activities set in natural surroundings are seen as just as important as debates and informational events. KEEC Seoul enjoys a very close relationship with the local administration and government and has moved into a position where they educate teachers in public schools on environmental issues, while at the same time educating and training policymakers and other officials involved in the administration. This relationship does, however, fluctuate according to the whim of the government in power at both national and municipal levels (KEEC, 2010). In terms of the development of environmental education on a national level, KEEC is also very active in the Korean Environmental Network (KEEN), where Local Agenda21 and the Ministry of the Environment also play a central role. KEEC Seoul works to maintain contact with all the important actors in the field and also draws inspiration from international and Asian settings (KFEM, 2011). Being the main Korean contributors to the central Environmental Education for Citizens in Asia Network, and also taking part in international networks and conferences, has created an influx of educational ideas and inspiration that is often 
incorporated into national activities (KEEC, 2010). In spite of its size and national importance, it is becoming harder to recruit new staff and activists as the workload of the average Korean seems to be spiralling towards a situation where there is very little leisure time available to use on organizational work and where a career in an NGO is for many a dead-end with little possibility of advancement compared to the many Korean megacorporations that recruit most of the highly educated workforce. This has forced KEEC to focus more on recruiting and nursing activists to prevent them leaving to join other NGOs or abandoning voluntary work completely, thereby draining KEEC of the possibilities and activities that are upheld by activists (Chang, 2007).

\section{Green Korea}

Together with CMEJ and KFEM, Green Korea is the one of the large and established Korean environmental NGOs. The organization shares strong roots in the democratic movement of the 80 s and 90 s with the other major NGOs and has successfully managed to remain one of the leading environmental NGOs in a changing and dynamic field. From their Seoul headquarters they run a vast number of activities, practical, political and educational. Ten local branches scattered all over Korea, from Busan in the south to Incheon in the north, focus on local activities and maintaining contact with the over 15.000 members of the organization. The overall focus is on ecological conservation, wildlife and a growing voice against GMO-products. Still, the ongoing transition, from the early work against tangible and visible pollution to a more holistic approach in line with contemporary organisations has strengthened Green Korea's emphasis on 'lifestyles' and 'values' among their members and the general public (Green Korea, 2010).

Green Korea has a quite substantial focus on education related to environmental and climate issues, covering formal education in schools, adult education and teacher training. They run popular educational programmes for so-called 'Eco-moms' (Green Korea, 2010). This concept centres on the rather traditional role of many Korean women as responsible for almost all domestic chores and for childcare (Jang et al., 2010: 1608). This traditional gender pattern is rapidly changing in Korea as women struggle to reconcile ambitions of a career matching their, frequently very high, qualifications with more traditional activities such as childcare and housekeeping. Sadly this seems to be a 
difficult task as the traditional Korean male still adamantly refuses to take part in household work and the exhausting working schedule of Koreans leaves precious little time for family duties. This has led to a situation where many highly educated women either choose to have children very late, or not at all, as the choice of a husband and children is, for many, a choice that makes an active career almost impossible (Kim \& Lee, 2006). Green Korea, alongside other environmental NGOs, has special strategies to try and tackle this challenge. On one hand, many of the professionals in environmental NGOs are part of the emerging trend of career women with little focus on fostering children, and on the other hand, they exhibit strong opinions about this and the loss associated with choosing either a traditional gender role or a more progressive and independent approach. Offering an educational program for 'eco-moms' can be regarded as an effort to bridge two worlds and not only stress the importance of the household, but also focus on the women that have not chosen the path taken by many of the NGO employees to break with the traditional gender patterns.

As with the other major Korean environmental NGOs, Green Korea has strengthened its focus on education during the last 10 years. Not only has the non-formal educational work with eco-moms and children after school hours seen a rapid rise in activities, their work with children in formal school settings has also been strengthened with a number of published educational tiles aimed at primary schools, and also activities designed at engaging with primary school pupils.

\section{Citizen's Movement for Environmental Justice (CMEJ or Ecojustice)}

The Citizen's Movement for Environmental Justice (CMEJ), alongside Green Korea and KFEM, is seen as one of the central NGOs to be established as a result of the democratic movement's success in the early 90s and the urge to focus on environmental issues (Kim, 1996). It was established in 1992 as part of the powerful civil society movement the Economic Justice Organization, and from the outset focused not only on environmental issues, but also on issues linked to energy and land ownership (CMEJ, 2010). The organization, with its staff of 18 , has 3,000 regular members who support the organization financially, making it independent of government funding. This independence has made it possible to take a strong and adamant interest in public and politically-charged issues, 
such as the controversial Four Rivers Project that affects most of Korea (Normile, 2010: 1568). It has also made it possible to work with changing governments and corporations from time to time, a process which has eased the often quite antagonistic relationship between large swathes of the environmental movement and various parts of both the large corporations and, especially, right of centre governments.

From 2000 CMEJ started to focus on lifestyle choices and how to incorporate environmental issues into a focus on consumption habits. This led to several widely documented activities such as a remake of the American film Supersize Me (2004), where a normal everyday person tries to live on a strict diet of McDonald's products for a month. In both the American and Korean versions, the test person had to stop before time due to severe health issues that resulted from the large amount of fast food. This, coupled with several other high profile activities, focused their efforts on corporations and how they handle issues linked to the notion of environmental justice. The focus on environmental justice also harbours a strong gender and poverty perspective. Women and mothers are paid particular attention as having great potential of instigating change in relation to environmental issues. A framing of high ranking men as exploiters of natural resources and of poorly educated women and children is central to their work and the way the organization targets corporations and their misdeeds (CMEJ, 2010). Even though many of the larger-scale activities aimed at corporations and the government take more of a policy-level lobbyist approach, considerable efforts are also made to focus on local issues around the Korean peninsula and work with local people in order to mitigate the many problems that arise from both pollution and the effects of global climate change.

\section{Local Agenda21 Action Council for Gyeonggi-do}

The Korean Gyeonggi-do province is, with its over 11 million inhabitants encircling Seoul, the most populous province of South Korea. Since 1946, Seoul has been granted Special City status, with its own administrative bodies, but Gyeonggi-do, housing the masses of people commuting to and working in Seoul, is often viewed as the centre of daily life in Korea. It covers a vast area, marked by the rapid industrialization of South Korea, but at the same time home to a beautiful countryside and impressive green mountains. Its administrative centre is at Suwon, just $30 \mathrm{~km}$ south of Seoul. A large 
complex houses the local government's many administrative bodies, but also provides a home to the very active Local Agenda 21 office. The status of the Agenda 21 office is somewhere between NGO and government supported organ. In the words of the interviewee they view themselves "as a bridge between Government and civil society, mostly NGOs" (Agenda 21, 2010). They are mostly funded by the government, but place great importance on their role as critics of "local government people" (Agenda 21, 2010), and with strong roots in the Korean democratic movement and the broader environmental NGO movement. The work to establish a strong Korean Local agenda 21 started with input from the Earth summit held in Rio de Janeiro in 1992, where representatives from Korean NGOs participated and brought back ideas and the overall concept of Local Agenda 21. This led to the official establishment of a Local Agenda 21 office in the Gyeonggi-do province in 1999, and it is now a prominent Agenda21 organization in Korea. With the slogan "We value the harmony between human and nature highest in the development and preservation" (Green Gyeonggi 21, 2011), the office focuses on 13 overall themes. These include: Forest/Green zone, Wetlands, Water Quality \& River, Waste, Urban planning, Community, Gender Equity, Child Care, Agriculture, Sustainable consumption and Production, Energy, Social Welfare and Culture (Green Gyeonggi 21, 2011)

Although this represents a dizzying array of important themes, the work to translate such focuses into real world activities is very action oriented. Themes are singled out and given special focus periods, ranging between three and five years, where the themes, are stressed and sought to be directly implemented in the work of the organisation. They not only initiate different activities, but also monitor Local Agenda 21 activities started by others, often environmental NGOs in the Gyeonggi-do province. As such they function as a central actor in the growing network of environmental NGOs and work hard to ensure that knowledge and experiences are shared and disseminated to the different organizations involved, both NGOs and government bodies. Another important part of their work is to pass on input from citizens and NGOs to the policymakers in the area and ensure that continued contact and discussion between the different actors within the field are upheld. 
The work to bridge the often quite intense differences between the government and civil society is expressed through efforts to focus on both ends of this scale, developing environmental education material and supporting projects within NGOs and schools, but also organizing seminars and workshops with representatives from many different stakeholders. Trying hard to walk the difficult line between being part of a largely grassroots driven environmental movement and being funded by the local government obviously requires a delicate understanding of how the often stressful and at times antagonistic relationship between civil society and government functions. Nonetheless, the interviewee is quite optimistic about the development of the Local Agenda21 initiatives and their continued work with both official representatives and a vast number of different NGOs (Agenda21, 2010).

A cluster of activities related to the notion of "enhancing local sustainability" (Agenda 21, 2010), has been the mainstay of the bridging work during the latter half of the last decade. A Campaign of Cities for Climate Protection has since 2006 led to international, national and local initiatives to develop a Korean take on sustainability. This led to participating in the Asia Good ESD Practice project and the ensuing Asian network on ESD and the publication of the Handbook for ESD in Asia (AGEPP, 2008).

\section{Hansalim Co-op}

This NGO is somewhat different to the others presented here. Even though the organization categorises itself as an NGO, it has a different, more commercial focus compared to the other Korean NGOs. 'Han' and 'Salim' are native Korean words. 'Han' refers to an understanding of togetherness and interconnectedness while 'Salim' can be interpreted in two ways: either to describe the work mothers do in the household, or to revive and give life (Hansalim, 2011). As such it is a take on the modern, member-based co-op, focusing on providing organic food through 110 stores all over Korea and emphasizing a 'friendly life method' focusing on upper middle class women (Hansalim, 2010). Hansalim also spends a considerable amount of the organisation's resources on educational efforts, both public information campaigns and more formal education with classes for both adults and school children. Hansalim is, relatively speaking, one of the 
older organizations in South Korea with an environmental focus. From its start during the tumultuous 80s, with strong roots in the democratic movement, it has grown to be the largest Korean organizations providing organic food to consumers. Because of its history, Hansalim is very closely tied to the other big NGOs that focus on environmental issues, and there is an ongoing influx of employees from e.g. KFEM. The Hansalim stores are also often to be found as part of building complexes owned by other NGOs. The Hansalim co-op is thus viewed by many of the other NGOs as a natural part of the quite close-knit core of the environmental movement of South Korea. Their activities are not limited to Korea as they have on several occasions supplied large quantities of food to both the often starving North Korea and more recently to peasants in Afghanistan (Hansalim, 2011). This is something Hansalim is very proud of, and often mentions together with the fact that South Korea received help from overseas not that long ago, and is now in a position where it is possible to go out and help other countries. Their educational approach, with close ties to the more traditional environmental NGOs, and with an international outreach programme, makes for a highly dynamic organization that still only manages to reach out to 300,000 of the almost 50 million South Koreans.

Once again the Korean women and mothers form the core of the organisations member and customers. Recurring waves of media focus on polluted food, scandals concerning health and safety, and an emphasis on child health concerns can be directly traced in the number of members, and this has also given the organization a certain political edge, with policymakers, the food industry and the media referring to them as everything from prime examples of how to transform society to tree hugging hippies that ruin the hard work of the many giant corporations that set the standards for Korean business life (Cho, 2009). The dual task of running a sustainable business and educating existing or future members of the organization is not made easier by the political interest surrounding the issues or the relative novelty of the political consumer in South Korea.

\section{Green Asia}

Green Asia is unique among the NGOs that form the Korean case in this study in that its primary area of activities is not South Korea, but in Mongolia. The organization has set as 
its goal to transform the vast Mongolian Gobi desert into a forest, or at least help combat the alarming desertification process that is well under way in central Asia (Green Asia, 2010). The dreaded red dust storms that have had a growing effect on Korea during the last decade stem from the Gobi desert to the north and are a particular problem in Seoul. Springtime in Korea is thus often marked by the red sand getting into all nooks and crannies, forcing people to wear masks and obstructing the daylight. These storms have been framed as some of the most tangible results of global warming in Korea (Kim et al, 2000). Green Asia was formed in 2000 and in 2002 they started the work to plant large belts of trees in the Mongolian desert, to try and stop the severe effects of desertification. The NGO is also very much a part of the strong network linked to the democratic movement, several of the organisations staff members spent months in jail during the $80 \mathrm{~s}$ as a democracy activist. The organisation was founded in 2000 as an effort to transcend the domestic focus of most Korean environmental NGOs. The educational focus was strong from the beginning, with the interviewee stressing that they "do not plant trees, they plant human beings" (Green Asia, 2010). Their model of operation relies on Korean volunteers that fly to Mongolia and stay there for several weeks, while planting trees and saplings in the desert areas and receiving information and education on the work they do and its possible consequences. In order to make this financially viable, Green Asia has been very good at securing support from several large Korean corporations. The largest Korean airline, Korean Air, sponsors 600 flights each year for volunteers travelling to Mongolia, and the largest Korean brewery, Cass, supports Green Asia with a percentage of the profit from each beer sold. This interest and support from corporations are linked to the new Korean 'Green Economy' strategy, but also stresses that there are historical connections between Green Asia and Cass as staff members from both organisation were part of democratic movement in to 80 s before moving into the private sector after the establishment of a more democratic government. This alliance is also symptomatic of the interesting history of the environmental movement in South Korea, where most of the current leaders of the larger organizations have a background in the democratic movement and remain in close contact with their old friends, who are to be found in many leading positions in both the private sector, political organizations and in civil society organizations (Kim, 1996). This not only presents unique possibilities for furthering the 
cause of the environmental NGOs, but also results in the occasional stirring up of old animosities with other political fractions. Aside from the ambitious project in Mongolia, Green Asia also works on several initiatives in Laos focusing on poverty and education

\section{Jeju Korea Environmental Education Center (KEEC)}

While most of the environmental NGOs in South Korea are centred in the megalopolis of Seoul, as reflected by the NGOs involved in this study, there is also a host of activities outside the urban sprawl of Seoul. In the far south, on the island of Jeju-do, it is also possible find a very active NGO, but the context and outlook also differ from colleagues in the north. Jeju-do is the largest Korean island, situated south of the mainland, with roughly 500,000 inhabitants. Because of its geographical position, it has a warmer climate than the rest of the Korean peninsula and enjoys a unique ecology with wildlife and botanic varieties that can only be found on the island. Because of this situation, the environmental movement has had a strong presence on Jeju-do since the establishment of the first independent environmental NGO on the island in 1994.

The organization on Jeju started out as an independent organization, but joined the umbrella of KFEM in 1997 and remains, with its 800 members, the largest of all the social movements on the island. KEEC is the educational wing of KFEM, and is present in all of the Korean provinces. The founders of the Jeju KFEM/KEEC can also trace their roots back to the democratic movement, but with a distinct Jejuian focus. What started out as a strong emphasis on preservation of the unique nature on Jeju shifted focus during the 90s to include a greater emphasis on social issues connected to environmental and climate change. One of the big issues for the organization, both regarding their educational and informational work is to emphasize the dangers of the growing number of tourists that visit the island every year. Jeju, often dubbed as 'Korea's Hawaii', is a very popular destination for fellow Koreans, but also from a steadily growing number of Chinese tourists. This has put the sights and distinctive nature of the island under great pressure, as the local government and tourist industry strive to combine the vulnerable nature and spectacular sights, like the unique columnar joints that rise out of the seabed at Daepo Coast and the impressive Halla-san Mountain, with the Korean ability to pursue and foster economic growth. The KFEM/KEEC of Jeju suffers to a lesser degree from 
governmental resistance to environmental issues because of the widespread focus on these issues throughout the island. Still, big issues like the instalment of a cable car crossing nature preservations have established feuds between the NGO, the political sector and local businesses. Even though some of the inhabitants live in close harmony with nature, such as communities of Haenyo female divers, the general level of knowledge about ecosystems and climate change is still at a relatively low level (Hong et al., 1991). The focus is not only on the local inhabitants, but also on the multitude of Koreans that visit the island each year, and the large number of pupils and students that attend the expanding number of eco-schools and eco camps on the island.

\section{Centre for Energy Alternative (CEA)}

The Centre for Energy Alternative was set up in 2000 as part of KFEM, with a special focus on Energy consumption and sustainable energy alternatives, and became independent of KFEM in 2003. The organization is relatively small, with 950 fee paying members and with a small staff, makes for an independent NGO, where decisions can be made and executed with relatively ease and flexibility (CEA, 2010). The organization benefitted from the presidency of Roh Moo-hyun (2003-2008), as he had been part of the democratic movement and was positive towards the NGOs and especially Centre for Energy Alternative (Lim \& Jang, 2007: 442). At the time it was relatively easy to maintain contacts with government officials, something that changed rapidly as the centre-right government of Lee Myung- Bak took control in 2008 (Doucette, 2010: 22). This situation has not halted the activities of the organization as the work to establish solar energy power plants continues. These power plants are arranged like a co-op with members owning shares in the plant and receiving a proportion of the profit after the power is sold to KEPCO, the largest Korean power company. This effort to produce locally based sustainable energy has been coupled with the construction of modern low energy housing, which is something rarely seen in the densely populated urban areas in Korea (CEA, 2010).

The educational efforts of the organization cover a range of activities, including a strong emphasis on non-formal education of adults and outreach work to school pupils. In the urban areas of Korea, and of course especially Seoul with its 11 
million inhabitants, very few people own their own houses, but instead live in smaller apartments. This has necessitated a more holistic educational focus on $\mathrm{CO} 2$ friendly housing, stressing the importance of collective action, as individuals or single families living in a housing complex have very little say when trying to change, for example, the frequently poor standards of thermal insulation in housing estates. Through the utilization of 'Saram-bam meetings', Saram-bam being the traditional word for a guest room where you invite friends, CEA tries to establish an open discussion space, not only presenting information to citizens, but also offering them the opportunity to actively engage with experts and question the ideas about alternative energy forms (CEA, 2010).

This approach to non-formal education is also represented in the organization's name, which is deliberate, and not only a consequence of Koreanization of the English language, but should stress that the organization not only wants to discuss alternative energy, but also alternatives to energy (CEA, 2010). The goal is to organize everyday lives such that energy consumption is reduced and generally try to establish a platform where it is considered possible to discuss other ways of arranging a society than currently prevalent (CEA, 2010).

\section{Korean NGOs: common history and differentiated future}

The nine different Korean organizations represented in this study cover a broad field of activities aimed at the public, but also very different concepts of why and how a NGO should operate in a dynamic society. All the organizations are relatively young with a span of little more than two decades, but most of them have also managed to establish a firm base in the Korean society and grow under difficult circumstances. These NGOs will act as the specific context for the forthcoming analysis, influencing the questions asked and the findings unearthed in a close relationship with their colleagues from the other side of the world, the Danish NGOs.

\section{The Danish Case: Environmental NGOs and the COP15 summit}

As mentioned, the two cases outlined in this chapter share many similarities, but also differ greatly. Not only in terms of cultural, historical and geographical setting, but also in 
the type of organizations involved. Focusing on the events before, during and after COP15 brought different types of organizations to light than might have been the case during other periods. The fact that the Korean environmental movement has not so far been mapped from a scholarly perspective in other languages than Korean made the initial efforts in Korea a somewhat hit and miss affair. The Danish environmental movement, on the other hand, was well chronicled before the study started and this enabled the luxury of singling out the NGOs that were perceived as the most interesting and promising for this study. This resulted in a greater focus on the broad umbrella organizations that have a strong popular base in Denmark, but it also resulted in qualitative difference between the two cases, a difference that will be explored in the analysis.

\section{People's Climate Action (PCA)}

PCA was the primary organizer and initiator of civil society activities during the COP15 summit in Copenhagen 2009. It was an umbrella organization made up of a host of stakeholders from the Danish environmental movement and civil society actors, based on the Danish 92-group. The 92-group is itself an umbrella organization, consisting of 22 member NGOs that all focus on sustainable development in their work. It can be viewed as the primary forum for development of civil society approaches to sustainable development in Denmark and remains a strong voice in the public debate and on a policy making level (92-gruppen, 2011). The initiative for PCA came from several key members of organizations within the 92-group, and they managed to create a structure that became the main forum for the organization of civil society activities during COP15. PCA established a close, but also at times troublesome, cooperation with the Ministry of Foreign Affairs that oversaw the COP15 summit, and PCA ended up channelling the financial support from the Danish government to several hundred activities in the time before, during and after the COP15 summit. PCA was born out of frustration among several of the key players in the Danish environmental movement and civil society about the government's lack of planning regarding civil society engagement and activities during the hitherto largest global climate summit in the world (PCA, 2010).

The underlying reasoning of the work conducted in relation to PCA was to ensure that COP15 should not end up as solely negotiations among leading political 
figures, but needed to incorporate a broader civil society perspective and at the same time ensure participation went beyond the familiar old faces of the environmental movement (PCA, 2010). The many actors involved, ranging from numerous activists, both young and old, some with humanitarian approaches, others with more militant and revolutionary aspirations, to professionals with decades of experience meant there were very different ideas about how activities should unfold, presenting the PCA group with a formidable challenge. It also resulted in a plethora of informational and educational activities that spanned a climate march with over 100,000 taking part, art happenings, and debates and public lectures by everyone from esteemed professors to members of threatened indigenous peoples from all over the world. As such PCA represented a wide variety of approaches, but also offers an intriguing insight into the chosen educational approaches of a majority of the larger Danish environmental NGOs.

\section{Danish Adult Education Association (DAEA)}

DAEA draws heavily on the Danish tradition of Folkeoplysning and a liberal approach to education, embracing most aspects of learning outside strictly formal settings in Denmark. DEAE is an Umbrella organization with close ties to local organizations all over Denmark that arrange everything from youth activities, to adult education in technical, language, and creative skills, to debates and theatre performances. The English version of the Danish name Dansk Folkeoplysnings Samråd does not entail that they only deal with adult education, but that they deal with a broad notion of liberal education, hinging on the hard to translate Scandinavian concept of Folkeoplysning (Korsgaard, 2002). The focus on sustainable development, environmental and climate issues forms part of many of the daily activities that are organized by the association's many member organizations, but was further boosted by the COP15 summit focus on international climate issues. Many of the 32 member organizations, such as Grøn Hverdag ${ }^{3}$ and Eco-net, routinely focus on environmental issues, but several other nationwide organizations joined the fray up to COP15 in order to try and engage the public on the many complex issues that arose during the period (DAEA, 2010). Existing agendas such as women's rights, democracy, or development issues were frequently linked to climate and environmental issues, creating

\footnotetext{
${ }^{3}$ Roughly translated: "Greening the everyday"
} 
an overlapping field of activities which also stressed a gap between the larger Danish cities, mainly Copenhagen and the countryside. This gap was in many ways underlined by COP15, where the capital city, Copenhagen, not only hosted the summit, but also saw the vast majority of civil society activities linked to the event. DAEA saw it as their job to stress the importance of activities outside the capital and the value of debate and interest from all areas of society, not just a small, die-hard nucleus of activists. This approach encompassed a range of activities that included both more traditional lectures by recognized authorities within the field and more participatory activities. A growing focus on how the individual could be engaged, focusing on lifestyle and consumption patterns, proved very popular. The possibilities of combining ideas of how to lead a more environmentally friendly existence while, for example, optimizing the insulation of houses and other cost-cutting efforts became a focus for many of the activities across Denmark sponsored by DAEA.

\section{World Wide Fund for Nature, Denmark (WWF)}

WWF Denmark has, in accordance with the international strategy of WWF, mostly focused on activities and lobbyism attempting to influence policymakers and corporate organizations. This work has in recent years received criticism, focusing on the often close connections between WWF and both governmental and corporate interests, making it difficult for WWF to criticise the actions of these parties (Huismann, 2011). The international nature of WWF's work and their focus on governments and large corporations has had the consequence that, for example, volunteers have not been a standard part of WWF Denmark's work. Up to the COP15 summit there was, however, great debate on how to involve not only politicians and existing members, but also reach out to a wider audience. The Burning Panda project, portrayed by WWF's famous panda logo with its 'fur' on fire, was WWF Denmark's effort to reach young people in particular and involve them in the climate issues linked to nature conservation. This led to various activities, both web-based and involving a growing number of WWF volunteers. The volunteers, who dressed up in giant panda suits, became a distinctive sight at many of the COP15 activities. Even though the Burning Panda was a strictly national project, it still 
included some large-scale activities that linked informational and educational efforts with active participation.

A 'turn off the light' campaign focused on the role of individual households in climate change, as families all over Denmark where urged to turn off all the lights in their home during three specified periods during the lead-up to COP15. This was followed by a massive focus on information concerning climate change and its consequences for wildlife all over the world. Other activities such as 'Make some noise for the Climate', which enabled, primarily, young people to compose their own symphonies of noise on the web, were more focused on the individual. A distinctive and controversial effort to apply an approach focused on the emotions linked to climate and 'talking to the stomach', makes WWF stand out compared to the other NGOs involved in this study (WWF, 2010).

\section{Climate Movement of Denmark (CMD)}

The Climate Movement of Denmark is part of a growing group of young NGOs with a distinct focus on climate and environmental issues, and with reservations about older and more established NGOs. As part of the media hype surrounding the COP15 summit, the Climate Movement of Denmark attracted strong interest from politicians and other civil society groups. CMD was officially formed in 2008 and was very active during the period up to the COP15, with a strong agenda of public involvement in the summit. In contrast to the other Danish NGOs presented here, CMD focuses specifically climate issues, and does not per se focus on environmental issues, as hard as it can be to draw a line between the two. What this emphasis does add to the organization is a distinctive international and global outlook with strong ties to international NGOs. This does not mean that the organization does not work locally, as a key part of their mission is to stress the importance and responsibility of the individual Danish citizen. Very much seen as being part of a perceived grassroots movement in Denmark, the focus of the organization is on how participation and engagement is understood and secured in the work with both supporting members and the public. The organization is small, with no paid staff members, thus entirely relying on volunteers and also both benefiting and suffering from the possibilities and restrictions that this situation presents. 
The interviewee from CMD stresses that the organization should not be understood as a radical departure into eco-fascism, or as an organization that sympathizes with groups with violent tendencies which are also to be found among the group of new organizations with a voice in the debate about climate and environmental issues (CMD, 2010). In contrast CMD is trying hard to offer a broad base of participation for everyone in Denmark. While this might be hard to establish, there has been considerable success in setting up local CMD groups in over 10 Danish cities. The educational aim of the NGO is very explicit, with great emphasis on communicating information on the ongoing climate changes, and exploiting the possibilities of reaching already established societies, organizations and groups in Denmark. This has resulted in initiatives aimed at cooperative housing associations, which house a great number of Danes, public debates, and work to soften what is often highlighted as a perceived dichotomy between civil society and liberal market mechanisms.

\section{Climate Justice Action (CJA)}

The final NGO to be included in this study is one of the more controversial NGOs that took part in the COP15 activities. With a declared goal to 'Change the System, not the Climate', CJA framed itself in a more radical position than the umbrella like organizations of PCA and DAEA, but also in contrast to the activities of WWF Denmark (CJA, 2011). Not being a traditional NGO in itself, CJA works more as a global network, with a very active Danish group that set the standard for many of the activities that happened outside the official venues during the summit. Over 70 different 'groups/networks/organizations/collectives', as CJA put it, are listed as part of the network, primarily consisting of a large number of international actors, with considerable emphasis on groups from regions threatened by climate change, and several left wing political organizations (CJA, 2010). This makes CJA a hotbed of different approaches to climate change and the challenges it brings. From islands threatened by rising sea levels came activists that tried to increase awareness of how their way of life is on the brink of extinction; from the radical left came groups with a long history of political happenings and the occasional bad reputation as trouble makers (Isherwood, 2009). But more traditional environmental activists also played a central role in the network, not only as 
members of supporting organizations, but also as part of the group that organized the activities during COP15.

The organization framed itself as a more radical alternative to the wellestablished, older NGOs. CJA was established to ensure that there would be a debate outside the summit, and that such a debate would include the voices of those hit hardest by climate change. As the interviewee from CJA says "We did not just pull a few Africans into the game, we consisted of those Africans" (CJA, 2010). As such, the focus on 'justice' as part of the network's aim was used to point to global inequalities and also to present a confrontational attitude that differed markedly from, for example, WWF's more adaptive approach towards large corporations and established political systems. In an effort to inform and educate the public about activism and counter politics, a great deal of energy was spent on establishing alternative narratives of how it is possible to live and be a citizen in a modern society, yet still be critical and sceptical about the mechanisms and consequences that derive from it. This strategy led to a wide number of varied activities that tried to draw on international resources in order to avoid the official happenings like 'Hopenhagen', which was an official initiative from the municipality of Copenhagen, held at city hall square and involving large companies such as Vattenfall and Siemens, but also in order to critique the activities of many of the larger NGOs, including most of the other Danish NGOs involved in this study (CJA, 2010). As such, CJA marks the more radical end of the continuum of Danish NGOs, with WWF having a bias towards a more corporate like structure and outlook, DAEA linking directly to the Danish Folkeoplysning tradition, PCA representing the established NGOs, and the Danish Climate Movement trying to start all over in order to initiate a new grassroots movement.

\section{The Korean and Danish Environmental NGOs - Spanning Different Societies}

The NGOs that form the Danish and Korean cases vary immensely: not only do they differ between the two countries, but even at a national level their histories, activities and approaches toward engaging the public are very different. This translated into a broad and varied picture of what understanding of what constitutes a NGO and how such a NGO relates to ideas of non-formal education for sustainable development. In both countries the field that is described by the chosen NGOs criss-crosses different political perspectives, 
types of organizations and principles, but all of them share a focus on non-formal education, environmental issues and subjects linked to climate change, and sustainability or other takes on a Green Agenda. Not all of them do so explicitly, and concrete discussions of 'non-formal ESD' are rare, but the initiatives, activities and aims of the organizations at the time of the study all draw on different concepts of how to change society through a focus on moving and engaging the public. How this role is perceived and understood by the individual interviewees will be the subject of the next chapter. 


\section{Chapter 4 - Perceptions of the Public as a Learning Entity in Denmark and South Korea}

The different NGOs represented in this study not only describe a wide palette of notions regarding how to involve the public and engage them via explicit or implicit educational strategies and ideas. This chapter continues to narrow the field of analysis, by looking into the perceptions of the individual interviewees that take part in this study. This not only means that individual statements and discussions are objects of this part of the analysis but also that the opinions of the individual and the perceived goal of the NGOs overlap, differ and complement each other. Such a perspective entails that it becomes increasingly harder to refer to the overall objectives and goals of entire organizations, as the individual perspective does not always mirror the stance of the entire organization. The picture is, however, fuzzy as the individual interviewees invoke the organizations as platforms for thoughts and ideas. While the focus might be on the individual's perception of the public and their own work, these perceptions are also interlinked with notions of how the respective NGOs are understood by the interviewee. While a clean-cut analytical demarcation line is therefore hard to draw, the emphasis of this part of the analysis is on how the individual key persons perceive the public as an entity that must be engaged via the activities of the NGOs.

The chapter will focus on the Why, Where and How of the didactical question in order to get closer to the perceptions of the interviewees and understand their particular ideas and notions. The question of Why, as interpreted in section 4.1, is concerned with the reasons for the NGOs to engage the public, and, in turn, the public's perceived reasons for being attracted towards the work and cause of the NGOs. It does, however, impose on the empirical data the perspective of the Why, which in itself is far from an objective and non-biased position. The basis of the analysis is the perceived practice of the NGOs as articulated by key NGO personnel. As such, the Why relates to what the interviewees perceive as being the mission, the work, the goal, or the aim of the organization they are involved in.

This focus is followed by an inquiry into the Where. This question can be understood in many ways, but in section 4.2 it refers to the groups, the narratives, and the 
physical settings that are perceived by the interviewees as carrying the greatest potential for facilitating learning. This is described in different ways by the interviewees, e.g. as 'fields of learning', 'areas of change', 'windows for emancipation' etc., but does not always relate to explicit ideas of either education or learning, nor to the potential for change and long-term possibilities. From the outset, it is important to stress that discussing the educational goals, hopes, and work of the NGOs does not mean that the interviewees have explicitly used the term education, but often instead spoken in terms of learning, engagement, information, or stimulating support for a cause.

This leads to the question of How learning takes place, which is dealt with in section 4.3. This question is closely intertwined with the two preceding questions as it stresses which qualities the public is perceived as possessing as a learning entity by the NGOs. This concept revolves around the notion of 'participation' and the nature of it. Based on Jeppe Læssøe's fourfold mapping of the controversial term participation, the focus on How participation is perceived among the NGOs will add a fifth concept of participation based on the data from Korea and Denmark (Læssøe, 2011). This effort will pave the way to chapter seven and the theoretically driven analysis of What the significance of the different perception could be, in a Lacanian and Žižekian perspective.

Before that is possible, the focus will be on wringing as much detail and understanding out of the empirical data as possible without resorting to the always tempting possibility of pegging the square data into a theoretical round hole. Chapter 4 is thus an effort to focus on the perceptions of the individual interviewees in order to pave the way for a broader understanding of the relationship between the environmental NGOs and the always elusive notion of the public. 


\subsection{Why Engage the Public? The Perceived Role of the NGOs}

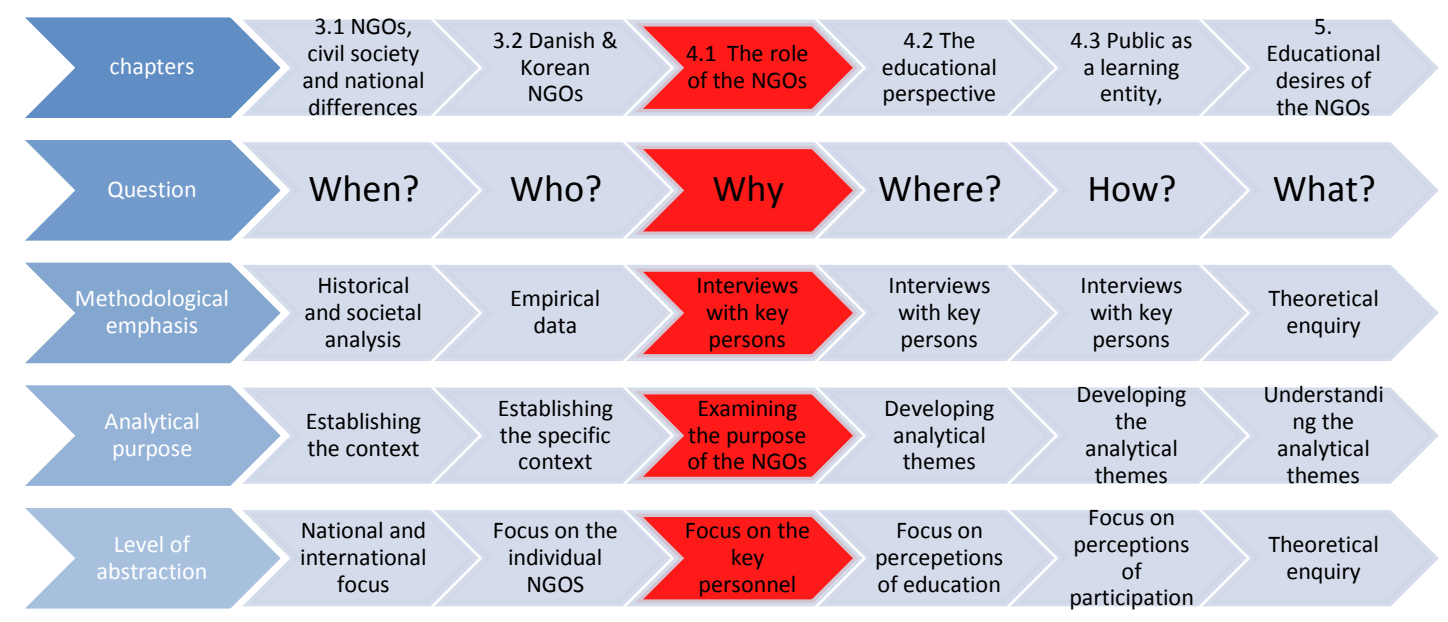

Why?

How do you justify the existence of a NGO with a specifically environmental focus? Surely other organizations exists that carry out work similar to the efforts of any given NGO? This is evident in both South Korea and Denmark as almost all of the key persons interviewed stressed that they saw themselves as part of a greater field of, often overlapping, NGOs, and that most of them had worked for several different NGOs over the course of their career. Why then this insistence on a multitude of different NGOs and all the hard work to establish a distinct identity for each of them? What might seem surprising is that not all of the interviewed key personnel single out a clear mission statement for their NGO. This is especially the case with the Danish NGOs where a broader focus on 'non-radical change' is mentioned by e.g. the representative from the Climate movement, whereas the Korean NGOs to a greater degree focus on more specific and tangible issues.

This part of the analysis will move from the general introduction of the national fields of environmental NGOs and the overall description of the individual NGOs towards how key personnel from these NGOs perceive their own organisation. More precisely, the focus is on how the interviewees from the different NGOs in Denmark and South Korea perceive the mission of their NGO. Additionally, the ways in which the individual interviewee understands notions of how their respective organizations relate to 
other NGOs are explored, and, most importantly, what is regarded by the interviewees as the given NGO's role within the national environmental movement. This step lays the foundation for the subsequent theoretical analysis of the approaches, perceptions and efforts of the NGOs, which are seen as intrinsically linked with the perceived societal role that the NGOs are expected to assume, and how the organization relates to the possibility of changing existing societal structures.

The choice to begin with the Korean case should be understood as an effort to 'make the familiar strange': an attempt to challenge the previously discussed natural bias towards the Danish setting through the backdrop of the Korean case (Vrasidas, 2001).

\section{The Perceived Role of the Korean NGOs}

As discussed earlier, the environmental NGOs in this study vary significantly, having taken different historical routes to their present situation. This variance is also expressed in the perceived societal roles or missions of the NGOs. As one of the older environmental NGOs, KFEM has had a traditional focus on passing along information to the public in the hope that filling knowledge gaps regarding environmental and climate issues would lead to change. This is stressed from KFEM Seoul where their representative describes the mission of KFEM as delivering "Direct information to the public about environmental issues" (KFEM, 2010), a notion of the societal role of civil society NGOs that comes as little surprise. Such a strategy and perceived mission is in line with a traditional understanding of the civil society NGO and its task of spreading information about areas where the state or commercial actors might not guarantee the individual citizen's rights and well-being. This mirrors the development of the democratic movement in Korea and

the rise of civil society actors on a more general international level; factors which have been known to emphasize the power of knowledge on under-illuminated issues (Kim, 1996). Even though this might be the overall focus of the large KFEM organization, their representative, speaking on behalf of the educational wing of KFEM, KEEC, wonders “... if we need a new mission, when we started it was simply informing the public. During that time not many knew about the importance, but in the last 10 years many knows. There is change, but we still focus on public information, but there is discussion" (KEEC, 2010) This quote exemplifies a new awareness that the more traditional approach might need to 
change as new issues and levels of understanding become apparent in society. The interviewee from KEEC Seoul indicates that it is no longer enough to simply unearth the environmental problems involved with the development of Korean society and present them to the public; something new is needed, but it is not yet clear how such an understanding will influence the overall mission of the NGO. This tension between the traditional role of the NGO as an awareness raiser and the looming difficulties of this role in a society that to a large degree is, in fact, already aware, but which, nevertheless, continues to act in ways which are frequently less than environmentally friendly, nicely illustrates the continuum of general issues raised in the Korean case regarding the role of contemporary environmental NGOs.

For most of the NGOs, the role of raising awareness about environmental issues remains extremely central to their work, but with subtle differences that mark their distinctive takes on that work. The Hansalim co-op naturally wants to push their products towards as many consumers as possible: "The overall mission [is], to provide organic food and products to consumers, for an open community" (Hansalim, 2010), but with an added focus on raising awareness on the link between consumer and producer, which arguably is often hard to recognize in the Korean supermarket-based food industry (Sternquist \& Jin, 1998). The Korean Agenda21 branch pushes for greater interactive relations between local governments and the civil society actors: "[our] main goal is to help and support local government to be more sustainable" ...[and] "bridge between local community and government" (Agenda 21, 2010). As this link has from time to time been weak in Korean society, their work also includes a strong emphasis on informing the local governments about the NGOs' activities and vice versa, and how support could be gathered by both sides by collaborating more openly on new initiatives and activities. Resentment toward government activities, especially when they align with interests from the vast Korean industrial companies, is also mentioned by the interviewee from the Korean Citizen's Movement for Environmental Justice, who adds an explicit focus on gender perspectives. "...[CMEJ] is especially concerned with how the rich, strong people, men, take advantage of the environment. This is hard on women, children [and] the poor" (CMEJ, 2010). The moral obligation of the NGO stressed by the interviewee, to protect the weak (women and children) from the powerful (rich men), illustrates the NGOs' 
strong ties to the democratic movement and their outspoken criticism of the close relationship between the former authoritarian regime and the large Chaebol business conglomerates like the internationally known Hyundai, Samsung and LG (Hong, 2008). It also adds a much needed gender perspective and stresses how Korean society remains very much a patriarchal society, where the men in most circumstances are still seen as the heads of a household and where many women choose a life as a housewife rather than a career (Kim \& Kim, 2011).

The urge to change the basic conditions and values of Korean society is not limited to gender issues among the environmental NGOs. The representative from Green Korea argues that "Green Korea Education Centre's mission is not only the environmental problems, but to a great degree also the human values, human rights [and] respect for variation" (Green Korea, 2010). Such a radical approach thus goes beyond the confines of the preservation of nature and focus on pollution that dominated the agenda in the beginning of the Korean environmental movement. The early focus on the more tangible consequences of industrialization is, however, by no means extinct. This is evident at the branch of KEEC that is found on "Korean Hawaii", the Jeju-do Island at the southernmost tip of the Korean peninsula (Seo et al. 2009). On this evidently beautiful island, home to a wealth of rare plants and exquisite animal life, there is still a very firm emphasis on nature conservation and protection. The local KEEC might be part of the larger KEEC network, but its work varies from the emphasis of the mainland Korea branch, illustrating its highly independent roots. The representative from Jeju KEEC, thus states that their mission and role is to "focus on local development, dangers of tourism and protecting the environment" (Jeju KEEC, 2010). The interesting focus on the growing dangers of tourism is unique among the sample NGOs. However, it does strike a chord with a greater movement within Korean society, where trekking and other outdoor activities are becoming a fashionable pastime for a growing number of Koreans, and where a growing influx of eco-tourists from especially China are making their presence felt on the popular South Korean trekking paths (Weaver, 2002). While this trend is understandable, with the beautiful mountainous Korean countryside and the tendency for Koreans to cram together in the megacity of the Seoul area (with more than 24 million inhabitants), it is also hard on the popular tourist spots such as Jeju-do and several 
mountains that are often overcrowded during the spring blossom season and autumn Maple season. Swarms of urban dwellers from Korea and mainland China head for the mountains and often swamp them to a degree reminiscent of the jam-packed metro stations during rush hour in Seoul city (Oh, 2009).

While the perception that the inherent risks of eco-tourism might be especially important from a Jeju-do Island perspective, the importance of local development is also stressed by the interviewee from KEEC Jeju. Economic development has been the overarching goal of the Korean society since the Korean War, and Jeju-do is placed as far as possible from the all-important Korean centre of Seoul. The built in contradiction of the reliance on tourism and the acknowledgment of the possible harm it can inflict upon the vulnerable countryside is not lost on Jeju KEEC, and the problems that arise from this dilemma, which resembles the many issues linked with the notion of sustainable development, is very much at the centre of their work and of their overall perceived role and mission.

The perception of the NGO as a part time defender of both the environment and local development translates into related topics outside of Jeju-Do.

The Centre for Energy Alternative and their work to promote sustainable energy solutions in a country that has relied on mass consumption of imported fossil fuels for decades also relates to the inconsistencies of sustainable development (Geem \& Roper, 2009). Their approach is to try and "...transform the society into more renewable based [energy]" (CEA, 2010). While this in itself does not distinguish the organization from many other actors in the Korean society, the representative from CEA, stress that their goal is much broader: “We use the words 'Energy Alternative', not only 'alternative energy' - in this is included wind, ocean energy etc, but this is just a part of 'energy alternative'. We must focus on overall energy consumption. Energy reduction comes first, [but] energy itself is not the target. We need heating or cooling, not energy in itself" (CEA, 2010). A will to facilitate a change in the basic patterns of how resources are applied is evident. It is not enough for CEA that energy is supplied through alternative resources. The level of energy consumption in itself is also of interest and should be lowered and, where possible, replaced by sustainable alternatives; for example, carbon neutral housing that needs 
neither heating, nor, more importantly, cooling, which is required in the harsh and hot Korean summer months (Sungho \& Sungwoo, 2009).

A distinct feature of the NGOs presented so far, concerning the role and mission of their NGO is an interesting absence of international focus. While it could be argued that this corresponds with an often discussed trait among Koreans of presenting a view of themselves as distinctively Korean bordering an outspoken ethnocentric perspective, it nonetheless clashes with a society that for half a decade has been aggressively geared towards globalization (Ahn \& Lee, 2005). While this lack of an explicit international perspective in many ways defies established practices by many of the NGOs, who often have a growing tradition of working in other countries such as Laos, and also of co-operation with international NGOs and international forums, it still exemplifies how most of the Korean NGOs favour domestic issues and spend relatively little time on framing themselves as organizations with an outspoken international view. An exemption from this is Green Asia, who, in their representatives words focus on how to: "mitigate climate change, work on desert issues, desert storms, focusing on developing countries, and working with international NGOs"'(Green Asia, 2010). This relatively new NGO and its focus on international issues, and on operating in developing countries, mostly Mongolia for now, not only represent a marked difference from the other NGOs, but also from the history of the Korean environmental movement as such.

The early, more traditional 'pollution area' of the 80's and early 90's, has to a large degree been surpassed by a more holistic focus, not only targeting the tangible results of industrialization and urbanization in Korea, but also emphasizing the questionable sustainability of most Koreans' lifestyle. In many ways, Green Korea's international focus is a continuation of this effort, searching for the consequences of climate change and pollution outside the national borders, but at the same time, this also leads to a focus on the tangible consequences that resembles the early period of the Korean environmental movement.

Speaking of a unified perception of what the Korean environmental NGOs aim to do, is based on the data at hand not a question of a clean cut stating of obvious mission statements. The discursive field presented by key persons from the Korean case is in many ways defined by the balance between KFEM's hope to deliver "Direct 
information to the public about environmental issues" (KFEM, 2010) and the expressed consciousness about the need for something more found within KEEC and several other organizations. Whether this more is channelled through a gender focus, close cooperation with local government or attempts to stress the importance of energy alternatives, it marks a steady move away from the historical roots of the unified Korean democratic movement and towards a more fragmented effort to target multiple specific areas at once. It also represents practical doubts about the long term viability of disseminating information about the perceived state of affairs to the public and expecting behavioural change as a result.

Green Asia's international focus mirrors in many ways how Danish NGOs moved from a local/national focus towards embracing the international nature of the challenges at hand (Jamison et al. 1991). While the international focus might be part of the 'new mission' the representative from KEEC wonders about, it does little to alter the fact that most of the interviewees view their organization as part of a classic civil society constellation of interests that try to better society through a form of power that builds primarily on popular support from the population interested in the different areas (Kim, 1996).

Idealism is very much at play when the importance of 'sustainability' and 'transforming society' is part of the perceived role of the organizations. To which degree these ideals saturate the actual activities of the NGO will be analyzed later, but an idealistic outlook on the work of the NGOs nonetheless forms an important part of the statements from all key persons interviewed. A transition in the position of Korean NGOs, from their roots in the antagonistic democratic movement, which placed itself in direct opposition to the existing government and most of the business sector, towards a more agonistic or even friendly relationship with the authorities is also an ongoing theme that characterizes the continuum of different NGOs. While several of the older NGOs, like KFEM and CMEJ, still perceive the government and big business as the main adversaries in their daily work, others, like Agenda21 Korea, work directly with the government, often via local offices. Likewise, organizations like Green Korea and Hansalim have a very close relationship with large companies and the business sector. The notion of the 'Korean environmental NGO' is perceived by the interviewees as something that works between 
established power structures and the general population, but this role is clearly changing as attachments to different agendas and actors are changing, and with that the missions and roles of the NGOs.

\section{The Perceived Role of the Danish NGOs}

Like their Korean counterparts, the Danish NGOs' perceptions of their role also cover quite a continuum. An important difference between the two cases that must be repeated is that three of the Danish interviewees represent umbrella organizations with a large number of member organizations. This not only means that the outlook of the interviewees can differ, but also that these three interviewees on one hand offer a view of what their own distinct organization focuses on, and on the other refers to what the over 100 organizations represented by these umbrella organizations deem the most important issues to be dealt with. This also includes the perspectives and approaches these organizations apply in order to try and constitute coherent platforms for cooperation and action.

In all bar one of the organizations, all of the interviewees refer to the Danish concept of 'Folkeoplysning' when describing the role of their organization. The interviewee from WWF differs from the rest by stressing an approach that aims at influencing policymakers through lobby activities, and to a lesser extent, almost as a necessary evil, includes information to the wider public as part of creating a strong democratic pressure on authorities. As the representative from WWF Denmark puts it, the organisation's mission is to “... influence the politicians, with more focus on the men in power than on the public and only on the public to influence upwards. "(WWF, 2010) This does not mean that that there is no attention towards the public and how to involve it in WWF, but it suggests that the overall aim of the organization is not to work in accordance with the traditional 'Folkeoplysning' theme of empowering the public through knowledge and sustained participation, but instead to focus on the people that deal with more widereaching decisions related to nature conservation and environmental issues.

At the other end of the participatory scale we find the Danish Adult Education Association (DAEA) which deals with many different types of liberal education in both formal and non-formal settings. With a distinct focus on 'Folkeoplysning', it comes as no surprise that a broad and participatory approach with the aim of embracing 
every nook and cranny of the Danish society is of utmost importance to their work. Their representative argues that their work linked to climate issues and especially the COP15 initiatives tried to "... create widespread debate about climate issues on an informed basis" (DAEA, 2010). The interviewee is, however, also quick to point out that DAEA does not hold the master key to decide how 'Folkeoplysning' should be understood, and that the member groups of the association represent very different ideas related to liberal education and how it should be executed. Even though it can be argued that 'Folkeoplysning' constitutes one of the foundational qualities of contemporary Danish society, the interviewee from DAEA signals a growing unease about the future role of the concept. It is argued that "there is a declining respect for the importance of 'Folkeoplysning' and its role in combating injustice and social conflict' (DAEA, 2010) As in the Korean case, there is an important idealistic trait, and here it is very much linked to the foundations of the Danish 'Folkeoplysning' tradition. While DAEA might stand as a traditional defender of liberal education and the principles behind 'Folkeoplysning', their involvement in climate and environmental issues is also influenced by other trends which are not necessarily seen as natural extensions of the existing ideals.

People's Climate Action (PCA), the initiative put together by several large Danish NGOs in order to organize civil society activities, also relies on the traditional 'Folkeoplysning' perspective when discussing the role of the organization. Their representative points out that "We needed a strong civil society contender that could not be circumvented, [in order to] focus public awareness and ensure that not only random projects survived" (PCA, 2010). It can be argued that PCA was seen by staff as a quite pure distillation of what sums up 'civil society' in the environmental field in Denmark. With a strong focus on how to establish a coherent civil society base, and with the central Danish environmental NGO network, the 92 group, embracing the initiative, PCA can be said to be perceived as the pinnacle of what the established Danish environmental movement could present, especially by its members and supporters, of course. The role of the initiative was thus to "Activate civil society, and not only the usual activist kind; we want to reach a broader audience" (PCA, 2010).

The notion of the 'usual activist' is an interesting reoccurring character that seems to represent a wide spectrum of environmentalist stalwarts, from the archetypal 
'tree hugging hippies' over ecologically aware urbanites to green intellectuals (PCA, 2010, DAEA, 2010). However interesting this group might be, and not disregarding that all of the interviewees could be argued to be part of such a group, they are nonetheless deemed of too little importance as the urge to engage a 'broader audience' remains undiminished. This translated into an initial goal of engaging at least 100,000 individuals around COP15 as stated in the official mission statement of PCA. The plan was to"mobilize, coordinate and ensure a broad engagement and involvement of Danish people in the activities before and during the COP15 "(PCA, 2010).

Another take on the notion of a broad and inclusive approach is The Danish Climate movement, which, as a very young NGO, lacking the strong organizational foundation of PCA, struggled to establish new ways of thinking about civil society activities and how to engage the public in new ways. Envisioning itself as being closer to the grassroots organizations than the larger NGOs represented in the 92 group and PCA, the interviewee from the Climate movement stressed how they did "not want to push radical statements, but instead try to include a broad appeal"'(CMD, 2010). At the same time they had an explicit agenda about not being caught up in the often heavily politicized scene that surrounds many of the NGOs working with environmental and climate issues.

Often being criticized as having an implicit left wing bias, many actors within the different organizations have spent a great deal of energy and effort on distancing themselves from the legacy of the 70's grassroots organizations (Jamison et al 1991, Læssøe, 2007). A sizable proportion of the environmental movement, including a number of PCA member organizations, and especially CJA, positions themselves in opposition to a conservative political stance. Among their work and many appearances in public media, there are strong references to ensuring non-affiliation with both the right and the left wing of the Danish political landscape, while nevertheless still striving to influence policymakers and the population alike (Nielsen, 2008; CMD, 2011). This, however, does little to diminish the argument that most of the environmental movement still shares many of its ideas and values with the centre-left of the Danish political scene. This does not imply that direct organizational links exist between the political centre-left and the environmental movement, but it implies that there is a shared history of promoting state intervention in order to ensure environmental goals. While this tendency might have 
been less obvious during the last couple of decades, political support for the environmental case is still stronger from the centre-left than from the liberal-right (Læssøe, 2009).

A sign that the NGOs working with climate issues are trying to establish new patterns and identities is found in their overall embrace of the possibilities embedded in large-scale market-driven initiatives like $\mathrm{CO} 2$ trading. As the interviewee from the Danish Climate Movement argues "The market is a strong driver, and it would be foolish of us to try and circumvent that mechanism, we are not saying that the market can solve the issues related to climate change, but we insist that the market mechanisms can help the push for a more sustainable development" (CMD, 2010). This perspective is linked with the notion of ecological modernization and has an interesting impact on the work of the Climate Movement of Denmark (Christoff, 1996; Hajer, 1995). The organization set the goal to create a broad collective movement focusing on climate change: something that turned out to be a formidable task, and one not easily solved from a small office in Denmark, despite good intentions and inspiration from the historic development of the popular environmental movement of the 70's and beyond. Established before COP15, and struggling to meet the more lukewarm climate agenda post-summit, the origins of the Climate movement, emphasize the strong effort to establish a broad demographic and topographic anchorage. The choice to refrain from ties to more radical left-wing organizations, and include a focus on market driven solutions, makes the organization a link between the environmental movement of the 70's and the contemporary focus on the role of the market.

In contrast to the Korean case, the overall mission of the involved Danish NGOs is not to focus on specific groups (housewives, children, farmers etc.) that are perceived as especially obvious targets. NGOs forming the Danish case to a greater degree emphasize unifying efforts in order to establish 'society wide changes', not pinpointed emancipation. This is very evident in the Climate Movement and its work to establish a "democratic and popular movement" (CMD, 2010). The majority of their activities during the COP15 aimed at establishing such a movement through local groups in larger Danish cities. However, it became very difficult to continue this work post-COP15 with the loss of popular attention and the overall change of political agendas. 
The perception of the role of the NGO as a popular platform that enables interest throughout society to surface is shared by Climate Justice Action. This organization bills itself more as a network than as a traditional NGO, with the intention to "build a global movement for climate justice that encourages urgent action to avoid catastrophic climate change" (CJA, 2011). In contrast to the other Danish NGOs mentioned, CJA has an outspoken focus on linking global actors through their activities, spending a lot of effort on hosting global activists and organizations that visited Copenhagen around the COP15 summit. The representative from CJA argues that "the Danes did not control what the global guests organized during the COP, the important thing was to establish counter activities towards the established NGOs and the official COP15 program" (CJA, 2010). As much as their work was born out of an urge to include global activists, CJA also represented an effort to establish a platform from which it was possible to criticize the existing environmental movement without being labelled as leftwing extremists. The interviewee stress that "The larger NGOs are caught in an oldfashioned idea about informing and educating the public. The role of the established NGOs is now actually conservative. The work of, for example, Greenpeace could be seen as reactionary. What we need is something new" (CJA, 2010). Climate Justice Action is by the interviewee perceived as part of this something 'new', not only representing the global victims of climate change, but actually being made up of individuals from threatened societies from all over the world. The feeling that the existing traditional NGOs approach climate issues from a Danish perspective and that it is difficult for issues dealing with global justice to gain a foothold is also expressed very clearly by CJA "We need to create a forum for discussion, not only dictate the truth [and] the great thing about CJA was that we made it possible to talk justice...we did not just pull a few Africans into the game, we consisted of those Africans" (CJA, 2010). As CJA worked to establish a network for a large range of groups, some very much in favour of radical, societychanging actions, others with a more traditional approach to the public and understanding of how society ought to deal with the climate challenges, controversy and conflicts also surrounded their work. "We try not to be a consumerist organization that presents an easy choice to ourselves and members, but instead we try to fight hard for what we believe in, and, partly because of that, we are not mainstream, but function on the edge of the 
environmental and climate movement" (CJA, 2010). As such, the CJA organization and the network it represents repeatedly focused on the counter-establishment and often anticapitalist voice during COP15. The interviewee however still argues that as "all counterculture is co-opted by the market" (CJA, 2010), there exists little in the way of easy answers to the problems we face, and the only way to continue a truly critical perspective is to insist on an unrelenting participation in the democratic work to alter our society. The representative from CJA does, however, argue that the great fear of COP15 ending in riots and street violence could not be linked with the intentions of the CJA members that took part in the summit activities. "You cannot create something peaceful and positive through violent and negative means [...] openness and trust is the cornerstone of a functioning society" (CJA, 2010). The critique of government backed legislation to stop trouble at the COP, which sent the interviewee from CJA, among many others, to jail for a short period, is strong, however "Control does not lead to safety and people's notion of democracy has lost out if they are willing to sacrifice freedom for safety" (CJA, 2010). The envisioned role of CJA and the way the network influenced public debate surrounding the COP was thus not only based on a strong counter establishment critique of the more conventional NGOs and consumerism, but also on an effort to frame a strong link between how justice is understood in a national and global setting, and how the people most affected by climate issues should also take part in the task of confronting government and public alike with the issues that threaten local societies around the world.

The perceptions at play in the Danish context span from quite radical images of the revolutionary potential of the NGO, as perceived by CJA, to the hopes for slow and gradual societal change that WWF hope to encourage. The interviewees all return, to varying degrees, to idealistic visions of their own role and the possible impact of environmental NGOs. The common ground is the hope that their organizations can bring new levels of insight and understanding to the public. The role of the NGO is as a catalyst or instigator of the level of change that is deemed inevitable or realistic, depending on who is asked. The differences are marked: the established organizations rely on visions can arguably be understood as proposing that more of the same, i.e. the NGOs will succeed if they reach enough people disseminate more information etc., is the road to 
success. Younger and smaller organizations are at more of a loss as to what will lead to success, but they do envision that something different must be done in order to begin to approach a sustainable development.

\section{The Arborescent and Rhizomatic Structure of South Korean and Danish NGOs}

If the South Korean NGOs represent a field that is highly intertwined with the common history of the Democratic movement, then the Danish NGOs share strong roots in the Danish 'Folkeoplysning' tradition. In both cases the NGO is implicitly, and usually also explicitly, perceived as a societal actor that is set into the world to target a broad part of the population in order to change society. WWF works in other ways, with a greater focus on activities directed at a policy-level, but still ended up with an extensive orientation towards the general public when they were forced to come up with something new during COP15.

The Danish NGOs' urge to base their work on a broad support from the Danish public might reflect a wish to be taken seriously and be able to change the outlook of the many. However, it is interesting to note how this in CJA's perspective has led to a nation-centric approach. In the CJA representative's interpretation, this leads to efforts that risk missing the mark of combating global climate change. Also of interest is CJA's looser understanding of what makes an NGO, and how the civil society can manifest itself in organizations. The loose network that comprises CJA is, in its almost rhizomatic nature, very hard to define and pinpoint, with little central authority and even less will to dictate how the network should develop. The notion of the rhizome as a metaphor for how the social is structured can be understood as an expression of relations shaped by lines of desire, multiplicity, and creation. This could be used as a fitting picture of the inner workings of CJA (Deleuze \& Guattari, 1987).

The rhizome is in itself not an active organization, but a way to picture immanent relations, or, in other terms, an approach to the active potentials of performances to create something new and unpredictable. The idea that the Danish wing of CJA merely helped international guests and activists to be able to perform their own activities indicates how extremely vague the official structure can be of an organization that still managed to be a central actor in the diverse happenings and initiatives that 
surrounded the COP. In nature, rhizomatic (root-like) relations are seen in crabgrass, tubers, mosses, and "when rats swarm over each other" (Deleuze \& Guattari, 1987: 6-7). Rhizomes spread in every direction and are contrasted to arborescent (tree-like) hierarchical relations that to a greater extent can be used to describe how a number of the more established NGO work in both Denmark and South Korea. Defined roles for the different members and explicit power structures are very common in most of the NGOs, e.g. in the 92 group which, in its work prior to COP15, highlighted the need to construct an organizational setting for the civil society activities or else "...there would be fire in the streets" as the interviewee from DAEA puts it.

Two key characteristics of rhizomatic relations that are evident in the workings of the NGOs are connection and heterogeneity (Deleuze \& Guattari, 1987). In the case of both South Korean and Danish NGOs, the notion offers a way of understanding the difference between traditional NGOs and the efforts to create new understandings of what an NGO should be doing and how this translates into the described perceptions of the role of the NGO. Any point in a rhizome can be connected to any other, unlike the tree or the root "which plots a point, fixes an order" (Deleuze \& Guattari, 1987). While none of the NGOs described exist in a vacuum and it would be hard to pin them down as the proverbial unmoving tree, there is still great differences in how key persons from the different NGOs perceive the role and development of their organization. It is not only possible to use the rhizometric metaphor to describe how the organizations are organized, but also to stress how connections exist between various elements without regard for what category or type they represent. The constant tension between the perception of the overall role or mission of the NGO and the daily grind of sustaining an organization that encompasses different perspectives and agendas could be an example of how unlikely links are established. When the representative from Agenda21 Korea describes the organisation's focus on promoting the ideal of sustainability through local governments that often have little interest in environmental issues, and which to some extent push the development agenda with little regard for the sustainability of decisions, then a link between two different epistemological understandings must be established. One that resides at a more general overall level and one that needs to deal with the great challenges of making an organization run in an often hostile environment. How the 
different NGOs relate to this topic establishes connections between the NGOs overall outlook, as PCA's wish to establish a broadly based popular movement resembles KFEM's wish to develop the ancestry from the democratic movement. Both meet a range of challenges when trying to follow these ideal perceptions of the role of the respective NGOs. The inherent heterogeneity of the field, with its myriads of interests and mix of political, economical and social issues are also clearly present in the reflections regarding the role of NGOs. The interviewee from KEEC's thoughts about the need for something new indicate that what they are offering no longer matches the expectations of the public “...that already know" (KEEC, 2010). The extreme diversity of the actors involved in the field is to a degree reflected in the loose network that makes up CJA. As a network with little central power and a very vague border between what is considered inside the network and outside it resembles the notion of the heterogeneous rhizomatic network, where connections can be made between any parts of the network, and where distinctively different networks within the network can work with the tension between different understandings of climate challenges, the ideal of sustainability, and how to (with or without success) deal with these through actions.

In interpreting the environmental NGOs, connection and heterogeneity can be ways to challenge how talk, discourses, material texts, human bodies, and material objects are related within a perception of the work of an organization. Rather than conceiving all of these perceptions as having centres of meaning that can be mapped, these principles prompt understandings of uncontained semiosis as an active, dynamic process that produces effects, many of which move in unpredictable directions. Another key principle of the rhizome is multiplicity: Lines extend in all directions (Deleuze \& Guattari, 1987). Emphasizing rhizomatic connections can thus function as a critique of point-driven, either/or, dichotomous thinking. Deleuze remarked that it is not "beginnings and ends that count, but middles" (Deleuze, 1995: 160). The movement and relation among objects (the line) is the focus rather than the identification of what is connected (the point) and where it is located (the position) (Deleuze \& Guattari, 1987). The aforementioned tension that exists in most of the NGOs, between the inherent will to do good, to change the world to something better and the harsh realities, can be seen as a way of trying to understand not only the end processes of a given organization, but also focus on how perceptions are 
constantly changing and that in principle nothing stops them from being very much out of tune with the surrounding society.

The diverse field exemplified by environmental NGOs has strong heterogeneous traits, with great differences between the organizations as well as within them. The work they carry out also moves in a multitude of directions, but this does not clash with the fact that connections continuously happen, exist, and disappear within the field. In both countries it can be argued that there exists an overall tension between the established organizations' urge to represent as large a part of the public as possible, with strong roots in albeit different democratic inclinations, and younger smaller organizations like Green Asia and CJA that employs different methods with a radically different take on international and global interaction. In CJAs case this is also linked to a decentralized structure that radically reinterprets the notion of democratic participation, in so far that participation is the only thing that constitutes the network, with little to speak of in terms of an independent organizational structure outside the input from the different involved 'member'-organizations and interested activists. The will to establish a popular organization does, however, in the Danish case not alter much according to how loose or following a rhizomatic pattern the NGO might be, as in the case of the Danish Climate movement. In both countries the key persons' perception of their NGOs do focus on how they can be vehicles of societal change and aid in a development that, although potentially radical, must be sought through popular support and participation, something that for all of the NGOs is in one way or another linked to notions of educating, informing or otherwise engaging the public in the environmental issues that are understood to be of highest importance.

\section{Ideals as a Driving Force?}

Why then spend an entire life being involved in NGOs and non-formal education on climate and environmental issues and sustainable development? The question could lead to suspicion about a widespread tendency towards flagellantism, with the seemingly insurmountable difficulties that characterize the work of the NGOs. Nonetheless the interviewees often return to the importance and ineluctability of their work to engage the public. Even though they often express that society is moving in the opposite direction of 
what they hope for, there is, apparently, no escaping working with the climate, environmental issues and ways of making these issues relevant for the public.

\begin{tabular}{|l|l|l|}
\hline $\begin{array}{l}\text { Why, are the NGOs } \\
\text { engaging the public? }\end{array}$ & $\begin{array}{l}\text { South Korea } \\
\text { Ideals about changing } \\
\text { the political structure }\end{array}$ & $\begin{array}{l}\text { Ideals about changing } \\
\text { lifestyle structures }\end{array}$ \\
\hline & $\begin{array}{l}\text { Stopping the } \\
\text { exploitation of nature } \\
\text { by state and industry }\end{array}$ & $\begin{array}{l}\text { Marrying a sustainable } \\
\text { emphasis with } \\
\text { continued growth }\end{array}$ \\
\hline & $\begin{array}{l}\text { Learning and change } \\
\text { as means to an end. } \\
\text { Radical change. }\end{array}$ & $\begin{array}{l}\text { Learning } \\
\text { knowledge as a goal in } \\
\text { itself. }\end{array}$ \\
\hline
\end{tabular}

Fig. 3-1. Perceptions of the public as a learning entity, Why?

As expressed in Fig. 3-1 ideals about changing the political and social structure is important for NGOs in both countries. As discussed, the interviewees from both cases return to ideals of changing society and the environment, when asked about why they do what they do, albeit in different ways. The Korean interviewees revolve around questions of being able to defend nature and the society in a setting where the government and big business are understood as being in opposition to large parts of the society, and especially to the hope of a sustainable development. This does ad a feeling of ongoing struggle against overwhelming odds to the Korean NGOs. The NGO as a defender of the greater public and the environment is a popular image, used by both KFEM and CEEJ.

The representatives from the Danish NGOs also ponder the essential reasoning for doing what they do. Almost always linked with the ambiguous notion of 'Folkeoplysning', the Danish NGOs return to the idea that not only do the public need somebody to speak on their behalf; there is also a strong urge to inform, educate and move the public in a direction that is most often viewed as an inevitable path. Thoughts on sustainability are in Denmark seldom linked with revolutionary moves against the power that be, but to a greater degree linked to how Denmark and the existing institutions are 
going to survive globalization while keeping the level of welfare that is recognized as the norm today. This does not answer for the more conflictual line sought by NGOs such as CJA, but the other larger umbrella organizations like PCA and the 92 group link the continued wellbeing of the country to thoughts of sustainability. The ideal is in many ways not a move towards a radical different society, but towards a society more in tune with environmental and climate challenges, based on the existing structures. Engaging the public and focusing on participatory efforts often draw on a similar ideal, bound in daily life challenges.

The Korean NGOs perceive their work as something that to a much more explicit degree clash with Korean government's notion of and wish for continued 'Green Growth'. Most of the NGOs interviewed see their efforts as empowering the public to move beyond the growth doctrine of 'Green growth', which is a popular shooting target when the talk turns to 'green washing' of activities that do not have a sustainable core, but are made to look like they do through primarily communicative strategies (Ng-A-Fook, 2010). The question of how Korea is going to survive in a globalized economy is, however, not a returning issue, as it is in Denmark. Korea is pictured as a country still in development, but with a natural role to play as one of the worlds industrial leaders. Growth has been the mainstay of the last 50 years, and little seems to indicate that the NGOs see this change in the near future.

As such The Korean NGO representatives very much perceive themselves as actors who try to intervene with a society that is feeling the strains of a run-away development and has forgotten about the environmental and climate cost of this growth. This situation can be compared to how Danish NGOs described their role in the 70's and early 80's (Jamison et al, 1990). In Denmark, the NGOs retain a critical edge, but is largely consensus based, and discuss the reason for their work as not only trying to help save the environment, but also ensure that there will be continued development of a state that is not seen as a natural frontrunner in a globalised (economic) context.

Ideals might play a role regarding how the NGOs perceive their own work, but several distinctive layers of added reasoning surrounds or corresponds with these ideals. In trying to understanding their work towards a cause, whether that may be a perceived radical criticism of society or a more consensus driven effort to marry existing 
structures with sustainable ideals, it is interesting to note the NGOs' reason for involving the public. Spanning a continuum between seeing the efforts to engage the public as a means to an end and perceiving the educational activities as the end in itself, there are great differences between the Korean and Danish case.

Based on the interviews it can be argued that the Korean NGOs are more geared towards focusing on distinctive cases, with a strong interest in tangible results of the continued development of the Korean society. Trying to change consumption patterns, empowering identified marginalized groups and direct harsh criticism towards large corporations and the state are the returning issues of the Korean NGOs. General empowerment and provoking thoughts that could lead to different ways of living and thinking are also an important part of the Korean perspective, but in many ways this serves as a vehicle for addressing tangible problems and issues that are seen as being forced upon society by men in power and a Korean appetite for growth and commodity driven lifestyle.

In Denmark there is less focus on a coherent case or tangible changes in society and the environment that drives the educational work with the public. With the notable exclusion of WWF, there is a heavy emphasis on how information, debate, and participation are ends in themselves. How this then is thought to be translated into individual and societal changes, is a topic that remains very fluid and hard to grasp for the individual NGO representative. Focusing on initiating debate, raising levels of knowledge and having an impact on individual lifestyles remain the fussy core of why the Danish NGOs engage the public.

The two cases thus share the focus on a strong ideal of altering society as the core of their work to engage the public, but where the Koreans tend to try and counteract the existing structure, the Danish NGOs wish to redirect the established structures in a more sustainable direction. The Korean NGOs focus on explicit challenges and see education as a way of affecting these issues through the public, whereas the Danish NGOs mostly focus on the informational and participatory work towards the public as an end in itself that might hopefully change society in a longer perspective. 


\subsection{Where is Learning Happening? The Perceived Educational Perspective of the NGOs}

\begin{tabular}{|c|c|c|c|c|c|c|}
\hline chapters & $\begin{array}{c}3.1 \text { NGOs, } \\
\text { civil society } \\
\text { and national } \\
\text { differences }\end{array}$ & $\begin{array}{l}\text { 3.2 Danish \& } \\
\text { Korean } \\
\text { NGOs }\end{array}$ & $\begin{array}{l}4.1 \text { The role } \\
\text { of the NGOs }\end{array}$ & $\begin{array}{l}\text { 4.2 The } \\
\text { educational }\end{array}$ & $\begin{array}{l}\text { 4.3 Public as } \\
\text { a learning } \\
\text { entity, }\end{array}$ & $\begin{array}{c}5 . \\
\text { Educational } \\
\text { desires of } \\
\text { the NGOs }\end{array}$ \\
\hline Question & When? & Who? & Why & & How? & What? \\
\hline $\begin{array}{l}\text { Methodological } \\
\text { emphasis }\end{array}$ & $\begin{array}{l}\text { Historical } \\
\text { and societal } \\
\text { analysis }\end{array}$ & $\begin{array}{c}\text { Empirical } \\
\text { data }\end{array}$ & $\begin{array}{l}\text { Interviews } \\
\text { with key } \\
\text { persons }\end{array}$ & $\begin{array}{l}\text { nterviews } \\
\text { with key } \\
\text { persons }\end{array}$ & $\begin{array}{l}\text { Interviews } \\
\text { with key } \\
\text { persons }\end{array}$ & $\begin{array}{l}\text { Theoretical } \\
\text { enquiry }\end{array}$ \\
\hline $\begin{array}{l}\text { Analytical } \\
\text { purpose }\end{array}$ & $\begin{array}{l}\text { Establishing } \\
\text { the context }\end{array}$ & $\begin{array}{l}\text { Establishing } \\
\text { the specific } \\
\text { context }\end{array}$ & $\begin{array}{l}\text { Examining } \\
\text { the purpose } \\
\text { of the NGOs }\end{array}$ & $\begin{array}{l}\text { Developing } \\
\text { analytical } \\
\text { themes }\end{array}$ & $\begin{array}{l}\text { Developing } \\
\text { the } \\
\text { analytical } \\
\text { themes }\end{array}$ & $\begin{array}{l}\text { Understandi } \\
\text { ng the } \\
\text { analytical } \\
\text { themes }\end{array}$ \\
\hline $\begin{array}{c}\text { Level of } \\
\text { abstraction }\end{array}$ & $\begin{array}{c}\text { National and } \\
\text { international } \\
\text { focus }\end{array}$ & $\begin{array}{l}\text { Focus on the } \\
\text { individual } \\
\text { NGOS }\end{array}$ & $\begin{array}{c}\text { Focus on the } \\
\text { key } \\
\text { personnel }\end{array}$ & $\begin{array}{l}\text { Focus on } \\
\text { ercepetions } \\
\text { f education }\end{array}$ & $\begin{array}{c}\text { Focus on } \\
\text { perceptions } \\
\text { of } \\
\text { participation }\end{array}$ & $\begin{array}{l}\text { Theoretical } \\
\text { enquiry }\end{array}$ \\
\hline
\end{tabular}

\section{Where?}

The varied, but outspoken wish among the interviewees to have environmental NGOs influence and change, not only stretches across the different NGOs represented. It is also something that characterizes both the Korean and Danish case. All of the NGOs adhere to the idea that one of the most useful ways to create societal change, no matter how change is understood, goes through engaging the public - albeit in very different ways. This does not entail that all of the NGOs explicitly stress that education or learning is what they are doing and trying to push, but it does mean that all of the NGOs represented work with more or less developed ideas of how to pass on knowledge to the public, or parts of it. The NGOs all try to engage the public in order to establish a process that could eventually change their daily behaviour or living conditions in a more sustainable direction.

Grasping how the non-formal educational missions of the different NGOs are expressed and perceived will be done through a focus on the perceived educational perspective of the NGOs, the activities that are born out of such perspective and the perceived audience for all of this. Again this does not entail that the interviewees necessarily discuss education explicitly. However, these three overall topics were reoccurring during the interviews and discussions with interviewees in both Denmark and South Korea. The multitude of ways that different concepts of educational approaches relate to the public and how such relations translate into actual activities imply that just as 
many groupings of the different NGOs are possible. Of special interest is how the perceived societal role of the NGO is reflected in the educational outlook of the different NGOs. There is little hope of entering a discussion on educational perspectives and strategies on a non-biased basis as the battleground of how to understand teaching, education and learning continues to be a hotly contested area (Lave, 1996). The following section therefore constitutes an effort to emphasize and analyze the perceptions of the interviewed key persons from the Danish and Korean NGOs regarding the public in relation to their own work.

A recurrent theme is how the interviewees perceive their efforts to translate into change or learning. Even though there might be different interests invested in the use of approaches towards the public, the interviewed NGO staff have different ways of describing what constitute the core of the potential transitional or learning process, including where they understand such a process to be taking place. This is not to argue that any of the interviewees think that a physical setting of some kind holds the trick to making change or learning successful. The argument relates to the returning descriptions from the interviewees about the places, groups or activities that hold the greatest potential for a positive development. Change, learning and development are not per se comparable or interchangeable terms, but the empirical data at hand often presents examples of these terms being used rather inconsistently. The focus on Where, is thus a focus on the discursive settings and the plateaus the interviewees perceive as having the largest potential for learning and change, in the many forms it may take. These perceptions often revolve around understandings of where the greatest emancipating potential is to be found, and consequently it clutters the distinction between learning and change. The distinction between learning as a means and as an end is not always clear among the interviewees, which greatly influences their perceptions of the potential for learning and change to happen. This leads to a range of descriptions that relate to the perceived core of learning, and the change that is hoped to be a consequence of such learning. The effort here is to draw on the empirical analysis with a question on where the individual interviewee believes learning to happen.

While the phrases used to describe these perceived potential learning arenas differ, many of them draw on the notion of something that can be identified and used 
consciously by the NGOs. It is possible to subscribe different concepts to these 'arenas'. Giorgio Agamben might call them potentialities that harness potential choices. Laclau would call them empty signifiers that offer scope for redefining and uniting differences. Lacan might call them discourses of perversion something, which is sought for the sake of a greater cause. Žižek would call them ideological fantasms suggesting that they are ideas that cover up the ever present imperfection of the social reality (Agamben, 1999, Laclau, 1996, Lacan, 2006, Žižek, 2008a). These theoretical perspectives and notions are far from identical, and some would possibly argue that they do not even overlap, but this is also the case concerning the myriad of perceptions the interviewees bring to the table. What they do connote is that some areas of the social are perceived as harnessing a greater potential for change and something new to arise than others. The theoretical perspectives are in other words abundant, but based on the empirical data the question of Where the interviewees invest their hopes and energies furthermore displays vastly different concepts. The different descriptions of areas, fields, groups etc. that are believed to have an inherent potential for bringing learning and, importantly, instigating change based on that learning thus reveal interesting similarities and differences among the NGOs. This describes the areas that are mentioned as inherently good or productive, as areas that help the organization and the perceived cause. The point of talking about a Where is thus not only to establish a common denominator for the different approaches and perceptions, but also to focus on the distinctiveness of what is emphasized by the interviewees, and to be able to cross-reference between the foci that their perspective delivers.

It is important to note that the different categories mentioned below do not always exist as exclusive formations, but tend to bungle up, and overlap in the interviewees' efforts to describe where learning happens, or where they envision it might happen.

\section{Youth in Korea and Denmark}

When the representative from Green Asia describes the organization's work to include volunteers in the planting of trees and saplings in the Mongolian desert it is argued that "growing trees are slow, just as with humans, we need great perseverance with both (...) 80 percent of the trees survive, but how many of the humans survive as 
environmentalists?" (Green Asia, 2010). This displays an interesting focus on how trying to reach out to the public demands a relatively long time span in order to be gauged as successful or not. At the same time it risks sounding like an almost 'cliché like' notion of how to involve people in the work of environmental NGOs, and not to be tempted by the desire for instant change. The perspective furthermore clashes with the overall sense of hastiness that in many ways permeates the Korean society. The country does have a long tradition of focusing on the importance of education and learning as something that continues throughout life. However, the rise from a poverty stricken feudal developing country to a global economic powerhouse in half a century has also prompted a desire to see changes happen quickly (Easterlin \& Sawangfa, 2009).

When asked about who is seen as the primary audience for the work of his organization, the interviewee from Green Asia mentions the large number of students that they have managed to draw into their activities ${ }^{4}$. This includes both Korean and Mongolian students as both groups take part in the activities in Mongolia and form part of the large groups that plant trees in the desert. The representative claims that these new activities differ greatly from the ones that formed the backbone of the environmental organization just 10 years ago. "Until 10 years ago almost all our members were from the democratic movement. Until lately the typical Korean did not know about climate change. That changed from 2007 were Koreans started to [show] interest for climate change because the Koreans' meteorological agency told that big changes are on their way, they politicized it [...] Many students now know about the environment, they are eco-savvy" (Green Asia, 2010). In order to reach these 'eco savvy youths' and other potential members Green Asia place great importance on high levels of participation. Each year the organization, with sponsorship from Air Korea, fly thousands of volunteers from Seoul to Mongolia in order for them to physically take part in planting trees and making a very tangible personal effort to stop desertification. Their work in Mongolia includes several formal lessons on not only the work involved when planting trees, but also sustained information on how the desertification evolves, the consequences of pollution and climate change and not least the effect that a continued desertification would have on the Korean peninsula and on the greater Asian continent. A long range of guidebooks and textbooks

\footnotetext{
${ }^{4} 5000$ students primarily high school and university in 2011 ( Green Asia, 2012)
} 
have been developed for this purpose and the successful partnerships with several large companies have made it possible for Green Korea to reach a wide audience also outside the environmental stalwarts. In order to create awareness several yearly "Eco-festivals" are also held, not only stressing the climate change perspective, but also the cultural meeting between the Mongolian students that take part in the projects and the Korean students as well as other members that fly to Mongolia. With an outset in the idea that "We do not employ, we only educate" (Green Asia, 2010) the organization has, in the eyes of the interviewee, so far been quite successful in drawing in new volunteers and creating awareness on the link between climate change and the dust storms that pester every Korean during the spring and summer months.

Another quite tangible approach is the one utilized by the organic food specialists at Hansalim. In their case the very direct focus on food and lifestyles extends into their educational programmes. An early focus on food quality and nutrition has now changed to a more adamant focus on lifestyles. What began as a strong focus on how to educate members via informational meetings and the greater Korean public via e.g. campaigns, emphasizing the often polluted Korean groceries and consumables, has changed into a more active focus on how housing, cooking and consumption have a severe effect on the environment as well as the individual. The representative from Hansalim speaks of how it must be possible to "survive the food", which might sound like an overly radical interpretation of just how harmful food can be. However, when viewed in light of the severe problems with e.g. heavy metal traces in fish caught near the Korean waterfront and ongoing problems with pollution of the countryside, the interviewee's opinion might not be that far of target (Dai-Yeun, 2007, Kim, 1996).

While the overall development in the Korean Society and a growing awareness about the issues might have made it easier to 'survive the food' which is consumed, the audience for the message and the participants in the activities that Hansalim initiates very much still consist of women. As discussed in chapter 4.1 this reflects an overall trend within the environmental movement in Korea, where women by far outpace men, and form the greatest part of both activities and members of the different organizations. Hansalim does try to involve men, but as women still very much run the households and most of the products that Hansalim stock caters for the domestic needs, 
women remain at the centre of their attention. While little is expressed by the repetitive from Hansalim in the form of direct critique of the patriarchal society, the tendency of an overall critique of how society is run, and the fact that this is done mostly by men, is never far away. Their self proclaimed focus on the importance of developing a "friendly life method" is hard not to see as a critical assessment of a perceived 'unfriendly' state of the contemporary male-driven society.

A focus on challenging this societal condition from 'within' via food and consumption, and on how the existing situation ought to be changed as quickly as possible, is also clearly expressed by the representative from CMEJ who explicitly aims at giving the oppressed, understood as women and children, a voice through education and information on how society is organized. Their goal can, to some extent, be understood as an attempt to empower groups that in the eyes of CMEJ are not given equal opportunities to decide in which direction their society should be headed. "There is a limit to the effectiveness of trying to influence the corporations. Often they will just find a way around the problem, if not putting sugar in the food, then fat. If we want to change this we have to do more to stop them" (CMEJ, 2010). To counter this issue CMEJ is not only publishing books about environmental and nutritional issues, but also endorsing more active resistance towards how things are being done in Korea. As an example the controversial four rivers project, has been halted in some areas by environmental activists climbing trees that are bound to be cut down to make way for the large scale project. (CMEJ, 2010) While actions such as these are far from the norm among the very law-abiding Koreans, they none the less indicate how some of the Korean organizations understand themselves as the voice of societal groups that remain without much influence on the established dominant governmental, corporate, and male-led society. That this understanding influences the NGOs' perspective on how the concepts of education and information are thought and executed is clearer in some of the organizations than others. However, it often translates into activities that very much emphasize participation and the importance of both a high level of knowledge on the issues, as well as how this should be translated into actions that can influence how the individual understands what is going on.

The Center for Energy Alternative also stresses direct participation and the importance of individual action in their work. Their use of traditional Saram Bam form of 
discussion, which opens up a "communication field" (CEA, 2010) as the representative puts it, is one way of involving members in the discussion on how to understand and influence the society around them. At these meetings CEA invite "scholars, activists and members to present their thoughts and actions from their daily life" (CEA, 2010). As a way of establishing a window of opportunity for communication especially across gender, generational and social bonds the interviewee stresses the possibilities that the Saram Bam method entails: "Debate and discussion is crucial ... [and we] ... always think about actions that could come out of Saram Bam" (CEA, 2010). Some of these activities have led to actions on policy levels, even with some successful efforts to change legislation.

As an echo from the democratic movement there is a great focus on direct participation. Some of the activities, such as the creation of the member funded wind turbines and the erection of several small $\mathrm{CO} 2$ neutral houses, required manual labour and very hands-on work by members. These members are understood as largely upper middle class with a high level of education. The representative argues that "Many members returned to [the] countryside and throw away a normal life. They pursue a happier life, not only money. They focus on energy issues and energy transition is [a] kind of ecological transition in the Korean Society" (CEA, 2010). In a society such as the Korean, where hard work and a seemingly unstoppable urge to succeed has been the driving force behind the educational system and the rest of the country, such a choice in many ways clashes with the norm (Lim \& Jang, 2006). Apparently such initiatives mostly come from the generation that took part in the democratic movement and now feel the hardship of living in a capitalist and highly competitive society. The interviewee continues: "There is a generation change coming. [people in their] 30's and 40's are now the main power, not [people in their] 20's. We do have that kind of students, but there is less focus from people in [their] 20's. The younger people focus more on income. They learned to compete very hard and it is difficult to get a job” (CEA, 2010).

Several of the interviewees return to the idea that the Koreans on one hand have a very intimate relationship with the idea of prolonged training and education and seldom have any problems working hard to attain new insight, which helps the NGOs in their educational work. On the other hand the huge importance of landing a well paid job, especially for the generation currently enrolled in universities or just finishing their 
degree, preferably within one of the huge Chaebol business conglomerates, is something that permeates a large part of both society and the educational institutions.

A new development bucking the trend of young people with little concern for environmental issues is the rise of the so called 'Candlelight movement'. A spontaneous and initially peaceful mass movement was started by middle school and high school girls as an effect of the criticized Free Trade Agreement from 2008 between USA and South Korea, where the conservative President Lee Myung-Bak wanted to lift the ban on US produced, allegedly mad cow disease riddled, beef. This activism spurred a new movement that, although supported by the existing NGOs such as CEA, was mostly based on the use of internet and mobile phones to organize demonstrations that at its high point counted more than 500.000 daily participants in peaceful protests in Seoul (Lee, 2004). The representative from CEA argues that it is extremely important to learn from the new generation and their ways of engaging in environmental and social issues, especially when it comes to education and how to understand the public. "They used mobile phone, internet, but wanted an offline demonstration. They took their interest and motivation from the contacts they made online and made it into something that happened in the streets of Korea. These very young children [that are] 10-15 years old are very interested in politics, and move faster than we can!" (CEA, 2010).

While these activities echo earlier discussions on the possible rhizomatic nature of the Climate Justice Action Network from the Danish case, they also display how very young people, in fact the children of the very generation that supported the democratic movement, are now not only audiences for the efforts of the NGOs, hoping that they might grow into active and responsible adults. These 'children' are already powerful actors in the Korean environmental movement (Lee, 2004). The NGOs problems reaching the youths and incorporating them into traditional participatory activities, could suggest that the generational divide is still very much alive in the Korean environmental NGOs. That all of the NGOs included in this study have close ties to the Democratic movement, with several leaders being drawn from the ranks of the once oppositional movement, stress the importance for the environmental movement to benefit from the renewed interest from the Korean youth (Lee, 2004). 
The theme of focusing on the youth as an important audience also carries over to the Danish NGOs among which the greater part of the interviewed key persons argue that the youth is the most important target for their educational efforts. Even though an organization like the Danish Adult Education Association might sound like it has an inherent gearing towards adults, their representative none the less argues that: "Young people are using a language that embraces change, and that language is exactly what makes change possible" (DAEA, 2010). Also the interviewee from WWF stress how their Burning Panda campaign tried to engage the youth, as they were seen as the group that harbours the greatest potential for changing society, but also as the group that can establish the most visible support for an organization like WWF. This differs from DAEA and Centre for Energy alternative's view of 'youth' as carriers of almost spontaneous potential for learning and change, as the point for WWF is not only to instigate change among the youth, but also use them as political leverage. Youth thus either play the role of a group that can be co-opted into an organization and caressed to support the already existing approaches, or 'youth' is understood as something that in itself harbours borderline revolutionary forces. When CEA's representative describes the candlelight movement as something that started outside the established organizations by school children, she also stresses that NGOs must learn from them and their special potential for harnessing learning and instigating change that is outside of the formal structures.

The idea that youth and children have a special potential that goes beyond what can be channelled through the organizations is mentioned by several of the interviewees. The description of youth varies; sometimes picturing primary and secondary school children (CEA, Green Korea) and sometimes includes university students as well (KFEM, Green Asia). In Denmark youth as an audience denotes a somewhat older group with emphasis on high school and university students in their 20's, compared to the picture of 'youth' that the Korean NGOs present, which also includes younger primary and secondary school students.

When the interviewee from DAEA talks about youth she focuses on their language and how it has the potential of describing change and thus bringing change. This corresponds with the idea of a special bond between youth and capabilities of change. The 
representative from DAEA not only argues that this bond should be exploited by the NGOs, but also that NGOs should learn from the youth as their "...language is what makes change possible" (DAEA, 2010). It is interesting to note that several of the Korean organizations not only talk about the youth as those who carry the greatest potential for change, but also talk about a generation of 'lost youth'. The lost youth is understood as the generations born in the mid and late 1980's and raised during the economic boom and prosperous aftermath of the democratic revolution (KFEM, 2010; CMEJ, 2010). These are depicted as being overly focused on financial and career success and with little regard for the environment or environmental NGOs. Such a thing is not mentioned by the Danish NGOs and in relation to the summit in Copenhagen several of the NGOs did draw heavily on a large number of willing activists. While there is great appreciation of the work of the activists, several of the Danish NGOs also express some trepidation about the actual benefit that young people get from their involvement in climate and environmental issues. The representative from CJA argues that: "There might be a lot of summit hoppers who just go from one COP to the next, but I do not think that they were the primary people at the COP15 and CJA' (CJA, 2010). 'Youth' thus does not for all of the interviewees, describe a group of people for whom learning and change is always an automatic outcome, but in both cases there is a returning focus on how the potential of especially youth is something that must be at the centre of the NGOs attention.

The gender issue is, however, almost completely missing from the Danish case, while being high on the Korean agenda. While a number of reasons for this are presented by the Korean interviewees, stressing the patriarchal society, the role of the woman as the caretakers of the health of the family, there is little in the Danish data that explains the missing gender focus. This could lead to speculations about different gender roles in Denmark, but does not diminish the fact that an adamant focus on youth is shared by both cases. That youth and gender, especially women, act as a arena, where change and learning can be instigated, is not a ground shattering insight, but the fact that especially the Korean interviewees feels out of touch with youth might also lead them to see more potential than the youth can deliver. As youth in both countries are caught up in a rigorous regime of educational obligations and the need to function in a demanding 
society, it could seem that instigating societal change is not at the forefront of their daily life.

\section{Daily life}

A theme closely linked with both youth is how the interviewees see their work relate to the daily life of the public. This focus draws on issues linked to how the individual understands its own role in the greater scope of environmental and climate challenges, but also stresses the NGOs' roles as reducers of complexity that turn highly abstract topics into something which can be translated into the concrete everyday lives of the public.

The interviewee from DAEA points towards the growing awareness on how the individual can influence where the society is heading: "A lot of people involved in our initiatives are very focused on their own role, things are very much moving" (DAEA, 2010). In which direction things are moving is not easy to pin point but, "Direct information is one possibility, but creating a field where they can learn is also a way to motivate. People learn and get motivated in vastly different ways, now more than earlier. We need to establish a situation where people have the possibility to manage how to choose, or else they will not choose" (DAEA, 2010). In trying to establish such fields the representative stresses that DAEA work hard to create possibilities in everyday settings. "The idea that change will come suddenly clashes violently with reality, the world will not change the $1^{\text {st }}$ of January. Revolutionary romanticism is wonderful, but not very effective; we need to remember the everyday perspective” (DAEA, 2010). This perspective led to several initiatives during the COP15 that all stressed the role of the individual citizen and the family in creating a 'better tomorrow'. Going into people's homes in order to address where they could benefit from new ideas on sustainable heating technologies and how the daily routines of the family could be altered in order to save energy, time and money proved popular (DAEA, 2010). DAEA funded and guided a vast number of activities, with e.g. the Danish version of lower secondary schools - one year boarding schools being very active in the focus on resources and traffic issues. Likewise local organizations across Denmark tried to incorporate an environmental and climate perspective in their activities (DAEA, 2011). These activities were closely followed by DAEA, which tried to establish links between how young people envision their lives and the environmental challenges at 
hand, by emphasising how the challenges creep into everyday lives of the youth and their families. The interviewee from DAEA still argues that even though the activities of the organisation are considered successful they still run a constant risk of simplifying what ought not to be. "[The notion of] Climate change simplifies very complex issues, education about climate change also run this risk. This can be seen in for example opinion polls on climate issues which reduce the complexity a lot. How people think and feel about climate issues is in itself very complex, with farmers that view themselves as being climate sceptics, but still favouring the idea of solar power as not only an economically viable option, but also something that helps the environment and in the end the climate" (DAEA, 2010). Part of the job for a big umbrella organization like DAEA is to develop approaches that make it possible to deal with the overly complex issues related to climate change, but at the same time accept that such issues in their very nature will always be exposed to levels of reduction in complexity in order for them to be integrated in the daily life. "People live with enormous contradictions in their daily life, something that is made possible by our culture and way of life" (DAEA, 2010). These contradictions extend to almost all issues that involve climate or environmental perspectives, and make it very hard for an organization like DAEA to present action oriented solutions that do not end up being contradictions in themselves. As the representative says: "We do not need a Garfield solution, where new kinds of diet chocolate make it possible for us to eat more of it” (DAEA, 2010).

While such a focus on the inherent contradictions of living an average life in Denmark or Korea and at the same time working to get closer to a sustainable lifestyle echoes the representative from KEEC's thoughts on the possibility of a new mission for the environmental organizations, it clearly stresses a more overall issue for all of the NGOs involved. How to translate the perceived role of the NGOs into approaches that do not just add even more contradictions to everyday lives that are already unsustainable? Avoiding yet another Garfield solution that adds a light coat of sustainable frosting on a very environmentally unhealthy cake, is also pondered by the representative from Climate Justice Action. The interviewee thus argues that most of the government backed projects and NGOs, and especially the initiatives backed by the business sector, did little more than create an escape route for the bad consciousness of the participants in the different 
activities. "People do tend to engage in the fun parts and scorn much of the hard, personal work (...) we try to take the hard choices and insist that problems are there to be taken very seriously. This is hard when dealing with the public, as the link between problems in another part of the globe and your life here in Denmark is not always that clear"(CJA, 2010).

The everyday contradictions that stem from proximity issues of global challenges and local answers influence the work of especially the South Korean NGOs. The strong focus on women and children, from e.g. Hansalim and CMEJ, can be seen as a way of emphasizing how sustainability can find its way into the day to day tasks that keep the Korean family afloat. Trips into the endangered areas as organized by KFEM and KEEC also stress the Korean NGOs link the global challenges to the close environment. One could argue that the fact that environmental and climate challenges are in many ways more evident in Korea, with tangible changes in rainfall and increasing dust storms, could lead to a greater sense of close proximity and a tangible experience of the changes and in turn different paths of educational efforts.

While it can be argued that Green Asia and CJA try to invoke daily life with the potentials of global cultural meetings, and thus foster learning and change, such a perspective still differs markedly from the heavy investment in 'everyday life' or 'daily life' which is the focus of several of the NGOs. Perhaps influenced by the notion of 'Folkeoplysning', most of the Danish NGOs have some kind of perspective on 'daily life' as an important place for learning to unfold. The majority of the Korean NGOs also view 'daily life' as an opportunity to go from very abstract issues to tangible and applicable perspectives linked to 'daily life'. Thus the overarching notion of 'daily life' is something that the majority of the interviewees stress. It is perceived as a field with special potential for change and as the place where the public has the possibility to merge different agendas of health, proximity and consumption in order to reduce some of the complexity and the inherent contradictions that are linked with environmental and climate issues.

\section{Emotions and Rationality}

The heavy focus on youth and 'daily life' from the Korean NGOs can also be understood as an effort to empower the families to deal with the daily contradictions that are 
constantly a part of life in modern Korea. "We really try hard to meet the citizen and especially the families. The women are working hard to get information about what is going on, but the problem is that often they just want information, they do not always want to participate" (Green Korea, 2010) as the representative from Green Korea puts it “(...) our most successful education programs are those that involve the people more. Participation is the key, but participation outside the class room is the most important" (Green Korea, 2010). The strong focus on facts and the urge to get hold of causal solutions to given problems, which can be found in almost all aspects of the Korean educational system, seemingly also permeates the participants' expectations towards the NGOs (Lee, 2006). Not only do some of the participants in the NGOs' activities mostly strive for facts and information, they are also very keen on getting it before others. The representative from KEEC argues that "Many come to meetings to get more knowledge, but knowledge does not always lead to active participation or action. The idea is to influence people when they are young, or in their families, then turn them into activists and volunteers and then later environmental professionals that are able to take part in many sustainable activities. [The] problem is the effect is hard to measure. Do they change?" (KEEC, 2010). Even though the participants are believed to be highly motivated to take part in the educational activities, the actual value and impact of the knowledge they obtain is hard to grasp for the NGO employees. This is not to argue that the activities fall flat or that the many arguably successful indoor or outdoor activities have problems attracting participants. Instead the core problem of working in a society where knowledge and formal education is held in highest esteem does trickle down to the daily work and efforts of the environmental NGOs.

In order to motivate the participants to take action, the KEEC branch at the Jedu-do Island utilize a somewhat different educational strategy. Their approach draws on a concept of 'sentimentalism', which exploits possible emotional links to the environment and nature. "We used to have very functionalistic ways of educating the public before sentimentalism. The way we use sentimentalism is as a way of raising awareness, making connections to the environment"(Jeju KEEC, 2010) as the representative from KEEC on the island of Jeju-do puts it. Adverse impacts on the unique environment, fauna and animal life on the island, have lead to a vibrant public discussion of environmental issues, 
compared to many other areas of Korea (Jeong, 2011). Moving from what the interviewee from Jeju-do coins as a 'functionalistic' way of approaching the public and towards the notion a 'sentimentalism', presents different educational perspectives (Kim \& Lee, 2006). When asked how sentimentalism translates into educational work the representative argues: "Building an emotional relationship with the environment is very important, especially for children. When going into the country side one thing we do is to make the children name their own personal flower, in order to make [a] connection" (Jeju KEEC, 2010). While this could border on clichés of evoking a natural spirit in the surrounding environment in order to dazzle the young ones, it is by far not limited to children, but has been found equally usable on adults. "Adults are as inadequately educated on the environment as children, so we do in many circumstances use the same methods, but more academic. They get the information, but also have to name plants, flowers or animals, and they often have the same reaction to the information and experience as the children" (Jeju, KEEC, 2010). Even though this method is quite unorthodox compared to the other NGOs, traces of it could be found in several of the workshops that became part of the data collection process. With the help of the interviewee from KEEC Seoul it was possible to participate in several of their weekly workshops aimed at the before mentioned segment of well educated house wives who want to get a more firm understanding of environment and climate issues in order to integrate them into their home and family.

In order to establish notions and pictures that could be communicated one of the methods employed was the use of characters from popular culture juxtaposed with pictures from nature. As an example a PowerPoint slide was shown from the Disney animated movie Finding Nemo (Disney 2003), depicting Nemo, the starring clownfish in all its cuddly glory. After a short discussion about the many virtues of such a nice fish, the picture of a caught slimy real world fish out of its natural habitat was introduced, and the discussion continued with an emphasis on how to understand the difference between the cuddly animated depiction of nature, which is arguably something that is an important part of the growing phenomenon of Korean or K-Pop, but also how we could extend our feelings for our colourful, talking and animated, cartoon friends to the real world nature that in so many ways needs our attention more (Shin, 2009). While the interviewee from KEEC Seoul does not employ the notion of 'sentimentalism', when describing the work of 
KEEC Seoul, their approach still in many ways reflects what is done in Jeju-Do. Finishing an evening educational session, which normally lasted for around two hours, there would often be outdoor activities involved. Here the adult students would partake in games, playing animals and learning about the environment through actively taking the role of trees, animals, water or other nature examples, something which was taken quite seriously by the participants, but of course also lead to laughter and bonding within the group.

The reasoning behind the Korean "sentimentalism" efforts could be described as an effort to install a possible emotional link to the surrounding and often suffering environment in Korea, while at the same time not turning against the already existing narratives that guide the Korean culture (Jager, 2003). Neither the example from Jeju-do or Seoul tries to force a rejection of the ideas of the cuddly fish or the idea that human love is something different than what can exist among animals or in nature. Instead the existing culturally dependant notions of love and the picture of a cuddly lost fish needing our help is used as a gateway to get to grips with the environmental challenges, while maintaining a link to everyday references. It can be understood as not so much an effort to overthrow existing understandings of nature, but instead as an effort to widen already existing perceptions, while extending notions from the 'daily life' into quite foreign areas for many Koreans. This could be seen as a part of the new role of the environmental NGOs in question, which, as the interviewee from KEEC Seoul states, slowly are recognizing the need to evolve from the more revolutionary outlook that hinges on the democratic movement heritage, but also on the often antagonistic relationship with the government and state institutions. Trying to establish links to existing social patterns with less emphasis on radical departures from everyday narratives is for the Korean NGOs a powerful way of reducing complexity and constitutes conscious attempts to ease their work with environmental and climate challenges.

It can be argued that the Danish NGOs involved in this study draw less on perceptions of emotional involvement. As the representative from DAEA argued it seems important for the Danish NGOs to avoid the trap of using climate change as a vehicle for reducing the potential complexity of environmental and climate issues. A tendency to emphasise an emotional involvement can none the less a tendency be found among the Danish NGOs. WWF Denmark's initiative to light their beloved Panda symbol afire and 
let it dance in the streets of Copenhagen echoes the Korean effort to establish an emotional link and make it easier for the public to get to grips with the issues at hand (WWF, 2012). The interviewee from WWF argues that: "The public is a varied group, but most of it shares that the rational kernel of the climate debate does not interest that many" (WWF, 2010). The complex issues arising from climate change are arguably hard to communicate in detail, which also leads to a heavy emphasis on getting the public emotionally involved. "Branding is of utmost importance if we want to do this right. We want to speak to the stomach, give people a feeling of being able to do something and this means moving from the rational to the more emotional" (WWF, 2010). Linking emotional aspects of the environmental and climate challenges to daily life is sought through the use of simple activities that do not exclude anybody, but establishes a common playing field for anybody wanting to take part: "A demonstration like 'Turn of the Light', is something that couple emotions with a sense of daily action" (WWF, 2010). Making a direct and concrete link between the perceived ills of the world and the way daily life is put together, and handing the public a way to react on its own behalf, giving them a "feeling of being able to do something" (WWF, 2010), might mirror the described Korean activities. Further it has little ambition of a more radical break with existing structures. The interviewee from WWF Denmark's described emphasis on a very pragmatic approach to driving change in the public stresses, how the educational perspective of the organization could be understood as having more to do with arousing interest for the NGO and securing donations, than actually affecting how the public thinks and acts. Going after the 'gut feeling' and being a catalyst for emotional identification with the cause is in that perspective a way of reducing complexity, not only of the message, but also of the role of WWF while emphasizing the organization as a means to an end. This, however, can be seen as being at odds with the representative from WWF Denmark's notion of why so many educational efforts have led to so little change: "We need more democratic pressure for change, if it did not work, then it was because it was not intense enough" (WWF, 2010). This raises the possible paradox of how to establish democratic pressure on politicians though the public, when the public is not the primary concern of the organization. It also poses the question of whether a strategy that seemed to fail can actually be bettered through 'more of the same'. 
Utilizing distinct strategies to establish an emotional link between the goal of the NGO and the public is not to be seen as a novelty that only gets a chance until 'proper' information takes over, but as a powerful way to connect with the public in especially Korea, but also in Denmark. It is deployed in different manners and with different perspectives, but in both cases it is seen as a 'gateway' towards grapping the attention of the public, which could lead to an engagement with the issues from different perspectives.

\section{Conflict and Consensus}

As a direct consequence of linking the emotional aspect of engaging the public with a tendency to frame perceived instigators of pollution, 'conflict' is a returning topic in especially the Korean case. CMEJ's focus on the media and their use of e.g. The Supersize Me movie is thus not only an example of lessening the complexity of the issue and channelling it into tangible expressions of 'daily life'. The movie also stresses the consumer aspect while linking it with a social indignation aimed at the large corporations. The goal to "Empower the women, the children, to take the right choices, and stop consume bad products" (CMEJ, 2010) is to a large degree reached through framing a distinct and tangible villain. In this instance large corporations or the government is mentioned as the actual perpetrators behind environmental and climate issues. Climate issues could in this perspective be understood not as a universal threat that stems from society in general, but more as a synthesized issue, which is born out of the perceived greed and lacklustre humane qualities of the men in power. This not only represents a way of reducing the complexity of the issue and giving it a face, it is also a method that divides the different NGOs involved in the study. Whether it is possible to frame a distinct group as the instigators of challenges at hand or whether such challenges are believed to be bound to a more general level of society is something that has a great influence on how the public is met by the different NGOs.

In general it can be said that the Korean NGOs are more adamant in framing distinctive actors as main barriers to their educational work. The government is for instance framed as one of the main culprits. This does not mean that the representatives from the NGOs do not acknowledge the great progress that has been made within the South Korean government and the greater administration since the success of the 
democratic movement in the early nineties (Hwang, 2009). It is, however, still widely argued that in many occasions the government, which in 2009 declared Green Growth as the number one priority of the country, can be seen as the direct opponent to their work on influencing the public. KFEM's representative describes how this has had a huge influence on their work with environmental issues and educational programs. "We have made educational programs about nuclear issues and how they influence Korea and the atmosphere. This however did not work with the government who accused us of being too critical and too much focusing on the bad sides of nuclear energy. Several times the government actually sued the educational program for showing there is a problem with nuclear power plants" (KFEM, 2010). This has not halted KFEM's efforts to try and highlight the problematic side of the government's initiatives - especially its cooperation with large corporations. Several of the Korean NGOs thus have an often strained relationship with the government and the large corporate complexes that they criticize.

This struggle against 'the bad guys' is an important part of the way several of the Korean NGOs understand themselves and their role in relation to the public. Mimicking the historic democratic movement they very much see themselves as the public's active defence against "The government and big business [who] focus very much on growth and give little room for NGOs" (KFEM, 2010). Such a perception of being engaged in a struggle against a powerful and identifiable enemy, which expresses explicit animosity against one's mission, has greatly influenced how the NGOs' work is thought and carried out in relation to the public. With a continued mission to "Tell the truth, make people realize what they should do and how they should stop doing the easy thing and take the struggle” (Green Korea, 2010) the emancipating perspectives of the democratic movement is still not far away.

This should however not be understood as an attempt to present the Korean NGOs and the key persons interviewed as rowdy rioters that plot against the government and big business in order to throw a revolution, far from, but the perception of these actors as being responsible for many of the challenges at hand does add several dilemmas to the educational work of the NGOs. The interviewee from the Jeju KEEC discusses the problems of how to remain neutral when dealing with issues that are so permeated by political agendas: "Trying to uphold political neutrality is a dilemma. More sustainability 
or more growth? It is often agonizing to decide whether we should tell the students what is wrong, or let the students figure it out themselves" (Jeju KEEC, 2010). It could be argued that the attempts to remain neutral are often futile as the educational efforts of the NGOs lead to the very conclusions that they see. "Regarding the cable car that destroys much of the nature on Jeju-Do, it was hard to decide whether to talk about the problems, we decided not to tell [the students], but after the field trip the students actually figured it out. Not telling them led to greater interest than telling them "(Jeju KEEC, 2010). Even if the problems that have risen out of the construction of the cable car on Jeju-do might have been self-evident, there is still a clear tendency to stress an antagonistic perspective in many of the Korean NGOs overall perspective and their educational work.

Some of the Danish NGOs also use an active framing of single actors as a part of their activities and efforts. CJA for instance framed the municipality of Copenhagen's efforts during COP15 as directly harming to their cause and projects. While CJA understands itself as one of the Danish NGOs that has a greater focus on conflict, another trend is more evident in Denmark. When developing material, campaigns and publications, the focus is to a greater degree anchored in the problematic issues of 'daily life' and less in an antagonistic perception of the societal relations. "There is a lack of focus on how to include people's individual focus and problems" (CMD, 2010). The representative from the Danish Climate Movement stresses that "We cannot tear individuals in half, but need to identify that we live in larger systems that force us to do things that might be harmful" (CMD, 2010). What is instead emphasized is a holistic understanding of society and that the problems that arise from it need to be broken down into more manageable entities. This is coupled with a belief that the problems that need to be addressed cannot be seen as stemming from a single identifiable source, but related to our lifestyle (CMD, 2010). This point of view is reflected in The Danish Climate Movement's efforts, as the organization tries to include societal and social questions in its work. "When trying to get people involved and working with the environmental practice and the life of the individual you cannot only do the case, you also have to include the social, or you will lose both perspectives" (CMD, 2010). In fact all of the Danish NGOs, to a different degree, work to include understandings of how the individual is a part of society, and how it is possible for the individual to take an active part in shaping society. 
This seldom leads to outspoken criticism of individual societal actors in the activities and efforts, but instead to a greater focus on how individual actions influence the environment and how a general transformation in behaviours and attitudes is important if societal and environmental change is be realised. There is much less emphasis on framing a distinct enemy as the sole instigator of the problems facing us. While an overall and barely suppressed criticism of the centre-rightwing Danish government (2001-2011) is widespread in the interviews, it has little influence on the described educational activities of most of the NGOs. While the interviewees from larger umbrella organizations like the 92 Group and PCA present an overall scepticism on the political system and the market economy (92 Group, 2010; PCA, 2010), such criticism still differs greatly from the antagonistic perspective of their South Korean colleagues. With the aforementioned greater focus on activities that stress lifestyle choices and consumption patterns, the Danish NGOs do not take the conflictual look on societal dynamics to anything near the level of revolutionary undertones that characterizes their Korean counterparts.

The Danish NGOs instead stress the possible harmonious ways that could govern the relations between civil society actors, financial actors and the state. The representative from the Danish Adult Education Association's view on politicians illustrates this point: "Politicians can be a problem, especially their free interpretation of climate issues, and that is something that must be worked on and would not cost anything" (DAEA, 2010). Guiding the efforts of DAEA is not a perception of politicians as the main culprits, who should be held responsible for their wrongdoings, but to a greater degree that all parts of the society must work together in order to add traction to climate issues. This obviously does not mean that all is good and harmonious within the scene of Danish environmental NGOs. A growing scepticism on how the state and big companies might be manipulating the public to gain short-term benefits is e.g. represented by the Climate Justice Action Network. With their chosen slogan of 'System change, not Climate change', they pushed hard to inspire activism during the COP15, often by framing the state or various big corporations as the 'bad boys' (CJA, 2011). The interviewee from CJA argues that much of their time and work related to the many involved groups ended up focusing on how to establish themselves as an empowered group with one voice. "We 
tried hard to counter the demonizing of the activists and for the right to be one" (CJA, 2010).

As in Korea this effort in many ways not only complemented their focus on climate issues, but from time to time took over their entire agenda. "Especially in relation to the government's notorious "Lout law", we worked hard to establish a forum for talking politics, but it quickly became work to secure the right to do counter-politics", (CJA, 2010). This meant that many of their activities to engage the public in climate and environmental issues, ended up focusing on conflict with the government, and a few of them even escalated into arrests, violent demonstrations and riots. While the clashes between activists and police caught headlines all over the world, it would be unfair to judge the efforts toward to public of CJA as being only examples of aggressive counter politics. Instead the network covered a large array of different actors and activities. That also rings true for the other Danish NGOs as they struggled to engage and activate the public through issues related to climate change, often from an overall holistic and consensus driven point of departure.

Something that is framed as being a limiting factor by the individual interviewees is other NGOs in the field and their efforts to engage the public. While the Korean NGOs appeared very close-knit and very little criticism of other NGOs emerged during the interviews, the situation in the Denmark is very different. The representative from Green Asia is the only interviewee from Korea who explicitly discusses anything that could be interpreted as a critique of his colleagues from other NGOs. Arguing that "Many Korean NGO focus too much on domestic problems, and not enough internationally" (Green Asia, 2010) they set out to create a more international Korean NGO, hence the 'Green Asia', name that comes very close to e.g. the long established Green Korea (Green Asia, 2010).

The situation in Denmark is different, especially when discussing possible barriers to their educational work. The representative from the large People's Climate Action umbrella organization argues "very different NGOs are involved, with vastly different foci and interests. This created tensions between the organizers of the Climate

\footnotetext{
${ }^{5}$ The Danish "lømmel-pakke" officially: L 49 Om straffeloven og lov om politiets virksomhed - also known as Uro-pakken. The law was introduced before COP15 was to take place in Copenhagen as a method to subdue any eventual troublemakers and riots.
} 
Forum 09 and Peoples Climate Action" (PCA, 2010). These tensions not only boiled down to organizational differences, but also very much centred on the level of engagement with the public and the level of anticipated participation. "The group behind Climate Forum 09 wanted a top meeting; we [PCA] wanted something with a wider basis. This started a discussion of the desired focus of our activities. When are we inclusive in our work, and when are we exclusive?" (PCA, 2010). Across the different NGOs involved in the many COP15 activities rivalry and often harsh criticism of the different educational approaches were abound. While some level of infighting might not come unexpected when different groups are working within a small field, the representative from the loose network Climate Justice Action argues that: "The group of people involved in climate issues in Denmark is small, and it is very hard to establish new ideas, because of existing grudges and old agendas" (CJA, 2010). This does not mean that the entire field of Danish environmental NGOs is a war field with entrenched organizations battling each other. Had the interviewees originated from other NGOs the picture would, no doubt, have been different, as alliances and preconceptions change, but the fact that some kind of rivalry and often harsh critique exist among the Danish NGOs involved in this study remains.

It can be argued that the continuum of the represented Danish NGOs incorporates a rather diverse range of actors. And that such diversity leads to more conflicting perspectives, compared to a more univocal Korean group of NGOs. It is therefore interesting and somewhat counterintuitive to note how the Korean NGOs' approach to a greater degree is formed by an antagonistic relationship with the government and big corporations. However ideas of establishing tighter links to corporations as well as government is starting to seep in and influence some of the younger NGOs, notably Green Asia and Hansalim. This movement from a conflictual outlook on actors in the society, towards a more consensus driven perspective in many ways mirrors the development that happened in Denmark in the 1980s. This change eventually brought forth the notion of 'ecological modernization' in the Danish setting (Læssøe, 2007a).

The recent development in Denmark in many ways shows traits of moving in a different direction. While the largest part of the represented NGOs appear to support a consensus driven approach to dealing with climate issues, engaging the public and 
understanding the society at large, a network like Climate Justice Action push in another direction. With a return to the conflictual outlook, blaming the state and corporations and actively inviting to civil disobedience and in some instances breaking the law, the network, not only represents something new among the Danish NGOs, it also represents a return to the historical roots of the environmental movement.

The question of how conflict and consensus emerges in the two cases as potential fields of change presents a dynamic picture of the NGOs. The historical roots of both societies have no doubt influenced the approaches. The history of fast paced radical change in Korea and the focus on distinct instigators of pollution does show in the conflictual outlook of the Korean NGOs. Conflict is not only perceived as a negative thing, but also as something that can lead to important and positive change. This perspective is shared by the Danish CJA network, but the rest of the Danish NGOs involved in this study can be understood as heavily influenced by the long tradition for consensual development that has marked Denmark for the last century. In both cases it can be argued that the tension between the perceived urge for change and the hope that change can happen via peaceful and inclusive means has an important influence on the perceptions of where the potential for learning and change exist.

\section{Four Fields of Learning}

The figure below ads the perceptions of Where the NGOs place their efforts and hopes of engaging the public to the ongoing analysis of the how the NGOs perceived the public as a learning entity. As shown the NGOs return to topics related to Youth, Daily life, Emotional/rational involvement and Conflict and Consensus. These rough boxes contain other topics such as the differences between generations, the inherent contradictions of modern life, the urge to minimize the staggering complexity of the issues at hand and the very different historical settings of the Danish and North Korean environmental NGOs. 


\begin{tabular}{|c|c|c|}
\hline & South Korea & Denmark \\
\hline \multirow[t]{3}{*}{$\begin{array}{l}\text { Why, are the NGOs } \\
\text { engaging the public? }\end{array}$} & $\begin{array}{l}\text { Ideals about changing the } \\
\text { political structure }\end{array}$ & $\begin{array}{l}\text { Ideals about changing } \\
\text { lifestyle structures }\end{array}$ \\
\hline & $\begin{array}{l}\text { Stopping the exploitation of } \\
\text { nature by state and industry }\end{array}$ & $\begin{array}{l}\text { Marrying a sustainable } \\
\text { emphasis with continued } \\
\text { growth }\end{array}$ \\
\hline & $\begin{array}{l}\text { Learning and change as means to } \\
\text { an end. Radical change. }\end{array}$ & $\begin{array}{l}\text { Learning and knowledge as a } \\
\text { goal in itself. }\end{array}$ \\
\hline \multirow[t]{4}{*}{$\begin{array}{l}\text { Where, are the fields } \\
\text { of learning? }\end{array}$} & $\begin{array}{l}\text { Youth and children as } \\
\text { spontaneous activists }\end{array}$ & $\begin{array}{l}\text { Youth having a language of } \\
\text { change }\end{array}$ \\
\hline & $\begin{array}{l}\text { Daily life as daily struggle to } \\
\text { sustain sustainability against } \\
\text { odds }\end{array}$ & $\begin{array}{l}\text { Daily life as a vehicle for } \\
\text { working with contradictions }\end{array}$ \\
\hline & Sentimentalism as a way to learn & $\begin{array}{l}\text { Rational knowledge as the } \\
\text { key to learning }\end{array}$ \\
\hline & $\begin{array}{l}\text { Conflict as popular vehicle for } \\
\text { learning }\end{array}$ & $\begin{array}{l}\text { Consensus and gradual } \\
\text { change }\end{array}$ \\
\hline
\end{tabular}

Figure 3-2. Perceptions of the public as a learning entity, Why and Where?

Other issues also manifested themselves during the interviews, some of the Korean interviewees are for instance keen on issues related to proximity, on how climate change, actually changes their close environment. Likewise some of the Danish NGOs return to the issue of globalization, and how the need to constantly move beyond the national setting which is so often highlighted is of paramount importance to them. None the less the overall issues described are touched upon in different ways by all of the NGOs. How the individual interviewees perceive these perspectives at the crossroads of such different fields or areas underline the complexity of the issues at hand, and how non-formal ESD, in its many forms, is highly contextualized. The four categories do however illustrate the elusive core of where learning is perceived to take place. 
While this study accepts that there is no such thing as a clean cut mapping of something as bewildering as the social, the patterns depicted raise interesting points for further inquiry on their own related to How learning is perceived. Whether hope rests in youth, engaging the daily chores of the masses, establishing an emotional contact or conflict, the notions of potential learning areas remain hard to grasp and overlap as learning and participation travels between being the main objective for the NGOs to being mere means or processes aimed at spurring change. This dual nature of the work of the NGOs blurs the line between learning, in its many perceived guises, and the perceived form of change (in behaviour, in the social, in society etc.) that is often seen as the end goal (KEEC, 2010, 2010; Green Korea, 2010; PCA, 2010). In this case it can be argued that the notions of where the potential lies resemble the shape shifting blob in a lava lamp, sometimes unified with a clear direction, but the next second fragmentized and travelling in all directions, but seemingly always twisting and moving. The potential for learning and change is clearly perceived as being there. The interviewees continuously return to notions of what settings, groups or parameters are most interesting and tempting to engage in. Several of the NGOs and representatives refer explicitly to both notions of education, learning and participation (DAEA, KFEM etc), while others manage to avoid using formal descriptions of the type of engagement that they spend their energy on (PCA, CJA).

That the interviewees often touch upon learning and change in the same sentence and not always perceive them as being two distinct notions, is clearly illustrated in the above, and emphasizes that the field of non-formal ESD is hard to pin down in its myriad of links to different settings. A common denominator for most of the NGOs and something that permeates the abovementioned four fields is that any potential learning or change that might result of the NGOs' work is directly linked to public participation. It seems that for the interviewees it is not enough merely to push the agendas and try to fill the heads of the youth with facts, or stimulate the emotions of housewives. This focus on participation will therefore form the basis of the subsequent concluding chapter of the empirically driven analysis of the educational perceptions of the NGOs. 


\subsection{How is Participation Perceived? The Public as a Learning Entity}

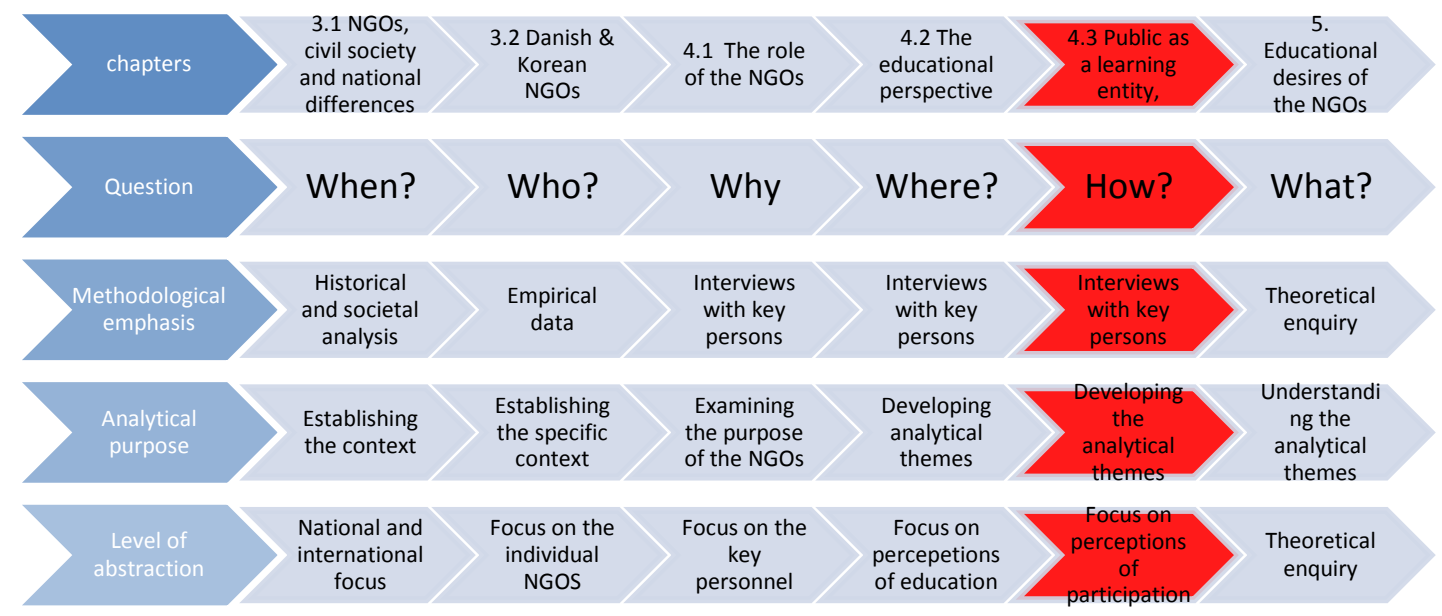

\section{How?}

The learning fields related to Youth, Daily Life, Emotional/ Rational involvement and conflict/consensus as identified in the previous chapter do not only stand as areas where learning and change is perceived to be possible, but also areas that relate to different levels of public involvement and interaction. Such a focus does not only cross-cut between the different themes or educational fields, it also relates very closely to the concept of 'participation'. While the descriptions used by the interviewees such as 'interactivity', 'involvement', 'activation of the public' refers to different concepts of engaging the public and the role that activity plays, it can be argued that they all in one way or another link to the notion of participation.

Participation is a much coveted concept in educational theory and practice, and as the effort to primarily rely on the voice of the data slowly succumbs to the lure of theoretical insights, this section will draw on four distinct theoretical conceptualisations of participation (Læsøøe, 2011). Accelerating the level of theoretical implications of the empirical findings will be the main job of the upcoming chapter 5, but here the simple categorizing of the perceptions of the NGOs will seek not to be limited by existing categories, while not ignoring that they exist. Added to four existing notions of participation will be a fifth notion, which stresses participation as accepting knowledge 
and delivering support. Focus is put on how the interviewees want their audience to take part in their activities, and on the role of the individual activist, student or member of the public who is hoped to engage in the work of the NGOs.

As displayed in chapter 4.2 above there is different ways of understanding the work of engaging the public and these translate into very different takes on what kind of participation is seen as a justifiable means or end goal of the efforts of the organizations. What the NGOs want with the public is very much at the centre of attention. Læssøe (2011) argues that there are four basic ways to categorize participation in the field of environmental education: 1) Participation in the direct meeting with nature, 2) Participation as social learning, 3) Participation as action oriented learning, 4) Participation as deliberative dialogue. While these four categories describe a wide variety of approaches to participation within the field, they also draw on distinctive schools of theory and describe applicable ways of structuring and undertaking environmental educational activities.

A perspective that talks to and from the standpoint of the informed and didactically advanced educator, does not, however, always match the world of non-formal ESD. The strategies, activities and educational perspectives of the involved NGOs are, as shown, not always the results of careful and thorough deliberations. The activities and strategies are thus not necessarily developed along a coherent path; instead they also draw on experiences from everyday work and layman knowledge, which are also important parts of the NGOs' foundational base. As such this chapter does not take its outset in the four theoretical categorizations of participation, but in the empirical data, and this entails that it is necessary to add one more category, namely 5) Participation as a means to create support for a given organization. This final category can be understood as having a more instrumental approach to the public, and it thus ads something different than the four other described categories. It is based on the empirical material and is needed in order to cover what the interviewees describe as their desired form of participation. Again, the ideal world of desirable educational outcomes, does not always match the elusive and multifaceted realities, something that will be further stressed in chapter 5 . 


\section{Participation in the Direct Meeting with Nature}

Different conceptualizations of participation should be understood in light of the different historical and political contexts of the two cases. Different settings spawn different understandings of participation. This makes it quite interesting that most of the NGOs involved in this study draw on a notion of participation in the direct meeting with nature (Læssøe, 2001: 63).

From a theoretical standpoint the category is based on the concept that learning draws on an aesthetic base that cannot be accessed without a physical participation in nature. The hope is that existing mental concepts and experiences are brought to play and redeveloped via intentional, but often not reflexive, practice in nature. Such processes are not seen as independent from the social context, but always include the important aspect of nature as something that cannot be boiled down to a social and human core (Læssøe, 2011: 64). KFEM, Hansalim and others work hard to bring children and adults into nature and arrange camps and excursions to the countryside of Korea. Some interviewees focus on explicit perceptions of participation, and the interviewees from KEEC Jeju and Green Asia are very adamant about the need for a close contact with nature. The close proximity of the Jeju-do inhabitants to vast spaces of relatively undisturbed nature is one of the reasons mentioned for stressing participation as directly linked with close contact to the varied environment on the island. Especially in relation to the field of 'sentimentalism', participation is seen as a way of transcending the distance between human beings and nature and establishing a strong emotional bond. While the Green Asia's interviewee's thoughts on the organization's work in Mongolia are very much characterized by a hope that the social context will facilitate learning, there is still a heavy emphasis of how learning develops in 'the field', when working in nature and establishing an understanding that there is a direct link between the climate induced challenges of Korea and the soil in the barren steppe land of Mongolia.

The concept of participation here centres on the active work in nature and the learning benefits that might spring from those activities. As the social side of participation is also of great importance to Green Asia it is not far from resembling participation as social learning, which is the category that brings together most of the NGOs. While the Danish environmental movement has a long tradition of engaging with 
nature (Jamison et al, 1991: 78), none of the Danish interviewees emphasize direct contact with nature. This lack could partly be explained by the urban COP15 setting that governed the Danish environmental and climate agenda during the interviews, but it does mark a distinct difference compared to the Korean NGOs.

\section{Participation as Social Learning}

One of the questions that came to be part of all interviews was how the interviewees understood the social as an element in their work on engaging the public. Nearly all of them expressed great acknowledgement of the importance of the social setting for their work. Many did however also display hesitations on the possible negative consequences of focusing too much on the social side of things. That being said Green Asia, Agenda21, Green Korea, Jeju KEEC, Seoul KEEC, CEA, KFEM from Korea and PCA, CJA, CMD, DAEA from Denmark all focus on the social as an important part of participatory learning.

Læssøe draws on Lave and Wenger and Vygotsky in his conception of socially situated learning in environmental education. The notion of 'communities of practice' covers areas where learning happens in a space between the more experienced practitioner and the less experienced practitioner (Læssøe, 2011: 64). This resembles some of the 'fields of learning' described earlier, with the important difference that the interviewees do not express an understanding of the social as a unique field of potential learning, but something that adds to the level of participation and often is seen as the stepping stone towards what is perceived as real engagement.

In Korea discussions of the importance of the social are often framed as the importance of reaching out to or establishing a community. This can be interpreted, as in educational material from KFEM, as an extended version of the traditional Korean village community from before the industrialization, which is less than 30 years ago for some (KFEM, 2010). It can also be understood as part of abstract discussions on the importance of building a community among members of an organization or establishing contact and communication between existing communities on the countryside as well as in Seoul. The Danish interviewees speak less about establishing an abstract or concrete close-knit community, and more about the importance of social interaction as the primary motivation for the individual for engaging in the organizations' work. In Korea the discussions focus 
on how it is possible to establish a bond in a group, in Denmark the focus is on how the individual expresses her/himself through the social. During COP15 the People's Climate Action network worked to establish online forums, social gatherings and parties in order to reach out to activists and keep the attention of the all important youth. They experienced greater success with the direct social interactions, than with the web-based initiatives (PCA, 2010).

While the overarching tendency among NGOs in both countries is to underline the importance of the social, there is at the same time an outspoken critique of the heavy involvement in the social side of the field. The interviewee from Climate Justice Action e.g. raises a voice against a focus on the beneficial potential of stressing the social as a way of engaging the public. The critique of 'summit-hoppers' and many of the people involved in the Climate Forum 09 event points towards the risk of taking too lightly on serious matters at hand. CJA's fear is that efforts toward the public are often marred by other agendas such as the desire to have a good time (CJA, 2010). As discussed CJA does, as a more informal network, rely on the social bonds between members and different stakeholders. The danger therefore persists that their emphasis on the social might draw in some of them so called 'summit hoppers', but as the interviewee from CJA argues, there is a qualitative difference between what is done to attract the public in other NGOs and the work done by CJA (CJA, 2010).

With its many pitfalls the importance of the social is emphasised by the majority of the interviewees. Participation is perceived as something linked directly to the social and as a very important tool for engaging the public and ensuring that something worthwhile will result from their efforts.

\section{Participation as Action Oriented Learning}

Participation as action oriented learning can be understood as participation in projects where learners together identify a problem, examine and consider it, develop visions and proposals for action and at the end of it evaluate the result of their work (Læssøe, 2011: 64). This notion of participation rests on a theoretical base consisting of Paulo Freire's 'Pedagogy of the Oppressed', John Dewey' work on 'educational philosophy' combined 
with the concept of 'action competence' as developed by Karsten Schnack and Bjarne Bruun Jensen (Freire, 2006, Dewey, 1916, Schnack \& Jensen, 1997).

Participation as action oriented learning is as a concept explicitly normative in nature, and rests on a democratic ideal of what education and learning can achieve (Schnack, 2005). This does however not hinder the interviewees in expressing ideas about how they understand participation, which could be seen as overlapping with the theoretical outset. When the respondent from The Citizen's Movement for Environmental Justice talk about issues linked to nutrition and exploration of natural resources in Korea, this touches upon how participation is perceived to establish a social forum where it is possible to discuss and develop ideas for joint actions: "Discussions among our members of where they stand in relation to pollution and garbage led to many activities that where led by the members themselves and have now changed the issues so we not only think of pollution, but also [of] nutrition and lifestyle. They learned, by themselves that they are not outside of the environment" (CMEJ, 2010). Returning to the Saran-Bam activities of Centre for Energy Alternative, many of the thoughts behind those open forum discussions also mimic the notion of participation as action oriented learning. The Saran-Bam activities, where it is possible to discuss different aspects of climate and environmental change and challenges, while focusing on how these discussions and thoughts can lead to action, e.g. spawned the idea of funding and establishing commonly owned wind turbine power plants. It should be noted that the tradition of free and equal sharing of thoughts and discussions has had a very different trajectory in Korea compared to Denmark. The years under a totalitarian regime during the latter part of the $20^{\text {th }}$ century and the great value added to hierarchy and respect do not always lend themselves to such a notion of participation. This has however been altered by the successful democratic movement, but democratic action and participation is still something different than what it is in Scandinavia (Becker, 1986, Kim, 1996).

Most of the Danish NGOs are very focused on involving the public in their activities and ensuring a lively participation. None the less the interviewed employees from the umbrella organizations and the larger NGOs does arguably not express explicit interest in developing action and initiatives that stress action oriented learning as Schnack emphasise it. The history of the Danish environmental movement, with organizations like 
NOAH at its core, contains a great backlog of initiatives that stressed the individual role in the social processes of developing ideas and skills that could lead to direct action. The activities discussed by the majority of the Danish interviewees do not, however, display that participation should take the form of local developed ideas that would lead to applicable actions, even though several of especially the DAEA activities did stress that aspect.

\section{Participation as Deliberative Dialogue}

While this approach mimics some of the characteristics of the above action oriented learning approach, it has less emphasis on action and remains a more distanced way to understand the concept of successful participation. The Danish 'Folkeoplysning' tradition with its emphasis on cohesion and rational discussions of often abstract issues is close to this ideal of participation and very visible in the Danish case. PCA organized several debate nights, the organizations belonging to DAEA organized hundreds and the Climate movement also organized their share of activities that stressed the open discussion between the equal citizen as a method for understanding and learning about the issues at hand.

When discussed with the interviewees this approach rests on a belief in sorting the irrational emotional outburst from the rational solution-oriented ones and in a democratic manner settling on the best viable options or settling on agreeing to disagree. While the action approach might not be visible in all the Danish NGOs' perception of their roles, the deliberative approach certainly hits the mark. Emphasizing deliberative discussion and debate as a way to enable individual and social emancipation is one of the cornerstones of the Folkeoplysning tradition in Denmark and in many ways acts as a constitutive ideal of how to involve the public in the development of the society. Several of the Korean NGOs also stress the importance of the deliberative dialogue, and there is a qualitative distinction between Korean organizations like KFEM and Green Korea's use of dialogue as a way of reaching consensus on the understanding of challenges and between a tendency among groups like PCA and DAEA to stress the importance of and productivity of some kind of dissensus. 


\section{Participation as a Political Leverage}

The four described concepts of participation rest on established positions within theory on learning. The empirical nature of this study does, however, mean that some of the perceptions among the interviewees differ markedly from existing conceptualisations of participation. Most of the NGOs do in some way or another link to the four presented concepts, but radical departures are also part of the data forming this study.

For instance WWF Denmark's interaction with the public is not seen as just a way to create awareness among the masses, but to a certain extent also to create a strong base for their work as lobbyists working at a policy level. The interviewee from WWF Denmark argues that "COP15 created great potential for influencing Danish and international politicians, which for us is more important than the focus on the general public. This time we choose to try and focus on the public as well, as a way of establishing a broad product that could influence the politicians (WWF, 2010). The direct interaction and work to engage the public is more a tool that can be leveraged in order to affect policymakers and politicians, than an outright goal in itself. None the less the interviewee also stresses that the all important democratic pressure is one of most important means to ensure societal change. This opinion did not halt the many WWF initiatives aimed at especially young people, but leads to an interesting concept of participation that does not match the theory driven earlier mentioned categories. This leads to a situation where the information and educational material do not have the goal of discussion or direct interaction with the challenges at hand, but to a greater degree rely on creating a base for highly symbolic actions that create the maximum level of media coverage and raise the public profile of WWF. The 'Turn of the Light Campaign' is highlighted as a way of "Giving people a feeling of being able to do something" (WWF, 2010) and instigating participation through "speaking to the stomach" (WWF, 2010). There is no need for WWF to move into the more critical, deliberative or action oriented approaches to participation as the level of participation wanted is little more than a general accept of the overall agenda of WWF and support of the organization in its political work. 
Agenda21 in Korea does not entirely mimic WWF Denmark, but it does bring a comparable understanding of what is to be gained from participation. The interviewee argues that "Working as NGO everything we do and try should be organizational work, always try to boost civil society and trying to organize it" (Agenda 21, 2010). The other side of their work, focusing on the work of the government authorities, both local and national, does also position them as having a need for more overall political support than creating widespread participation. The strategy is less explicit and single minded than that of WWF Denmark, but their main goal is to "support the local government to be more sustainable”, which has an important impact on the approach towards to public. "We are the link between the government and civil society (...) and paid by the government but not part of the government" (Agenda 21, 2010) which has led to a situation where the publication of a range of popular books is one of the main outputs of the organization, as they can be used as political leverage. The desired level of participation is thus different from the rest of the Korean organizations as Agenda21 have to navigate the muddy waters in between political agendas and the perceived civil society. The interviewee's hope for an achievable mission is thus not to secure widespread participation, but to support "local sustainability management, showing clearly and charmingly the way to go" (Agenda 21, 2010).

This category differs from the before mentioned four by having less focus on the learning potential and more focus on how the use of participatory activities can act as leverage in a political setting. It is however not unreasonable to suggest that many of the NGOs involved in this study also includes this perspective when organising activities.

\section{Perceptions of the Public as a Learning Entity}

Drawing on the questions of Why, Where and How change and learning is understood by the interviewee present a varied picture of a highly dynamic field. Addressing the question of How is becomes visible how the energy and hope that the representatives from the NGOs invest in different methods illustrate a diverse interest in the potential of participation in ensuring learning and change. Participation is thus not only a way of engaging the members of the NGOs and the public, but also perceived as a way of 
establishing a powerful vehicle for achieving learning. Whether such learning is able to trickle down, into the life and actions of the individual is harder to grasp.

Within the different 'fields of learning', activities that try to encourage participation are pushed by both the Korean and Danish NGOs. The Koreans are keen on direct interaction with nature, whereas the Danes at large push for types of participation that draw on notions of deliberative dialogue. The Koreans' fondness for sentimentalism and the Danish 'Folkeoplysning' tradition could be used as explanations for these biases towards different types of participation. There is thus a distinct link between the where and how dimension.

The five interpretations of participation further exemplify the perception of the public as a learning entity. As can be seen from Figure 3-3, the effort to map the individual perceptions of the public as a learning entity and the role of the NGOs in engaging the public leads to no overarching unanimous picture of the trends in Denmark and Korea. 


\begin{tabular}{|c|c|c|}
\hline & South Korea & Denmark \\
\hline \multirow[t]{3}{*}{$\begin{array}{l}\text { Why, are the NGOs } \\
\text { engaging the public? }\end{array}$} & $\begin{array}{l}\text { Ideals about changing } \\
\text { the political structure }\end{array}$ & $\begin{array}{l}\text { Ideals about changing } \\
\text { lifestyle structures }\end{array}$ \\
\hline & $\begin{array}{l}\text { Stopping the } \\
\text { exploitation of nature } \\
\text { by state and industry }\end{array}$ & $\begin{array}{l}\text { Marrying a sustainable } \\
\text { emphasis with } \\
\text { continued growth }\end{array}$ \\
\hline & $\begin{array}{l}\text { Learning and change } \\
\text { as means to an end. } \\
\text { Radical change. }\end{array}$ & $\begin{array}{l}\text { Learning and } \\
\text { knowledge as a goal in } \\
\text { itself. }\end{array}$ \\
\hline \multirow[t]{4}{*}{$\begin{array}{l}\text { Where, are the fields } \\
\text { of learning? }\end{array}$} & $\begin{array}{l}\text { Youth and children as } \\
\text { spontaneous activists }\end{array}$ & $\begin{array}{l}\text { Youth having a } \\
\text { language of change }\end{array}$ \\
\hline & $\begin{array}{l}\text { Daily life as daily } \\
\text { struggle to sustain } \\
\text { sustainability against } \\
\text { odds }\end{array}$ & $\begin{array}{l}\text { Daily life as a vehicle } \\
\text { for working with } \\
\text { contradictions }\end{array}$ \\
\hline & $\begin{array}{l}\text { Sentimentalism as a } \\
\text { way to learn }\end{array}$ & $\begin{array}{l}\text { Rational knowledge as } \\
\text { the key to learning }\end{array}$ \\
\hline & $\begin{array}{l}\text { Conflict as popular } \\
\text { vehicle for learning }\end{array}$ & $\begin{array}{l}\text { Consensus and gradual } \\
\text { change }\end{array}$ \\
\hline \multirow[t]{2}{*}{$\begin{array}{l}\text { How, is participation } \\
\text { perceived? }\end{array}$} & $\begin{array}{l}\text { Participation as } \\
\text { learning in nature for } \\
\text { youth and adults }\end{array}$ & $\begin{array}{l}\text { Emphasis on } \\
\text { participation as social } \\
\text { learning }\end{array}$ \\
\hline & $\begin{array}{l}\text { Few examples of } \\
\text { participation as action } \\
\text { competence }\end{array}$ & $\begin{array}{l}\text { Great belief in } \\
\text { participation as } \\
\text { deliberative dialogue } \\
\text { and examples of } \\
\text { participation as } \\
\text { political leverage }\end{array}$ \\
\hline
\end{tabular}

Figure 3-3 Perceptions of the public as a learning entity 
Having insisted so far on diminishing the effects of theoretical violence has left us with a scattered landscape with a wealth of perceptions represented. It is however possible to decipher patterns in this landscape, as such both similarities and differences can be identified with the Danish and Korean cases. Taking a stab at When, Who, Why, Where, and How the interviewees perceive the public as a learning entity and their own role towards it draws out some overall trends.

Based on the previous chapters it can be argued that the Danish NGOs are left at a standstill with great frustrations on how to influence a society that on the surface takes the issues of the NGOs very seriously, but at the same time moves in the opposite direction of what is hoped for. The emphasis on participation as deliberative dialogue exemplifies the entire effort of the Danish NGOs. Discussion and the time honoured principle of bringing information to the table and reaching a solution through intellectually driven consensus, is still the main perspective deployed by most of the Danish NGOs. At the same time, the obvious failure to reach their goal of change, especially during the rather depressing post-COP15 period, displays a frustrating lack of traction, as expressed by the NGOs. The picture of a unanimous group of NGOs quickly disintegrates, as internal strife and bickering marks their work and outlook on the work of their colleagues. Hopes of engaging a rational public that is eager and willing to learn and change their ways is crumbling, with new initiatives like CJA undercutting the impact of the established NGOs' work.

The Koreans also face a diminishing impact of their work to engage the public, as they express great frustrations about the level of interest from the general public. Their roots in the revolutionary democratic movement cast a heavy shadow over the contemporary efforts. It also leads to situation where the idea of a unified voice has split into very different approaches to moving the public in a different situation than the existing on. Korea has witnessed unprecedented growth and entire generations have been drawn from a feudal state into the cutting edge of globalization over a very short time span. The country has also felt the impact of a greater emphasis on the individual, and the NGOs now bear the brunt of that development, with problems to draw the interest of young and old alike. Even though Green Growth is the overall development strategy for the country, there are continued problems of actually reaching the public on issues linked 
to the environment and climate. The very evident gender issue is also a returning challenge for the Korean NGOs as they struggle to get information to the housewives that run the households, but often fail to engage the men who are still perceived to hold the power of a largely patriarchal society.

In both countries great efforts are spend on getting information to the public about issues at hand and these are coupled with frustrations about the perceived meagre impact of this work. In Denmark the challenges is framed as dealing with a population that has a high level of knowledge about the issues, but has a hard time incorporating such knowledge about abstract issues into the daily life. In Korea there is still a great concern about the level of knowledge and a firm belief in the power of bringing information to the greater public, but also great focus on how to manage something as complex as the issues at hand in the high strung Korean daily life.

All is not impending doom and gloom though. NGOs from both countries draw on a long and diverse range of perceived successful activities and proudly discuss how many of the organizations have managed to grow during political headwind and varying interest from the public. The Korean combination of 'sentimentalism' and participation as learning in the nature is interesting and the efforts to create commonly owned projects are important. The work of Green Asia, drawing on a large number of volunteers and combining corporate sponsorship with a global outreach is also unique. This further stresses the impressive results that have been achieved by environmental NGOs, which from a Danish perspective are not only very young, but also have managed to operate successfully in hostile waters.

The Danes might operate on a strong tradition of empowering the public through civil society and consensus driven dialogue, but the constant risk of being stuck in status quo, has also brought new perspectives into light. The move from grassroots to large bureaucratic organizations has not resulted in straightforward and efficient engagement and information to the public. In a return to the logic of the 1970s new and interesting approaches stem from the smaller organizations. The dissolution of a rigid organizational framework paired with a stronger critique of the established ways of thinking about learning brings about new ways of thinking about the public and engaging it. The trends represented by the Danish Climate Movement and the Climate Justice 
Action Network open up for different distillations of discussion and participation than the established NGOs.

That, however, is merely scratching the surface of the significance of the perception of the Danish and Korean NGOs. The bewildering array of empirical findings now prompts theory driven analysis into the core of what the meanings of these perceptions of learning, education and the public are, and how new directions and understandings could be wrought from them. 


\section{The Significance of Perceptions and the Educational Desires of Environmental NGOs}

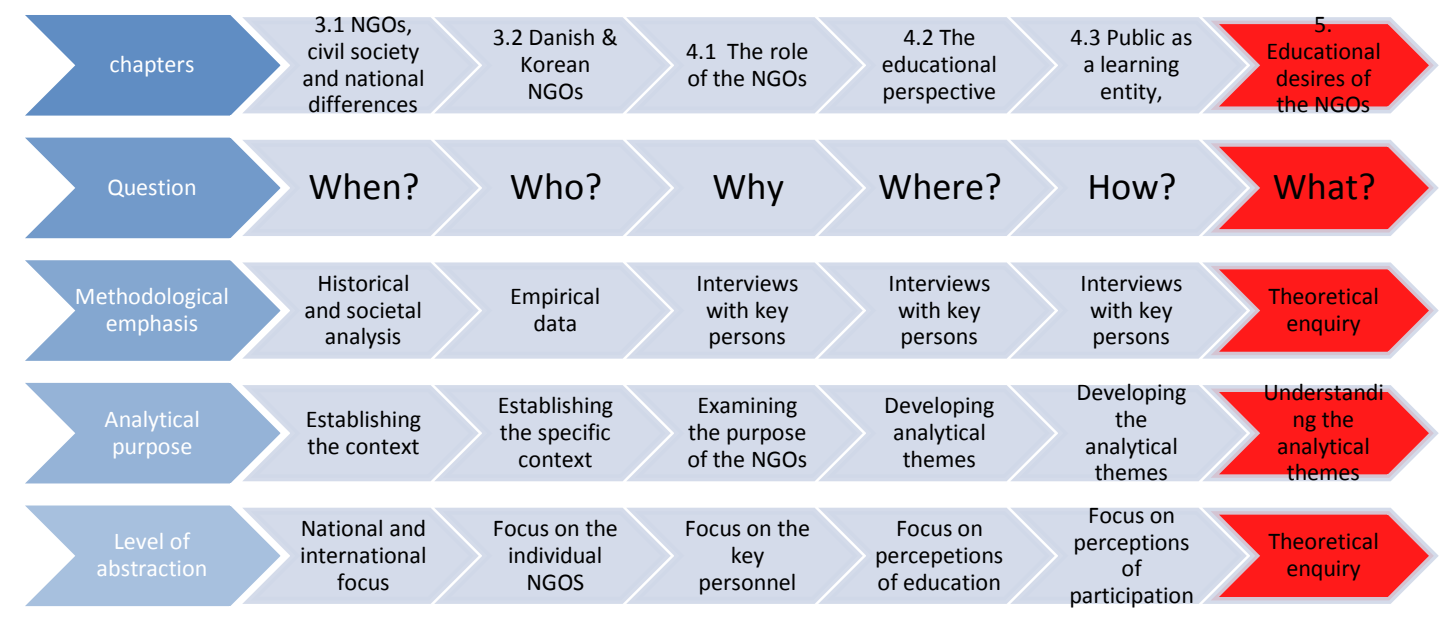

\section{So What? The role of Theoretical Inquiry}

What can be said based on the analysis of the past and current situation of the Danish and Korean NGOs? What do the interviewees' perceptions tell us about themselves and their relationship to the public as a learning entity? To answer these questions theories about the social arena are needed. While the former chapters have been products of an inductive effort to let the environmental NGOs take the stage, the time is now ripe for probing into the different perceptions via the perspective that political theory and philosophy offers.

A vast range of possibilities appear when the discussion turns to a theoretically embedded analysis of empirical material. The onslaught of the 'real' has already taken place via previous efforts to present a 'non-biased' landscape of the individual NGO employee's perceptions. This has laid waste to the notion of a scientific, clean cut presentation of the most likely trends that emerge from the empirical material. While previous chapters have evolved with a distinct eye towards minimizing the level of 'theoretical violence', the above results could probably also have been reached with the aid of the most volatile philosophy and political theory imaginable. The point is, however, that they were not. Themes have been emphasized as they sprung out of the empirical material and presented themselves as irresistible to the reader and the entire backlog of preconceptions, interests and fancies that travel with any person at any time. Thus the 
analytical themes; ideals, fields of learning, youth, daily life, conflict, participation etc. do not only reflect the innermost perceptions of the interviewees, but of course also the constellation of this study, the interests of the scholar, and the situation where the dialogical interview took place.

This statement is not made in an attempt to cut off the branch that this study is sitting on, the empirical data is very much based in a real setting, but it is important to remember that it is also influenced by the myriad of different interests that are linked to a complex setting such as the environmental NGOs and their work reflected in a research agenda. Still the analytical themes, perspectives and framing of the cases could not have been developed without the empirical data and neither could the choice of theoretical stance.

The role of the empirical data in the forthcoming part of the analysis will be that of 'privileged examples'. Of the many different approaches to embedding empirical data in theoretical analysis and vice versa, two philosophical approaches highlight the one chosen; a platonic-idealist approach and a Hegelian material approach. In an idealist perspective examples are always imperfect, they never perfectly render what they are supposed to exemplify, which makes it important for the scholar not to take them too seriously (Cornford, 2010, Bubner, 1995). For the Hegelian materialist there is always more in an example than in what it exemplifies. An example always threatens to undermine what it is supposed to exemplify, since it gives body to what the exemplified notion itself represses and is unable to cope with. This is why the idealist approach always draws on a multitude of examples. Since no example is fully fitting one has to enumerate them to indicate the transcendent wealth of the idea, which they exemplify, the idea thus being the fixed point of reference of different examples. A materialist on the contrary, tends to repeat one and the same example. The particular example, which remains the same, offers a wide range of understandings based on a changing notion of the general, which can change and incorporate new forms. This enables a multitude of perspectives on the general, through the eyes of the particular (Beiser, 2005, Pinkard, 1996).

The method of applying the empirical findings, and returning to different perceived notions of the interviewee, is thus not an attempt to generalize to an all encompassing truth that speaks for all Danish, Korean or global environmental NGOs. 
Instead it is an attempt to present examples of different shapes of the general that particular notions pave the road for. The choice of this materialist approach grows out of the theoretical affliction with Hegel and Lacan through Žižek that the empirical data has inspired to (Žižek, 2008a).

Of course, any number of theoretical perspectives could be adhered to the data at hand with differing, and ultimately interesting and worthwhile conclusions that might not always be identical. The choice to draw on Slavoj Žižek's mix of Lacanian Psychoanalysis, Marx and Hegel, while stressing the roots of Jacques Lacan, is thus not an effort to identify and choose the theoretical approach that might be recognized by anybody as the most obvious or powerful theoretical approach that will wind out the optimal analysis of the data at hand. Instead it represents a distinct choice to apply a theoretical perspective that has been inspired by the work with the empirical analysis and is viewed as very promising in relation to the material by the author. The choice rests on a strong belief that this particular theoretical perspective harnesses great explanatory power and has the possibility to not only push the research agenda of the field of environmental education and the education for sustainable development research, but also return the favour to the practitioners and formulate new possible ideas and inspiration for the educational work of the NGOs.

The following analysis stresses not only the perceptions and understandings that exist in the field of non-formal education for sustainable development as found in the Danish and Korean NGOs, but to a greater extent how to understand the significance of such perceptions. In the words of Swedish sociologist Johan Asplund “...after the cause for a phenomenon is indicated, we can continue with the question of, what is the significance of this phenomenon" (Asplund, 1970: 65). The primary concern is not only to contextualize, map and present how the environmental NGOs engage the public as a learning entity, as this has already been dealt with in the empirical analysis. The job for this analysis is instead to inquire into the significance or meaning of the perceptions of the public and the interviewees' own role. The point of interest is to understand what role the perceived themes play for the NGO key persons and what the significance is of engaging the public with and without success? 


\section{The Importance of Perceptions, a Lacanian Take on the Perceived}

Throughout former chapters focus has been on inductively presenting and understanding perceptions of individual interviewees, as opposed to how things might look from the perspective of others involved, e.g. the public or colleagues from the same or other NGOs. This focus on individual perceptions does not only represent a distinct choice in delineating the empirical framework and ensuring that every analytic theme is deeply embedded in the data at hand, it also lends itself rather well to the application of Lacanian inspired theory. Talking about how individuals perceive themselves and their actions in a framework of Lacanian psychoanalysis stresses the importance of how we as individuals create meaning, where none might be, and work hard to establish a perceived level of rationality as our basis for actions.

From the outset the choice of applying a strand of psychoanalysis, such as the work of Lacan with its clinical connotations, might seem unnecessary or simply outside the scope of analyzing a field like non-formal ESD. A way of answering such a critique is by appreciating that Jacques Lacan's psychoanalysis does not build on an egopsychology and that the point of Lacanian psychoanalysis is not to shed light upon the unconsciousness of the ego. Ego-psychology draws mainly on Freud's structural model of the psyche, as presented in the Ego and the Id (Freud, 2011). This model comprises three agencies: The Id, the Ego and the Superego. Focus is on the role of the Ego as mediating between the conflicting demands of the instinctual Id, the moralistic Superego and the external outside (Hartmann, 1964). In Lacanian psychoanalysis the perspective is quite different.

What is seen as most important by Lacan is the subject and language. An important lesson from Lacan's motto "the unconscious is structured like a language" (Lacan, 1999:48) is that the unconscious comes to show through speech. This counters the notion of the unconscious as the domain of irrational drives, as something that opposes a rational and conscious self. Lacan understands the unconscious in another way. Unconsciousness is not the preserve of wild drives that have to be tamed by the rational ego, but instead the site where traumatic truth speaks out. This also marks the approach of Lacan, compared to other schools of psychoanalysis, as having a more philosophical aim. For Lacan psychoanalysis is, at its most fundamental, not a theory and technique of 
treating psychic illnesses or disturbances, but a theory and practice that confronts individuals with the most radical dimension of human existence (Laustsen, 1999: 164). It does not show an individual the way to accommodate demands of social reality: instead it tries to explain how something like 'reality' constitutes itself in the first place. It does not merely aim at enabling a human being to accept the repressed truth about himself; it tries to explain how the dimension of truth emerges in human reality (Žižek, 2006a). The goal of applying Lacan and Lacanian theory to the case of environmental NGOs is thus not to disclose some kind of brutal underlying logic that controls the actions of the NGOs, but to understand how the 'truth', as the interviewees see it in their relationship to the public as a learning entity and themselves, emerges and what the function of such a 'truth' might be.

Another famous claim from Lacan is that "the unconscious is the Other's discourse" (Lacan, 2006: 10), which basically means that the human desire is structured through the desire of others. Lacan thus claims that what human beings deep down desire is to be recognized, desired and even loved by others. Lacan got this idea from Hegel, via Kojéve, who argues: "Desire is human only if the one desires, not the body, but the Desire of the Other...that is to say, if he wants to be 'Desired' or 'loved', or rather 'recognized' in his human value...in other words, all human anthropogenic Desire ... is, finally, a function of the desire for 'recognition'", (Kojéve, 1969: 6). In such a perspective we desire the desire of others, which has far-reaching implications, but the most important aspect of it is that in a Lacanian perspective, desire is a social phenomenon. This makes social processes that shape and affect the subject and the desire of the subject the centre which everything revolves around in Lacanian psychoanalysis. By focusing on language and desire as something that is created in the social and forms the platform from which the subject is able to partake in the world, leads to a social theory that analyzes and reflects the societal processes of subjectification (Laustsen, 1999).

This perspective emphasizes the importance of the social and how the unconsciousness is structured via the social. It also entails, in a Lacanian and Freudian sense, that it remains an impossibility to gain full knowledge of what goes on in the unconsciousness and even the consciousness. The aim of Lacanian psychoanalysis is not to gain Hegelian 'ultimate knowledge' as this is seen as being out of reach to the individual - something is always alien to the individual. According to Lacanian 
psychoanalysis there is always something which cannot be articulated, which escapes the construction of meaning and returns to the idea of the irreducibility of the unconscious, i.e. the idea that the unconscious is not that which is not known, but that which cannot be known. There is in other words always 'a lack' present, which cannot be fulfilled. This lack is what forces the subject into new, ultimately unsuccessful efforts to identify itself and follow new paths of consumptions, action or opinion. The notion of an ever present unconscious lack as a strong motivator for the individual to engage in new activities and as a background for perceptions of activities makes Lacanian psychoanalysis a viable perspective when trying to understand the social, the discourse, and, to use another much criticized concept, ideology (Žižek, 2005: 229).

Slavoj Žižek has developed this Lacanian concept of an ever-present lack further in his effort to use Lacanian psychoanalysis to rejuvenate the critique of ideology. His work takes the groundwork of Lacanian psychoanalysis and applies it in an effort to understand and analyze ideologies as vehicles of desire that offer the subject scenarios of fulfilled desire. The job of ideology, as Žižek interprets the concept, is to present narratives that aim at fulfilling the desire of the individual and close the existential gap that makes us all head for new boundaries and challenges. The point being that no matter what objects we take into our possession, what strategies we employ in order to fulfil our desires the gap will never be closed - the desire never truly fulfilled. The lack, or the gap, can never be completely filled and our desire will head in new directions and try to find fulfilment (Žižek, 2009a: 9).

Lacan uses the French term for enjoyment, Jouissance to describe the imagined fulfilled desire (Lacan, 1991: 217). No matter what level of enjoyment is presented to us, true enjoyment is still beyond the possible. This Jouissance is in fact no longer interpreted by the subject as true enjoyment, but as suffering or painful pleasure, as the subject steps beyond what is considered to be socially acceptable levels of pleasure, and into an area lacking social coordinates. In a Lacanian perspective this also makes Jouissance something that is craved for i.e. the vision of fulfilled desire and at the same time something impossible as the lack remains and there is no way to circumvent the social. The other cannot be fully reached or understood and it is impossible to posses his or her true recognition or love, which in effect makes the process of covering this lack 
never ending. This does in no way stop us from trying to cover the gap. Lacan argues that the subject actually has no other choice than to constantly pursue ways of enjoyment and fulfilment of the existential lack. In fact attempts to stop doing so or to move beyond the constant search would not only be foolish and in vain, but also potentially harming for the subject as the construction of meaning that the desire linked to enjoyment accomplish would also be stopped, leaving the subject without methods to navigate the social (Lacan, 1991: 269).

An important part of such a notion of the unconscious as something that is always, in its totality, out of reach is that we will always attribute other people with desires that are not theirs. As we have no way of reaching full understanding of the people around us, or believed to be around us, we do both consciously and, more important unconsciously view them as having qualities and urges that we have no access to. This translates into a situation where our unconscious assessment and understanding of the desires of others have great impact on the way we organize our own desires. This not only means that we are strangers towards others as even our spouses or children are fundamentally unknown to us, but also that we in effect are strangers to ourselves. At least we remain strangers to the parts of our unconsciousness that cannot be accessed, that cannot be known. That such a gap or lack will remain unarticulated, and that efforts to cover it up will always be unsuccessful, makes us alien towards ourselves.

The perception of one's own opinions, work and desires is thus not a complete mapping of innermost beliefs, but a mirroring of what we perceive as the desires others and what we think they desire of us. In short our perceptions are driven by an aim to be recognized, seen and ultimately loved. Therefore an analysis of the perceptions of NGO staff might, in a clever way, reveal what is hidden behind the 'masks' worn by the individual interviewees. What is really meant and implied when discussing the youth, the potential of conflict and the lure of participation? Is there some kind of hidden truth that can, in line with the tradition of critical theory, be ensnared from the oppressed individual? Alas the žižekian and Lacanian perspective does not offer that route of exposing the hidden truth. Žižek argues that what is false is not our mask, the way we act in daily life and conform in order to manage in the social, what is false is our belief in an innermost 'self' that truly express who we are: 
"There is more truth in a mask than in what is hidden beneath it: A mask is never just a 'mask' since it determines the actual place we occupy in the intersubjective Symbolic network; what is effectively false and null is our 'inner distance' from the mask we wear (The 'social role' we play), our 'true self' hidden beneath it. The performative dimension at work here consists of the Symbolic efficiency of the 'mask': Wearing a mask actually makes us what we feign to be" (Žižek, 2008a: 38).

According to Žižek there is nothing more than the mask. Underneath it is nothing but a constructed notion of what constitutes our self. This is not to argue that the notion of a mask is not important, far from. In fact it is this mask that makes it possible to survive daily life, the myriads of daily challenges, successes and failures. It might be a fake, but the mask is what makes a coherent whole of the messy social. This means that looking for a secret truth behind the mask, behind the social, is in itself unfruitful. Lacan and Žižek argue that such a thing cannot be successfully brought into the light and incorporated into the Symbolic, the social, without losing its link to the all important gap. When ultimately trying to pry something into the light, to uncover what is really going on, the danger is that we forget that we can never bring all into the light. The importance of what cannot be known constantly lingers by each individual and in turn produces our ability to enjoy and desire.

This led Lacan to state that "Les Non-dupes errent" (Lacan, 1974), which in effect means that those not fooled (by the social structures), are mistaken. If we take a step back in order to view 'reality' then we are in reality still stuck in the Symbolic, the social with little hope of achieving tacit knowledge on whatever kind of 'reality' we were aiming for. Precisely because of the irreducible unconsciousness and the persistent lack, we need to accept that there is no way of presenting the 'bare facts', but that we will always remain fooled by the social structures, always carrying a set of pre-existing values and ideas, and have no chance of escaping the social structures.

This is, however, not to say that the discursive field does not exist. Both Lacan and especially Žižek draw heavily on the concept of discourse when working with the social, and none of them deny that it is possible to identify discourses, but it is not seen 
as enough. The focus on discursive formations and structures must be joined by a focus on the function of these discourses. Lacan draws on a Socratic use of the term dialectic, in order to describe how the process of psychoanalysis deals with the different layers of understanding. Socrates often started his dialogues by bringing his opponent into a state of confusion and almost helplessness. This can be compared to the first step in Lacanian psychoanalysis, where the aim is to identify and confront contradictions and gaps in existing narratives. Just as with Socrates, the second step then is to proceed by drawing out 'a truth' from the associations and perceptions of the individual.

In a Žižekian perspective this translates into a two step foray into the social and what he coins as the ideological structures. First is to historicize and contextualize, to show how a discursive formations and structures, a discursive truth in other words, could have been different. Second is to claim that even references to historical and contextual settings are fake and that behind discourses rests a structural and non historical necessity. This necessity takes form of exactly the irreducible unconscious lack that constantly forces us to wander into new areas of construction of meaning. The effort of mapping the perceptions of interviewees could be understood as the first step in such an analytical process, and the use of Lacanian inspired theory to understand the function of these perceptions as ways of making meaning - step two.

In a Lacanian perspective the perceptions of individual NGO staff members take the role of efforts to structure the social reality in order to install a level of meaning into highly differentiated and elusive educational practices and ideals. At the centre of attention for the following will be how it is possible to understand these perceptions as indicators of efforts, ideals, and practices, or in Žižekian terminology, ideologies, which attempt to cover up the existential lack we all carry in order to create meaning in a tumultuous world. 


\subsection{What is the significance of the NGOs engagement with the public?}

\section{The Significance of Ideals}

Following this idea of looking into what perceptions of the interviewees signify, the interviewees' own reasoning for doing their work in the first place provides an interesting point of departure. When the Korean NGOs talk about their engagement with the public as being grounded in an ideal of changing the political structure of their country and the Danish NGOs to a greater degree push for a consensus based change in lifestyles, they not only describe good reasons for establishing educational efforts toward the public, they also set the stake very high. This translates into more everyday applicable missions of informing the public about the state of the world in order to initiate such large scale changes. This does not make the scope of their perceived mission any less mundane as the overall ideals still infuse their work, even in its most everyday guise. Wanting to “...create widespread debate about climate issues on an informed basis.”(DAEA, 2010) as the interviewee from DAEA pushes for, or "...transform the society into more renewable based [energy]" (CEA, 2010) as the Korean Centre for Energy Alternative stresses is still a quite radical outset, compared to the frustrations linked with the sluggish of the 'public' and the society at large inertia that is expressed by both the Danish and Korean NGOs. It can be argued that such perspectives are part of an established notion of enlightenment with not so subtle overtones of more Marxist connotations of ridding the subject of a 'false consciousness' in order to reach the point, where the individual is able to go beyond the snares of an oppressive system (Eyerman, 1981). This is especially evident in the Korean setting, where the constant return to the heritage of the democratic and revolutionary movement of the 80 s and 90 s draw on a notion of changing the society for the better through an adamant focus on the wrongs of the existing system and the possibility of a better, less suppressing and volatile system. While the Korean Democratic movement at large focuses on the oppression of human beings, the environmental movement and the NGOs represented have extended this fight to include oppression of the environment as part of the struggle to create a sustainable society and future. 
While the Danish concept of a baseline ideal also harbours the notion of working for a greater cause and a greater ideal there is a qualitative difference in that the revolutionary streak of the Koreans has less traction in the Danish case. An exception is the more radical CJA network, but the concept of enlightening the public, ridding it of false insights and thus overcoming some sort of internal or external resistance towards change still constitutes the base of the work of most of the NGOs from both countries.

While the different cases present different notions of idealism, both share the focus on idealism as a foundation of their work. Žižek is a stalwart critic of the concept of idealism. He aims his critique at two distinct versions of the concept of idealism. First the notion of an idealism emphasizing that the object of thought and reflexivity is ideas, following Marx' critique of the German philosophical idealism of the $18^{\text {th }}$ century, as prioritizing contemplation in favour of the material fight against oppression. Secondly, Žižek criticizes an idealism harbouring a potential for an idealizing movement, as an expression of something complete, perfect and good (Žižek, 2008a: 104).

While the Korean NGOs can only to a limited degree be accused of being at the sharp end of Žižek's first level of critique, with their active outreach and conflictual outlook on society and the changes needed, the Danish NGOs represented can arguably be said to have inclinations towards favouring discussions and contemplations (deliberative dialogue and learning as a goal in itself) as a way of reaching insight and potentially change. NGOs from both cases could, however, be seen as expressing an urge to move the society in the direction of a more idealized position. As an example the frequent use of notions like sustainability and sustainable development could be seen as describing such an ideal position, where the needs of the human race, on a local and global scale could be met without sacrificing nature and the environment (Hansalim, 2010, KFEM, 2010, CJA, 2010, PCA, 2010, DAEA, 2010).

Arguing that sustainability and other environmental and climate ideals can be understood as ideology is far from new (Wals \& Jickling, 2002, Söderbaum, 2009). Sustainability has been accused of serving many interests, of being the new hope for a disillusioned global Left after the collapse of communism and as an unreachable moral standard that can be used to criticize almost everybody (Dresner, 2002, York \& Clark, 2010, Böhm \& Dhabi, 2011). An adamant critique is also that the term 'sustainability' 
enables 'Green washing' of industrial production of lifestyles that remain harmful to the environment, but have been given a frosting of sustainability (Ortega, 2009, Traies, 2005). The notion of 'sustainability' thus talks to many different interests, and it is now possible to find claims of sustainable food, kindergartens and schools, but also claims of sustainable nuclear power plants, cars and computers (WNA, 2012, Dresner, 2002). This open ended and vague nature and use of 'sustainability' raises the argument that it can be seen as an 'essentially contested concept'. This idea introduced by the political scientist W. B. Gallie emphasizes that certain concepts draw their strength from the fact that their core is virtually empty and thus has the potential to mean very different things for different people. Other essentially contested concepts could be 'Democracy' or 'Freedom', as they also bear different meanings around the globe. To be democratic in India is not necessarily the same as it is in Spain, and freedom in USA could be understood as something different than freedom in Japan. The point being that an essentially contested concept, such as sustainability, enables different opinions and notions to gather around a single concept, and agree on the possibilities that it harbours, but still approach it and ultimately understand it in very different ways (Gallie, 1956, Connelly, 2007). Emphasizing the constructed aspects of a notion such as 'sustainability' opens up for a discussion and critique of its use in the Danish and South Korean cases. It also links the use of these notions to Žižek's understanding of ideology: Žižek's take on ideology is not to be compared with a standard political or sociological take on grand ideologies like socialism or liberalism. Instead it offers the opportunity of asking what the ideals and 'ideology' expressed by the NGOs bring to the table in the form of construction of meaning, or in a Lacanian sense how the ideals propose to bridge the gap between what is known and what cannot be known. What does the ideals that bring the NGOs to engage the public offer in the attempt of constructing meaning for the individual interviewee? In order to understand perception and ideals, it is necessary to take a look at where they are located in the three Lacanian orders.

\section{The Symbolic, the Imaginary and the Real}

For Lacan the reality of human beings is constituted by three intertangled levels: The level of the Symbolic, the Imaginary, and the Real. These three orders are central for the way 
Lacan developed his theories and how Žižek subsequently critiques society and ideology. Of the three, Lacan devotes most energy to the Symbolic. The Symbolic is understood as the field of language, this is where communication happens, where the social unfold and human beings relate to each other as well as the Other. Lacan is inspired by Lévi-Strauss' idea that the social world is structured by certain laws which regulate kinship relations and the exchange of gifts. Since the most basic form of exchange is communication itself, and since the concepts of law and structure is unthinkable without language, the Symbolic is essentially a linguistic dimension (Evans, 2010: 201).

The Imaginary is something different from the Symbolic, but still deeply intertangled with it and can be understood as structured by the Symbolic. It is the realm of image and imagination - of deception and lure. The principal illusions of the Imaginary are those of wholeness, synthesis, autonomy, duality and most importantly similarity. The Imaginary thus becomes the order of surface appearances, which are deceptive, observable phenomena that hide underlying structure (Žižek, 2006a: 9).

The third order, the Real, is not only opposed to the images of the Imaginary, but also lies beyond the Symbolic. Lacan defines the Real as what is outside language and inassimilable to symbolization. It is "What resists symbolization absolutely" (Evans, 2010: 159). This can be seen as a radicalization of the Kantian Ding an sich (Žižek, 1993, 2008b: 221). The Real is what is impossible. It is impossible to imagine, impossible to integrate into the Symbolic via language and impossible to attain in any way. Žižek uses the metaphor of a game of chess in order to illustrate the three orders:

"The rules one has to follow in order to play are its Symbolic dimension: 'knight' is defined only by the moves the figure can make. This level clearly is different from the Imaginary one, namely the way in which different pieces are shaped and characterized by their names. (...) Finally, real is the entire complex set of contingent circumstances that affect the course of the game: the intelligence of the players, the unpredictable intrusions that may disconcert one player or directly cut the game short” (Žižek, 2006a: 8).

The Symbolic is not only the realm of language and the social rules that surround us, but also the place where ideal and ideologies unfold. One take on this is to 
understand ideals as variations on the concept of the always present Other. Ideals like sustainability, societal change towards such an ideal, be it revolutionary or evolutionary, can be manifested as the big Other. This is an entity goes beyond the normal other, and becomes something larger that transcends the notion of the individual subject. The big Other express itself as a constant, which has the power to influence all areas of the subjects life. In other words something that stands above the individual other. Hitherto God has been the archetype big Other, the one who is always there and watches our every step, but with the advent of modernization, and post modernity new concepts present themselves as potential big Other(s). Socialism, Democracy, Freedom and lately climate change presents themselves as causes which have the potential to be ever present in our social contact with others. In spite of all this power the big Other is fragile, insubstantial, and properly virtual, in the sense that its status is that of a subjective presupposition. It exists only in so far as the subject acts as if it exists.

\section{Global Climate, 'Sustainability' and the Symbolic big Other}

Returning to the cases, is it possible to understand the ideals about changing the world towards a more sustainable future as something that expresses the interest of the Lacanian big Other? Do the ideals that the interviewees describe follow their every step and is there a third party in all our communication and interaction with others? From a Lacanian perspective the outset of serving society in order to mitigate the effects of an abstract notion of climate change, does hint notions of something that stands above and is in supremacy to the relationship to the other. Engaging in activities that have their roots in abstract issues like climate change, and being able to link this abstract issue to most of the everyday professional and private life, hints that something more far reaching and omnipotent is at play, when referring to the ideals that govern the work of engaging the public (Lacan, 2006).

To describe the ideals of the NGOs as abstract is not to suggest that climate change and environmental hazards that are addressed by the expressed ideals are not true. Addressing the perceptions of the interviewees on what drives them in their efforts and their work, does relate to something i.e. the environment and climate, which is partly seen as being outside of the social - in other words something that 'truly' exists. At the same 
time it can be argued that their work, their horizon of engaging the public is pre-eminently social. In a Lacanian sense their work is situated in the Symbolic, in language and in how to engage others in using the language and understanding surrounding structures. Their work is driven by perceptions of concrete changes that happen outside of the social in the global environment, while the remedies that are sought have to be conveyed through the social. Such a distinction is not clear cut, and has levels of intertangled logics, but from a Lacanian perspective the Symbolic is the field of the NGOs work, based on a notion of something greater than the Symbolic. In other works the field of the NGOs are the social, but their work in embedded in arguments that draw on a notion of the 'environment' and 'climate change' as something that also exists outside of the social.

\section{The Global Climate as the Lacanian Real}

As such concepts of climate change or environmental challenges, as discussed by the interviewees, share several characteristics with Lacan's notions of the Real. One of these is the understanding of the global climate as a system that acts with no reason and no strategy, but merely exists in its totality. It can be argued that in the global climate there is no such thing as coincidence; what happens, happens with no mastermind pulling any strings (Anderson \& Willebrand, 1996: 158). The results might be catastrophic, benign or anything in between, but that something happens is beyond doubt, and in its totality beyond direct experience of the individual. The 'climate' describes a system of such colossal reach that it includes almost everything on a global scale is included.

This corresponds with Lacan's notion of the Real, as Lacan argues: “there is no absence in the Real" (Lacan, 1991: 313). Whereas the Symbolic opposition between presence and absence implies permanent possibility that something may be missing from the Symbolic order, the real, "is always in its place: it [the subject] carries it glued to its heel, ignorant of what might exile it from there" (Lacan, 2006: 25). This quality of ignorance is something shared with the global climate. Mathematical models and scientific explanations of the climate belong in the realm of the Symbolic as a way of translating the real and existing climate into something comprehendible. Models of climate change, calculations of future water levels, maps of growing deserts etc. remain social translations, and in a Lacanian perspective efforts to depict the real via a Symbolic setting. This does 
not alter their value as scientific arguments or how true they might be, but it stresses how such translations and interpretations of notion like the global climate will always fail to incorporate the totality of the real. For the purpose of this argument, a distinction must thus be made between global climate, as a metaphor for the Lacanian Real, the unintelligible incomprehensible global climate of the entire globe, with its untold facets, impacts and consequences, and its Symbolic interpretations, as used by the interviewers such as 'climate change' and 'sustainability'. Again this is not to designate that the NGOs are wrong in their outlook or approach to these issues, but to clarify the point that in a Lacanian sense something is always lost when introducing the Real into the Symbolic language, which is a necessary baseline for human interaction.

The consequence of this is that to believe in the (albeit overwhelming) scientific suggestions that we are upsetting the working of our globe is exactly that; a belief. Such beliefs are hopefully based on sound and informed judgment. To believe that "97-98\% of the most published climate researchers think humans are causing global warming" (Anderegg et.al, 2010) seems quite reasonable, but the point is that in a psychoanalytic perspective we are still dealing with beliefs, not facts. Individuals will never have direct access to such facts, they first have to be assessed and translated into the Symbolic. It is possible to refer to abstract scientific knowledge, presented by scientist that have insight into a demarked specialized area, and this link to science has been wielded as a constant and strong argument for the case of changing society. It is, arguably, still rare that the individual member of a NGO involved with the public has direct insight into this scientific knowledge, and it still requires an amount of belief to be able to act upon such notions of knowledge.

While the framing of this process is distinctively Lacanian, it also echoes the insights pioneered by social constructivism and social constructionism, regarding how the individual constructs meaning via the social (Vygotsky, 1978, Piaget, 1977). The differences between e.g. Piaget, Vygotsky and Lacan are, however, many and particularly build on Lacan's emphasis on the irreducible unconscious as the kernel of the subject. A shared perspective is that perceptions are acquired through the social and very little can be said to be 'natural' conceptions of a neutral existing world. Ideals about pushing society in a better direction are thus far from a common sense acceptance of the state of the world, 
but involve a social will to believe in what is presented. Along this argumentation it would seem plausible that a ship breaker at the notorious Alang beach in India, or a political oil lobbyist would find their own work and views of the world just as straightforward and self-evident, as the interviewees might find theirs.

At the same time most of the NGOs, especially the Danish, but also the Korean, address the problems they face as something which happens because of global changes. When the Danish NGO Climate Justice Action brings in representatives from the global south and Green Asia ships volunteers to Mongolia in order to mitigate the effects of desertification, it is exactly an acceptance of the fact that the challenges that are addressed via the work of the NGOs have their roots in the global. Implicit in the work of the NGOs is thus an abstract notion of a global problem that threatens the livelihood of societies around the world.

Another nature of notions of the global is, as with global climate, that there is no way to individually experience it in its totality. Consequences of the global climate can be experiences, as weather phenomenon, but the totality of the Climate is out of reach for the subject. It is, as many of the NGO employees do, possible to travel around the world and piece together a vision of the state of things, but in any effort to move, we are still bound by the limitations of always being in one place, we as humans are in a sense always local. There is of course no limit to the level of information it is possible to attain from all over the world, informing us about how things might develop on the other side of the globe. The point in a Lacanian sense is that we have no way of actually experiencing, learning about the global without the Symbolic. There is a need for language in order to communicate what happens, where we are not present. The global can never be experienced or understood without the Symbolic, without the social translation of the totality.

Thus the notion of global issues, such as climate change, relates to believing more than to actually knowing. The way that the NGO representatives talk about the ideals of changing society, but at the same time express doubts of which exact change is needed and what such change should end up with further illustrates this point (KFEM, 2010, KEEC, 2010). As such there is something deeply humanistic about how the interviewees present their doubts about how to deal with the issues at hand. Had the interviewees 
presented precise visions of how they should carry out their work and what the end goal should be, they would have shown an potentially 'fundamentalist' approach (examples of which can be found within strands of e.g. radical environmentalism, deep ecology and among hardcore climate change 'sceptics' (Schlembach , 2011, Switzer, 2001, Bookchin, 2010, Freudenburg \& Muselli, 2010, )). The point is that, even though individuals rely on abstract ideals as reasons for the work they perform; their beliefs are still beliefs. Had they known for a fact what problems they were addressing and how they would do it, then it would have been possible to claim that they had some kind of perceived hard knowledge.

Žižek argues that a fundamentalist does not believe, he knows, and the interviewees at large, do not seem to be fundamentalists in their approach toward their ideals (Žižek, 2006a: 118). The reasoning by KFEMs representative that something new might be needed in their work to engage the public shows how doubt plays a role. The general frustration among the NGOs, when it comes to choosing strategies and pointing in the right direction, hints how the NGOs rely on a humanistic doubt and belief that what they are doing is right, while they have little actual way of knowing to which degree they are in fact right (KFEM, 2010).

This can not only be identified in the interviewees' relationship with the notion of 'climate change', but also how they try to understand and deal with the public. Across the continuum of different NGOs from both countries the will to pass from belief into a fundamentalist 'knowing', is arguably differing, with more radical and concrete versions of what must be done presented by e.g. the Danish network CJA, compared to the bigger and older organization from both countries. Also the WWF Denmark interviewee again represents a somewhat different take on the work of his NGO. With a style more in line with rhetoric's found within political organizations he expresses doubt of the other organizations' work and methods and argues for a supposedly more 'pragmatic' approach (WWF, 2010). This highlights the differences embedded in the way that the interviewees deal with the continuum of believing in something like 'climate change'.

\section{The big Other of 'Sustainability' and 'Climate Change'}

Having looked into how the beliefs of the NGOs differ from clean cut fundamentalist knowledge, leads us to the question of how these beliefs manifest themselves in distinct 
ways compared to the everyday other of the fellow human being. Lacan use of the notion of a big Other to describe beliefs that go beyond the individual relation between human beings installs a third element that enables structure and direction for the individual. Looking at the qualities of a potential big Other of 'sustainability', and 'climate change', poses the question of what the function of such a big Other is? What does such a concept demand from the subject and what does it in return offer to the ones who manage to apply to such demands? In trying to understand such a Lacanian big Other, through the ideals that the interviewees discuss, it becomes clear that what is present is not a strict, easily read entity, but something more vague, fragmented and postmodern in nature.

The cause or the ideal that drives the different interviewees is not the strict, authoritarian big Other of the old days. It is not an omnipresent father figure, as found in Catholicism and Judaism that dictates, with full authority, what is right and what is wrong (Tamney \& Johnson, 1998: 209). Climate change and environmental challenges are no less omnipresent, with schools, daily life, food, transportation, clothing and consumption at the forefront of the debate between 'believers' and 'non-believers' of 'climate change' and 'sustainability' (Nisbet, 2009). It is found everywhere, but it is at the same time also less instructive, with no direct rules and asymmetry between intentions and impact for the individual citizen (Whitmarsh, 2009).

The early years of the environmental NGOs in both countries and in the environmental movement at large belonged to a different, less fragmented discourse, which identified potential problems (e.g. industrial waste, farmers overusing fertilizers, and areas lacking clean water) and sought for remedies (Rose, 1993, Jamison, 2001). This was to a greater extent a time of addressing tangible problems, while applying pressure to change policies and practices in the hopes of countering environmental hazards (Jamison et al. 1990).

Another characteristic of that time was that the identified tangible problems to a greater degree offered the possibility of finding a potential instigator of the problem. Framing a polluter, either in the form of an individual, a group, an industry or certain distinct actions and practices was often possible. During the 70s in Denmark and the latter part of the 80s and the early 90s in Korea the environmental NGOs presented a strong voice on what could be considered environmentally right or wrong behaviour (Læssøe, 
2007; Kim, 1996). Even though social and political processes in Denmark and Korea that led to these movements were often framed as part of an overall emancipation from structure and hierarchy, it can be argued that there was a link between tangible problems and tangible solutions.

With the advent of a globalized perspective of 'environmental issues', 'climate change' and the notion of 'ecological modernization' things have changed (Lash et.al., 1996, Christoff, 1996, Mol \& Sonnenfeld, 2000). It is now harder to identify 'climate issues' and even 'environmental issues' as isolated tangible changes in a national context. Furthermore the task of identifying an instigator is often nigh on impossible, especially concerning the role of $\mathrm{CO} 2$ emissions in causing 'climate change', which is emitted by all industrialized societies, thus blurring the picture even more. Politically the intangible nature of climate change has often led to collective apathy, following the notion of 'when everybody's responsible - nobody is'. Compared to the earlier focus on tangible problems the task is now, in the words of John Foster, to pursue the mirage of sustainability, with slim chances of identifying a concrete core of the issue (Foster, 2008: 17). The interviews from Korea stress how some, like the interviewee from KEEC Jeju, are still able to identify environmental hazards and put the blame on industrial or financial actors (Jeju KEEC, 2010). In Denmark the direct tangible link to environmental issues might still be evident in some areas, but the interviewees from the NGOs do not stress such links. Instead they emphasize abstract issues linked to global climate change. The issues are now framed as being more serious than ever, something all of the NGOs agree on, but the local consequences and the causal link between action and impact are harder to find.

The consequence is that the big Other of global climate change has little to say in form of concrete guidelines that could be applied in order to feel certain that the right thing is being done - at least on a personal level. The old authoritarian take on pollution as something that could be viewed as a "matter out of its place" (Douglas, 2002: 203) and hence something that should be removed and stashed where it belongs or could be recycled (industrial waste in marshes, chemicals in the ground etc.) is being replaced with a view of environmental changes as stemming from almost anywhere. What is seen 
as unwanted is now so intimately linked with daily life that there is little chance of separating it and doing the right thing.

This does not stop the NGOs from interpreting and translating 'climate change' and 'sustainability' through a large array of vague notions on what constitutes fitting 'climate behaviour'. Living a 'low carbon life', being 'climate friendly' or taking care of the planet is not just a question of spending the weekend walking beaches and collecting unwanted debris. There is a greater commitment involved that goes beyond what can be managed in a few hours every week. The scope of impact is more radical when it is related to notions of 'climate change' and compared to tangible levels of pollution (Ungar, 2000: 297). What is required, according to the IPCC, is change and adaptation at an individual, institutional and societal level, something which can only be described as potentially all permeating and omnipresent (Adger et. al. 2005; Adger et. al. 2009). How this is to be addressed is widely discussed with no easy answers as the root of the environmental problems now lies at the very core of contemporary society.

Even though the concepts of 'climate change' and 'sustainability' in many ways join hands in the perceptions of the interviewees, there is a qualitative difference between the two. 'Climate change' is depicted as a discourse emitting directly from the Real - as something that happens outside the will of mere humans. Even though it is, in a Lacanian perspective clearly something that belongs to the Symbolic social order, the notion still draws on connotations of something that objectively happens, something that is outside of the social, even though it needs the translation from the Real to the Symbolic in order to become understandable for the subject. 'Sustainability' is perhaps more explicitly placed in the Symbolic realm via its direct political connotations and links to notions of 'democracy', 'freedom' and 'equality' (UN, 1987). 'Sustainability' resides in an interlinked web of meaning that draws both on notions embedded in science (sustainable waste management, sustainable energy production etc.) and on notions stemming from the moral argument (inter-generational commitments, the good life, equality etc). It is not only placed in the Symbolic, it is also presented as such by the interviewees, as they make little use of the notion of 'sustainability' as an objective non-negotiable fact (KFEM, 2010, PCA, 2010, Green Asia, 2010). Even though these qualitative differences exist and have an impact on the use of the notions, they are both in a Lacanian sense embedded in the 
Symbolic. The link to the Real of the Global Climate is arguably obvious, but the concept still consist of Symbolic interpretations of a Real, which means that something will always be left out; there will always be a lack. The use of the terms here, as representing the 'big Other' of the NGOs, will involve both 'sustainability' and 'climate change', as the concepts are closely linked in the work of the NGOs. The term sustainability has been developed in light of the term climate change and vice versa, making the dependency of both terms in describing the ideals of the NGOs indispensable. They are linked both in use and in meaning.

It seems that what the big Other of 'climate change' and 'sustainability' does entail is an individual combination of abstinence and enjoyment. On one hand there is a marked concern about for instance the level and type of consumption in many of the Korean and Danish interviews. The interviewee from Centre for Energy Alternative exemplifies this via the organizations' focus on energy reduction: "We use the words 'Energy Alternative', not only 'alternative energy' in this is included, wind, ocean energy etc, but this is just a part of 'energy alternative'. We must focus on overall energy consumption. Energy reduction comes first, [but] energy itself is not the target. We need heating or cooling, not energy in itself."(CEA, 2010) The important thing is not only to push for new forms of energy, but to argue for an overall lowering of the consumption of energy, and if possible a move away from the high levels of use of energy towards different methods of covering our basic needs. In the same vain the representative from CMEJ argues that the organization's first priority is to fight for 'Ecojustice', especially through focus on additives in food and healthy nutrition for children and grownups alike. "The environment means a lot for food and problems for children. There is ecojustice and food justice. There must be a right time, right place, right food for the right children" (CMEJ, 2010). What the existing industrial and societal patterns deliver is not good enough, neither in the concrete form of food, or in the overall structures regarding 'ecojustice'. A part of the mission of the NGOs is thus to refrain from lapsing into existing discourses and instead actively create new ones. In the Danish case this approach is illustrated through the interviewee from DAEA and the discussion of the problems inherent to a 'Garfield solution'. "We are not interested in approaches that just lead to more consumption. We do not need a Garfield solution, where new kinds of diet chocolate 
make it possible for us to eat more of it" (DAEA, 2010). It might be possible to imagine a development that could ensure the same level of welfare which is enjoyed in western countries today with the aid of cheap sustainable energy. If such development would just lead to a further acceleration of global consumption, as it would no longer be touted as harmful, might be fine for some, but not for the interviewee from DAEA. Optimizing and streamlining existing patterns of consumptions and practices are clearly not enough. What is implied is the wish for a change that not only renders existing practices harmless towards the nature, but something more radical that leads to abstinence from the cultural and individual excess.

At the same time there is something else at play. Abstinence is not sufficient. It is not enough to minimize consumption, cut back on excess and limit the level of emitted CO2. While performing these rituals of abstinence, exemplified for instance by WWF's 'turn of the light campaign', it is important to enjoy them at the same time. What the big Other of 'sustainability' dictates is not abstinence from the good life. The ideals and missions of the NGOs does not coincide with a dull, drab future society where everything is regulated and all there is left is the bare necessities for survival. Enjoyment is an intrinsic part of the ideal, of what the big Other offers in return for the hard work to do the right thing. The Hansalim Co-op with its mission to "give organic food and products to consumers, for an open community" (Hansalim, 2010) serves this double purpose. On one hand abstinence is needed, from the regular products found in commercial supermarkets, as they are not alone deemed unhealthy, they also threaten the climate and the environment, but on the other hand the biodynamic products of the Co-op are not reproduced fibres with added vitamins, but depicted as delicious, albeit more expensive, products aimed at "heightening the quality of life" (Hansalim, 2012). Abstinence is thus linked intrinsically with enjoyment. The imminent dangers of climate change and the potential catastrophes that could follow are thus not to only be met by harsh criticisms of the way individuals live and consume, but also linked to the easier, better life that is the way to salvation. 


\section{Objet Petit a and the Cause for Desire}

Following this argumentation is seems that it is not only important to be aware of the shortcomings of living in an industrialized society, or to fight for a change in how society is organized, it is also important to install a higher level of enjoyment into the sustainable life. It is not only a 'simpler life', with less stress put on the 'climate' and 'environment'; it is also a better life, that adds new qualities to the everyday treadmill of post-modernity. Based on this it can be argued that the Symbolic cause for the work of engaging the public is to mitigate the dire consequences of Climate change and environmental challenges. This is the bottom-line of the NGOs; they want to create a future with the same potential as the contemporary. All the same there is an excess. This is enjoyment that is intertwined with abstinence; something which can be desired. This takes shape as visions of a better, more fulfilling life. The question then remains: How a 'sustainable life', with all its inherent rituals of abstinence, can be better than the life of a prosperous hyper consuming Dane or Korean? An answer is hinted by the interviewee from the Danish Climate Movement, as the potential for the public of acquiring a sustainable mindset is discussed. "We try to talk to groups, not only targeting individuals, but also engaging co-op's, and trying to figure out how a group can be sustainable and not only the individual. It is possible to save money and energy, but it is actually more interesting to meet people and socialize around a 'third' thing that might just make more sense: the social" (CMD, 2010). Not only is change needed and eminent, it also brings along the possibility of having a better more authentic life, with a greater level of quality and social interaction. Believing there is a new and better way of performing the social, that there is a method that will infuse life and society with a hitherto lost quality, is a way of understanding the leftover that is not integrated seamlessly into the Symbolic. This is the surplus of the work to mitigate 'climate change', and an important part of the notion of 'sustainability': the vision of a fulfilling coexistence with fellow human beings. Such a surplus, which at the same time returns as the object of desire is in Lacanian psychoanalysis designated objet petit a.

The objet petit a (the first letter of the French word autre, or 'other'), denotes the 'little other', in opposition to the capital 'A' of the big Other. Unlike the big Other, which represents the radical and irreducible alterative, the little other is "the other which isn't another at all, since it is essentially coupled with the ego, in a relationship which is 
always reflexive, interchangeable" (Lacan, 1991: 321). Whereas the big Other, as an agent who brings structure to the social, is part of the Symbolic order, the objet petit a, with its connotations of harmony and fulfilment resides in the Imaginary order. Thus furthermore shows how the Symbolic and Imaginary intersects. The Imaginary is what makes it possible to imagine concepts of uniformity and wholeness, while the Symbolic remains the social arena where such ideas can interpreted in practice into, often with lacklustre results (Evans, 2010: 83).

Lacan conceives objet petit a as the cause for desire, rather than that which desire tends for. This also means that objet petit a is something that can never really be obtained. The subject can circle around the objet petit a, but not quite reach it. This means that the objet petit a can be understood as the leftover, the remainder, when the real is introduced into the Symbolic (Lacan, 2004).

Interpreting the leftover, the enjoyment, that is involved when the NGOs discuss their perceived missions and their ideals of working to engage the public, as the kernel of desire, the objet petit a, emphasize a number of characteristics of this desire. Notions of the possibility of reaching a path to sustainable development, no matter how unlikely it might seem, has the potential of offering a strong image of potential harmony. Even though such images of societal harmony, from the Christian garden of Eden to ideological images like a true communist society, have so far failed to materialize, the urge to invest hope and work into such an ideal is in a Lacanian sense almost inevitable. An ideal like a 'sustainable society' might be dismissed as mere utopia, but as a Lacanian objet petit a, it holds only greater potential insofar that it cannot be reached. As the cause of desire it enables great levels of energy and enjoyment to be linked with a cause that seemingly offers little in the way of a guarantee for acquiring an ideal like a harmonious sustainable society. On the contrary, discussions of 'ecojustice', 'climate justice' and the 'north-south divide' illustrate how citizens in industrialized, developed countries carry the greatest responsibility for the 'climate changes', and if anything radical cuts in our consumption and welfare seem to be an answer to the problems at hand (CJEM, 2010, CJA, 2010). The big Other of 'climate change' and 'sustainability' does, however link this to the objet petit a, the fantasy of a qualitative better harmonious society, and thus enables the subject to escape visions of an eco-fascistic future, and instead combine two 
contradictory terms like 'sustainable' and 'development' in an impossible, but no less important, vision of a utopian balanced society.

Apart from the return to the kernel of desire, to the irreducible unconscious lack, that the Lacanian perspective offers us, there is also a qualitative difference between how this cause of desire translates into ideological takes on the big Other in the two countries. The ideals that are expressed in the two cases differ, insofar that the Danish interviewees present a more consensus driven understanding of their work, while the Koreans stress a more radical approach and the potential of conflict. The ideologies, the vehicles of desire, thus differ slightly. It can be argued, that the Danish outset is embedded in the perception of an already established, albeit arguably still flawed, harmonious model for universal welfare; the so called Scandinavian model of welfare. The emphasis on an evolutionary transition of the Danish society towards a more sustainable position shows how Imaginary notions of wholeness and harmony are already present in perceptions of the existing society (PCA, 2010, DAEA, 2010, WWF, 2010). Such an outset could be seen an easy way to try and include images of the feasibility of a utopian goal like a sustainable society into the Symbolic. The reasoning seems to be based on the understanding that the Danes comparatively are closer to the goal - if not 'almost there'. This of course has little causal correlation with the impact of the Danish individual or society, but opens up for the possibility that the Danes might wear the mask of a 'sustainable' mindset. Such masks makes them consider the needed change less of a contradiction, compared to other regions or countries where the contrast between individual actions, behaviour and the issues of global climate change is more apparent. In short a consensus driven society can, in Lacanian terms, make the inhabitants believe that 'consensus' is actually possible. This does not make the objet petit a any less unapproachable, as the lack will remain and utopias remain utopias, but it does make an assumption of a future society, as a mere positive modulation over the existing one, easier to obtain. The contrast between the big Other of 'climate change' and the petit objet a of social harmony is perceived as being smaller and thus change is believed to be more easily incorporated.

The Korean ideals and the perceived roles of NGOs are a bit more radical than the Danish. The utopian notion of a sustainable society and better social quality that it would enable, as imbued in the objet petit a, is comparable to the Danish. The outset is, 
however, different. With a more conflictual outlook on society and a greater impact of 'climate change' on current daily lives the contrast between the big Other, and the objet petit a, is more visible and self-evident. The Korean NGOs do not have the luxury of believing that things will eventually, due to the order of things, work out fine. Their focus on the cynicism of the large Chaebol industries and various governments, when it comes to exploiting nature and natural resources, is founded in the current scenery and not in history. Large schemes like the Four River Project show how the intent and actions of some of the incumbent politicians and industrial leaders clash directly with their ideals of how 'sustainable development' should progress. The contradictions between perceived human induced changes within the 'environment' and the Symbolic ideology of the big Other of 'climate change' and 'sustainability', in many cases arguably move in opposite directions. This not only makes the impossibility of acquiring the objet petit a more visible, it also feeds the cause, the objet petit a, and permeates the work of the NGOs with the desire caused by the objet petit a. In other words the impossibility of acquiring the ultimate aims of the NGOs makes it possible to uphold these aims. Such a link between the material indispensability of the huge obstacles towards reaching one's goal and an almost counterintuitive growth of the will and desire to overcome these obstacles can also be seen as part of the reason for e.g. CJA's effort to bring in representatives from the global south to the COP15. By inviting people in a dire situation with a closer link to the contradictions of ideals and their lives, it is possible to claim a greater level of 'authenticity', stressing the lack in the ideology of 'sustainability'. In an almost counterintuitive move the lack in the ideals of 'sustainability' and 'climate change' is covered by the introduction of people who is perceived to actually live in the midst of such challenges. This does not remove the lack, but enables a seemingly less abstract link to a perceived 'truth' of the ideals.

In the Korean case there is also a tendency that points in another direction. The Koreans' closer relationship to the contradictions connected to 'sustainability' does of course not hinder their continued daily work in the light of the objet petit a, but it does surface as a potential enabler of radical change. The close proximity of the revolution in the $80 \mathrm{~s}$ and the democratic movement as well as the whole idea of a nation that has jumped from the status of a feudal state to the ragged edge of high-tech development in a 
matter of decades, also spur notions of future possibilities of revolutions, which could be driven by the objet petit a. It seems that in Korea, change is perceived to happen fast, if it happens, while in Denmark change is perceived as more of a sliding evolutionary slope towards 'sustainability'.

\section{What do You Want From Me?}

In conclusion, what does the Lacanian big Other of 'climate change' and 'sustainability', as illustrated through the ideals of the NGOs, want from us? As such the ideals, the cause, of negating 'climate change' and pursuing 'sustainability' represents an otherness, something outside the mere Imaginary, something that adds a sense of meaning and of pursuing a greater cause that reaches beyond the perceived limits of the individual. As shown we are not dealing with the traditional authoritarian big Other, but instead one that opens up for countless of versions of what is the right way to behave and of what climate friendly behaviour really is. This makes it possible to ascribe the big Other with an almost limitless number of desires, with only the guarantee that the subject has no way of positively knowing that what one perceives as the desire of the other, is truly the desire of the other. The lack remains, but also opens up for an ideology of structuring desire through, albeit, vague notions of what is right and what is wrong. The big Other of 'climate change' and 'sustainability' is thus promiscuous, lacking standards of selection, but as a true postmodern ideal facilitates the desire to structure and reshape society.

In a Lacanian psychoanalytic perspective it is important to ask not only what the big Other offers, but also what the big Other wants. What is the desire of the big Other which then again controls our own desire? Put differently: what does the big Other want from us? In effect nothing. The Lacanian question of 'Che Vuoi' or 'what do you want?' is posed by the big Other and at the same time little is offered by the big Other in terms of an answer (Žižek, 1989: 125). If the big Other of 'sustainability' and 'climate change' offers any hints in direction of what the individual wants, it is the notion that only through rejection of the material wealth can the ideals be reached. The harsh answer to the 'Che vuoi' of the big Other could thus be: Nothing! Not only in the sense that as individuals it is extremely hard to make a difference, alter practices and habits, scorn yearly flight travels and high levels of consumption, but also in a more radical sense. Not only do individuals 
in industrialized countries have nothing to offer to mitigate 'climate change', the best would also be if the individual managed to negate itself. To disappear, be unborn or kill itself, in order to circumvent the fact that individuals in the industrialized world could be seen as being more a part of the problem, than anywhere near a part of the solution of the problem. That traumatic kernel of the relationship between the individual and the ideal or big Other of 'climate change', leaves the individual with little ground for hoping that a difference can be made.

This could lead to suspicions that there is nothing to desire for the individual interviewees, but as the interviews show that is far from the case. Exactly the lack of imminent hope for a change for the better as well as the lack of a tangible link between action and impact have the possibility to infuse the work of the individual with energy and the desire to attain the impossible. Exactly the contradiction that engaging the public is per se almost always a fiasco on a large scale reassures that the objet petit a remains intact.

The role of a big Other that offers little and wants nothing is none the less of utmost importance. The reward is the surplus or the leftover that cannot be integrated in the move from the Real of the global climate to the Symbolic big Other of 'sustainability' and 'climate change'. The leftover, the objet petit a, constitutes the cause for a desire that follows the big Other in its all permeating presence. This cause for desire is embedded in the Imaginary order and takes shape of notions of a quest for a better social life that could incorporate the cultural, political, social or economic differences between human beings, even on a global scale. This is, as history shows, very hard to reach, and in a Lacanian sense even impossible to attain, but serves as an important drive in the work to engage the public. This objet petit a can only be formulated on the backdrop of the mix of abstinence and enjoyment that the big Other of 'sustainability' offers. On one hand the scale of the change needed is monumental and drastic, and on the other hand it can only be done if it is linked with the possibility of enjoying such a process.

Understanding the significance of the Why in a Lacanian perspective is thus to understand that the subjects reason for engaging the public is not simply to influence the global climate. Such influence is for the subject, out of reach. The emphasis is to a higher degree on the process of creating meaning through the adaption of the Symbolic big Other of 'sustainability' and 'climate change', and yet again circle the cause of the 
desire, the objet petit a, the social harmony, in an effort to close the gap between the big Other and the other. In other words it can be argued that the effort to mitigate the chosen challenge of a given NGO is not the only or even the primary reason to engage the public. The Lacanian perspective offers the possibility that the primary concern instead is to establish meaning for the individual interviewee through the construction of an ideal of social harmony. 


\subsection{What is the Significance of 'Fields of Learning'?}

The different themes identified in chapter 4.2 Youth, Daily life, Emotional/rational involvement and Conflict/consensus present a varied picture of what is perceived to be most pressing for the individual NGOs. The nuances and differences between the two countries tell us about how the NGOs think of the public as a learning entity. These nuances assist when trying to understand how the future of their work might be formed, and it can even be argued that based on insights into these themes it is possible to try and formulate alternative methods, activities and inspire towards new educational practices. When the nuances are categorized into broad and complexity reducing themes like the ones presented above, they might not present themselves as groundbreaking revelations, but more as interesting points of departure for further analysis and discussion. In a Lacanian perspective the question of the significance of these themes does however remain.

The mere fact that a pattern can be established, and that it seems that several of the involved NGOs return to these patterns suggests that, in a Lacanian psychoanalytic perspective, there might be something more at play. Returning to Johan Asplund's sociological stance (Asplund, 1970), the question remains: What is the function or the significance of attributing a certain field, groups or activity with a special potential for instigating change, popular involvement or 'best practices' in the abstract case of 'climate change'?

One of the most striking features of these themes is not only their particular nature, but the notion that they exist at all as well as overall groupings of interests. That hope remains, in spite of setbacks and misfortune, and that there is a potential for change is envisioned on a daily basis by the interviewees. If the ideals and the big Other of 'climate change' and 'sustainability' manage to establish and nourish a strong drive for change, where change is not always easy to identify, the particular themes express this in a much more tangible way, adding real life heft to the ideals, but also risk. The risk of testing ideals against the backdrop of the Symbolic reality is that it might not work out. This on one hand has the potential to spur further activities, but on the other hand it also has the much more troubling potential to actually work out. A success, a powerful demonstration of what individual subjects can do if they work together of course has the 
potential to bring people together and create momentum. However, it also has the potential to give the individual a glimpse of the impossibility of attaining the objet petit a, a glimpse of the utopian core that reaching the goals of the NGOs really is. This is not to argue that the goals of the very different NGOs are wrong or even unrealistic, but to argue, from a Lacanian point of view for the significance of the unattainable and the importance of the impossible. This is thus not an effort to destabilize the discursive foundation of these themes, to argue that they rest on false perceptions and that they should be thrown aside in order to reach some kind of 'truer' form of insight. Far from that the goal is to try and understand what the roles of these themes are in relation to the desire, to the enjoyment, that is also a part of the work of the environmental NGOs.

\section{Fields of Learning as ideological fantasms}

Slavoj Žižek's understanding of the critique of ideology facilitates a Lacanian take on concrete sociological phenomena like the different themes of the NGOs. Žižek's idea of ideologies as fantasies about the fulfilment of desire, including the stance that ideologies aim at a certain sublime level of existence, entails that the role of ideological fantasms is in fact to make it possible to desire. Ideology not only presents opportunities for desire, it at the same time teaches us how to desire. This is the reason why Žižek does not talk about ideological 'fantasies', but instead of ideological 'fantasms', thereby stressing the psychoanalytic connotations of the term.

Freud's use of the term 'fantasy' was highly influenced by his realization of the fundamentally discursive and imaginative nature of memories of the past, and how such memories are constantly being (re)shaped in accordance with our unconscious desires. Fantasy for Freud came to denote a scene, which is presented to the imagination and stages an unconscious desire (Freud, 1991). Lacan draws on Freud's concept of 'fantasy', e.g. when emphasizing the protective function of the fantasy. For Lacan the fantasme, in French, is a scene that veils the shortcomings of the subject. The fantasm is from a psychoanalytic perspective characterized by an unmoving and fixed quality (Evans, 2010: 59, Lacan, 2006a: 48). In a Lacanian sense the fantasm is a relatively stable way of defending oneself against the lack in the big Other. By adhering to a fantasm, and investing effort and energy in pursuing such a given fantasm, the subject acquires the 
potential for explaining and artificially covering up the lack of the big Other. The role of the particular fantasms is thus, in a Lacanian sense, to make sense, where little sense is present. This is done by explaining why the social is not perfect, and as importantly what could and should be done in order to make it perfect and without any cracks. An interesting feature of the notion of the fantasms is how it makes it possible to go from the singular Lacanian 'desire' into its plural manifestations 'drives'. This makes it possible to distinguish between different fantasms by being aware of how they translate the singular desire into particular ways of establishing a scene that veils the lack in the big Other (Evans, 2010:47).

The different themes can be understood as such particular versions of an overall ideal that motivate the subject. Looking for how the different themes present potentialities and scenarios of change and best practices makes it possible to view them as possible particular ideological fantasms that open up for particular versions of how to integrate the desire of the big Other into the Symbolic. Understanding the themes presented by the NGOs as fantasms, one could argue that for example 'youth' takes on the role of a fantasm in the eyes of the NGOs. When the spontaneous 'candlelight movement' from Korea is put forward as an example of how youth has the potential to display revolutionary traits without direct input from the NGOs, this not only describes something that might happen. It also highlights how the interviewee invests hope in the children of the 'candlelight movement' as vehicles of the desire of the big Other of 'sustainability' and 'climate change' (CMEJ, 2010). In the same vein, the interviewee from DEAE's discussion of the 'special language' of the youth that harbours the potential of change reflects a possible real world potential, but at the same time her personal hope that youth will inevitably nourish a 'sustainable development' (DAEA, 2010). This does not make the two of them wrong, but underlines the notion that there is more at play than the actions of the individual young person; this 'more' is in a Lacanian sense the ideological fantasm, which enables the NGOs' belief in the big Other to be upheld.

In other words fantasms are, in a Lacanian and Žižekian perspective, the anchor of the social, they are not only illusions, but the foundation of the social reality. This social reality, the Symbolic, will always be formed by the lack in the other and as discussed the lack can never, in a Lacanian sense, be truly fulfilled. Something will always 
resist all efforts to bring it into the Symbolic, and a leftover cannot be addressed. Even though there will always be something in a desire that cannot be satisfied, such a lack can be made to appear covered, given an explanation and this is exactly the function of the Žižekian 'ideological fantasm' (Žižek, 1994; Bjerre \& Laustsen, 2006). The ideological fantasm becomes the particular manifestation of an ideology that promises a meaning and contextual purpose for the individual. Žižek's take on ideology and its close relationship with fantasms is very broad and something explicitly linked with all forms of the social. Ideology is, because of its reliance on language staged in the Symbolic order. The ideological fantasms take the shape of the tangible expressions of an overall ideology, something that cannot be escaped as it both enables and influences interactions.

This leads to a focus on the role of the different themes as notions of ideological fantasms, as entities that enable potential and change towards the perceived aim of the big Other of 'sustainable development' and 'climate change'. How is it possible to understand the significance of the different themes as particular manifestations of the ideology of the big Other of 'sustainability' and 'climate change? Such a perspective draws the attention to the function of the Žižekian notion of ideology, and how this meshes with the themes of the NGOs.

\section{The Mirror Stage}

Žižek's notion of ideology not only relies on Lacanian psychoanalysis, it also builds on Louis Althusser's take on Marxist critique of ideology (Žižek, 1989, 1994). Althusser claims that the interesting thing about ideologies, are their ability to sustain a social structure, making the focus of his work reproduction of structure, compared to the classical Marxist focus on production. An important feature of different ideologies, is that they contain something 'eternal' in that they always guides the subjects' relationship to the social, because an ideological semantic must be applied in order to communicate in the social. Ideologies thus become all-permeating and at the same time draw on the need for instalment of something 'eternal' into its structure (Althusser, 1972).

In the cases of the environmental NGOs such an eternal trait could arguably be seen as the potentially all-encompassing impact of notions of 'sustainability' and 'climate change'. Especially the notion of 'climate change', with its connotations of 'hard 
science' and firm 'knowledge' draws on ideas that are linked to something eternal: A truth that exists outside of the subject and presents a possible background for all of the subject's actions. 'Sustainability' also draws on scientific notions, but, perhaps more importantly, also brings in 'human rights', 'democracy' and 'equality' as ideological 'eternal truths' that remain central in the work of the NGOs (United Nations General Assembly, 1987; The Earth Charter Initiative, 2000).

Ideology is thus not something that distorts the reality of society, but something that creates an Imaginary relationship to a social formation, which then makes the presentation of such a reality possible (Althusser, 1972). Althusser is directly inspired by Lacan's concept of Imaginary identification, as it is described by his central notion of the mirror stage (Althusser, 1969). This concept is still widely discussed and criticized by other schools of psychoanalysis, but it remains central, when applying Lacanian psychoanalysis to the social. The mirror stage describes a development in the infant subject and was originally set during an infant's 6th to 18th month, when the child either watched itself in a mirror or sensed itself through the actions and attention of others. Lacan developed the concept of the mirror stage throughout his working life and it became a foundational pillar of his analysis and was understood as a fundamental aspect of the structure of subjectivity. The importance of the historical aspect of the concept, as a specific moment in a child's early life, slowly receded and was replaced by a far-reaching structural emphasis of the notion.

The mirror stage describes the formation of the subject via the process of identification. The child sees its image as a complete entity, which contrasts with uncoordinated perception of a body not yet fully under control. This introduces a level of fragmentation into the subject. The body and the individual are viewed as a whole in the mirror, but the physical experience is of something that is not a whole, something that is different from the mirror image. While the coordinated whole in the mirror is seemingly a complete entity, the experience by the child of its own body and itself is of a still uncoordinated and incomplete entity that cannot be experienced via the human senses. The eyes only offer a restricted point of field of view, the limps do not always follow orders, the body sends signals that are hard to explain etc. (Lacan, 2006b, Lacan, 2004: 227, Webster, 1994) 
The argument of the concept of the mirror stage is basically that the subject's perception of itself is the product of a misunderstanding and the site where the subject becomes alienated from itself (Lacan, 2004, Lacan, 2006b, Evans, 2010). This is not only a foundational aspect of Lacanian psychoanalysis and the reason for the never fulfilled lack; it is also, according to Althusser and Žižek, an important part of the nature of ideology (Althusser, 1969, Žižek, 1989).

Althusser argues that the Imaginary identification with the subject in the mirror blinds the subject for the importance of the constitutive character of the social or the Symbolic surrounding it. Emphasizing the structural importance of the Imaginary identification through the mirror stage opens up for a situation where ideologies attain a naturalizing trait. Ideologies have the ability to go beyond perceptions of them as the social constructs they are, and act as truisms that exist outside the subject. This holds the potential that ideologies are not seen as a direct part of the individual whole of the subject, but something that is linked to a perceived Real (Althusser, 1972).

Žižek adds to this that not only are ideologies perceived as something outside of the individual, they at the same time automatically fall short of addressing the social as the subject experiences it. There is always something amiss in a Žižekian perspective, as the subject not only becomes alienated trough the wholeness of the mirror image, but also by the lack that the image also purveys. Even the image is not whole, there is always something missing there as well. When you see your face, your neck is hidden etc. This translates into a situation where the subject not only remains alien to itself, but also where ideology will, in its attempt to be natural, remains somewhat alien. Žižek sees this as one of the most important characteristics of ideology and why it always to some degree fails to address the life of the subject:

"The status of the subject as such is hysterical: the subject does always maintain a minimal of 'inner distance' towards the apparatuses and rituals in which ideology acquires material existence - his attitude towards this externality is always 'I am not that' (my true self does not hinge on this stupid mechanism); Ideological identification is always, as it were, an identification with fingers crossed" (Žižek, 1996: 165-166). 
This entails that the subject retains a notion of a truer more complete core of itself that exists prior to the Symbolic, that exists outside of what the social and the society wants from it. Žižek argues that the idea that it is possible to be totally embedded in ideology is impossible, exactly because ideology always leaves a rest, something that cannot be addressed. But ideology, as the subject it tries to address, is already alien to itself. At the same time the individual acknowledges and takes the ideologies for granted, but still believes that something outside of this exists, as the lack remains and the identification with oneself and the social can only be partially successful (Žižek, 2008a: 104, Žižek, 2008b: 1xiii). This not only means that misunderstandings remain an inexhaustible core of the individual, but also stress the futility of escaping ideologies, as they make a common denominator possible, where there is none, and thus cover up the lack. This makes the role of the ideological fantasms even more important as they remain the glue that binds society together, in the way that they create relations to a common desired object (Žižek, 2006a: 16).

In this perspective it can be argued that for the NGOs the learning fields take the shape of areas of potential, that not only have the possible promise of being catalysts for change and learning, but also have the unconscious potential to be a defence mechanisms towards the lack in the big Other of 'sustainability' and 'climate change'. What the big Other of 'climate change' and 'sustainability' lacks in direct demands or applicable guidelines, can be found through the different themes, or fantasms, as expressed in the interviews. This is not limited by the abstract nature of the fantasms. The themes only emerge as more tangible exactly because the potential they embody is inherent to the even more abstract ideological fantasms. The themes discussed by the NGOs might to a certain extend be abstract and hard to grasp, but they are still easier to apply in the social than isolated concepts of 'sustainability' and 'climate change'. While the different themes of course do overlap, they do not do so perfectly, making it possible to ascribe different levels of significance to what is perceived to happen 'in the field' and the construction of the fantasms around these fields.

The ideological fantasms in that respect enable the desire of the big Other, and as a consequence the desire of the NGOs. This process is of course linked with the actual human beings and settings where the potential is perceived to be found, but the 
ideological fantasms of the themes have also acquired a life of their own that makes them able to survive without a constant reflection on the development within the themes. The fantasms are able to reproduce ideology, while retaining a deep involvement in the different themes. There might be continuous pitfalls, missed opportunities and lack of support, but the fantasm remains strong as it represents an outlet for the ideology of the big Other, and presents and facilitates concrete and abstract potential that covers up the lack in the big Other.

\section{The NGOs and the Constant Risk of False Activity}

When viewing the activities that are part of the NGOs work to address the four themes of Youth, Daily life, sentimentalism/rationalism and conflict/consensus as vehicles of desire, it is interesting to delve into the practical function of these as part of the covering up of the lack of the big Other. This also draws on the arguments of chapter 4.3 that are related to the different notions of participation found across the NGOs.

A characteristic that is obvious among the themes is their focus on the importance of interactivity or participation. As discussed in chapter 4.3 this can be viewed from different angles, drawing on different concepts of learning, related to the process of participation and the aim of it. This intersects with perspectives of Lacanian psychoanalysis and a Žižekian critique of ideologies' focus on interactivity or participation, as they attempt to address the same object, the idea of engaging a cause via other subjects, through another set of eyes. This is not to argue that 'participation' and variations of 'interactivity' cover the exact same set of notions, norms, ideals or activities, nor is it an attempt to pigeonhole any of the described approaches to participation as inherently better or worse than others. On the contrary, the effort is to add a Lacanian perspective on the unconscious function or significance to the arguably ideal notions of learning as participation. Returning to the cases and the actions the interviewees describe in relation to notions of participation and interaction also means that neither of the described approaches to participation can be truly isolated, as the notions inevitably get intertangled in the efforts of the NGOs.

The interviewees all stress the importance of interaction or participation. As an example several of the NGOs stress that in order for the youth to engage in the 
challenges at hand, it is important to develop their sense of being part of something bigger, part of a group that can change things (WWF, 2010; PCA, 2010; CJA, 2010; KFEM, 2010; CMEJ, 2010). This comes alight in the description of the candlelight movement, where the spontaneous actions became remarkable in the sense that they summoned large numbers of people representing the voice of a generation, and not only the voice of individuals (CEA, 2010; Agenda 21, 2010). Also the work of Green Asia's volunteers in Mongolia is seen as infused with the importance of acting in unison and together accomplishing what individuals have little chance of doing.

When the discussion turns to the hardship of daily life and the many contradictions that are part of such everyday dealings in the life of Danish and Korean citizens, the importance of interactivity also becomes central. DAEA's efforts to bring together people and discuss how their houses and practices could be altered in order to become more 'climate friendly' demonstrate this (DAEA, 2010). The utilization of the traditional 'Saram bam' meetings by the Koreans CEA also illustrates how the themes draw on the importance of developing new notions together of participating in something and thereby reaching new understandings through discussions with others. This characteristic extends to the discussions of conflict by the Koreans and the emphasis on deliberative dialogue and consensus by the Danes in chapter 4 . The efforts of the NGOs do, across the themes, draw on the inherent possibilities of learning together and the importance of interaction and participation. Not all of the NGOs aim directly at participation as social learning, but the concept of learning though a community in interaction with others is still prevalent by all of the NGOs.

Lacan suggests a diversified reading of this reliance on interactivity. Not only is an 'Other' established through a group or taking part in certain activities, this Other, in the form of a group, real, virtual or make-believe, can perform in several important roles for the individual subject. It can be a vehicle for reaching goals through interactivity, but it can also act instead of the subject. It is possible for the subject to use the Other and make it experience the innermost and spontaneous feelings and attitudes of the subject, instead of the subject (Lacan, 2004). Žižek uses the example of hired in 'weepers' (women hired to cry at funerals see Pastina et al., 2003) to illustrate this point: "they can perform the spectacle of mourning for the relatives of the deceased, who can 
devote their time to more profitable endeavours (like dividing the inheritance)" (Žižek, 2006a: 23). The feelings attached to the activity are still upheld, but the subject is relieved from actually having to live it out. Another less exotic example is the use of canned laughter in TV-shows. Even after a hard day's work, the canned laughter does the laughing for the subject who watches, no matter if he or she joins in. The Other actively lives out our joys and sorrows, thus relieving us from actively engaging in the activities (Žižek, 2003).

This perspective suggests that the often used notion of interactivity, and in turn also participation should be supplemented with its uncanny double 'interpassivity' (Pfaller, 2003). This notion describes the obverse of interacting with the object (instead of just passively following the show) as the situation in which the object itself takes from the subject, its own passivity, so that it is the object itself which enjoys the activity instead of the subject, relieving the subject of the duty to enjoy itself (Žižek, 2006a). This is not to say that the many activities that the NGOs instigate take the power from the public to participate in activities that bring them enjoyment. It is to focus on the double sided nature of the NGOs ascribing the themes' special characteristics, that in effect opens up for a possibility that leaves the NGOs or their audience interpassive.

An example of this could be the roots of the candlelight movement as an internet based virtual community. "They used mobile phone, internet, but wanted an offline demonstration. They took their interest and motivation from the contacts they made online and made it into something that happened in the streets of Korea (CEA, 2010). The move from a virtual community, towards a real world demonstration can be seen as the fulfilment of the great hopes invested in notions like a social 'Web 2.0'. This draws on the idea that with the advent of the internet and especially with social media like Facebook, the passive consumption of information, text or images is over. It is no longer sufficient just to stare at the screen; it has become possible to interact with it, entering into a dialogic relationship with it and through it. This can be as part of virtual communities, interactive plots, forums or other interest groups (O'Reilly \& Battelle, 2009). The democratic potential of this has received a surge of interest, especially after the revolutionary activities in northern Africa during 2011, which in Egypt affectionately was dubbed the Facebook revolution (Hauslohner, 2011). 
The advent of COP15 also spurred masses of activities driven by different kinds of interactive, social media, with WWF Denmark, PCA and CJA spending a lot of energy and effort on trying to instigate activities via social virtual platforms (Holliman, 2012, WWF, 2010, PCA, 2010, CJA, 2010). The democratic potential of the web might still be unclear, but features such as the possibility of giving the chance for a large majority of people to break out of the role of the passive observer following a spectacle by others, and to participate not only actively in the spectacle, but also in making the rules of the spectacle (Breindl \& Francq, 2008).

Such notions of the potential of interactivity does, however, pose the question of the role of the opposite of this perceived activity; the interpassivity. The Korean Centre for Energy Alternative did not instigate and was not a direct part of the candlelight movement as the perceived spontaneous qualities of the youth and children led to them pushing the headlines, and acting instead of the NGOs. The NGO staffs are involved in the overall case, trying to push for interactivity, but in some cases the belief that the children, the youth, or the challenges of the daily life act instead of the NGOs lead to a situation, where none might act, or only act superficially.

This interpassivity is the opposite of Hegel's notion of List der Vernunft (cunning of reason), where the subject is active through the other (Taylor, 1999). The subject can remain passive, sitting comfortably in the background, while the Other does the work. Instead of instigating mass demonstrations the children do it on behalf of the NGOs or the individual NGO staff members, instead of changing behaviour the 'challenges of daily life' do it, instead of having an emotional link with nature the members establish it, and instead of being part of a radical shift in power, the 'conflict' or the 'revolution' will fix it.

The subject achieves its goal by way of interposing another object, the fantasm, between itself and the object of desire. The possibility of course exists that the activities that the fantasms take care of succeed to some level; in such circumstances the subject has arguably remained active through Others. This is however not the most pressing danger, instead chances are that nothing will happen, that the activities that the subjects see as possible though the fantasms never materialize or when they do will draw no consequence and lack impact. This would be a situation where the subject would be 
passive through the other: the subject would concede to the other the passive aspect (enjoying) of the subject's experience, while the subject could remain actively engaged (working in a proper organization, doing international work, going to meetings etc.).

This brings forth another take on the notion of interpassivity, namely the idea of 'false activity'. The idea that it is not only possible to act in order to change something, it is also possible to act in order to prevent something from happening, so that nothing will change. In Lacanian psychoanalysis this is the typical strategy of the obsessional neurotic: he is frantically active in order to prevent the real thing from happening. In psychoanalytic treatment, obsessional neurotics talk constantly, overflowing the analyst with anecdotes, dreams, insights: their incessant activity is sustained by the underlying fear that, if they stop talking for a moment, the analyst will ask them the question that truly matters - in other words, they talk in order to keep the analyst immobile (Evans, 2010).

Some traits of this behaviour could arguable be found among the wealth of activities that were part of the COP15 summit. Not only did Copenhagen overflow with events, activities, speeches, marches, parades, demonstrations and frantic levels of action that made it almost impossible to get a coherent picture of all the different things going on, the city also returned to normal afterwards, with both a deep felt sorrow that so little had changed, but perhaps also a sigh of relief as the comfortable life of the Danes could go on as usual (Haug \& Berkhout, 2010; Black, 2010). Activities for the sake of the activity itself, with little more impact than a short episode of general entertainment and attention for the organization or individual that hosted the activity, is as such a returning criticism of the representative from Climate Justice Action (CJA, 2010). This is especially aimed at corporations, who "greenwash, but in reality do nothing and want nothing to happen" (CJA, 2010) as the interviewee argues. The 'Hopenhagen' event at the city square, as organized by the Copenhagen Municipality, is an example of what the interviewee from CJA aims at: "The City Centre was horrible during COP15. All over the place you found companies with little direct interest in sustainability or climate change, but instead with a strong focus on how to make money and position themselves. You also had companies and people sponsoring events, with their names all over the place, but with little actual 
happening at these events, except uninhibited self-promotion. 'Hopenhagen' was horrible in that aspect” (CJA, 2010).

Such 'false activity' does, however, still require an unconscious urge to secure status quo and a lack of wanting to push any development. This could arguably be identified in some of the participating organizations and corporation, and the unconscious drive for the return of business as usual is open to question (Anshelm \& Hansson 2010).

What is arguably more evident among the NGOs and their perceived audience is, however, not the direct danger of false activity, or even passivity, but 'pseudo-activity', the urge to be active and to participate, without accomplishing much. The host of activities during COP15 was not just seemingly endless in their own account, but also quite well attended by a swarm of interested groups and individuals (Black, 2010). People from all over the country, and from all over the world took part in the activities organized by the NGOs interviewed as well as the wealth of other involved organizations, authorities and individuals. Apparently people wanted to intervene, attempting to 'do something', which resulted in continuous debates, forums, discussions, presentations and so on. This is different from 'false activity' in that there might have been pretensions about changing something, doing something, grasping the moment and pushing it in the right dimension. Again the interviewee fro, CJA was painfully aware that this seemed to be the big risk of COP15 and the largest continuous event ClimateForum09. "There might have been a lot of 'summit-hoppers' who go from one summit to another. (...) Many people who already live here came just to shop some 'climate conscience', for them eco-burgers might be cool, but only if they come at half price" (CJA, 2010). The interviewee hints the dangers of such pseudo-activity, where everybody engage, but little come of it, as a real possibility during events like COP15.

Participation comes in many guises, and not all aspects of ideal notions of learning as participation is covered within such a Lacanian and Žižekian understanding of 'interactivity', 'interpassivity', 'false activity' or 'pseudo-activity', but the concepts do enable an understanding of the unconscious function of these crosscutting aspects of the ideological fantasms of the themes. They do not only act as direct realizations of potential for the subject, but also as a way of relating to the big Other, through particular fantasms. This does not necessarily have an impact on the everyday actions of people, who are seen 
as part of the youth, ingrained in the contradictions of daily life, possessing the potential to engage emotionally with nature, or engage in conflictual practices, but relates to the perceptions of these themes by the interviewees.

By applying such a perspective on activities and participation one does, however, run the risk of only seeing failed attempts at engaging the public, where all perception and ideals simply hide the backside of impossible ideals and functions to cover the impact of this impossibility. This is a fair critique and one that both Lacan and Žižek sustains, as very little in their efforts seem to point at the possibility of positive change, but instead always hints the already realized failure of the subject's efforts to understand and change its situation. This of course requires certain levels of caution as there is no overarching reason to dismiss the work of the NGOs as entirely embedded in notions of 'interpassivity', 'false activities' or 'pseudo-activities'.

In a return to Lacan it is possible to say that also these notions fail to address the full Real nature of what is going on, as they remain Symbolic efforts to try and describe a situation where the lack will remain. Something always escapes the effort to draw it into the Symbolic and is thus missed in the different attempts to understand what is going on. The rhizometric structure, as described earlier, is thus not only a picture of ways to organize a loose network, but also resembles the impossibility of covering all aspects of a subject. Just as the unconscious, according to Lacan, has the structure of fiction, this fiction always leaves something open, as something does not quite fit into the structure and pop up in different places. Žižek's own advice on how to avoid the snares of the different forms of activity is thus to try and escape it altogether: "... the truly difficult thing is to step back and to withdraw from it. Those in power often prefer even a critical participation to silence - just to engage us in a dialogue, to make it sure that our ominous passivity is broken. Against such an interpassive mode in which we are active all the time to make sure that nothing will really change, the first truly critical step is to withdraw into passivity and to refuse to participate. This first step clears the ground for a true activity, for an act that will effectively change the coordinates of the constellation" (Žižek, 2006a: 26-27).

Withdrawal as a way of getting closer to 'interactivity' and 'participation' that would lead to change, might not be what the interviewees want from their audience. It 
can still be argued that the frustration and hardship of recruiting new members, the scramble to instigate activities, and the possibility that these activities lead to nothing that reaches beyond the activity in itself illustrates the constant risk of interpassivity. The wide range of activities that the NGOs work hard to establish draw on very different notions of what is considered the right setting, of where some kind of best or promising practice might develop and how people should get involved. An understanding of how these fantasms might lead to activities that on their own have little other impact than preserving the existing, and why this might not be unwanted, can be drawn from a Lacanian perspective. This does not necessarily entail perceptions of the events as unsuccessful, as the fantasms are established as an Other with its own kind of logics and aims, but it does disclose part of the psychoanalytic function of these fantasms: they enable both interactivity and interpassivity, as a way of shielding the lack of the big Other from the overall perceived failure of something like the COP15.

At the same time the fantasms' inherent risk of interpassivity reassures that the cause of the desire, the petit objet a, remains circumvented. If true participation or genuine interactivity (however that might look), would be the normal state of things, the danger would persist, in a Lacanian perspective, that the impossibility of objet petit a would be at risk, and thus the entire structure of desire that enables the subject to interact and enjoy. The themes, understood as fantasms, do however ensure that the big Other of 'climate change' and 'sustainability' and its lack remains through the ideological promises of enjoyment and potential, which are interlinked with the fantasms. As such the importance of the fantasms, the themes, is not only their potential for establishing promising practices or best practices, but also exactly the opposite. Their strength is that success through them is so abstract and ultimately unlikely that they ensure the upholding of the possibility of desiring a better world. They cover the lack of the big Other: The missing answer to the big Other's Che vuoi - what do you want from me - what do you desire from me? Insisting that some themes or fields holds special potential for learning, change or emancipation, thus helps to translate the ideals linked to 'sustainability' and 'climate change' into more tangible approaches. This on one hand offers the possibility of working with the abstract aims of the ideals in more concrete term and linking them to a known context. On the Other hand it also establishes a situation where the exact opposite 
can happen. The ideals can remain intact in spite of scores of interpassivity with little outcome outside of the context of a given activity. This enables a situation where the ideals are both linked to a context and de-linked in case of failure. The meaning making processes are thus not harmed by negative results of engaging a theme or a field, but actually thrive on it. Continuous frustrations and lack of success can in this light arguably also be understood as a positive thing as it facilitates a situation where it is possible to continue the work of the NGO instead of retracting and asking whether or not a chosen approach makes any sense.

\section{The Public as the Subject Supposed to Know}

Discussing different notions of activity leads to the question of the overall role of the public and the significance of believing that the public can actually learn anything and in the end change. What is invested in a notion of the public as a learning entity, and on what foundation of knowledge does the public build? Projecting feelings, hopes, attitudes, and desires onto some figure of the Other, as illustrated through the themes or the ideological fantasms of the NGOs, is a mechanism that is at the very core of Lacan's notion of the big Other. Lacan used the notion of the 'subject supposed to know' to designate this displacement of the subject's knowledge onto another. This does not mean that there actually exists a subject that knows, on the contrary the point is that knowledge cannot be located in any particular subject but, is, in fact, intersubjective (Evans, 2010). In clinical Lacanian psychoanalysis this is a description of the relationship between the patient and the analyst. The term 'subject supposed to know' does not designate the analyst himself, but a function which the analyst may come to embody. He embodies a certainty of the patient's unconscious desire. For Lacan, this strange transposition of what is already known in the unconscious of the subject onto the figure of the analyst is at the core of the possibility of a treatment. It is only possible to arrive at the unconscious meanings of symptoms if the subject presupposes that the analyst already knows their meaning (Žižek, 2006b).

The NGOs in this study are, however, not in clinical psychoanalysis, and while it might be possible to claim that the NGOs rely on expert bodies like the UN Intergovernmental Panel on Climate Change as 'subjects supposed to know', that is 
perhaps not the most interesting point to be drawn from a sociological application of the notion of a 'subject supposed to know'. Lacan also stresses how a reverse mechanism is part of the concept of the 'subject supposed to know'. Not only does the patient suppose that the analyst has a special insight and knows about hers/his desires, the same can be said about the analyst's perception of the patient. The analyst believes and supposes that the patient has an insight into what it is all about, and that this will ultimately be revealed through the common work of the analyst and the patient.

This reversal makes it possible to view the NGOs perception of the public, or at least of the parts of the public represented by the ideological fantasms as having the potential of expressing such a 'subject supposed to know'. This can be exemplified with the representative from DAEA's discussion of the 'special language' that the youth posses, which has the potential to instigate change (DAEA, 2010). The discussions of the contradictions in the daily life of both Koreans and Danes, and how the public, especially in the Danish case, is assumed to know what could or should be done, also relates to the idea that the NGOs identify parts of the public as, not only, learning entities, but also as 'subjects supposed to know', who already have some kind access to the truth. Notions of best practices and promising practices could be seen as part of the process of supposing that amidst the different themes, the ideological fantasms, there is a potential for such exemplary practices to develop. There is already a supposed level of knowledge and insight among the public, an inherent capability of actually choosing the right path towards a more sustainable development. This has a twofold consequence. An investment of hope and perceived knowledge into the public makes it possible to engage it as already embodying an emancipatory potential. Common sense imbues the public with a notion of what is right or wrong. The backside of this is that while a common sense might an omnipresent, it has so far not aligned itself with the hopes and aims of the NGOs. This is not to say that the hope is in vain, but that a perceived level of almost spontaneous knowledge among the public also makes it possible for the NGOs to cover an arguably frustrating reality and partially withdraw to a more comfortable situation of believing that change inevitable will rise from the public.

Another point that can be drawn from the concept of the 'subject supposed to know' is that efforts to create new content can be seen as an illusory return to a past or 
inherent truth. Ascribing the themes or the public with potential for change and an imminent level of knowledge, in a Lacanian perspective entails that such supposed subjects in the know has access to an existing truth that needs to be released. The Jeju-Do KEEC and their activities of hugging trees and naming flowers in an effort to build an emotional relationship can be seen as such an expression. Not only does something new happen when such a perceived emotional relationship comes into existence, it is also a return to pre-existing perception of a special bond between nature and human beings that can be 'activated' through the work of the NGO. The Danish take on this is less driven by direct focus on emotional between concrete parts of nature, but the mechanism remains the same. When WWF Denmark "speaks to the stomach" of the public in an effort to move from "a more rational focus to a more emotional focus" (WWF, 2010) it might look like a neat trick to con the public into responding to the activities of the NGO, enabling a later focus on the 'rational kernel' of the topic at hand. At the same time, however, the public is still ascribed with the potential to be moved by, not only the highly abstract issue, but by how it intersects with already existing knowledge of what is right and what is wrong. This does still not entail that such an illusionary 'subject supposed to know' actually exists, but in the work of the NGOs, the public via the themes or the ideological fantasms, are supposed to already have a predetermined link to a 'truth' existing within the field.

This 'truth' can be understood as the same truth that the big Other possesses and which, linked with the objet petit a, makes it possible for the NGOs to install an illusionary concept of "Sustainable Development' and (the combating of) 'climate change' as inherently good concepts that bind together their own work and the public as a potentially eager learning entity or subject. An interesting example of this imminent return to a supposed predefined truth is the Korean emphasis on a more conflictual outlook with strong reminiscences of the revolutionary democratic movement from the late $80 \mathrm{~s}$. As several of the interviewees either actively took part in the movement or supported it the link is quite strong and the core of the larger Korean NGOs is made up of former members of the democratic movement (Kim, 1996, Ahn \& Lee, 2005). Almost all of the interviewees express criticism of the current Korean government, and the overall direction of the development of the Korean society, and the hope for a return to the values that 
guided the democratic movement is briefly touched upon by interviewees from Jeju KEEC, Green Asia, and Agenda21 Korea (Jeju KEEC 2010; Green Asia, 2010; Agenda21 Korea, 2010). It can be argued that what is missed in such a perspective on the inherent qualities of a return to a supposed shared history is how this 'return' constitutes the very object to which it returns: in the very act of returning to something, it is invented.

Such an emphasis on a return to a 'truth' that is imminent in select parts of the public and historically contingent also raises its head in the Danish context in the form of a broad investment in the notion of 'folkeoplysning'. Even though the term is used to describe very different approaches it still carries the weight of both an ideal perspective on how to enlighten the public, which is very much situated in a historical notion of when and how Denmark as it looks today took shape, and a contemporary use of the term that opens up for a vast variety of connoted understandings (Korsgaard, 2002). In such a context the emphasis is not so much on that the 'subject supposed to know' through the fantasms should create something entirely new, but instead on how the subject could re-discover a kind of truth already embedded in the very fabric of the Symbolic notion of 'folkeoplysning': the individual has the inherent potential to do the right thing and already knows it. The direct push for something new to develop is thus, in a Lacanian perspective, often linked to a move towards an already existing illusory kernel of truth, no matter its actual existence or not. This does not mean that something radically new cannot come into existence; it merely means that it will often be sought out under the illusion that it already exists and merely needs disclosing (Evans, 2010: 152)

The earlier discussion of the relationship between 'knowledge' and 'belief' can also be applied to this discussion. According to such a distinction it can be argued that there is not only an unconscious drive to identify the 'subject supposed to know' for the NGOs, but possibly also to identify a 'subject supposed to believe'. Reviving the argument of the impossibility of gaining 'knowledge' about the Real, as it is situated outside the language and thus requires to be translated into something that can be understood via the Symbolic, it is perhaps even more important to look for subjects that are supposed to actually believe in the case. When Danish NGOs bring in representatives from the global south to the COP15 activities, or when the volunteers and students from Korea go to Mongolia in order to work together with the locals in order to mitigate 
desertification, it can be argued that what is looked for is not only someone who knows, but more importantly someone who actually believes. According to Žižek the logical next step in trying to identify such a true believer would be to confront individuals with nature of their beliefs, and arguably there would still be traces of doubt left (Žižek, 2006a: 29). Is the work that the NGOs carry out really helping? Is it possible to combine sustainability and development and still try to save the place where the supposed 'subject to believe' originates from? In an uncanny way, some beliefs always seem to function at a distance: in order for the belief to function (e.g. what we are doing is both right and helping the climate), there has to be some ultimate guarantor of it, some true believer, yet this guarantor is often deferred, displaced, and not present in persona. The people whose livelihood is challenged by 'climate change' are often found on the other side of the planet and in completely different positions, especially in the Danish case. How, then, is belief possible? How is this vicious cycle of deferred belief cut short? The point is that for the belief to be operative, the subject who directly believes needs not to exist at all: it is enough precisely to presuppose his existence, to believe in it, either in the guise of the mythological founding figure who is not part of our reality (the climate refugee), or in the guise of the impersonal 'one' ('one believes...') (Žižek, 2006a: 30). That the NGOs views the public as a entity that embodies a potential for change again demonstrates the double sided nature of such an investment in the notion of the public. On one hand the perception of the public maintain a focus on the possibility of change, on the other hand the intangible and diffuse nature of the 'public' ensures that a realization of the impossibility of reaching the 'public' is hold at bay.

This is not to argue that no one believes in the changes that threaten their own life and family, but to argue that for the individual interviewee in this case arguably living in relative safety from the challenges that meet inhabitants of Tuvalu or the deserts of Mongolia, there is still a need to embed a belief in what they are doing. Despite the continuous frustrations connected with their work aimed at the public their belief is substituted through a supposed other subject who actually believes in the big Other of 'climate change' and 'sustainability, no matter whether such a subject exists or not. 


\section{The Fall of 'Sustainability' and 'Climate Change'}

Analyzing the desires invested in the work of the NGOs from a Lacanian and Žižekian perspective emphasizes the importance of the underside of the apparent work to engage the public as a learning entity. There is more at play than a simple will to inform the public. Through the activities aimed at the public meaning is constructed that enables desire to be harnessed and directed towards the socially constructed big Other of 'sustainability' and 'climate change'. This in itself, from a Lacanian perspective is not something that should be viewed as a problem, as it simply renders mechanisms possible that will always find an outlet: The need for an identification with an Other that enables desire to exist at the first hand. What can be the target of discussion or even critique is how the activities for the NGOs unleash a certain level of frustration, by the lack of progress, political or popular support etc. while the NGOs at the same time continue to engage in patterns of activities that, in their own perception, often fail to reach their audience or instigate the desired change (WWF, 2010, PCA, 2010, KFEM, 2010, CMEJ, 2010). The aim of Lacanian psychoanalysis is to a large extent to identify the ways in which desire operates and identify which Symbolic structures that it clings to, but also to offer the possibility of traversing the fantasms and question individual practices and activities.

The ideological fantasms of the four themes and the focus on participation entails a double understanding of their roles. On one hand the fantasms represent a perceived idea of fulfilled desire, as fields that harbours the potential for establishing best practices and where it is possible to circle the objet petit a of the big Other of 'sustainability' and 'climate change'. On the other hand the fields also represent obstacles for this fulfilment of the desire. If it was possible to convince the youth to tag along, there might be a completely different development? If just the contradictions inherent to daily life could be overcome, the normal family could sustain an environmentally sound lifestyle, and if an emotional link could be established between the public and the environment the rational choices of a sustainable choice would follow. These two characteristics of the function of the fantasms leave the question of how to engage in these dilemmas without being stuck in the same processes that both uphold a certain sense of 
meaning, but also arguably works to reproduce patterns that bring about a great level of frustration and possibly fails to instigate change.

Lacan developed a concept of 'the end of analysis' as an effort to try and answer this question and draw out more from the psychoanalytical process than an awareness of how individuals fool themselves in order to avoid facing the lack of the big Other and the traumatic Real of daily life. It is still important to be aware that the there is a distinction between the aim of psychoanalysis, which is not the 'end of analysis', but for the patient to articulate the truth about his or her desire. End of analysis thus practically describe the point at which it becomes possible for the subject to change position and accepts the fall of the big Other. This not only involves a repositioning of the big Other, but also that the 'subject supposed to know' as part of the big Other is accepted as not knowing. While this concept has been developed on the basis of clinical psychoanalysis, Žižek argues that it is possible to apply it to the social in an effort to change the discursive settings (Žižek, 2006b).

The role of Žižek's critique of ideology is to enable a process where it is possible to traverse the fantasm, not to push it aside, but understand what it does for the subject and thus render it less powerful. The point is to understand that some of the most adamant cultural and personal perceptions are projections of the wish for the fulfilment of desire onto a specific object. This fantasm can both be something that enables or blocks the fulfilment of desire, but in the end serves as a vehicle for desire. To identify with one's own symptom would thus mean to discover one's own perceptions and logic in the image of the Other. The question of the Other is thus returned to the subject, which now has to develop new ways of enabling desire. This is the meaning of the idea of the fall of the big Other: the abandonment of the perception of an unfathomable context, which the Other wants to sustain, thereby defining the role of the subject. The end of analysis is not the disappearance of a symptom, nor the cure of an underlying problem, since analysis is not essentially a problem solving process, but still a search for truth and truth is, in a Lacanian perspective, not always beneficial.

The question is whether it is possible to traverse the fantasms, to move through the ideological ties to the socially constructed big Other and thus acquire a new perspective on practices and activities that act as vehicles of desire? Neither Lacan nor 
Žižek harbours great hope in the notion of changing something for the better, as the new always manifests itself as different efforts to cover up the same irreducible lack. The lack cannot be overcome, but the way it is covered and explained can alter and possible in a more productive direction. Again it seems possible to turn Lacan's teachings against his own concept of psychoanalysis. Just as the Symbolic will always fail in its effort to describe the Real, so will Lacan's concepts always fail to address what is truly going on and how the social develops. With his slogan Les non-dupes errent, this is taken into consideration as the phrase seems to propose that only a fool is not fooled, so we might as well be the lesser fool and believe in the words of Lacan. While this does enable interesting discussions of the significance of non-formal ESD, fantasms and ideology, a freer interpretation might be what is needed in order to establish how these insights could be applied to the cases at hand, with the intention of actually moving into a position where it is possible to return something to the practitioners in the field.

The next and concluding section of the appliance of Lacanian psychoanalysis and Žižekian critique of ideology is an effort to take the points that have been discussed so far and try to speculate how the field of non-formal ESD can be strengthened by this focus. 'Speculation' should not be understood as a return to pre-critical philosophy and a dogmatic belief in the powers of pure reason. Instead it is an effort to emphasize the limitations of the critical and linguistic focus of the applied theoretical perspective and question how the field of non-formal ESD could benefit from this perspective (Bryant et al. 2011: 3).

This will be done, not by suggesting that Žižekian withdrawal is the only proper way to act, but to argue that by focusing on, not only the rare examples of possible 'best practice' and 'promising practice', but also on the more common, but less discussed 'bad practice', it is possible to understand what makes the interviewees tick and become critical friends that not only criticize, but also acknowledge and support their hard and impressing work with non-formal ESD. 


\subsection{The Importance of Bad Practice and Possibilities of Traversing the Fantasm}

Taking the abstract theoretical arguments of Lacan and Žižek and applying them to a practice related settings does not happen without a certain amount of jumping through hoops. Both of the theorists must be critiqued for their missing effort to apply or test their theories on empirical data. Both have thus been accused of relying too much on anecdotal evidence, and Žižek for favouring pop-cultural references to movies and TV (Sokal \& Bricmont, 1998; Sharpe, 2004). This study is an effort to try and apply the theories of Lacan and Žižek to a tangible empirical setting, without destroying the potential of neither empirical data nor theory.

As such applying their theories to any empirical material is a relatively risky affair with great potential of 'proving' something quite unrelated to the empirical setting. Much effort has therefore been spend on trying to avoid this trap, but the result is still a consequence of marrying an empirical outset with a highly abstract set of notions and theories. How this approach influence the practical perspective of such an analysis remains an open question and in a more general setting continues to spur heated debate (Lapping, 2011; Butler, 2000). Under these circumstances the effort in this study has been to try and remain faithful to both the empirical setting and the chosen theoretical perspective while acknowledging all the entailing pitfalls. This last section represents the hope to be able to move beyond the horizon of the above discussion and draw out possible new perspectives that could feed back into the empirical settings. As such a discussion of the importance of bad practice is understood as speculative 'friendly knowledge' that might be able to push for further discussions on how to develop the field and practice of non-formal ESD. The effort is not to argue that the work of the NGOs is lacking in impact and potential, but to analyze the perceptions of the interviewees as a critical friend and perhaps help to explain why some practices are valued and others not so much. The notion of $\mathrm{Bad}$ Practice is levied in order to understand what Liisa Uusitalo calls the 'inconsistencies of knowledge and behaviour'. This is not only applies to perceptions of the public, but also the everyday work of the interviewees. Here the objective is not to eradicate these inconsistencies, but to wield the empirical and theoretical findings on order 
to make it plausible why 'bad Practice' always seems to stick to the activities of the NGOs (Uusitalo, 1990: 211).

A discussion of the notion of 'bad practice' is both founded in the cases at hand, but also in an intriguing scholarly use of the term. Different types of 'bad practice' now and then rears their heads when discussing issues related to learning, but also within fields drawing on notions of climate change and the challenges of a sustainable lifestyle (Flecha, 2000; Ward, 2008; Svejby \& Simons, 2002). 'Bad practice' is often mentioned in direct contrast to different notions of 'best practice' or 'promising practice'. Especially in the field of learning theory 'bad practice' has been brought up when discussions have turned to questions of 'evidence based research' and 'what works' (Hargreaves, 1997; Corcoran, Walker \& Wals, 2004; Oliver \& Conole, 2003). In such research the notion of 'bad practice' have maintained the role of something that should be overcome, pushed aside or transformed in the quest for examples of 'best practice' or 'promising practice.'

The environmental NGO interviewees that are part of this study use the term 'bad practice' several times in along these lines. The representative from Green Korea mentions that their concept of 'ecojustice' aims at "minimizing bad practice and doing the best that is possible for future good practice" (Green Korea, 2010). In the same vein the interviewee from the Center for Energy Alternative several times mentions 'bad practice' in relation to how the individual could learn to save energy instead of indulging in mass consumption of expensive energy (CEA, 2010). In the Danish case none of the interviewees use the notion 'bad practice' directly. There is however abundant use of a large number of examples that serve much the same purpose. The interviewee from DAEA discusses the "need for debate via information, not just an expert communicating facts" (DAEA, 2010) and the interviewee from The Danish Climate Movement argue that "You cannot scare or inform people into taking action, we must present the good life, the interesting things and the life that comes with such a notion"(CMD, 2010). This does, however, not subtract from the point that a notion of practices that is 'bad' i.e. should be avoided or mitigated is part of both cases. Whether the term 'bad practice' is directly applied or not it can be argued that a general set of arguments surfaces among many of the interviewees: some things and some practices are best to be avoided or minimized in order to reach the goal of sustainability. The intention of stressing a discussing of a notion like 
'bad practice' is thus not only to enter into a concrete discussion of the use of the term by the interviewees, but instead to use the notion as an analytical term. This is an effort to bring forth a focus on the function of the underside of the 'good', 'best' or 'promising' practices which are pursued in the name of sustainability. This last section will thus try to understand the function and importance of the arguably much more common Bad Practice.

It is important to recognize the distinction between 'bad practice' as an everyday term that is used in a wealth of different settings in order to describe something unwanted, and capital Bad Practice as an analytical concept that draws on the everyday use of 'bad practice', but infuse it with the Lacanian and Žižekian perspective and emphasize the significance of the term. The outset is again in the cases, but the difference between the empirical use of the term 'bad practice' and the analytical use of Bad Practice is important. This line of demarcation between the everyday use of the term and the analytical metaphor is essential, and the intention is not to argue that every time 'bad practice' is mentioned by a practitioner; some hideous truth is barely suppressed. Instead the point is to argue for the significance of the overall topic that Bad Practice can be understood to describe. The outset in an everyday term, which is arguably not pondered endlessly by the practitioner, is thus not a way of ascribing the individual with a specific set of norms or desires that can be found among all and everybody. The aim is to understand a slice of what is going on and in a return to the materialist stance argue that there will always be more in the individual example than what can be covered in any attempt to analyze it. As Lacan would say the Symbolic interpretation always falls short, but there is no other way to approach it (Evans, 2010: 201).

The goal of this perspective is not to push for more 'bad practice', far from, but instead to argue that a better understanding of the everyday examples of educational and personal 'bad practice' could serve as a vehicle for applying Lacanian psychoanalysis to real world settings in an effort to traverse the ideological fantasms linked with 'sustainability' and 'climate change', and perhaps become a little wiser on why so much always fails within non-formal ESD. 


\section{Everyday Bad Practice}

Taking a cue from the empirical theme of 'daily life' and the inherent contradictions that follow it can serve to illustrate Bad Practice. What is contradicted is arguably the drive towards the hitherto discussed ideals and the varied pattern of mundane everyday tasks that must be accomplished throughout a normal day. The representative from DAEA argues that "The idea that change will come suddenly clashes violently with reality" (DAEA, 2010). And it is indeed not difficult to imagine the daily situations where the ideals, the Lacanian big Other of 'sustainability' and efforts to mitigate 'climate change' have to be circumvented in order to stitch together a bearable day.

This calls for a bit of fictional scenario-making in order to grasp the kernel of the everyday challenges that can inspire to an analytical notion of Bad Practice. The situation is probably well-known: Hurrying home from the job what awaits is the dizzying array of tasks, duties, and activities found in most family homes. Of course there should be time to cook a wonderful nutritious meal, consisting of locally produced organic vegetables and all the vitamins needed to nourish and sustain the body. This, however, is not always the case, often the energy needed to perform such a wonder is simply lacking and the result is somewhat less inspiring and consists of a fast dinner, which everybody finds, at least, acceptable. As an example organic food struggle to gain $10 \%$ of the pioneering Danish market (Thøgersen, 2010). After that, precious time should be spend getting wiser and sociable by playing board games, discussing art, going to the theatre or at least watching a Von Trier movie. Again this probably clashes with the real world, where the television is watched for 4 hours a day by the average Dane with an emphasis on fast entertainment programs (Gallup, 2012) Topping of the evening would be a couple of hours of sensuous lovemaking and finally deep sleep in the arms of a loved one, or perhaps not. Such a short and crude rendering of the possible contradictions in just one fictional evening stresses how hard it is to live up to the ideals of just a perfect evening with loved ones. When the discussion turns to following the ideals of 'sustainability' and 'climate change' the situation is arguably even bleaker.

The point is that while the ideals linked to the big Other of 'sustainability' and 'climate change' are important references for the work of the NGOs and have great influence on how both the Danish and Korean societies are developing, they are also, from 
the individuals' perspective, almost impossible to combine with a daily life (Adger et al., 2009; Whitmarsh, 2009). More important is that in order to relate to these contradictions, the protagonist of the little scenario above, already knows that something is slightly wrong. As Paul said to the Romans: "The good which I desire, I don't do; but the evil which I don't desire, I practice" (Romans 7:15), and that is exactly the kernel of the notion of Bad Practice. On one hand the interviewees adhere to the great democratic and sustainable ideals, but on the other hand they have to inhabit a very different world, where realities force practices that are perceived as 'bad', but none the less impossible to live without. 'Bad' is in this case not to be understood only as what the bewildering number of experts, scholars, politicians, or environmentalists point out as harmful to the subject's health or society at large. Instead, and drawing on the discussions of Lacanian psychoanalysis, the focus should be on the desire of the subject to engage in 'climate friendly' behaviour. This of course covers a multitude of situations ranging from the urge to buy organic vegetables instead of cheaper and perkier conventional ones, to the great moments that arise when researchers, working with environmental and climate issues, meet at conferences around the globe and quietly discuss how much $\mathrm{CO} 2$ emission their plane trip coming there had resulted in. It is well known that something is amiss, but circumstances, life, make other choices inescapable. This does not necessarily constitute a break with the ideals of 'sustainability' or 'climate change' on the contrary it is still possible to view practices that deviate from 'best practices', as something which in the overall picture pushes for something good. This is not to argue that personal perceptions of what the subject should or should not do are some kind of mystic gateway to transcendental knowledge of right or wrong, but instead to focus on the dilemma that continuously arises in the midst of what ideals dictate and what reality demands.

The history of the environmental NGOs involved in this study and the overall history of the rise of the global awareness of issues linked with climate change hint how these challenges remain resistant to the work of the NGOs. The interviewees argue how the problems at hand are supported by the very mechanisms; overconsumption, ignorance, political hesitation etc. that have been around for ages (KFEM, 2010; CMEJ, 2010; CMD, 2010; CJA, 2010). In many ways it seems the continued work to rid societies of relevant suppressing ideologies and presenting the possibility of gaining emancipation, 
does have a distressingly small impact on the societies like the Danish and South Korean. The utopian struggle towards the ideals embedded in 'sustainability' and 'climate change' over and over loses out, to the daily life and its myriad of convenient choices and comfortable positions. That in no way diminishes the importance of having a democratic utopia as a useful ideal, but it opens up the question of the importance of Bad Practice, and how the metaphor can facilitate possibilities of traversing the ideological fantasm. The question discussed in the former chapters, of the significance of ideals that are so hard to disperse, also leads to the question of why these ideals arguably have so little influence on the individual subject or the individual NGOs' practices.

Surely laziness cannot be the overall culprit? A common characteristic of the NGOs in both cases, and a trait shared by most of their countrymen, is a will to work hard and focused in order to reach goals. Laziness does not enter the equation when discussing the thousand of man hours poured into the COP15 preparations and activities or the 10 hours a day, 6 days a week work schedule of the employees in Korean NGOs (PCA, 2010; CMEJ, 2010; KFEM, 2010). Hardship, also physically, and the continued postmodern need to find a substantial meaning behind all of this, often combines efforts to make people perform wondrous deeds for their own and sometimes for the greater good. Bad Practice, in its many forms, cannot, as such, be dismissed as modern human beings search for lazy comfort. Instead it might be possible to view Bad Practice as part of a kind of mental laziness or more accurately as a continued quest to secure a robust level of mental comfort. The notion of actually changing the way a subject lives its life, in its most radical form: the idea that it is possible to make critically informed choices considering the world via the ideals of the big Other, is surely a potentially far-reaching concept that demands great devotion.

In such a situation aspects of Bad Practice, daily rites of overindulgence in consumption, passivity and choices that feed contradictions could be seen as, not only barriers toward 'good practice', but as coping strategies that keep the subject from facing the lack in the big Other and the potentially traumatizing effects of such an insight. Much has been written on the barriers toward a more sustainable world and how to possibly overcome these (Dryzek, 2005; Kemp \& Nielsen, 2009; Selby \& Gray-Donald, 2008). A heavy emphasis on 'good' and 'promising practices' saturates much of the contemporary 
work on these issues, which has resulted in a substantial and growing body of knowledge on the continued effort to communicate and educate on climate and environmental challenges (UNESCO, 2011). The proposition to include a more systematic approach to the Dark Side of this equation, the Bad Practice, should not be seen as an endorsement of all the, arguably interesting, ways in which a life with a heavy $\mathrm{CO} 2$ footprint is expressed, but instead as a possibility to widen the scope of the existing research and, in quite a conventional way, perhaps pave the way for even more Promising Practices.

\section{Bad Practice as Lacanian Disavowal}

Taking the notion of disavowal from Lacanian psychoanalysis it is possible to view Bad Practice, as not only something that should be abandoned with haste, in search of a better life, but as a very successful way of reducing complexity (Lacan, 2006a: 269). It keeps the subject from stepping into the totality of a distressing world, and instead upholds a belief that there is a meaning with it all, and most importantly that the subject still tips the balance toward something Right and Worthwhile. The search for something behind all of this, a big Other, something that lends a sense of purpose is not to be underestimated as a strong individual and social driving force. Disavowing through Bad Practice could be seen as a way to secure a level of ontological security that enables the individual to function and aids in constructing a sense of order and continuity in regard to different experiences (Giddens, 1991: 36)

The notion of disavowal was used by Freud to describe "a specific mode of defence which consists in the subject's refusing to recognize the reality of a traumatic perception" (Laplanche and Pontalis, 1973:118). Denying a fact, even though it is clearly evident, can be a way of establishing a robust structure of meaning, in the face of reality. Lacan adds something important to this: the idea that the subject not only denies the knowledge of the traumatic, but at the same time also recognizes it. The subject knows very well that the world is heading towards global environmental crisis, but to mask the gap in the structure of the big Other the subject must both acknowledge that this is reality and at the same time continue living life 'as normal' in order to uphold the distance towards the objet petit a of an (im)possible harmony (Lacan, 2006a; Evans, 2010). When talking about 'sustainability' and 'climate change' disavowal could be seen as the 
psychological mechanism that enables the subject to live a meaningful life, uphold the belief in both the big Other and the ideological fantasms, in a world that is seemingly falling apart, while the subject through the lived life supports the structures that continue the distressing development toward non-sustainability.

This is also the mechanism of Bad Practice the subject does not only need high ideals of the possibility of a better world through its actions. The subject also needs to live the very opposite life, consuming and producing waste like few others. A focus on the significance of Bad Practice is thus also a focus on the fallibility of the subject. It also represents a possibility of accepting that there is little escape from actually living amidst the social structures that embrace the subject. Even though evidence for the lack of sustainability of modern society is presented on a daily basis, politicians try to convene popular demand for change, and only few can argue that they have no clue of the adverse impact of pollution large-scale behavioural change is still hard to be found.

The question then arises of why the subject and in this case the Korean and Danish public as well as the NGOs do not simply 'do as they teach' or 'practice what they preach', by scorning the disastrous ways of contemporary society and turning toward a more sustainable path?

It could be argued that doing so would not only make the subject a social leper, insisting on living a truly sustainable life with no flights, no imported food or other remedies that might not be perceived as being truly sustainable, it would also have the potential to disclose the big Other. In effect this would result in the fall of the meaning making structure of the ideological fantasms and objet petit a. From a Lacanian perspective this would not only lead to a possible reinstatement of other ideals, but also risk distorting the foundation of the subject and the stress of traumatic detachment.

The ideals or utopias which form the basis of the work of the NGOs e.g. sustainability and notions of mitigating climate change are not minor league notions easily incorporated into the way society is currently organized. They are quite radical notions that demand utmost attention from all citizens and constant hard work and courage in order to avoid slipping into the easy trap of behaviour modification, instrumentalization of fellow human beings and the chances of implicit selfishness. Buying a crate of organic tomatoes, supporting WWF with a bit of money each month and keeping somewhat up to 
date on the conflicts around the world, does not really cut it when discussing the radical emancipative ideals that form the cornerstone of a notion like 'sustainability'. The alternative is, however, almost too horrible to consider. The function of Bad Practice, as a coping strategy, is thus to keep the subject from doing the impossible: Stepping, with eyes wide open, into the void of the chaotic surrounding world, with all its wrongs and randomness. Such a move would demand a radical acceptance of the consequences of the subjects own life. That the cherished ideals are far from real life realities, and that the stereotyped successful life, with comfortable living and effortless consumption, is arguably at odds with a path to radical sustainability (Ehrenfeld, 2004). This correlates with the notion of enjoyment as part of Bad Practice. Not only is Bad Practice a coping strategy, it also doubles as a facilitator of enjoyment. By establishing a field of meaning that includes both ideals and their contrasts, it is possible to continue to formally adhere to the ideals while enjoying the sinful pleasures of travelling around the world, enjoying a steak or driving the car to work. Bad Practice is as such both oppressive, pointing out where ideals are not follows and liberating as it establishes venues of enjoyment.

Everyday examples of Bad Practice could thus be seen as a way to avoid taking this confrontation with the harsh realities of the world, as a way to structure and define the subject's life as something good. It enables the subject to actually perceive it to live at the level of ideal fantasies, and not accept the 'unsustainable practices' that both the Danish and Korean public are part of and support through normal daily actions (Mullins et al. 2004: 29, Thøgersen \& Ölander, 2002: 605). Doing something that seems wrong or 'bad' according to the ideals of 'sustainability' or 'climate change', could be seen as a way of structuring meaning by acknowledging the fact that 'we are only humans' and actually deserve a delicious daily treat.

\section{The need for a Cynical identification}

A life based on idealized 'good practice' is a thought provoking prospect: Contemplating every move and its possible consequences, not only within a personal limited scope, but on a larger scale, would be a formidable task. As Kant put it in his categorical imperative: "Act only according to that maxim whereby you can, at the same time, will that it should become a universal law" (Kant, 1786: 80) By investing hope and effort into the 
ideological fantasms it might be possible to argue that life can be led according to the categorical imperative and that all actions should reflect a greater good. The individual works hard, studies, embraces helping the poor, and generally tries to be good humoured and helpful. The problem is of course that while this might be true in relation to ideological fantasms, the lived lives and practices of many Danes and Koreans are directly opposite that, with an enormous emphasis on individual success, consumption and producing waste along the way, all the while ignoring conflicts and horrors around the globe. Not that many can argue to be unaware of what is going on in the world, but it does have surprisingly little effect on daily life in Denmark and South Korea that children are starving in Africa or wars waged all over the globe.

The underlying structure of many industrialized countries and especially the Danish society, is far from 'sustainable' in the sense that the CO2 footprint is enormous and nature often pushed aside in the name of greater agricultural and industrial production (Aldy, 2006). On the contrary the Danes eat more meat per capita than anybody in the world, produce comparatively more waste than the rest of the EU countries, and have the $12^{\text {th }}$ most cars pr. capita in the world and Korea is not lagging far behind in any of these categories either (WRI, 2011). These facts clash violently with a popular notion of Denmark as a Green country at the cutting edge of 'sustainable development' (Wiegand, 2006; Kahn \& Lostys, 2009). It can be argued that this paradox brings a certain need for a cynical identification with the ideals at hand in order to successfully incorporate them into an everyday setting. The idea of a Cynical Identification with our ideals, as proposed by the German philosopher Peter Sloterdijk, manifests "itself in the world of logic as a paradox, in the world of literature as a joke and in the world of business simply as business as usual" (Sloterdijk, 2005: 41).

Whereas Marxist critique of ideology talks about ideology as something that forced a form of false consciousness upon the subject that did not realize that the capitalist profited from its work, but was simply happy to receive pay, the idea is now that it is possible to live in a state of enlightened false consciousness (Pines, 1993; Eyerman, 1981). It seems that the Marxist definition of ideology no longer applies: "they do not know it, but they are doing it" (Marx, 1970: 91). Sloterdijk bring sin the cynical identification with ideals "they know very well what they are doing, but still, they are 
doing it" (Sloterdijk, 2005: 21). Even if the subject acknowledges and accepts the different concepts of democracy, human rights etc. that should ideally be building blocks of modern society, it at the same time knows that true sustainability does not come into play in a competitive work sphere and sustainability has to wait, while the entire family goes on vacation at the Mediterranean sea. To reverse this logic and take a critical stance towards the world, and accept that the life the subject lives is not fair, honest, just etc, but to a large degree a coincidence, is not only daunting, but also, according to Lacan, almost impossible, as there is a constant need to turn to larger fantasms and ideals of the big Other as guidelines for living and making informed choices.

So is the subject doomed to eternal cycles of Bad Practice in order to escape the traumatizing reality of contemporary life? Such a realization would open up for the possibility of turning the subjects into even more hardcore cynics, with seemingly little regard for the realities of the Symbolic, social setting of daily life, and present a comfortable position as grumpy declarer of an imminent climate catastrophe. This, however tempting, would arguably leave the subject considerably worse off than mere 'normal' cynics. In this case it is essential to remember Lacan's slogan 'Les non-dupes errent'. Those who do not let themselves be caught in the Symbolic deception/fiction and continue to believe their eyes are the ones who err the most (Žižek, 1989). Via efforts to try and transcend the existing social structures and talk some straight talk, the individual is revealed as totally embedded in the social structures surrounding it. When trying to 'believe only your eyes' there is a chance of missing the efficiency of the social structure and its Symbolic order in arranging reality. As in the concept of the mirror stage the intuitive image of a seamless reality does not convey the multitude of factors that operate 'behind the scenes', beyond what a first glance will reveal.

With the Lacanian Real out of reach, it is all-important to take the Symbolic social world that surrounds every individual seriously, as there is no escaping it. The unfathomable complexity of the world and the unapproachable Real should not be held hostages when trying to talk about sustainability and how to develop educational methods and strategies that will facilitate a more sustainable world. Posing the substantial and structural questions about the social structures or ideologies that form society should 
always be of utmost importance, and will more often than not happen on the backdrop of ideals.

The notion and ideal of 'sustainability' is not a bad venture point when trying to quiz the substantial structures of society as it offers a possible far-reaching vision of identifying quite radical attempts at understanding the scope of sustainable development. It does, however, also harbour the possibility of being turned into an impotent bringer of not much more than scores of Bad Practice, with little or no relevance toward achieving a more tangible level of sustainability. A focus on the importance of Bad Practice should not be taken as an effort to shrug of the world's problems and state that progress is impossible, but on the other hand instead enable a focus on the idea that the social structures, which guides everyday lives and facilitates the ways in which good and Bad Practice is communicated and perceived, are culturally dependant. The human race has not been voracious polluters and consumers for the entire span of humanity, but the suggestion that we have always been involved in some kind of Bad Practice is on the contrary not unthinkable and if so, Bad Practice as a human condition has not halted great leaps in both societal and industrial ingenuity.

Grasping with the underlying values of sustainability and democracy at large is indeed heady stuff, when viewed against the back drop of daily life, but perhaps the understanding of why sustainability has such a hard time making a real world impact, could be developed with a critical eye towards the functions of Bad Practice? Binning the idea that Bad Practice acts primarily as barriers to promising practices, opens up for a critical understanding of why these exact barriers are so stubborn and why they in some forms will continue to exist no matter what kind of educational approaches are levied on them.

\section{The two levels of Bad Practice}

Based on the Danish and South Korean case it can be argued that two levels of Bad Practice are at play. At one level the public is perceived by the interviewees to be involved in various patterns of Bad Practice. This is especially visible in the NGOs frustrations about the public unwillingness to participate in activities, and, on a more general scale, change behaviour according to notions of 'sustainability'. The greater share of the 
interviewees arguably view the public as a field where Bad Practice is a daily companion that thwart a great deal of the efforts of the environmental NGOs. The different themes or ideological fantasms at play can thus be understood as scenes where Bad Practice is recognized as a problem, but at the same time areas that open up for the potential of changing such practice into something different, something better. Utilizing the concept of the Lacanian 'end of analysis' and its effort to traverse the fantasm, a focus on the significance of Bad Practice could help the environmental NGOs illuminate the desires and enjoyment that are involved when the public continually acts in ways that clash with concepts of 'good practice'. The idea that everyday Bad Practice is a type of laziness that flows from the individual subject with little perspective on the potential consequence, should be abandoned in order to understand the social processes of meaning making that the perceived Bad Practice entails. In such a perspective, choices that do not align with the educational efforts, wishes, and desires of the NGOs should not be viewed as inherently malevolent, but instead as basically 'friendly' efforts to create meaning in a world that demands a lot from the subject and offers little in the way of applicable guidelines, especially outside the gospels of consumption. This is not to argue that Bad Practice should be viewed as having the potential to fill the void of the big Other, but to argue that disavowing the consequences of the way the subject lives his or her life is a powerful way to uphold a structure of meaning for the subject, and therefore daily doses of Bad Practice could be seen as part of the process.

Recognizing the importance of Bad Practice is thus not to support such a practice, but to understand that it is a psychological way of reducing complexity, and facing the inherent and obvious contradictions that is part of contemporary society. Educational practices, activities and efforts that aim at the public as a learning entity could arguably benefit from such an perspective as it would stress how meaning making structures cannot be swiped aside without the desire to install a sense of meaning heading in other directions that might, or might not be beneficial in the light of the challenges that 'sustainability' and 'climate change' bring.

Arguing that the NGOs work with the public as a learning entity brings different perspectives and potentialities to the surface. The public is not a 'subject', and as stated by a number of the interviewees (WWF, 2010; DAEA, 2010), the potential of 
installing too simple perceptions of the public as a uniform entity is not beneficial, when facing the untold facets of just a relatively small population like the Danish or Korean. The understanding of the public as an entity that can learn and should be engaged in order to try and change views and behaviour is, however, shared by all of the NGOs. While approaches to the public vary across the cases as well as the efforts undertaken to understand and engage the public and it can be argued that quite a functionalistic approach continues to influence the work of some of the NGOs. A heavy emphasis on informing the public about problems related to 'sustainability' and 'climate change' and how the public could act on this is the core of many of the activities described. This focus coexists with what seems as an insight into the futility of presenting environmental information and hoping that it will instigate a causal change in behaviour. In spite of the shared frustrations of working with the public as a learning entity, the NGOs apply strategies and efforts that they know are not that effective, which inspires a focus on a second level of analytical Bad Practice.

Such a second level of Bad Practice is of no less importance. Not only is it possible to identify variations of Bad Practice among the public, it is also clear that the environmental NGOs themselves engage in Bad Practice, in their efforts to engage the public. Where the interviewees are adamant to point out the problems they face when they meet repeated cycles of Bad Practice among the public, it is seemingly harder to identify how they themselves draw on disavowal and cynical identification related to their own activities. Bad Practice at the level of the NGOs can be illustrated by the interviewee from WWF's consideration on what could be done to address the public post-COP15 in order to get the wanted result: "We need a more intense democratic pressure for change to happen. If it did not work then it was because it was not intense enough. We need to make it more intense" (WWF, 2010). The point being that what is needed is more of the same. Even after the interviewee argues that the efforts during COP15 lead to almost nothing, the aim still is to continue down the same path, next time just with more commitment. There is of course the possibility that the interviewee might be right, that a greater democratic pressure could bring results, but it does bring food for thought that not even fiasco seems to change the overall trajectory of the efforts. 
That the notions of disavowal and cynical identification are at play in this case demonstrated with another quote from the same interview "If you insist that your method is right, that it is the world that is wrong, then you yourself make a mistake. We need to look at why it does not work. We try to redefine, but it is not sure that it will work if we have a demonstration with 150.000 thousand people instead of 100.000 next time" (WWF, 2010). While this might seem in direct contrast with the previous, it displays that a certain level of duality is needed in order to operate within the field of ideals and pragmatic actions dictated by the social. There is thus both a view of the remedy for the situation to be more of the same, and an acceptance of situations where this fails to have any influence. The educational Bad Practice of the NGOs could thus be understood as a continuation of efforts that are known not to bring any result. The social meaning making mechanisms do, however, also apply here. In order to make sense of a world that is moving in the opposite direction of the wishes of the NGOs, it is vital to continue forays into Bad Practice in order to position themselves as doing something good and concealing that their daily actions are far removed from what could be considered radically 'sustainable' or mitigating 'climate change'. Only through the fallibility of the subject is it possible to relate to ideals of a world devoid of fallibility. This ensures the reproduction of the social structures that makes it possible for the subject to navigate the apparent chaos that surrounds it. Bad Practice for the NGOs is to focus on the Bad Practice of the public, and thus conceal the Bad Practice they themselves set in action and sustain.

\section{Traversing the Fantasm of 'Sustainability' and 'Climate Change'}

The question then arises of whether this leaves the NGOs in an unsustainable eternal limbo of Bad Practice - caught between a desire to follow 'sustainable' ideals and the impossibility of living by them? History reveals that change is persistent and the fact that social structures have changes rapidly in both cases clearly shows that constant evolvement of the way Bad Practice, desires and ideals are framed is inevitable.

The possibility of a Lacanian attempt to traverse the ideological fantasms of the NGOs could present new ways of perceiving the work of the NGOs and their relationship with the public. The aim of Lacanian psychoanalysis of infusing the subject with possibilities of liquefying what has become stale and fixed in its form is a way to 
establish new and perhaps more beneficial patterns. In a return to Lacan this might not entail anything positive. The argument that "the end of analysis is not the disappearance of the symptom, nor the cure of an underlying disease, since analysis is not essentially a therapeutic process but a search for truth, and the truth is not always beneficial" has to be taken into consideration (Evans, 2010: 55). The Lacanian 'truth' about the desires of the environmental NGOs could thus be a vehicle of new understanding and emancipation, but also be dismissed as there is no possibility of removing this desire, as it would always find new ideals, new fantasms and the big Other would take on another face. Part of the problem is that the notion of 'traversing the fantasm' presents the problem as the goal. The subject strives to cover the lack in the big Other. Bad Practice remains a part of the lives of even the most stalwart NGOs, but the end of analysis means the fall of the big Other; the exact event that so much energy is spend on avoiding. In its outset such an idea of the 'end of analysis' seems to put an almost unbearable strain on the subject in a social setting, which is why different or new ideological fantasms or ideals are most likely to emerge and cover such a void. To embrace what is considered a step into a traumatic void with no social reference points seems a radical solution (and inherently almost impossible), but perhaps a watered down take on the concept could spur changes via a social perspective.

It could be proposed that some of the underlying structures that guide the work of the Korean and Danish environmental NGOs could deserve to be at the sharp end of analysis by the NGOs themselves as the potential for them to become 'kitsch' social images so far removed from the social that they become absurd, exists. It is neither the scope nor the intention of this study to deliver any ideal measures of Best Practices, as this would require another more dialogical approach of communicating the horizon of this to the NGOs. It is however possible to develop potential new reflexive practices based on an insight into the indispensable nature of Bad Practice.

It can be argued that the link to the revolutionary democratic movement that permeates the Korean case and the insistence on 'folkeoplysning' and consensus that remain central in the Danish case could be used as stepping stones to traversing the ideological fantasms. Accepting that the ideological fantasms are something constructed that might not aid the efforts of the NGOs, and understanding that the notions of 
'sustainability' and mitigating 'climate change' can lead to more pseudo-activity than interactivity could be a way of applying the analytical insights drawn from this study. It could, however, also cause disarray and loss of momentum among the NGOs and weaken their effort to understand and engage the public.

The point of Lacan's slogan of Les non-dupes errant remains: The subject can only face the social via the social, and only the greatest fool would try to move beyond the existing social structures, but this does not mean that efforts to do so should ever be abandoned. It is not possible to transcend the situation of the environmental NGOs in Denmark and Korea and their efforts to engage the public remain impressive and create structures of meaning, but it should always be remembered that the individual NGO staff member arguably remain more a part of the problem than a solution to it. An eye towards the significance of the educational desire of the NGOs and the Bad Practice that is part of daily life in Denmark and Korea is, however important in order to navigate between the cynical identification with ideals that can hinder continued discussions of what is going on. All bearing in mind that this will not enable an abandonment of Bad Practice, but perhaps create possibilities for sustainability, desire, ideals, fantasms, and Bad Practice to work together instead of merely provoking an even more cynical identification with our actually quite worthwhile ideals. 


\section{Chapter 6 Perspectives, Findings and Emerging Thoughts}

This study has been an inquiry into how one can understand non-formal ESD as reflected in the cases of Danish and South Korean environmental NGOs. The cases present a varied but also recognisable pattern of how the interviewees view themselves and their organisations as navigating diverse concepts of engaging the public and getting their messages across the table. The result of this is the twofold perspectives of the empirical data and the theoretical approaches applied to it. Questioning the significance of engaging the public in the Danish and South Korean cases, not only leads to an understanding of the complex construction of meaning that is continuously going on, but also reveals how it is important to insist that this study only represents a single distinct perspective on a large and elusive field. This concluding chapter will position a critique of the applied Lacanian and Žižekian perspective, and present the findings and potential ideas that emerge from this study.

\subsection{The Lack in Lacan and Žižek}

The move from the empirical material to theoretical analysis put an end to any ideas of minimising the level of 'theoretical violence'. It did also underline how the broad and varied perceptions of the reality of the two cases were translated into a more narrow and focused attempt on understanding the cases in a very specific light. As such the theoretical analysis argues that working with ideals on an everyday basis installs a need for some kind of conscious or unconscious distance from these ideals. This distance translates into Bad Practices in an attempt to deal with the inherent contradictions of our lives. As mentioned several times the purpose of this analysis and the focus on Bad Practice, is not to dismiss the work of the environmental NGOs involved in this study or the environmental movement at large. Arguing that even the best intentions have a flipside, which is impossible to avoid should not be understood as a cry for abandoning the notion of sustainability or an urge to mitigate the cause and effect of climate change. On the contrary the outcome of the analysis is a critique and stance that both applaud much of the work of the NGOs, and also points to the inherent challenges and short-comings when working with ideals such as sustainability. 
While the analysis might read like an overall dismissal of the values that drive the NGOs, such a dismissal is not levelled at the importance of having such ideals, but a way to understand that the individual always finds a way to create meaning, even in an unsustainable world that only offers limited scope for change toward the better. This also installs a certain distance to the use of Lacan and Žižek as their theories struggle to pave the road toward practical change and a better world. As such it can be argued that despite the radical and even revolutionary rhetoric's of Žižek and Lacan, both can be viewed as quite conventional and close to other theoretical perspectives in their overall approach to emancipation and change, and in return so can this study.

Lacan and Žižek present meta-theories with the explicit aim of explaining and structuring an understanding of how the individual, the subject, interacts with the social. The scope of their theories is from the outset not limited to a distinct field or context, but instead plastic in nature with an almost limitless horizon. The structure of production of desire and the foundational misunderstanding, stressed through the concept of the mirror stage, are concepts that are seen, by Lacan and Žižek, as having an omnipotent analytical potential. This perspective rests on the interesting mix of the psychoanalytic attempt to present a 'science of the mind' that transcends former reliance on religion or superstition in order to understand the inner workings of the human being, the unconscious, and link this notion with very little regard for the later neural insights into what physically and chemically goes on inside the brain and body. The 'evidence' that much of their work rests on is purely anecdotal. Lacan developed most of his work through a rereading of Freud, and Žižek primarily relies on pop-cultural references and political statements in order to develop his bridging of Lacan, Hegel and Marx.

However, it can in their defence be argued that it would be very hard to develop an all-encompassing theory based on exhaustive empirical material, as something will always stick out and jar the picture. The methodology of Lacan and Žižek is as such not far removed from the host of philosophers that have established ideas of how society and the individual intervene. The use of their theories with all their pitfalls and flaws does, however, open up for a critique of developing an understanding of the environmental NGOs and the use of the analytical concept of Bad Practice. 
Such an analysis is not complete without an eye towards the potential of Lacan and Žižek as well as their inherent limitations. As has been proposed earlier it can be argued that it is possible to turn both Lacan and Žižek against their own theories in order to understand the possible impact of their thoughts. Lacan famously argued that some of his writings were deliberately written to be incomprehensible as this reflects how some things in the social and in the subject cannot be understood (Bailly, 2009: 42). This not only makes reading Lacan an occasionally frustrating affair, it also hints a certain level of arrogance and perhaps even academic laziness from Lacan's side. The point is still valid though, it does seem that there are still parts of the social, e.g. mechanisms and structures of correlation that it seems we are not fully able to understand or map. Lacan offers, with his take on the unconscious, a way to structure these 'unknown knowns', the things we don't know that we know, which is precisely the psychoanalytic 'unconscious' or the "knowledge which doesn't know itself" as Lacan argues (Žižek, 2004). Following this argument it seems reasonable to suggest that no matter how many evidence-based studies of learning environments that are carried out, learning will never be a seamless process. Barriers, both in the student, the teacher and context will remain, and continue to make learning and change a frustrating and uphill endeavour and not less so when the 'student' is the public and the matter environmental and climate challenges.

This insistence on the importance and insurmountable character of the unknown does, however, also apply to the ideas and theories of Lacan and Žižek. The equation might always come full circle when Lacan interprets the subject and finds the repressed desire, or when Žižek analyzes society and looks for the fundamental traumatic truth that drives people, but as their own theories emphasize, pictures of coherence and wholeness, especially when it applies to a explanation of the social, are always a dangerous lure. Their analysis might always be successful in its own terms, but what do they miss? Some might have the urge to completely dismiss Lacanian theory and Žižek's musings, but at least it is possible to critique the theories from the built in characteristic that they also, through the foundational aspects of their own theoretical framework, misunderstand what is going on in the social and in their concept of the 'Real'. Just as the subject inherently, in their perspective, lacks the cognitive powers to understand the 'Real' and the totality of the 'Symbolic' so do Lacan and Žižek. They too act as subjects and 
their theories are also burdened by a limited scope that of course has little possibility of addressing the inner workings of the subject or the 'Real' as it is. This prompts the question of what the 'traumatic truth' of Lacanian psychoanalysis and Žižekian theory is.

Such a question would no doubt spiral into an even longer study than the one at hand, but it demonstrates that the theories of Lacan and Žižek are fallible, speculative and at best offer an opportunity of handling what we otherwise have no chance of integrating into our language as well as much of our daily work and efforts. This is no mean feat though and the argument of this study remains that there are issues to be learned and understood via the use of Lacan and Žižek, but one must, as always when dealing with philosophical theories, remember not to take them too seriously. Other theories exist and present different, but no less valuable, lessons. Theories of the individual and the social are after all only feeble attempts to comprehend and give meaning to something extremely dynamic and changing. Grand theories should at best comprise a healthy tool cabinet, one can wield at with a problem at hand. But as in the world of the craftsman, academic problems always seem to arise just outside the scope of one's knowledge, skills and the tools at hand prompting a never-ending search for new tools, understandings and skills. Such reasoning forced this author into the lap of Lacan and Žižek well knowing that the perspectives they offer, only offer that much.

\section{The Inescapable Enlightenment}

The above 'internal' critique from the grounds of the Lacanian and Žižekian perspectives can fruitfully be linked with a more external critique of the eventual outcome of their theories and perspectives. One can question the value and inherent 'real world potential' of an analysis taking empirical material and analytical themes and understanding them through the spectacles of Slovenian Žižek and French Lacan. After all the individual subject still has to take some kind of action after the process of gaining insight into the importance of the lack and how fantasies make it possible to lend sense to a situation that might seem like it is spinning out of control. It seems that the Lacanian psychoanalysis offers little more than 'traversing the fantasm' and thus understanding that the ideals that we cherish are only superficial constructions that make us endure life and perhaps enjoy parts of it. As Žižek argues: “This is how a true 'cultural revolution' should be 
conducted: not by directly targeting individuals. Endeavouring to re-educate them, to “change their reactionary” attitudes, but by depriving them of support in the big Other, in the institutional Symbolic order" (Žižek, 2008b: 1xxii). Such a situation, being left without ideals or guidelines, does, however, not seem as a suitable position from which to embark on the mission of changing one's life.

From a Lacanian point of view such a total lack of structure and ideals would most likely traumatise the individual beyond relief, and the chance of depression or stupor would be overhanging. From a more pragmatic standpoint it could be argued that very few individuals, at least in the described NGOs, would accept a world with no direction, no meaning or no ideals. Such a world would not only make for an almost impossible boring life, but also be very hard to actually live out as almost all actions in a society such as the Danish or Korean involves some kind of choice of something that is deemed better or more interesting than other things. Even the most mundane tasks of making dinner or buying clothes invariable demand from the individual some kind of perception of what is better or worse and what might suit the practical needs best. Not all would, arguably, subscribe to the impossibility of living a life without any strings attached to larger ideas of good and bad. It can still be argued that even the most hardcore self-confessed cynics believe that a take on 'cynicism' is better than e.g. engaging in religious spiritual awakening and thus still invests in some kind of notion that structures the world view of the subject. A consequence of this is that the practical outcome of Lacan and Žižek's proposed analysis of the individual and society is not to dismember all notions of how to live a fruitful life by believing that some things are more worthwhile than others. Instead the effort, in the lives of the individuals, arguably becomes to install some kind of new ideals, a different notion of the 'Big Other' that seems less invasive or oppressive than the existing structures.

Such a move does however deaden the impact of the revolutionary rhetoric of Žižek and Lacan's effort to 'circle the traumatic kernel of desire'. While the analytical insights that are to be drawn from a Lacanian perspective might offer several counterintuitive points, the end result could arguably be seen as being in line with conventional Marxist critique of ideology, social constructivist discourse analysis or even along the lines of a classic take on the enlightenment. It can be argued that is the option 
which left for the individual is to gain as much knowledge as possible, while accepting that the notion of the liberal fully enlightened individual is impossible. On this basis the individual can commence on a journey towards building a better and more worthwhile life that enables enjoyment and desires without mitigating a more holistic take on society and environment.

Linking empirical data and Lacan and Žižek might be a relatively rare approach because of the nature of their theories. The theories seem better at posing interesting questions than actually pointing towards a practical way of incorporating their perspectives into an everyday lived life. When hard pressed by bewildered interviewers' Žižek's answer to where we should be heading has often been the cryptic: "communism!" (Žižek, 2009b: 122). Not communism as in the former soviet union and perhaps not political communism at all. His concept seems to be of a revolutionary communism that constantly sheds existing dogmas and progresses towards a world that is just a bit better than the existing one, of course with the added disclaimer that the foundational fantasy of a whole harmonious society is impossible to achieve. The road to this 'communism' is, however, not clear at all and thus Žižek is arguably often trapped within the confines of his own theory with more emphasis on a critique of existing structures than on providing practical means towards change.

In that regard the theories of Žižek and Lacan could very well be coupled with discourse analysis, evidence based research or the interesting speculative realism approach of Harman and Meillassoux (Harman, 2010; Meillassoux: 2009). The latter could offer an eye for the rational or causal processes that mark the field of non-formal ESD, and is to a lesser degree caught in the net of Lacan and Žižek. Further development of the analytical concept of Bad Practice could also benefit from different perspectives as the qualities of this concept and potential benefits of working with such a notion in a practical setting could prove worthwhile and install new reflections on the purpose, significance and impact or our actions and thoughts, when engaging in environmental education and education for sustainable development.

The study represents no urge for a Žižekian communistic revolution within the field. As argued the impressive work that the NGOs undertake already, successful or not, beats the odds of social structures that are far from sustainable, by constantly pushing 
for another perspective. On the other hand, what should be carried out in both the Danish and Korean cases and among the NGOs involved in this study is a very critical take on how we as individuals relate to the ideals that we cherish and how it seems as an inescapable fact that both NGOs and the public remain more embedded in structures that reproduce the challenges at hand than in building structures that holds the potential of actual change. The point is not to induce despair and numbness, but to enable frustrations to flare and turn into critical and reflexive action. This could be productive in both the South Korean setting and especially in the Danish case where it seems that a strong belief in the powers of deliberative dialogue and consensus driven development has resulted in a distorted 'green' self-perception among the public and the NGOs.

\subsection{Findings and Emerging Thoughts}

This study set out with the aim of understanding the significance of engaging in nonformal ESD. All over the world great effort is being put by environmental NGOs in order to enlighten the public and change the way that our societies work and do not work. It seems puzzling how relatively small organizations like the environmental NGOs manage to engage themselves in the monumental task of changing the perceptions and lives of the public for more sustainable editions. The work is no doubt an uphill struggle, with political, social and economic barriers that leave many of the NGOs frustrated as promising examples can be few and far between. This does, however, not stop the NGOs in their work to engage, educate and activate the public, and push for societal change. On the contrary it seems that they nourish on the resistance they meet and continue to fight for the environment and mitigation of climate change, even though it is never easy.

This study chose the cases of Danish and South Korean environmental NGOs in order to establish a particular context for the analysis and to make it possible to link the overall curiosity to two distinctive settings. The empirical contribution of this study lies in the identification and analysis of central themes for the environmental NGO when engaging the public as a learning entity. Youth, Daily life, Emotional/rational involvement and Conflict/consensus are themes of utmost importance and potential when conducting non-formal ESD. The theoretical contribution hinges on the development of the analytical notion of Bad Practice. A notion meant to cover the processes of 
establishing meaning through everyday actions that we know are bad, but which nonetheless seem impossible to get rid of. The overall contribution of the study is thus not only an addition to the existing critique of the field of ESD and non-formal ESD and the concepts of sustainability and climate change. The point of the study is that such a critique must be taken a step further in that it must be possible to critique the position, desires and mechanisms of meaning making that are harboured within the subjects involved in ESD. Not only are academic and everyday understandings of the reality fallible and limited, so too are the possibilities of understanding why we as individuals perceive reality and act in it.

\section{Empirical findings - the Educational efforts of the Danish and South Korean NGOS}

The two cases of this study are very different. The strong currents of the South Korean conflict and the Danish emphasis on consensus driven development are present throughout the empirical material. Yet the cases present insights and understanding that are valuable across two such different settings. The South Korean NGOs are embedded in a history that spans a relatively short period and focus on tangible solutions to the environmental challenges that the country faces. The Danish NGOs on the other hand work in a country where pollution has been a hot topic for decades, which has translated into a situation where the environmental NGOs to a greater degree focus on the often abstract and global challenges related to climate change. Even though such differences are evident the cases also present a host of similarities that draw a larger picture of the development of environmental NGOs as such. The move from a focus on tangible issues to a more abstract focus on the foundational structures of society, the feeling of from time to time being overwhelmed by both political and commercial actors that lack focus and the general frustration of working with issues that are often hard to communicate are thus characteristics shared by both countries.

These differences and similarities make it possible to learn from the approaches to the public and concepts of learning the two cases combined illustrate. They are not describing a situation that applies to all industrialised societies, but draw a picture of two radically different settings, where some issues are still shared and approaches and 
understandings on several levels correspond or overlap. This facilitates certain levels of generalisable insights, but also points to the importance of cultural differences and the question of whether it is possible to learn from the success and failure of others. The empirical findings can be summed up through the focus on the four reoccurring themes that both cases have in common: Youth, Daily life, Emotional/rational involvement and

\section{Conflict/consensus.}

In both countries these themes are embedded in ideals of a better society and visions of how to move forward. In Korea this is expressed via the hope for a different political structure, while the Danish NGOs are part of a consensual focus on changing society through lifestyle changes and how the individual can participate via personal choices. The Korean NGOs spend much energy on the environmental challenges of state and industry, while the Danish NGOs have moved to a position where economic growth and caretaking of the environment are seen as entities that can be combined and interact. This of course varies between interviewees arguing for radical change and those arguing for a mere fine-tuning of the existing society. South Korea none the less paints a picture of a situation where engaging the public and focusing on learning for many becomes a means to the end of radical change. In the Danish case learning and knowledge seems to be a goal in itself, and there is less focus on instrumental usage of the public or the potential of moving beyond the existing structures.

The perceptions of where the potential in engaging the public lies form a changing and uneven landscape, but some common tendencies can be identified. In both cases there is great hope invested in the spontaneous potential of youth and children. This theme shows up in situations where young people and children undercut the NGOs and are able to act faster and with greater impact than the NGOs. This focus is in both cases coupled with great frustrations about the youth, a concern about their perceived lack of interest and the hardship of recruiting young people. Emphasizing the youth as harbingers of change is linked to perceptions of the contradictory daily life in both countries as windows of opportunity for learning and change. The interviewees question how it remains possible to construct a normal life with all the contradictions that are involved when it comes to having an eye for the environment and the climate while still making ends meet in the everyday struggle of both the Korean and Danish families. Most of the 
NGOs are arguing that these contradictions should not entail the easy choice of simplifying the diverse challenges at hand, but they still employ distinct methods in order to cope with the problems of educating and informing on issues that are incomprehensible for most people. Further, a reoccurring theme in the Korean case is a focus on the emancipatory potential of women and their double role as caretakers of domestic chores and highly educated women turning their backs on traditional ideas of marriage and family life.

Another theme, which is however most apparent in the Korean setting, is emotional involvement, as described by the concept of sentimentalism. The concept is coined by the Korean NGO WEEC on Jeju-Island, but it is also visible in the activities of several of the other Korean NGOs. It merges a quite rational understanding of the problems with an effort to engage the feelings and emotions of the individual. The effort extends to education of both children and adults and aims primarily of speaking to the gut by establishing an emotional link between e.g. the mostly urbanite Korean and the nature outside of the Korean cities. Apart from WWF Denmark the NGOs from the Danish case draw on a different concept of relying on the perceived power of showcasing cold facts and affecting the public via rational knowledge about environment and climate. This can be understood as a consequence of the Danish tradition of consensual development and the subsequent belief that an informed public will make right and timely choices.

All these themes are influenced by the overall perspectives on society and the potentials of change that are expressed in the cases. The South Koreans conflictual past, and their roots in the Democratic movement thus offers different perceptions on how the themes should be engaged. There is a greater tendency to frame a distinct 'environmental' villain in the Korean case, as part of the educational work. Most of the Danish NGOs return to a more consensual perspective that aims at embracing all the differences within a hoped for sustainable development. This has great impact on the educational work of the NGOs, but diminishes the urge to identify any 'villains' that might exist.

The empirical findings furthermore show very different concepts and perceptions of the purpose of how the public should participate in the work and activities of the NGOs. The Korean NGOs draw on the countryside of Korea (and Mongolia) in 
order to let the public participate and learn in nature. This is not the case in Denmark where most of the NGOs focus on learning via the social with great emphasis on building relationships and thereby attracting members that will engage in the issues. This goes hand to hand with a great belief in the potential of deliberative dialogue. On an overall level the Danish NGOs view the public as an entity that can learn though discussions of factual knowledge and by facilitating new insights and changes via the social side of meeting the environmental challenges. This also means that nature at times ends up being quite an abstract idea forming a platform for a struggle, while in its tangible form not being a big part of the work of many of the NGOs. It seems to be easier to show pictures of nature, than to actually get out there and be a part of it.

The Koreans do of course also engage in plentiful discussion, but as pollution and environmental degradation often have a more tangible character in Korea than in Denmark, nature is also dealt with in a different and less abstract way. A crude portrayal of the situation is that while the Danes discuss, socialize and demonstrate on behalf of perceived distant problems - the Koreans teach debate and learn in the light of more concrete questions of a healthy life and how to mitigate tangible problems.

As such there is much to learn from the Danish and Korean cases when throwing an eye on how non-formal ESD is translated into practice and perceptions of the public as an entity that should be engaged, educated and challenged. An important point is that the overall premise of this study, the notion of the public as a learning entity, is actually reflected in the approach of the NGOs. There is an understanding of how the public operates as an entity that can learn, as exemplified though the identified themes of the empirical data. When notions of the public are used, this often results in activities, practices and strategies that single out the individual from the erratic and hard two grasp concept of the public. Discussions of how the public learns and instigates change are evident throughout the empirical material and the road to sustainable change is understood by all of the NGOs as involving, albeit different, notions of the public.

The different perceptions of how the public should be engaged and what potential the understanding harnesses differ across the two cases. It can none the less be argued that in both the Danish and Korean cases the NGOs draw on a concept of enlightening the public on relevant issues, an approach that hopes to produce critical 
reflections and change. This does from time to time work, but it can also be argued that most of the time the goal of addressing the public while engaging it in actual change fails. This seems very hard to grasp for the NGOs in both Korea and Denmark, with their strong tendency to rely on 'proven' methods, whether they are effective or not. It can also be argued that while the Korean NGOs are heavily influenced by the heritage of the revolutionary Democratic movement, they also display a willingness to change their practices and question and revise their methods and practices - something the Danes could arguably learn from. 'More of the same' might not be the wisest approach, when previous efforts for the last four decades have had relatively limited impact on the way the public live, act and consume.

\section{Theoretical Findings - the Educational Desires of the Environmental NGOs}

The empirical material not only presents valuable insight in its own right, it also makes it possible to go a step further and question the dynamics of what is apparent. The theoretical analysis is an effort to understand the significance of the perceptions of the relationship between the public and NGOs in the field of non-formal ESD. Theoretical analysis of the empirical findings makes apparent that in a Lacanian perspective the urge to create meaning and coherence is a strong motivator for the work of the NGOs. The analysis suggests how it remains possible to construct meaning in an elusive environment, where truths are hard to grasp and good intentions also contain their opposites.

The ideals that flow through the NGOs' perceptions of the public and their work not only describe an effort to build a better world, but also establish a structure whereby the individual NGO employee can continue down a beaten path, while failure to reach these ideal are evident in the surrounding life as well as in the life of the individual employee. Ideals can be seen as ways of covering the fact that the world cannot be fully understood and our own lives are short and potentially meaningless. By drawing on notions of 'sustainability' and concepts of mitigating 'climate change' it becomes possible to move beyond such a depressing perspective and engage the world from a perceived authoritative position. This process also installs the potential of understanding the chosen ideals as concepts that transcend the individual and even the social, and thus act as structuring agents that make it possible to talk about what is good and what is bad. This 
introduces the question of how the psychoanalytic subject relates to the difference between knowing something and believing in it. Arguably, individual employees do, as subjects, only have the capability to uphold a belief that global environmental challenges actually exist and threaten our society. This does not diminish the reasoning behind concepts like 'sustainability' or 'climate change', but it does imply that what is described is more than just simple facts, even if they may be considered to be such. Consequently the difference between knowing and believing constitutes a path that combines an interesting mix of abstinence and enjoyment. The interviewees express how a limited consumption, less use of energy and a more simple life goes hand to hand with the aims of their work, but at the same time they stress that the goal is not a minimalistic life. Instead the embedded ideals suggest that mitigating climate change and reaching the arguably utopian goal of a truly sustainable society also promise a better more 'authentic' life.

In this view combining enjoyment and abstinence is a way of producing desire and of upholding a structure that ensures that there is always something over the horizon that makes it feasible to move along, while being convinced that our actions of today might create a better tomorrow, even when our current actions are in fact not directly doing any good. In that way it is possible to live at the level of ideals, with a firm eye on a ball that never actually materialises, but via its abstract and intangible presence lends sense to our often arbitrary actions. The ideals of 'sustainability' and mitigating 'climate change' thus not only becomes a strong motivator, but also a way of ensuring that it is possible to do good, while little good is being done. The ideals cover up the lack in our social reality, where the contradictions that the interviewees identify also extend to the work that they invest so much energy in. This is not to argue for the depressing stance that the only thing a modern human being has to offer in the name of climate change is suicide, but to point towards the idea that not only may some ideals lead us into believing something that is at odds with the lives we live, but to argue that all ideals do that. With Lacan's slogan of Les Non-dupes errent in mind, it is however only the greatest fool that tries to transcend all ideals and see the world 'as it really is'. There is no escaping believing in something, because of the fact that only by believing in something is it possible to structure the chaotic sensory bombardment that the social constitutes. 
The NGOs move from the abstract ideals into concrete settings via the different themes that structure their work. Focusing on Youth, Daily life, Emotional/rational involvement and the potential of conflict and consensus becomes means of introducing their ideals into particular settings. These settings are not only scenes of an impressive array of participatory interactivity, but also places where its arguably reoccurring underside of interpassivity manifests itself. This concept describes the natural consequence of many of the NGOs activities: That little is learnt and even less changed in the individual lives of the participants. In relation to COP15 in Denmark it can be argued that not only did masses of Danish and international interested and concerned citizens engage in the host of activities that marked the event, they also returned happily to their normal routines of enjoying the benefits of overconsumption after the event. The activities seemed successful, the participants where happy, the NGOs where happy (at least with their own activities), but the end result was status quo. Again the particular adaptations of the ideals covered the lack in the social, making the work and effort of the NGOs worthwhile and at the same time hiding that not much came out of it. This is not to argue that the effort was not worth it, but that it seems impossible to circumvent the ideals and that part of this is explained by interpassivity as well as interactivity. Interpassivity thus moves beyond being something primarily negative, and also acts as something that upholds the inevitable ideals, as the utopian nature of these are covered.

The interviewees and the NGOs at large are at least partially aware of the lure of their ideals. In a Lacanian perspective it can be argued that exactly the inherent lies and distortion of the Real that ideals represent, are what upholds and structures reality for the individual subject. The ideals act as coping mechanisms in a highly differential postmodern society that offers little in the form of existential guidelines. The work of the NGOs is admirable, but the danger persists that they might not understand that the things they are fighting against are inevitably a part of their own lives and actions.

This leads to the last argument, which suggests an alternative understanding of daily life and educational 'bad practices' among the public and the NGOs. The importance of a study such as this arguably hinges on not only the academic insights it can uncover, but also the possibilities of returning the favour to the NGOs and pointing towards possible new ways of performing non-formal ESD. The analytical concept of Bad 
Practice is the new perspective that this study offers. The concept draws on an understanding of the individual subject as substantially good, driven by the foundational urge to create meaning and enjoyment through every given act. When we look at notions of 'bad practice' among the public along with the NGOs' hard work to dispel these activities and habits, it becomes interesting to note how doing what we know is wrong seems to make sense.

What is the significance of Bad Practice? We are arguably living in a highly dynamic world where few truths continue to stand. By adhering to ideals it becomes possible to navigate between what is good and what is bad, but it also potentially showcases the impossibility of always doing what is considered the right thing. Savouring in daily routines of Bad Practice, eating too much meat, driving in cars or dreaming of the next exotic flight destination, is thus at odds with our ideals, but also enables a situation where the ideals are kept at arm's length. After all, ends must meet in daily life. By arguing that we are only humans and as such allowed to a little daily treat, we do actually not break with our ideals, but on the contrary uphold them. A cynical distance is enforced along with the idea that 'we are not only our ideals', and thus it becomes possible at a daily level to believe that our existence still upholds the values that we counteract with our very actions. We disavow our actions of bad practice by on one hand arguing that they are part of life and at the other hand knowing that we should not be acting this way. The point is that by doing what we know is bad, we at the same time reaffirm that we are good, by establishing a distance between the way we see ourselves and the way we act in the world. Bad Practice is thus a positive understanding of the individual's potential to make meaning in a situation where none is present.

This can be applied to the work of the NGOs at two levels: Firstly the NGOs perception of the public and their continued routines of Bad Practice could be altered by taking into account that Bad Practice is not just something that should be removed or circumvented, but also as something 'positive' that establish structures of meaning making it possible to relate to the very different demands that society puts on each of us. Secondly, the Bad Practice of the environmental NGOs themselves could also benefit from a long hard look. Applying the same educational approaches that have had depressingly little impact the last 3-4 decades, and arguing that what we need is 'more of 
the same', could be understood as a way of coping with a very difficult situation, and as such Bad Practice in its purest form. Such a 'Bad ESD Practice' is in other words expressed in both the NGOs' perceptions and critique of the public and the lack of critique of their own positions.

The Bad Practices of the NGOs enable a situation where the organisations not only risk being stuck with approaches that have a hard time reaching the public, but at same time construct a process where the NGOs can create meaning in such a setting. The problem is not the environmental NGOs as such, but their utilisation of ideals and the ESD-concept. It can be argued that Bad Practice is a human condition, and the interviewees from the environmental NGOs are indeed very much normal fallible human beings. It can also be argued that while Bad Practice cannot be eradicated, it remains just as necessary to insist on the importance of the impossible, that we need ideals to structure our lives. At the same time we do however need a critical eye on how these ideals are translated into educational methods, activities and strategies. Ideals can act as great motivators, but the analysis also shows how they can reproduce existing practices that do not necessarily lead to the change that the NGOs are hoping for.

The risk remains that the public and the NGOs involved in Non-formal ESD continue to establish situations that add meaning to the meaningless while the world around us slowly spins out of control. As such Non-formal ESD remains an important and viable method of engaging the public in the most important questions of our time, but we must not forget that the efforts of the NGOs do not diminish the fact that they and we remain a part of the problem not the solution. This entails the possibility that the significance of the efforts of the NGOs and participating in their activities act more as a way of constructing meaning for the individual than as a way of actually addressing radical questions of sustainability and climate change. Trying to negate this and traverse the ideals or the concept of Bad Practice is not enough. New and different ideals are needed and are emerging in both Korea and Denmark. NGOs in both countries are part of this process and are eager grasp these possibilities, albeit some more than others. By keeping an eye on the importance for the individual of Bad Practice and the significance of engaging the public, the opportunity remains to move towards a situation where the 
desire of Bad Practice can be outlived through practices that do not slowly destroy the world we live in. 


\section{References}

- Adger, W. Neil, N. Arnell, E. Tompkins (2005) "Successful Adaptation to Climate Change Across Scales", Global Environmental Change. Vol. 15, No. 2.

- Adger, W. Neil, Suraje Dessai, Marisa Goulden, Mike Hulme, Irene Lorenzoni, Donald R. Nelson, Lars Otto Naess, Johanna Wolf and Anita Wreford (2009) “Are there social limits to adaptation to climate change?" Climatic Change. Vol. 93, No. $3-4$.

- AERA (2006) Standards for Reporting on Empirical Social Science Research in AERA Publications. American Educational Research Association. http://weraonline.org/ResearchReportingStandards.htm. 29-3-2012.

- Agamben, Giorgio (1999) Potentialities: collected essays in philosophy. Stanford University Press.

- Agenda 21 (2010) Interview with key person from Local Agenda21 Action Council for Gyeonggi-do on the 15-10-2010.

- AGEPP (2008) Japan Council on the UN Decade of Education for Sustainable Development (ESD-J). Tokyo: ESD-Japan.

- Ahn, Sang-hoon \& So-Chung Lee (2005) "The Development of the South Korean Welfare Regime" in Chack-Kie Wong \& Alan Walker East Asian Welfare Regimes in Transition: From Confucianism to Globalisation. Bristol: Policy Press.

- Allardt, Erik (1976) "Dimensions of Welfare in a Comparative Scandinavian Study”. Acta Sociologica. Vol. 19, No. 3.

- Aldy, Joseph E. (2006) "Per Capita Carbon Dioxide Emissions: Convergence or Divergence?" Environmental and Resource Economics. Vol. 33, No 4.

- Althusser, Louis (1969) "Freud and Lacan". New Left review. Vol. 55.

- Althusser, Louis (1972) "Ideology and Ideological State Apparatuses". Lenin and Philosophy and Other Essays, Monthly Review Press.

- Anderson, Douglas R. (1995) Strands of System - The Philosophy of Charles Pierce. West Lafayette: Purdue University Press. 
- Anderson, David L. T. \& Jürgen Willebrand, (1996) Decadal Climate variability: Dynamics and Predictability. New York: North Atlantic Treaty Organization. Scientific Affairs Division.

- Anderegg, William R L; James W. Prall, Jacob Harold, and Stephen H. Schneider (2010). "Expert credibility in climate change". PNAS.

http://www.pnas.org/content/early/2010/06/04 /1003187107.full.pdf+html 29-32012.

- Anshelm, Jonas \& Anders Hansson (2011) Climate Change and the Convergence between ENGOs and Business: On the Loss of Utopian Energies. Environmental Values. Vol. 20, No. 1.

- Armstrong, Charles K. (2007) Korean Society: Civil Society, Democracy and the State. New York: Routledge.

- Asplund, Johan (1970) Om Undren overfor Samfundet. Copenhagen: Hans Reitzel.

- Bailly, Lionel (2009) Lacan, Oxford: Oneworld Publications.

- Becker, Carl, B. (1986)'Reasons for the lack of argumentation and debate in the Far East” International Journal of Intercultural Relations. Vol. 10, No. 1.

- Beiser, Frederick (2005) Hegel. New York: Routledge.

- Black, Richard (2010) "Why did Copenhagen fail to deliver a climate deal?" Outreach. http://www.stakeholderforum.org/sf/mediafiles/OutreachUNFCCC\%20COP\%2015FinalWrapUp.pdf 29-3-2012.

- Bookchin, Murray (2010) "Social Ecology versus Deep Ecology: A Challenge for the Ecology Movement". libcom.org. ftp://ftp.jp.scene.org/pub/scene/music/groups/ enough_records/enrmp278__united_consumer_fuckers__prepare_for_revolution/ 00_murray_bookchin__social_ecology_versus_deep_ecology_-_a_challenge_for_the_ecology_ movement.pdf 29-3-2012.

- Böhm, Steffen \& Siddhartha Dhabi (2011) "Commentary: Fault lines in climate policy: what role for carbon markets?" Climate Policy. Vol. 11, No. 6.

- Boyle, Kirk (2008) “The Four Fundamental Concepts of Slavoj Žižek’s Psychoanalytic Marxism” International Journal of Žižek Studies. Vol. 2. No. 1. 
- Borish, Steven M. (1991) The Land of the Living. The Danish Folk high Schools and Denmark's Non-violent Path to Modernization. Nevada City: Blue Dolphin.

- Breindl, Yana, Pascal Francq (2008) “Can Web 2.0 applications save edemocracy? A study of how new internet applications may enhance citizen participation in the political process online". International Journal of Electronic Democracy. Vol. 1, No. 1.

- Bryman, Alan (2004) Social Research Methods. Oxford: Oxford University Press.

- Bryant, Levi, Nick Srnicek \& Graham Harman (2011) The Speculative turn. Melbourne: re.press.

- Bubner, Rüdiger (1995) The Innovation of Idealism. Cambridge University Press.

- $\quad$ Bunkowski, Janine (2003) Introduction to Samuelnori. www.hampton.va.us/parks/icf/pdf/korean_samulnor_info.pdf 4-5-2003 26-6-2011

- Busck, Steen et al. (2002) Danmarkshistorien - I Grundtrak. Aarhus: Aarhus University Press.

- Butler, Judith (2000) "Dynamic Conclusions" in Judith butler, Ernesto Laclau and Slavoj Žižek: Contingency, Hegemony, Universality: Contemporary Dialogues on the left. New York: Verso.

- CEA (2010) Interview with key person from Centre for Energy Alternative (CEA) Seoul on the 15-11-2010.

- CEA (2011) Centre for Energy Alternative http://energyvision.org/52. 11-8-2011.

- Chang, Mee-Jeong (2007) Social Environmental Education of Korea. Paper presented at the 2007 International Workshop: Environmental Education for Citizens in Asia, Meeting and Networking.

- Charnovitz, Steve (1997) "Two Centuries of Participation: NGOs and international Governance.” Michigan Journal of International Law, vol. 18.

- Cho, Han-Gyu (2009) "Green Growth requires Lifestyle Change”, in Green Growth (II), Korea's New development Strategy. Seoul: Jimoondang.

- Cho, Hein (1997) “The Historical Origin of Civil Society in Korea”, Korea Journal. vol.37.

- Choe, Chang-Jip and Im, Hyon-Jin (eds.) (1993) The Challenge of Civil Society. Seoul: Nanam. 
- Chung, Chulhee (1997) "Social movement organizations and the June uprising". Korea Journal Vol. 37.

- Christoff, Peter (1996), "Ecological Modernisation, Ecological Modernities", Environmental Politics, Vol. 5, No. 3.

- CJA (2010) Interview with key person from Climate Justice Action on the 19-42010.

- CJA (2011) www.climate-justice-action.org/about/ 29-3-2010.

- CMD (2010) Interview with key person from the Climate movement of Denmark on the 24-3-2010 Copenhagen.

- CMD (2011) http://www.klimabevaegelsen.dk 29-3-2012

- CMEJ (2010) Interview with key person from Citizen's Movement for Environmental Justice (CMEJ) on the 21-10-2010.

- Connelly, Steve (2007) "Mapping Sustainable Development as a Contested Concept". Local Environment: The International Journal of Justice and Sustainability. Vol.12, No. 3.

- Corcoran, Peter Blaze, Kim E. Walker \& Arjen E.J. Wals (2004) "Case studies, make-your-case studies, and case stories: a critique of case-study methodology in sustainability in higher education" Environmental Education Research Volume 10, No. 1.

- Cornford, Francis MacDonald (2010) Plato's Theory of Knowledge. London: Taylor \& Francis.

- Cumings, Bruce (1997) Korea's Place in the Sun: A Modern History. New York: W.W. Norton \& Company.

- DAEA (2010) Interview with key person from Danish Adult Education Association on the 9-3-2010 Copenhagen.

- DAEA (2011) Danish Adult Education Association. http://www.dfs.dk 3-5-2011.

- Dai-Yeun (2007) "From the Ideology of Sustainable Development to Modeling a Sustainable Society: Conceptualizing Policy Change and Environmental Indicator Interactions in South Korea", Korean Social Science Journal. No. 2.

- Daly, Robert (1995) "From Paradox and Aporia to Cultural Hybridization and Complex Adaptive Systems: New Theories and the Uses of Cooper at the Present 
Time". In Hugh C. MacDougall (ed.) James Fenimore Cooper: His Country and His Art (No. 10), Papers from the 1995 Cooper Seminar (No. 10), The State University of New York College at Oneonta.

- Deleuze, G. and Guattari, F. (1987). A Thousand Plateaus: Capitalism and Schizophrenia (B. Massumi, Trans.). Minneapolis: University of Minnesota Press.

- Deleuze, G. (1995). Negotiations (M. Joughin, Trans.). New York: Columbia University Press.

- Dewey, John (1916) Democracy and Education, New York: The MacMillan Company.

- Douglas, Mary (2002) Purity and danger: an Analysis of Concepts of Pollution and Taboo. New York: Routledge.

- Doucette, Jamie (2010) "The Terminal Crisis of the "Participatory Government" and the Election of Lee Myung Bak” Journal of Contemporary Asia. Vol. 40, No. 1.

- Dresner, Simon (2002) The Principles of Sustainability. London: Earthscan.

- Dryzek, John S. (2005) The Politics of the Earth-Environmental Discourses. Ney York: Oxford University Press.

- Dubois, Anna, and Lars-Erik Gadde (2002). "Systematic combining: an abductive approach to case research." Journal of business research. Vol. 55, nr. 7.

- Easterlin, A. \& Onnicha Sawangfa (2009) Happiness and Economic Growth: Does the Cross Section Predict Time Trends? Evidence from Developing countries, Bonn: the Institute of the Study of Labour (IZA).

- Egmose, Jonas (2011) Towards Science for Democratic Sustainable Development. Roskilde: Roskilde University.

- Ehrenfeld, John R. (2004) "Searching for Sustainability: No Quick Fix". Reflections: The SoL Journal, Vol. 5, No. 8.

- Evans, Dylan (2010) An introductory Dictionary of Lacanian Psychoanalysis. London: Routledge.

- Eyerman, Ron (1981) "False Consciousness and Ideology in Marxist Theory". Acta Sociologica. Vol. 24, No. 1-2. 
- Eyerman, Ron \& Andrew Jamison (1991) Social movements: a Cognitive Approach. Cambridge: Polity Press.

- Esook, Yoon (2006)"South Korean Environmental Foreign Policy" Asia-Pacific Review, vol. 13, no. 2.

- Flecha, Ramón (2000) Sharing words: Theory and Practice of Dialogic Learning. Maryland: Rowman \& Littlefield.

- Flyvbjerg, Bent (2006)"Five Misunderstandings About Case-Study Research". Qualitative Inquiry. Vol.12. No. 2.

- Foster, John (2008) The Sustainability Mirage. Illusion and Reality in the Coming War on Climate Change. London: Earthscan.

- Foucault, Michel (1974). Prisons et a Siles dans le Mécanisme du Pouvoir' in Dits et Ecrits. Paris: Gallimard.

- Fordham, P. E. (1993) "Informal, Non-formal and Formal Education Programmes" in YMCA George Williams College ICE301 Lifelong Learning Unit 2, London: YMCA George Williams College.

- Freire, Paolo (2006) Pedagogy of the Oppressed. New York: The Continuum International Publishing Group.

- Freud, Sigmund (2011) The Ego and the Id - First edition text, New York: Pober publishing.

- Freud, Sigmund (1991) Introductory lectures on psychoanalysis. London: Penguin Books

- Freudenburg, William R. \& Violetta Muselli (2010) “Global warming estimates, media expectations, and the asymmetry of scientific challenge”. Global Environmental Change. Vol. 20, No. 3.

- Gallego, Aina (2008) "Where Else Does Turnout Decline Come From? Education, Age, Generation and Period Effects in Three European Countries". Scandinavian Political Studies. Vol. 32, No. 1.

- Gallie, W.B. (1956), "Art as an Essentially Contested Concept", The Philosophical Quarterly, Vol.6, No.23.

- Gallup (2011) “TNS Gallup TV Meter" cited in "Vi ser over fire timers fjernsyn om dagen" Information. 19-4-2011. 
- Geem, Zong Woo \& William E. Roper (2009) "Energy Demand Estimation of South Korea Using Artificial Neural Network", Energy Policy Vol. 37, No. 10.

- Gerring, John (2001) Social Science Methodology: A Critical Framework. Cambridge: Cambridge University Press.

- Giddens, Anthony (1991) Modernity and Self-Identity: Self and Society in the Late Modern Age. Stanford: Stanford University Press.

- Green Asia (2010) Interview with key person from Green Asia on the 13-10-2010 Seoul.

- Green Gyeonggi 21 (2011) Development Plan for Gyenggi and Korea. www.ggag21.or.kr/english/main.htm 29-3-2012 3-6-2011.

- Green Korea (2010) Interview with key person from Green Korea on the 14-102010.

- Hajer, M.A. (1995) The Politics of Environmental Discourse: Ecological Modernization and the Policy Process, Oxford: Oxford University Press.

- Hamadache, A (1991) "Non-formal Education a Definition of the Concept and Some Examples", Prospects, Vol. 21, No. 1.

- Hansalim (2010) Interview with key person from the Hansalim Co-Op on the 9-102010 Seoul.

- Hansalim (2011) The Hansalim Coop. http://www.hansalim.or.kr/ 10-9-2012.

- Han, Sang-Jin (1997) "The Public Sphere and Democracy in Korea", Korea Journal. Vol. 37.

- Haig, Brian D. (2005) "An Abductive Method of Scientific Method". Psychological Methods. Vol. 10, No. 4.

- Hargreaves, David H. (1997) “A Road to the Learning Society”. School Leadership \& Management. Vol. 17, No.1

- Hartmann, Heinz (1964) Essays on Ego Psychology. Oxford, England: International U. Press.

- Harman, Graham (2010) Towards Speculative Realism. Hants: Zero books.

- Haug, Constanze \& Frans Berkhout (2010) "Learning the Hard Way? European Climate Policy After Copenhagen" Environment: Science and Policy for Sustainable Development. Vol. 52, no. 3. 
- Hauslohner, Abigail (2011) “Is Egypt About to Have a Facebook Revolution?" Time World, 24-1-2011.

http://www.time.com/time/world/article/0,8599,2044142,00.html 9-10-2012

- Herder, Johann Gottfried von, (1967) Auch Eine Philosophie der Geschichte zur Bildung der Menschheit. Riga, 1774; Frankfurt am Main: Suhrkamp Verlag.

- Holliman, Richard (2012). "The Struggle for Scientific Consensus: Communicating Climate Science around COP-15”. In: Brady Wagoner, Erik Jensen and Julian A. Oldmeadow (eds.). Culture and Social Change: Transforming Society through the Power of Ideas. Charlotte, N.C., USA: Information Age Publishing.

- Hong Y, Park, Geon-Cheol Shin \& Sung Hahn Suh (2008) "Advantages and shortcomings of Korean Chaebols" International Business \& Economics Research Journal. Vol. 7, Nr. 5.

- Hong SK, Henderson J, Olszowka A, Hurford WE, Falke KJ, Qvist J, Radermacher P, Shiraki K, Mohri M, Takeuchi H, et al. (1991) "Daily Diving Pattern of Korean and Japanese breath-hold Divers (ama)." Undersea Biomed Res. Vol. 18, No. 5-6.

- Huismann, Wilfried (2011) "Der Pakt mit Dem Panda: Was uns der WWF verschweigt". Documentary broadcasted by the German ARD Television channel on the 22-7-2011.

- Hwang, Jang-Jin (2009) "Korea Champions Green growth (Interview with Kim Hyung-Kook)" in Green Growth (II) - Korea's New Development Strategy. Seoul: Edited by the Korea Herald.

- Ilyenkov, Evald (2008) Dialectics of the Abstract \& the Concrete in Marx's Capital. Delhi: Aakar Books.

- Isherwood, Julian (2009) “COP15: “Police Arrest CJA leader”. Politiken 15-122009.

- Jager, Sheila Miyoshi (2003) Narratives of Nation Building in Korea: A Genealogy of Patriotism. New York: M.E. Sharpe.

- Jamison, Andrew (2001) The Making of Green Knowledge: Environmental Politics and Cultural Transformation. Cambridge University Press. 
- Jamison, Andrew, Ron Eyerman, Jacqueline C. Cramer \& Jeppe Læssøe (1990). The Making of the New Environmental Consciousness: A Comparative Study of the Environmental Movements in Sweden, Denmark and the Netherlands. Edinburgh: Edinburgh University Press.Jeong,

- Jang, Soong-Nang, Ichiro Kawachi, Jiyeun Chang, Kachung Boo, Hyun-Gu Shin, Hyejung Lee, Sung-il Cho (2009) "Marital status, Gender, and Depression: Analysis of the Baseline Survey of the Korean Longitudinal Study of Ageing (KLoSA)" Social Science \& Medicine. Vol. 69, No. 11.

- Jeong, Dai-Yeun (2011) "Environmental Attitudes and Behaviours Among Jeju Islanders, South Korea". Island Futures. Global Environmental Studies

- Jepson, Paul (2005) "Governance and accountability of environmental NGOs". Environmental Science \& Policy, vol. 8.

- Kahn, Matthew E. \& Fran Lostys. (2009) "Living Green: Full Country and City Rankings. Reader's Digest. http://chicagoconservationcorps.org/blog/wpcontent/uploads $2 / 2009 / 07 / \mathrm{C} 17 \% 20$ Greenest $\% 20$ countries\%20and\%20cities\%20lis t.pdf 29-3-2012

- Kant, Immanuel (1786) Grundlegung zur Metaphysik der Sitten. J.F. Hartknoch.

- Jeju KEEC (2010) Interview with key person from Jeju Korean Environmental Education Center on the 27-10-2010 Jeju-Do.

- Kemp, Peter \& Lisbeth Witthøft Nielsen (2009) Klimabevidsthedens Barrierer. Copenhagen: Tiderne Skifter.

- KFEM (2010) Interview with Key person from KFEM on the 15-11-2010, Seoul.

- KFEM (2011) Threatened Biodiversity in South Korea 2010. Seoul: Korea Federation for Environmental Movements (KFEM)/ Friends of the Earth Korea.

- Kim, Sunhyuk (1996) Civil Society in South Korea: From Grand Democracy Movements to Petty Interest Groups? Journal of Northeast Asian Studies. Vol. 15 No.2.

- Kim, Soon-Kyung, Jong-Wha Lee \& Ae-Jung Kim (1998) "The Study on the seafood Pollution According to Environmental Pollution of the Western coast in Korea in Fish", Journal of the Korean Society of Food Science and Nutrition. Vol. 26, No. 5 . 
- Kim, Pan S. \& M. Jae Moon (2003) "NGOs as Incubators of Participative Democracy in South Korea: Political, Voluntary, and Policy Participation”. International Journal of Public Administration. Vol. 26, No. 5.

- Kim, J., K.-O. Boo, \& N.-O. Kim, (2000) "The Features of the Yellow-sand Phenomenon in Korea in Wintertime". Journal of. Korean Society for Atmospheric Environment vol. 16.

- Kim, Hyuk-Rae (2000) "The State and Civil Society in Transition: the role of Nongovernmental Organizations in South Korea”, The Pacific Review Vol. 13, No. 4.

- Kim, Sunwoong \& Ju-Ho Lee (2006) "Changing Facets of Korean Higher Education: Market Competition and the Role of the State", Higher Education. vol. 52, No. 3

- Kim, Seung-kyung \& Kyounghee Kim (2011) "Gender mainstreaming and the institutionalization of the women's movement in South Korea". Women's Studies International Forum. Vol. 34, nr. 5

- Klafki, Wolfgang (1995) "Didactic Analysis as the Core of Preparation of Instruction (Didaktische Analyse als Kern der Unterrichtsvorbereitung)" Journal of Curriculum Studies. Vol. 27, No. 1.

- Kojéve, Alexandre (1969) Introduction to the Reading of Hegel. New York Basic Books.

- Koo, Hagen (2002) "Civil Society and Democracy in South Korea”. The Good Society, Vol. 11, No. 2

- Korsgaard, Ove (2002) “A European Demos? The Nordic Adult Education Tradition-Folkeoplysning_Faces a Challenge.” Comparative Education, Vol. 38 No. 1 .

- Krohn, Søren (2002) Danish Wind Turbines: An Industrial Success Story. Copenhagen: Danish Wind Industry Association,

- Kvale, Steinar (1997) InterView. Copenhagen: Hans Reitzels Forlag.

- Lacan, Jacques (1974) Les Non-dupes Errent, unpublished seminar, 1973/4. http://www.scribd.com/doc/48830066/Jacques-Lacan-Seminaire-Livre-XXI-LesNon-Dupes-Errent. 29-3-2012 
- Lacan, Jacques (1991) The Seminar of Jacques Lacan: Book II: The Ego in Freud's Theory and in the Technique of Psychoanalysis 1954-1955. New York: W. W. Norton \& Company.

- Lacan, Jacques (1998) On Feminine Sexuality, the Limits of Love and Knowledge: The Seminar of Jacques Lacan, Book XX Encore (edited by Jacques-Alain Miller), New York: Norton, 1998.

- Lacan, Jacques (2004) The four Fundamental Concepts of Psycho-analysis. London: Karnac

- Lacan, Jacques (2006a) Écrits. New York: Norton.

- Lacan, Jacques (2006b) "the Mirror Stage as Formative of the Function of the I as Revealed in Psychoanalytic Experience. In John Storey's Cultural Theory and Popular Culture: a Reader. London: Pearson.

- Laclau, Ernesto (1996)"Why do empty signifiers matter to politics?” in Ernesto Laclau, Emancipation(s), London: Verso.

- Laclau, Ernesto and Chantal Mouffe (2001) Hegemony and Socialist Strategy towards a Radical Democratic Politics, London: Verso.

- Laplanche, Jean \& Jean-Bertrand Pontalis. (1973) The Language of PsychoAnalysis, London: Hogarth Press and the Institute of Psycho-Analysis.

- Lapping, Claudia. (2011) Psychoanalysis in Social Research: Shifting theories and reframing concepts. London: Routledge.

- Laustsen, Carsten Bagge (1999) "Ideologiske Fantasmer - Politisk filosofi med Jacques Lacan og Slavoj Žižek" in Den ene, Den Anden, Det tredje - Politisk identitet, andethed og fallesskab i moderne Fransk Tankning af Carsten Bagge Laustsen og Anders Berg-Sørensen (Red.). Copenhagen: Politisk Revy.

- Lave, Jean (1996)"Teaching, as Learning, in Practice" Mind, Culture, and Activity. Vol. 3, nr. 3 .

- Lash, Scott, Bronislaw Szerszynski, Brian Wynne (1996) Risk, Environment and Modernity: towards a New Ecology. New York: SAGE.

- Lee, Moon Hee (2006) “The 'Public' and the 'Private' in Korean Higher Education: one Private Dominating System”. Journal of Asian Public Policy Vol. 1, No. 2. 
- Lee, Sook-Jong (2004) "The Rise of the Korean Youth as a Political Force". In Richard C. Bush, Sharon Yanagi, Kevin Scott (eds.) Brookings Northeast Asia survey 2003-2004. Washington: Brookings.

- Lim, Hyun-Chin \& Jin-Ho Jang (2006) "Neo-liberalism in post-crisis South Korea: Social conditions and outcomes". Journal of Contemporary Asia. Vol. 36, No. 4

- Læssøe, Jeppe (2007a) ” Folkeoplysning om Bæredygtig Udvikling- En Historie om afradikalisering og Bagvedliggende Uklarheder”. I Jesper holm, Lars Kjerulf Petersen, Jeppe Læssøe, Arne Remmen \& Carsten Jahn Hansen (eds.) Økologisk modernisering på dansk. Copenhagen: Frydenlund.

- Læssøe, Jeppe (2007b) 'Participation and sustainable development: The postecologist transformation of citizen involvement in Denmark', Environmental Politics, Vol. 16, Nr. 2.

- Læssøe, Jeppe (2011) “Deltagelse og Miljøpædagogik” i Kari Kragh Blume Dahl, Jeppe Læssøe, Venka Simovska (red) Essays om dannelse, didaktik og handlekompetence - inspireret af Karsten Schnack. Copenhagen: Danish School of Education.

- Marshall. Catherine \& Gretchen B. Rossman (1999) Designing Qualitative Research. London: Sage.

- Marx, Karl (1970) Kapitalen, Kritik af den politiske økonomi” København: Rhodos.

- Meillassoux, Quentin (2009) After finitude - An essay on the Necessity of Contingency. London: Continuum.

- Meilstrup, Per (2010) “The Runaway Summit: The Background Story of the Danish Presidency of COP15, the UN Climate Change Conference". In Nanna Hvidt \& Hans Mouritzen (eds.) Danish Foreign Policy Yearbook 2010. Copenhagen: DIIS.

- Mol, Arthur P.J. \& David A. Sonnenfeld (2000) ““"Ecological modernization” around the world: An introduction”. Environmental Politics. Vol. 9, No.1.

- Mullins, Patrick, Dai-Yeun Jeong, John S. Western, Ian Lowe, Rod Simpson (2004) Consumerism and Sustainable Development: An Australian-South Korean Comparative Study Korean Social Science Journal Vol. 31. No. 1. 
- Ng-A-Fook, Nicholas (2010) “Another Bell Ringing in the Empty Sky: Green washing, Curriculum, and Ecojustice”, Journal of the Canadian association for Curriculum Studies, Vol. 8, No 1.

- Nielsen, Birger Steen \& Kurt Aagaard Nielsen (2005) 'Kritisk-utopisk aktionsforskning". In: G. Christensen and T.B. Jensen (ed.) Psykologiske og Padagogiske metoder. Roskilde: Roskilde Universitets forlag.

- Nielsen, Jørgen Steen (2008) “Klimaudfordringen skal ned på Jorden” 2-4-2008 Information.

- Nisbet, Matthew C. (2009) "Communicating Climate Change: Why Frames Matter for Public Engagement" Environment: Science and Policy for Sustainable Development. Vol. 51, No. 2.

- Normile, Dennis (2010)"Restoration or Devastation?" Science. Vol. 327 no. 5973

- Oh, Je Seong (2007) Urban Ecotourism: Applying Natural Ecological resources to Tourism in Seoul, Korea. Master Thesis from the Department of Public Administration in the College of Community and Public Affairs, Binghamton University, State University of New York.

- Oliver, Martin \& Grainne Conole (2003) Evidence-based practice and e-learning in Higher Education: can we and should we? Research Papers in Education. Vol. 18, No. 4.

- O'Reilly, Tim and John Battelle (2009) Web Squared: Web 2.0 Five Years On. Special report to the Web 2.0 summit. http://gossgrove.com/sites/default/files/web2009_websquared-whitepaper.pdf. 293-2012

- Ortega, Daniel H. (2009) "The Ecology of Practice: Spatial Tactics, the Present City and the Ideology of Sustainability”. InTensions Journal. Vol. 2

- Parajuli, Ranjan (2012) "Looking into the Danish energy system: Lesson to be learned by other communities" Renewable and Sustainable Energy Reviews. Vol.16, No. 4.

- Pastina, Antonio C., Cacilda M. Rego La, Joseph D. Straubhaar (2003) “The centrality of telenovelas in Latin America's everyday life: Past tendencies, current knowledge, and future research". Global Media Journal. Vol. 2, No. 2. 
- PCA (2010) Interview with key person from People's Climate Action on the 9-22010 Copenhagen.

- PCA (2011) Civilsamfundet og COP 15 - Erfaringer og Gode Råd. Copenhagen: People's Climate Action.

- Pfaller, Robert (2003) Die Illusionen der anderen: Über das Lustprinzip in der Kultur. Frankfurt: Suhrkamp.

- Piaget, Jean (1977). The Essential Piaget. Gruber, H.E.; Voneche, J.J. (eds.) New York: Basic Books.

- Pinkard, Terry (1996) Hegel's Phenomenology - The Sociality of Reason. Cambridge University Press.

- Pines, Christopher L. (1993) Ideology and False Consciousness: Marx and his Historical Progenitors. New York: SUNY Press.

- Popper, Karl (2000) Conjectures and Refutations - the Growth of Scientific Knowledge. London: Routledge.

- Rose, Chris (1993) "Beyond The Struggle For Proof: Factors Changing The Environmental Movement". Environmental Values. Vol. 2, No. 4.

- Salamon, Lester M. \& Helmut K. Anheier (1994) The Emerging Sector: The Nonprofit Sector in Comparative Perspective: An Overview. Baltimore: The John Hopkins Institute for Policy Studies.

- Schlembach, Raphael (2011) "How do Radical Climate Movements Negotiate their Environmental and their Social Agendas? A study of Debates within the Camp for Climate Action (UK)". Critical Social Policy. Vol. 31 No. 2.

- Schnack, Karsten \& Bjarne Bruun Jensen (1997) "The Action Competence Approach in Environmental Education" Environmental Education Research Vol. 3, No. 2.

- Schnack, Karsten (2005), "Handlekompetence", in J. Rasmussen \& N. J. Bisgaard (Eds.), Pcedagogiske Teorier. Værløse: Billesø og Baltzer.

- Schoenbrod, David (2002) "The Mau mauing of Bjorn Lomborg". Commentary Magazine, Vol. 114, No. 2. 
- Sebok, Thomas A. and Jean Umiker-Sebok (1979) "“'You Know My Method": A juxtaposition of Charles S. Peirce and Sherlock Holmes” Semiotica. Vol. 26, nr. 34.

- Selby, David \& James Gray-Donald (2008) Environmental Educators Dancing Away from Mechanism. Rotterdam: Sense.

- Seo, Joo Hwan, Sung Yong Park, Larry Yu (2009) "The Analysis of the Relationships of Korean Outbound Tourism demand: Jeju Island and Three international destinations" Tourism Management Vol. 30, nr 4.

- Sharpe, Matthew (2004) Slavoj Žižek: a Little Piece of the Real. London: Ashgate Publishing

- Shin, Hyunjoon (2009) "Have you ever seen the Rain? And who'll stop the Rain?: the globalizing project of Korean pop (K-pop)" Inter-Asia Cultural Studies, Vol. 10, nr. 4

- Sloterdijk, Peter (2005) Kritik af den Kyniske fornuft. Copenhagen: Det Lille Forlag.

- Söderbaum, Peter (2009) "Making Actors, Paradigms and Ideologies Visible in Governance for Sustainability”. Sustainable Development. Vol. 17, No. 2.

- Sokal, Alan, and Jean Bricmont (1998) Intellectual Impostures: Postmodern Philosophers' Abuse of Science. London: Profile Books.

- Sternquist, Brenda \& Byongho Jin (1998) "South Korean Retail Industry: Government's Role in Retail Liberalization. International Journal of Retail \& Distribution Management. Vol.25, No. 9.

- Stubager, Rune (2010) “The Development of the Education Cleavage: Denmark as a Critical Case". West European Politics .Vol. 33, No.3.

- Sungho, Tae \& Sungwoo Shin (2009) "Current work and Future Trends for Sustainable Buildings in South Korea". Renewable and Sustainable Energy Reviews. Vol. 13, No. 8.

- Sveiby, Karl-Erik \& Roland Simons, (2002) "Collaborative Climate and Effectiveness of Knowledge work - an Empirical Study", Journal of Knowledge Management, Vol. 6, No. 5. 
- Switzer, Jacqueline Vaughn (2001) "Influencing Environmental Policy in Rural Communities: The Environmental Opposition at Work" Policy Studies Journal. Vol. 29, No. 1.

- Taehee, Yim (2010)"Green Growth Strategy to Spur Job Creation" Korea Times, 04-22-2010.

- Tamney, Joseph B. and Stephen D. Johnson (1998) “The Popularity of Strict Churches". Review of Religious Research. Vol. 39, No. 3.

- Taylor, Charles (1999) Hegel. New York. Cambridge University Press.

- The Earth Charter Initiative (2000). "The Earth Charter." http://www.earthcharterinaction.org/content/pages/Read-the-Charter.html. 29-32012

- $\quad$ Thøgersen, John \& Folke Ölander (2002) "Human values and the emergence of a sustainable consumption pattern: A panel study". Journal of Economic Psychology. Vol. 23, No. 5.

- Thøgersen, John (2010) “Country Differences in Sustainable Consumption: The Case of Organic Food". Journal of Macromarketing. Vol. 20. No. 2.

- Turner, Brian (1992). Max Weber - From history to modernity. London: Routledge

- Traies, Samantha Jane (2005) Corporate Sustainability: Greenwash or a Path to Sustainable Capitalism? Ph.d.-thesis from Deakin University. Http://dro.deakin.edu.au/eserv/DU:30023253/traies-corporatesustainability2005.pdf. 29-3-2012

- Ungar, Sheldon (2000) "Knowledge, ignorance and the popular culture: climate change versus the ozone hole". Public Understanding of Science. Vol. 9, No. 3.

- UN (1987) Report of the World Commission on Environment and Development: Our Common Future. Transmitted to the General Assembly as an Annex to document A/42/427 - Development and International Co-operation: Environment. http://www.un-documents.net/wced-ocf.htm. 29-3-2012.

- UNESCO (2005) The DESD in Brief. Paris: UNESCO.

- UNESCO (2009) "Leading the International Agenda - Education for Sustainable Development". http://www.unesco.org/new/en/education/themes/leading-the- 
international-agenda/education-for-sustainable-development/education-forsustainable-development/. 29-3-2012.

- UNESCO (2011) http://www.unesco.org/en/esd/publications/good-practices/. 293-2012.

- Uusitalo, Liisa (1990) “Are Environmental attitudes and Behaviour Inconsistent? Findings from a Finnish Study". Scandinavian Political Studies, Vol. 13. No.

- Vrasidas, Charalambos (2001) "Interpretivism and Symbolic Interactionism: "Making the Familiar Strange and Interesting Again" in Educational Technology Research”. Research Methods in Educational Technology, Vol. 1986.

- Vygotsky, L. S. (1978). Mind in society: The development of higher psychological processes. Cambridge, MA: Harvard University Press.

- Wals, Arjen E.J., Bob Jickling, (2002) "“Sustainability” in Higher Education: From Doublethink and Newspeak to Critical Thinking and Meaningful Learning", International Journal of Sustainability in Higher Education. Vol. 3, No. 3.

- Ward, Robert E. T. (2008) "Good and Bad Practice in the Communication of Uncertainties Associated with the Relationship Between Climate Change and Weather-related Natural Disasters" in Geological Society, special publication: Communicating Environmental Geoscience vol. 305.

- Weaver, David (2002) “Asian Ecoturism: Patterns and Themes”, Tourism Geographies. Vol. 4, No. 2.

- Weber, Max (1995). Den protestantiske etik og kapitalismens ånd. Copenhagen: Nansensgade antikvariat.

- Webster, Richard. (1994) "The Cult of Lacan: Freud, Lacan and the mirror stage. http://www.richardwebster.net/thecultoflacan.html. 29-3-2012

- Wells, Kenneth M. (1995) South Korea's Minjung Movement: The Culture and Politics of Dissidence. Honolulu: University of Hawai i Press.

- Weiss, Thomas G. \& Leon Gordenker (1996) NGOs, the UN, and Global Governance (Emerging Global Issues). Boulder: Lynne Rienner Publishers

- White, Susan (1997) "Beyond Retroduction? - Hermeneutics, Reflexivity and Social Work Practice" British Journal of Social Work. Vol. 27, No. 5. 
- Whitmarsh, Lorraine (2009) "Behavioural responses to climate change: Asymmetry of intentions and impacts" Journal of Environmental Psychology. Vol. 29, No. 1.

- Wiegand, Bjarke (2009)'The Front-runners in the Climate Fight” Mandag Morgen. 4-10-2009.

- WNA (2012) World Nuclear Association - Promoting the peaceful worldwide use of nuclear power as a sustainable energy resource. www.world-nuclear.org/ 29-32012.

- WWF (2010) Interview with key person from the World Wide fund for Nature, Denmark on the 24-3-2010.

- WRI (2011) World Resources Institute, http://earthtrends.wri.org/ 8-10-2011

- WWF (2012) www.Burningpanda.dk 4-1-2012.

- Ying, Xu, Gao Xuejie and F. Giorgi (2009) "Regional Variability of Climate Change Hot-Spots in East Asia”. Advances in Atmospheric sciences. Vol. 26, No. 4.

- York, Richard \& Brett Clark (2010)"Critical Materialism: Science, Technology, and Environmental Sustainability”. Sociological Inquiry. Vol. 80, No. 3.

- Yu, Chong (1994). “Abduction? Deduction? Induction? Is There a Logic of Exploratory Data Analysis?" In Papers presented at the Annual Meeting of the American Educational Research Association. New Orleans, LA, April 4-8, 1994.

- Yu, Pal-Mu and Kim, Ho-Gi (eds.) (1995) Civil Society and Civil Movements, Seoul: Hanul.

- Žižek, Slavoj (1989) The Sublime Object of Ideology. London: Verso.

- Žižek, Slavoj (1993) Tarrying with the Negative: Kant, Hegel, and the critique of ideology. Duke University Press.

- Žižek, Slavoj (1994) “The Specter of Ideology” in Slavoj Žižek (ed.) Mapping Ideology. London: Verso.

- Žižek, Slavoj (1996) The Indivisible Remainder - Essays on Schelling and Related Matters. London: Verso.

- Žižek, Slavoj (2003) “Will you Laugh for me, Please?” In these Times. July 182003. http://www.inthesetimes.com/article/88/ 29-32012. 
- Žižek, Slavoj (2004) “What Rumsfeld doesn’t Know he Knows about Abu Ghraib. In these times. 21-5-2004. www.lacan.com/Žižekrumsfeld.htm 29-3-2012.

- Žižek, Slavoj (2005) "Between Symbolic Fiction and Fantasmatic spectre: Toward a Lacanian Theory of Ideology" in Slavoj Žižek, Rex Butler, Scott Stephens Interrogating the Real. New York: Continuum International Publishing Group.

- Žižek, Slavoj (2006a) How to Read Lacan. London: Granta.

- Z Žižek, Slavoj (2006b) “The Most Sublime of Hysterics: Hegel with Lacan“in Slavoj Žižek, Rex Butler, Scott Stephens Interrogating the Real. New York: Continuum International Publishing Group.

- Žižek, Slavoj (2006c) The Parallax View. Cambridge: MIT Press.

- Z Žižek, Slavoj (2006d) "Smashing the Neighbor's Face." in: Lacan.com. http://www.lacan.com/zizsmash.htm 29-3-2012.

- Žižek, Slavoj (2008a) Enjoy Your Symptom! New York: Routledge.

- Žižek, Slavoj (2008b) For They Know not What They Do: Enjoyment as a Political Factor. London: Verso.

- Žižek, Slavoj (2009a) First as Tragedy, Then as a Farce. London Verso.

- Žižek, Slavoj (2009b) In Defense of Lost Causes. London Verso.

- Žižek, Slavoj (2010) Living in the End Times. London: Verso: 2010.

- 92 gruppen (2011) http://www.92grp.dk . 29-3-2012. 


\section{Appendix 1 Interview Guide}

\section{Interview guide - semi structured interviews with Danish and South Korean Environmental NGO key personnel.}

The overall purpose of the interviews is to gain insight into the interviewees understanding of their respective NGO's role in relation to informing and engaging to the 'public', in other words; how they understand their NGO's and their own didactical role.

Working in a semi structured way, i.e. being willing to let the conversation unfold and ready to follow new interesting perspectives, the interview will still take its outset in a series of questions that will hopefully be able to guide the interview in the right direction, without forcing it into an unproductive call-response séance.

\section{Guiding interview questions or themes}

What is the person's understanding of:

- The mission of the NGO, why are they doing what they do, both at organizational level and at a personal level.

- The different messages that the NGO is representing and communicating.

- The 'audience' for this message, possible both a characterization of individuals and groups.

- View of the methods, tools, routines, approaches that are applied when developing, evolving or/and 'delivering' the message.

- View of the perceived effect of the NGO's work to influence, inform, and guide etc. their 'audience'.

- The possible barriers, positive or negative that influences the 'impact' of their work.

- The role of the social in their work, and their thoughts on the relationship between the 'cause' and the 'social'.

- Future developments of their message, methods, approach etc. 
The idea is not to rattle of all the questions, getting short concise answers that I can simplify and squeeze into a neat model; The idea is to a greater extend, to touch upon these questions or themes, in these or other words, and try to probe the perceived relationship between $\mathrm{NGO}$, their messages, methods, their understanding of the public as learning subjects, and the problems that arise out of their practice (or lack of same). 